NUREG/CR-1208 PNL-3093

\title{
Loss-of-Coolant Accident Simulations in the National Research Universal Reactor
}

Safety Analysis Report

Prepared by W. D. Bennett, R. L. Goodman, S. W. Heaberlin, G. M. Hesson,

L. L. King, R. K. Marshall, G. W. McNair, W. D. Meitzler,

C. Nealley, L. J. Parchen, J. P. Pilger, W. N. Rausch,

G. E. Russcher, R. E. Schreiber, N. J. Wildung, C. L. Wilson, C. L. Mohr

Pacific Northwest Laboratory

Operated by

Battelle Memorial Institute

Prepared for

U.S. Nuclear Regulatory

Commission 


\section{NOTICE}

This report was prepared as an account of work sponsored by an agency of the United States Government. Neither the United States Government nor any agency thereof, or any of their employees, makes any warranty, expressed or implied, or assumes any legal liability or responsibility for any third party's use, or the results of such use, of any information, apparatus product or process disclosed in this report, or represents that its use by such third party would not infringe privately owned rights.

\section{Available from}

GPO Sales Program

Division of Technical Information and Document Control

U. S. Nuclear Regulatory Commission

Washington, D. C. 20555

Printed copy price: $\$ 8.00$

and 


\section{SAFETY ANALYSIS REPORT}

LOS5-OF-COOLANT ACCIDENT SIMULATIONS IN THE NATIONAL RESEARCH UNIVERSAL REACTOR

C. L. Mohr, Project Manager

W. D. Bennett

C. Nealley

R. L. Goodman

L. J. Parchen

5. W. Heaberlin

J. P. Pilger

G. M. Hesson

W. N. Rausch

L. L. King

G. E. Russcher

R. K. Marshall

G. W. McNair

R. E. Schreiber

W. D. Meitzler

N. J. Wildung

C. L. Wilson

Manuscript Completed: January 1981 Date Published: February 1981

Prepared for Division of Reactor Safety Research Office of Nuclear Regulatory Research U.S. Nuclear Regulatory Commission Washington, DC 20555

FIN B2277

Pacific Northwest Laboratory Richland, Washington 99352 



\section{ACKNOWLEDGMENTS}

This work was performed in cooperation with the staff of Chalk River Nuc lear Laboratories (CRNL), Atomic Energy of Canada, Ltd. The detailed and useful discussions with D. J. Axford, I. C. Martin, and S. J. McAuley of the Reactor Technology Branch of CRNL are appreciated. C. L. Wi 1son, Pac if ic Northwest Laboratory (PNL) on-site representative in Chalk River for the LOCA Simulations in NRU program, was instrumental in coordinating discussions concerning safety concerns and guiding the safety analys is work to the final report. 



\begin{abstract}
Pressurized water reactor loss-of-coolant accident (LOCA) phenomena are being simulated with a series of experiments in the $U-2$ loop of the National Research Universal Reactor at Chalk River, Ontario, Canada. The first of these experiments includes up to 45 parametric thermal-hydraulic tests to establish the relationship among the reflood delay time of emergency coolant, the reflooding rate, and the resultant fuel rod cladding peak temperature. Subsequent experiments establish the fuel rod failure characteristics at selected peak cladding temperatures. Fuel rod cladding pressurization simulates high burnup fission gas pressure levels of modern PWRs.

This document contains both an experiment overview of the LOCA simulation program and a review of the safety analyses performed by Pacific Northwest Laboratory (PNL) to define the expected operating conditions as well as to evaluate the worst case operating conditions. The primary intent of this document is to supply safety information required by the Chalk River Nuclear Laboratories (CRNL), to establish readiness to proceed from one test phase to the next and to establish the overall safety of the experiment. A hazards review summarizes safety issues, normal operation and three worst case accidents that have been addressed during the development of the experiment plan.
\end{abstract}





\section{SUMMARY}

Pacific Northwest Laboratory (PNL) is conducting tests for the Nuclear Regulatory Commission (NRC), Division of Reactor Safety Research. Fuel Behavior Branch, to evaluate the consequences of a hypothetical loss-of-coolant accident ( $L O C A)$ in a light water reactor (LWR). PNL will provide the test train, the reactor fuel assembly for the test, data reduction and analysis, and management for the LOCA simulation program. Atomic Energy of Canada, Ltd., (AECL), Research Company will provide the test facility and irradiation space in the Canadian National Research Universal (NRU) Reactor at Chalk River, Ontario.

This program will develop a well-characterized data set for evaluating the consequences of a hypothetical LOCA in an LWR. Heatup, reflood, and quench will be simulated using low-ievel fission heat as a surrogate for the system enthalpy and decay heat that would drive the hypothetical LOCA termina? transient.

The data derived from the irradiation tests will be used to assess various calculational models for reactor safety analyses and to assess conclusions derived from the series of electrically heated tests and smaller scale in-pile tests being conducted elsewhere. 



\section{CONTENTS}

ACKNOWLEDGMENTS

$i j i$

ABSTRACT .

SUMMARY

vii

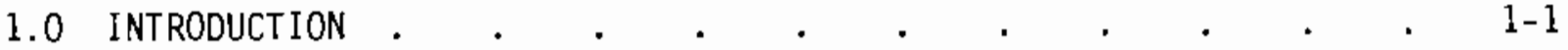

2.D SCOPE AND OBJECTIVES OF THE PROGRAM . . . . . . . . . 2-1

3.0 TEST SERIES DESIGN .

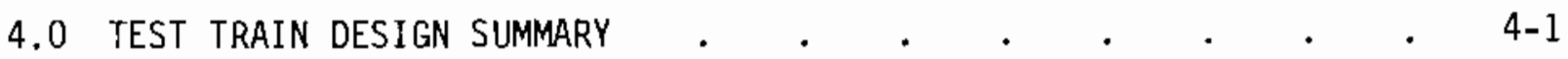

4.1 TEST TRAIN DESIGN BASES . . . . . . . . . . 4-1

4.2 DESIGN CRITERIA $\quad . \quad$. . . . . . . . . . 4 4

4.3 GENERAL DESIGN FEATURES . . . . . . . . . . 4-3

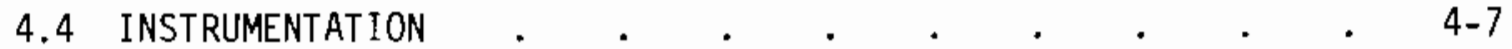

4.4.1 Test Train Instrumentation . . . . . . 4-7

4.4.2 Loop Instrumentation . . . . . . . 4-13

4.4.3 Alarms and Trips. . . . . . . . . 4-15

5.0 CRITICALITY AND TEST FUEL MANAGEMENT . . . . . . . . . 5-1

5.1 CRITICALITY $\quad . \quad$. $\quad . \quad$. $\quad . \quad$. $\quad . \quad$. $\quad$. $5-1$

5.2 TEST FUEL MANAgEMENT $\quad . \quad$. . . . . . . . . . . 5-2

6.0 OPERATING PROCEDURES AND CONDITIONS . . . . . . . . . $6-1$

6.1 INSTALLATION OF ASSEMBLY . . . . . . . . . $\quad$. $6-2$

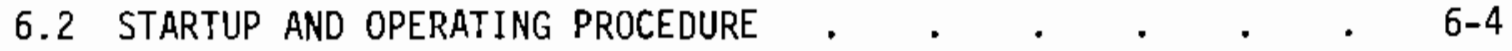

6.2.1 Preconditioning Phase . . . . . . . 6-4

6.2.2 Pretransient Phase . . . . . . . 6-5

6.2.3 Transient Phase . . . . . . . . 6-7

6.3 TEST OPERATING CONDITIONS . . . . . . . . . 6-10 
6.3.1 Operating Limits for Preconditioning . . . . 6-10

6.3.2 Operating Limits for Pretransient Operation . . 6-13

6.3.3 Operating Limits for Transient LOCA Simulation . . 6-14

6.4 DURATION OF IRRADIATION . . . . . . . . . . 6-18

6.4.1 Prototypic Thermal-Hydraulic Tests . . . . 6-18

6.4.2 Cladding Material Deformation Tests . . . 6- 61

6.5 RECORDS . . . . . . . . . . . . $6-22$

6.6 REACTOR CONTROL AND TRIPS . . . . . . . 6- 622

6.6 .1 Reactor Control . . . . . . . . 6- 6-23

6.6.2 Reactor Trips . . . . . . . . . . $6-24$

6.7 TEST TRAIN REMOVAL AND TRANSPORT . . . . . . . 6- 6- .

7.0 POSTIRRADIATION EXAMINATION . . . . . . . . . . . . $7-1$

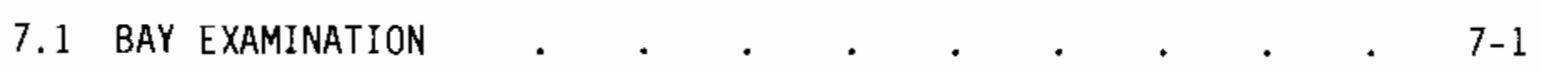

7.1 .1 Shroud . . . . . . . . . . . . 7-1

7.1 .2 Fuel Bundle . . . . . . . . . . $7-2$

7.1.3 Assembly of Replacement Test Bundle . . . . 7-2

7.1.4 Single-Rod Examination . . . . . . . . 7-3

7.2 UNIVERSAL CELL EXAMinATION . . . . . . . . . 7-3

7.3 Metallurgical examination . . . . . . . . . $7-3$

B.0 WASTE DISPOSAL . . . . . . . . . . . . . 8-1

9.0 HAZARDS ANALYSIS . . . . . . . . . . . . . . 9-1

9.1 ESTIMATES OF REACTIVITY . . . . . . . . . . . $9-1$

9.2 ESTIMATE OF NEUTRON FLUX AND TEST
ASSEMBLY-REACTOR POWER COUPLING . . . . . . . . . . . $9-3$

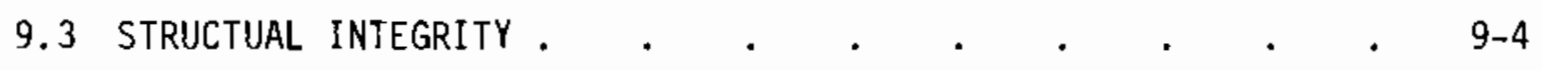

9.4 TEST ASSEMBLY SENSOR RELIABILITY • . . . • • . . 9 9-7

9.4.1 Thermocouples . . . . . . . . . . . 9-7 
9.4.2 Test Assembly Flow Measurement . . . . . 9 9-8

9.4.3 Test Assembly Power Measurement . . . . . . 9-9

9.5 NRU U-2 LOOP SENSOR RELIABILITY . . . • • . . 9-11

9.5.1 U-2 Loop Resistance Temperature Detector . . . 9-12

9.5.2 U-2 Loop Flow Measurement . . . . . . 9 9-12

9.5.3 U-2 Loop Power Measurement . . . . . . 9-12

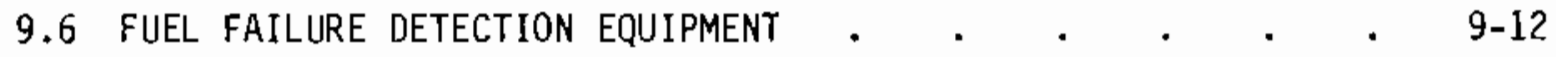

9.7 REACTOR TRIP CONDITIONS AND REQUIREMENTS . . . . . . 9-13

9.7.1 Preconditioning Phase Trips . . . . . . 9-15

9.7.2 Pretransient Phase Trips . . . . . . $9-15$

9.7.3 Transient Phase Trips . . . . . . . . 9-16

9.8 FUEL BEHAVIOR - NORMAL OPERATION .

9.8.1 Thermal-Hydraulic Tests . . . . . . . 9-17

9.8.2 Cladding Deformation Tests . . . . . . . $9-22$

9.8.3 Effectiveness of Fuel Rewetting . . . . . 9-31

9.9 FUEL BEHAVIOR--WORST-CASE CONDITIONS . . . . . . $\quad$. 9-33

9.9.1 Case 1: 80-Second Scram . . . . . . . 9-34

9.9.2 Case 2: 80-Second Reflood . . . . . . $9-35$

9.9.3 Case 3: Partial Reflood . . . . . . . 9-36

9.10 COOLING REQUiREMENTS FOR THE TEST ASSEMBLY . . . . . $\quad$ 9-45

9.10.1 Requirement for Cooling After Preconditioning . . 9-45

9.10.2 Requirement for Cooling Between Transients . . 9-46

9.10.3 Requirement for Post-Test Cooling . . . . 9-47 


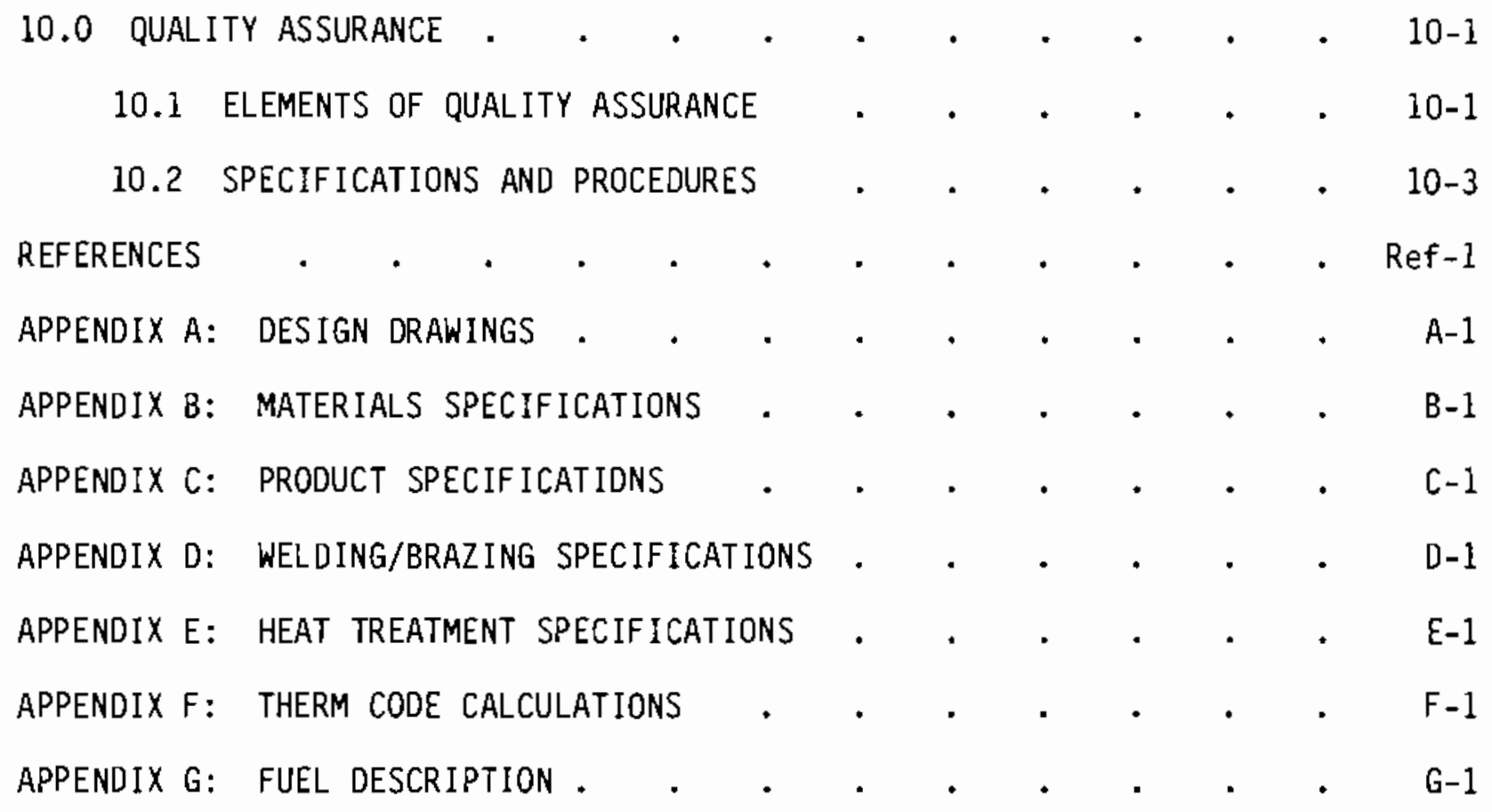




\section{FIGURES}

3.1. Schematic of Test Series Operating Conditions and Uncertainty . 3-4

4.1. Schematic of NRU LOCA Test Train . . . . . . . . . 4-4

4.2. Schematic Cross Section of Assembly Illustrating Instrument
Locations
.

4.3. PNL Thermocouple as Attached to the Outside Surface

of the Fuel Rod Cladding . . . . . . . . . . . 4-9

4.4. Schematic Arrangement of Neutron Detector and Signal Conditioner . . . . . . . . . . . 4-12

4.5. Simplified Schematic of U-2 Loop . . . . . . . . 4-14

6.1. Pretransient and Transient Phase Piping System . . . . 6-7

6.2. Outlet Coolant Temperature (OF) Distribution During

Preconditioning Operation . . . . . . . . 6-12

6.3. Axial Temperature Distribution During Pretransient Operation . 6-14

6.4. Predicted Peak Cladding Temperatures vs Reflood

Rate for Peak Power . . . . . . . . . 6-15

6.5. Nominal (worst case) Test Assembly and Pressure Tube
Expected Time-Temperature Behavior . . . . .

6.6. Preconditioning Phase in Water-Filled Loop . . . . . . . 6-19

6.7. Heatup/Reflood Test Phase . . . . . . . . . . 6-21

9.1. Cross Section of Assembly Illustrating Fuel Bundle
Array, SPND and Thermocouple Locations . . . . . . . . $9-10$

9.2. Schematic Arrangement of Neutron Detector and
Signal Conditioner. . . . . . . . . . . 9-11

9.3. Neutron Power Decay Following a Conditional Trip on Rod 16 . . 9-13

9.4. Power Decay Following a Conditional Trip on Rod 15 . . . 9-14

9.5. Power Decay Following a Conditional Trip on Rod 13 . . . 9-14

9.6. Cladding Temperature for Thermal-Hydraulic Tests -
0-Second Reflood Initiation Delay Time. . . . . . 9-18 
9.7. Fuel Centerline Temperature for Thermal-Hydraulic Tests -

0 -Second Reflood Initiation Delay Time . . . . . . 9-19

9.8. Cladding Temperature for Thermal-Hydraulic Tests -

10-Second Reflood Initiation Deray Time . . . . . . . g-19

9.9. Fuel Centerline Temperature for Thermal-Hydraulic Tests 10-Second Reflood Initiation Delay Time . . . . . . 9-20

9.10. Cladding Temperature for Thermal-Hydraulic Tests -

20-Second Reflood Initiation Delay Time . . . . . . 9-20

9.11. Fue? Center Tine Temperature for Thermal-Hydraulic Tests -

g.12. Cladding Temperature for Cladding Deformation Tests -

D-Second Reflood Initiation Delay Time . . . . . . 9-25

9.13. Fuel Centerline Temperature for Cladding Deformation Tests -

0 -Second Reflood Initiation Delay Time . . . . . . . g-25

9.14. Cladding Temperature for Cladding Deformation Tests -

10-Second Reflood Initiation Delay Time . . . . . 9-26

9.15. Fuel Center line Temperature for Cladding Deformation Tests 10-Second Reflood Initiation Delay Time . . . . . . 9-26

9.16. Cladding Temperature for Cladding Deformation Tests 2D-Second Reflood Initiation Delay Time . . . . . . . 9-27

9.17. Cladding Temperature for Cladding Deformation Tests -
44-Second Reflood Initiation Delay Time . . . . . . 9-27

9.18. Fuel Centerline Temperature for Cladding Deformation Tests 44-Second Reflood Initiation Delay Time . . . . . 9-28

9.19. Cladding Temperature for Cladding Deformation Tests 60-Second Reflood Initiation Delay Time . . . . . . 9-28

9.20. Fuel CenterTine Temperature for Cladding Deformation Tests 60-Second Reflood Initiation Delay Time . . . . . . . 9-29

9.21. Maximum Credible Temperatures Expected in the Test Train Assembly 9-33

9.22. NRU Power Decay After Trip . . . . . . . . . . 9-36

9.23. Test Assembly Temperatures After a Trip . . . . . . . . 9-37

9.24. Temperatures Above Test Assembly After a
Trip with No Steam Flow . . . . . . . . . 9-38 
9.25. Effect of Reflood Rate on Fuel Cladding Temperature Rise . . 9-39

9.26. Upper Steam Exit Temperature from FLECHT Data . . . . . 9-41

9.27. TRUMP Calculations of Hanger and Pressure Tube Temperatures . 9-42

9.28. Contribution of Metal-Water Reaction to Rod Power . . . 9-44

9.29. Shroud and Pressure Test, and Test Fuel Cladding Temperatures for 21-s Heatup (to $1800^{\circ} \mathrm{F}$ ), Slow Reflood $(0.5 \mathrm{in} / \mathrm{s}$ ) and Reactor Trip at $1478 \mathrm{~K}\left(2200^{\circ} \mathrm{F}\right) . . \quad . \quad . \quad . \quad . \quad 9-45$

9.30. Power Decay Curve Normalized to $0.38 \mathrm{~kW} / \mathrm{ft}$. . . . . . 9-47

9.31. Maximum Cladding Temperature Between Transient Operation . . 9-48

G.1. Schematic Cross Section of Assembly Illustrating
Instrument Locations. . . . . . . . G-2 


\section{TABLES}

3.1 Thermal-Hydraulic Test Series . . . . . . . . 3-2

3.2 Fuel Cladding Performance Tests . . . . . . . 3-5

6.1 Preconditioning Operating Summary . . . . . . . . 6-11

6.2 Pretransient Operating Conditions Summary . . . . . 6-13

6.3 Transient Operating Condition Summary . . . . . . 6-16

6.4 Limits for Dependent Variables During Transient . . . . 6-16

9.1 The Normalized Reactor Power After a

Ramp Reactivity Insertion . . . . . . . . 9-3

9.2 Reactor Powers Required to Obtain Power Levels

in the Test Bundle as Specified in LOCA Tests . . . . 9-4

9.3 Required Structural Integrity Evaluation . . . . . 9-5

9.4 GAPCON T-3 Code TH Test Predictions . . . . . . 9-21

9.5 Fission Product Inventory for Post Thermal-Hydraulic Tests . . 9-23

9.6 Fission Product Inventory for Post-Preconditioning . . . 9-24

9.7 GAPCON T-3 Code Cladding Deformation Results . . . . . $\quad 9-30$

9.8 Fission Product Inventory for Post Materials Test . . . . 9-31

G-1 Fuel Test Bundle Data . . . . . . . . . G-2 


\subsection{INTRODUCTION}

A loss-of-coolant accident (LOCA) in a commercial light water reactor (LWR) consists of four distinct phases: blowdown, heatup, reflood, and quench. Each of these phases has a path-dependent process that is a function of 1) the type of event that initiated the accident and 2) the reactor's operating cond $i$ tions at the time the LOCA was initiated. No single set of conditions would exist at the time of a LOCA; rather, a broad range of operating parameters could exist in one of many possible combinations.

The ideal simulation of a LOCA would include the entire LOCA sequence-blowdown, heatup, reflood, and quench. However, such a simulation would require examination of a large range of parameters related to the reactor event in itiating the accident, which in turn would require many in-reactor tests. Because of the technical difficulties of such an effort and the large number of parameters involved in a test program that would be typical of all LOCAs, it was decided that these experiments would address only those phases that are most damaging to the cladoing integrity: heatup, reflood, and quench.

During the most damaging phases, the highest fuel cladding temperatures are reached with the maximum relative pressure differential occurring across the cladding wall. The cladding typically will rupture, releasing fission products early in the heatup phase. During the heatup phase, the cladding temperature and the resulting cladding oxidation will continue to increase until the reflood water reaches a depth sufficient to halt the increase, turn the cladding temperature around, and finally quench the cladding.

Pacific Northwest Laboratory (PNL) has prepared th is document to define both normal operating and worst-case conditions that might occur during testing. This report is intended to help Nuclear Regulatory Commission (NRC) and Cha]k River Nuclear Laboratories (CRNL) staff members ensure the safety and integrity of the National Research Universal (NRU) reactor during the tests.

The following subjects are discussed in the rest of the report.

- test series design

- test train design 
- operating procedures and conditions

- postirradiation examination

- wastes generated by the tests and waste disposal

- hazards involved in testing.

Appendices $A$ through $G$ include detailed drawings of the test train and its components, copies of key specifications, and additional plots predicting peak cladding temperatures for different reflood rates and delay times. 


\subsection{SCOPE AND OBJECTIVES OF THE PROGRAM}

The LOCA simulation program will develop a well-characterized data set for evaluating the consequences of a hypothetical LOCA in an LWR. Heatup, ref1ood, and quench will be simulated using low-level fission heat as a surrogate for the system enthalpy and decay heat that would drive the hypothetical LOCA terminal transient.

Six full-length test assemblies will be irradiated. The geometric configuration of each assembly represents a $6 \times 6$ segment of a $17 \times 17$ pressurized water reactor (PWR) fuel bundle. The tests will be performed in the U-2 loop of the NRU Reactor at Chalk River, Ontario, provided by the Atomic Energy of Canada, Ltd. (AECL). The tests are expected to yield the following data:

- temperature distribution in a full-length bundle as a function of time

- interaction between thermal-hydraulics and cladding deformation

- quench front propagation

- quenching character istics of nuclear-heated, Zircaloy-clad rods for comparison with electrically heated, Inconel or Stainless steel-clad (ss) rods

- temperature-stress-time of cladding deformation

- distribution of cladding strain within bundle and information on failure propagation

- axial distribution of diametral strain in test fuel rods

- flow-area reduction caused by cladding expansion.

The data will be used to assess various calculational models for reactor safety analyses and to assess conclusions derived from the series of electrically heated tests and smaller scale in-pile tests being conducted elsewhere.

Experiments will be designed and conducted to use the advantages inherent in the NRU reactor for testing of this kind. These advantages include 1) capabilities for testing multirod bundles with lengths to $3.66 \mathrm{~m}$ (12 ft) under 
thermal-hydraulic cond itions representative of contemporary LWRs and 2) the ability to achieve requisite power densities using fuels with normal commercial enrichments. The former advantage will reduce uncertainties in scaling factors that must be applied to results from small-scale tests; the latter will permit reasonable uniformity in horizontal power distribution within a test fuel bundle and the use of actual commercial fuel rods in test bundles.

This program is related generally to those NRC programs concerned with performance characteristics of nuclear reactor fueis. Experimental work witl extend and complement thermal-hydraulic/cladding deformation tests that include out-of-pile tests (i.e., PWR FLECHT SEASET), the Power Burst Facility (PBF) test and loss-of-flow test (LOFT).

It is anticipated that this program will be conducted over a 5 -year period beginning with approval of the initial contract. The program's major milestones are:

AECL Subcontract Approved

Data Acquisition and Control System Delivered Final Safety Analysis Approved by AECL Loop Modifications and Tests Completed

Nuc lear Tests Begun

Nuclear Tests Completed

Final Reports Completed
December 1978

May 1980

June 1980

August 1980

Oc tober 1980

June 1982

September 1983 


\subsection{TEST SERIES DESIGN}

There will be a total of six tests and six assemblies; one assembly will be used for thermal-hydraulic testing for a maximum of 45 test runs, the other five will be used for mechanical deformation testing and will be limited to one test run each (Hann 1979).

The thermal-hydraulic test series will be conducted during the first of six testing intervals. All rods will be unpressurized; consequently, no severe cladding deformation will occur. The test series will provide replicate conditions for assessment of mathematical heatup and reflood models. It will also serve to calibrate the response of the system and further refine knowledge of boundary conditions of those pressurized rod assemblies that will experience severe deformation and rupture. The tests will provide a transition from wel1controlled and rather benign conditions to more severe test conditions.

Several options exist for performing test series that will allow replication of test parameters to improve data correlation and potentially reduce the number and types of instruments required for the testing. Some of the variables included in these options are reflood injection time, reflood rate, and heatup rate. The current design for the thermal-hydraulic tests is based on using one heatup rate to minimize reactor control problems and experimental perturbations. The reflood rate and reflood injection times will be used as the prime independent variables and will in various combinations be used to reverse the temperature transient at the desired peak cladding temperature limit. The proposed conditions for the thermal-hydraulic tests series are listed in Table 3.1. and shown in Figure 3.1 .

The five fuel cladding performance tests will be conducted for selected conditions based on the results obtained during the thermal-hydraulic tests. The objective of the tests will be to use a constant heatup rate and vary the reflood rate and reflood delay time to obtain peak cladding temperatures between $1033 \mathrm{~K}\left(1400^{\circ} \mathrm{F}\right)$ and $1255 \mathrm{~K}\left(1800^{\circ} \mathrm{F}\right)$. Table 3.2 shows the approximate range of variables planned for the fuel cladding performance tests. 
TABLE 3.1. Therma1-Hydraulic Test Series(a)

\begin{tabular}{|c|c|c|c|c|c|c|c|c|}
\hline \multirow{2}{*}{$\begin{array}{l}\text { Test } \\
\text { Day }\end{array}$} & \multirow{2}{*}{$\begin{array}{l}\text { Test } \\
\text { Series } \\
\text { Number } \\
\end{array}$} & \multirow{2}{*}{$\frac{\text { Reflood }}{\mathrm{m} / \mathrm{s}}$} & \multirow{2}{*}{$\frac{\text { Rate }}{i n . / 5}$} & \multirow{2}{*}{$\begin{array}{l}\text { Reflood } \\
\text { Delay } \\
\text { Time, s }\end{array}$} & \multicolumn{2}{|c|}{$\begin{array}{l}\text { Maximum } \\
\text { Heating Rate }\end{array}$} & \multicolumn{2}{|c|}{$\begin{array}{l}\text { Predicted (b) } \\
\text { Peak Cladding } \\
\text { Temperature }\end{array}$} \\
\hline & & & & & $\mathrm{K} / \mathrm{s}$ & ${ }^{\circ} \mathrm{F} / \mathrm{s}$ & K & $F$ \\
\hline 2 & 101 & 0.102 & 4.0 & $3^{(c)}$ & 8 & 15 & $<811$ & $<1000$ \\
\hline 2 & 102 & 0.102 & 4.0 & 20 & 8 & 15 & 922 & 1200 \\
\hline 2 & 103 & 0.102 & 4.0 & 29 & 8 & 15 & 977 & 1300 \\
\hline 2 & 104 & 0.102 & 4.0 & 37 & 8 & 15 & 1033 & 1400 \\
\hline 3 & 105 & 0.051 & 2.0 & 7 & 8 & 15 & 1033 & 1400 \\
\hline 3 & 106 & 0.051 & 2.0 & 19 & 8 & 15 & 1088 & 1500 \\
\hline 3 & 107 & 0.051 & 2.0 & 30 & 8 & 15 & 1144 & 1600 \\
\hline 3 & 108 & $0.048^{(d)}$ & 1.9 & $3^{(c)}$ & 8 & 15 & 1033 & 1400 \\
\hline 3 & 109 & 0.038 & 1.5 & 3 & 8 & 15 & 1144 & 1600 \\
\hline 3 & $110^{(9)}$ & $0.038^{(9)}$ & $1.5^{(g)}$ & 11 & 8 & 15 & 1200 & 1700 \\
\hline 3 & 111 & 0.038 & 1.5 & 11 & 8 & 15 & 1200 & 1700 \\
\hline 3 & 112 & 0.076 & 3.0 & 32 & 8 & 15 & 1033 & 1400 \\
\hline 4 & 113 & 0.204 & 8.0 & 39 & 8 & 15 & 1033 & 1400 \\
\hline 4 & $114^{(h)}$ & 0.204 & 8.0 & 46 & 8 & 15 & 1088 & 1500 \\
\hline 4 & 115 & 0.204 & 8.0 & 53 & 8 & 15 & 1144 & 1600 \\
\hline 4 & 116 & $0.254^{(d)}$ & 10.0 & 40 & 8 & 15 & 1033 & 1400 \\
\hline 4 & $117^{(h)}$ & 0.254 & 10.0 & 47 & 8 & 15 & 1088 & 1500 \\
\hline 4 & 118 & 0.254 & 10.0 & 54 & 8 & 15 & 1144 & 1600 \\
\hline 4 & $119^{(g)}$ & $0.155^{(g)}$ & $6.1^{(g)}$ & 52 & 8 & 15 & 1144 & 1600 \\
\hline 4 & 120 & 0.155 & 6.1 & 52 & 8 & 15 & 1144 & 1600 \\
\hline 4 & 121 & 0.076 & 3.0 & 48 & 8 & 15 & 1144 & 1600 \\
\hline 5 & $122(g)$ & $0.076^{(g)}$ & $3.0^{(g)}$ & 53 & 8 & 15 & 1200 & 1700 \\
\hline 5 & 123 & 0.076 & $3.0^{(c)}$ & 53 & 8 & 15 & 1200 & 1700 \\
\hline 5 & $124^{(f)}$ & 0.102 & 4.0 & 37 & 8 & 15 & 1033 & 1400 \\
\hline 5 & 125 & 0.102 & 4.0 & 51 & 8 & 15 & 1144 & 1600 \\
\hline 5 & 126 & 0.102 & 4.0 & 70 & 8 & 15 & 1255 & 1800 \\
\hline 5 & $127^{(f)}$ & 0.102 & 4.0 & 37 & 8 & 15 & 1033 & 1400 \\
\hline 5 & 128 & 0.033 & 1.3 & $3(c)$ & 8 & 15 & 1255 & 1800 \\
\hline
\end{tabular}


TABLE 3.1. (contd)

\begin{tabular}{|c|c|c|c|c|c|c|c|c|}
\hline \multirow{2}{*}{$\begin{array}{l}\text { Test } \\
\text { Day }\end{array}$} & \multirow{2}{*}{$\begin{array}{l}\text { Test } \\
\text { Series } \\
\text { Number } \\
\end{array}$} & \multicolumn{2}{|c|}{ Reflood Rate } & \multirow{2}{*}{$\begin{array}{l}\text { Reflood } \\
\text { Delay } \\
\text { Time, s } \\
\end{array}$} & \multirow{2}{*}{\multicolumn{2}{|c|}{$\begin{array}{l}\text { Maximum } \\
\text { Heating Rate } \\
\mathrm{K} / \mathrm{s} \text { of } \mathrm{F} / \mathrm{s} \\
\end{array}$}} & \multicolumn{2}{|c|}{$\begin{array}{l}\text { Predicted(b) } \\
\text { Peak Cladding } \\
\text { Temperature }\end{array}$} \\
\hline & & $\mathrm{m} / \mathrm{s}$ & $i n . / 5$ & & & & $\mathrm{~K}$ & of \\
\hline 5 & 129 & $0.038^{(d)}$ & $1.5^{(d)}$ & 20 & 8 & 15 & 1255 & 1800 \\
\hline 5 & $130^{(f)}$ & 0.102 & 4.0 & 37 & 8 & 15 & 1033 & 1400 \\
\hline 5 & 131 & 0.051 & 2.0 & 50 & 8 & 15 & 1255 & 1800 \\
\hline 5 & 132 & $0.204^{(d)}$ & $8.0^{(d)}$ & 71 & 8 & 15 & 1255 & 1800 \\
\hline 6 & $133^{(f)}$ & 0.102 & 4.0 & 37 & 8 & 15 & 1033 & 1400 \\
\hline 6 & $134^{(h)}$ & $0.254^{(d)}$ & $10.0^{(d)}$ & 72 & 8 & 15 & 1255 & 1800 \\
\hline 6 & 135 & $0.028^{(d)}$ & $1.1^{(d)}$ & 3 & 8 & 15 & $1310^{(\mathrm{e})}$ & $1900^{(\mathrm{e})}$ \\
\hline 6 & $136^{(f)}$ & 0.102 & 4.0 & 37 & 8 & 15 & 1033 & 1400 \\
\hline 6 & 137 & $0.038^{(d)}$ & $1.5^{(d)}$ & 32 & 8 & 15 & $1310^{(e)}$ & $1900^{(e)}$ \\
\hline 6 & 138 & $0.051^{(d)}$ & $2.0^{(d)}$ & 60 & 8 & 15 & $1310^{(e)}$ & $1900^{(e)}$ \\
\hline 6 & $139^{(f)}$ & 0.102 & 4.0 & 37 & 8 & 15 & 1033 & 1400 \\
\hline 6 & 140 & $0.102^{(d)}$ & $4.0^{(d)}$ & 76 & 8 & 15 & $1310^{(\mathrm{e})}$ & $1900^{(\mathrm{e})}$ \\
\hline 6 & 141 & $0.204^{(d)}$ & $8.0^{(d)}$ & 77 & 8 & 15 & $1310^{(e)}$ & $1900^{(\mathrm{e})}$ \\
\hline 6 & $142(\mathrm{~T})$ & 0.102 & 4.0 & 37 & 8 & 15 & 1033 & 1400 \\
\hline 7 & $143^{(9)}$ & 0.038 (g) & $1.5^{(d)}$ & $53^{(d)}$ & 8 & 15 & $1310^{(\mathrm{e})}$ & $1900^{(\mathrm{e})}$ \\
\hline 7 & 144 & $0.038^{(d)}$ & $1.5^{(d)}$ & 53 & 8 & 15 & $1310^{(\mathrm{e})}$ & $1900^{(\mathrm{e})}$ \\
\hline 7 & $145^{(t)}$ & 0.102 & 4.0 & 37 & 8 & 15 & 1033 & 1400 \\
\hline
\end{tabular}

(a) Operating conditions are described in Appendix C.

(b) Predictions are based on a FLECHT heat transfer coefficient correlation used in the TRUMP heat transfer code. Prediction uncertainty $= \pm 28 \mathrm{~K}\left(50^{\circ} \mathrm{F}\right)$.

(c) Minimum delay time $(<3 \mathrm{~s})$ is necessary for the reflood water to arrive at the bottom of the fue l column after steam flow is stopped.

(d) Final value will be selected from earlier tests in this experiment.

(e) Cladding temperature may exceed $1255 \mathrm{~K}\left(1800^{\circ} \mathrm{F}\right)$, based on parameters evaluated from earlier test results. For safety purposes $1310 \mathrm{~K}\left(1900^{\circ} \mathrm{F}\right)$ will be used as the maximum.

(f) Replicate of Test Number 104.

(g) FLECHT data comparison. The first test of each FLECHT data pair uses a fast fill rate up to the $0.306 \mathrm{~m}(1 \mathrm{ft})$ level of the fuel column, then the selected reflood rate. The second test uses a constant reflood rate.

(h) GE data comparison. 


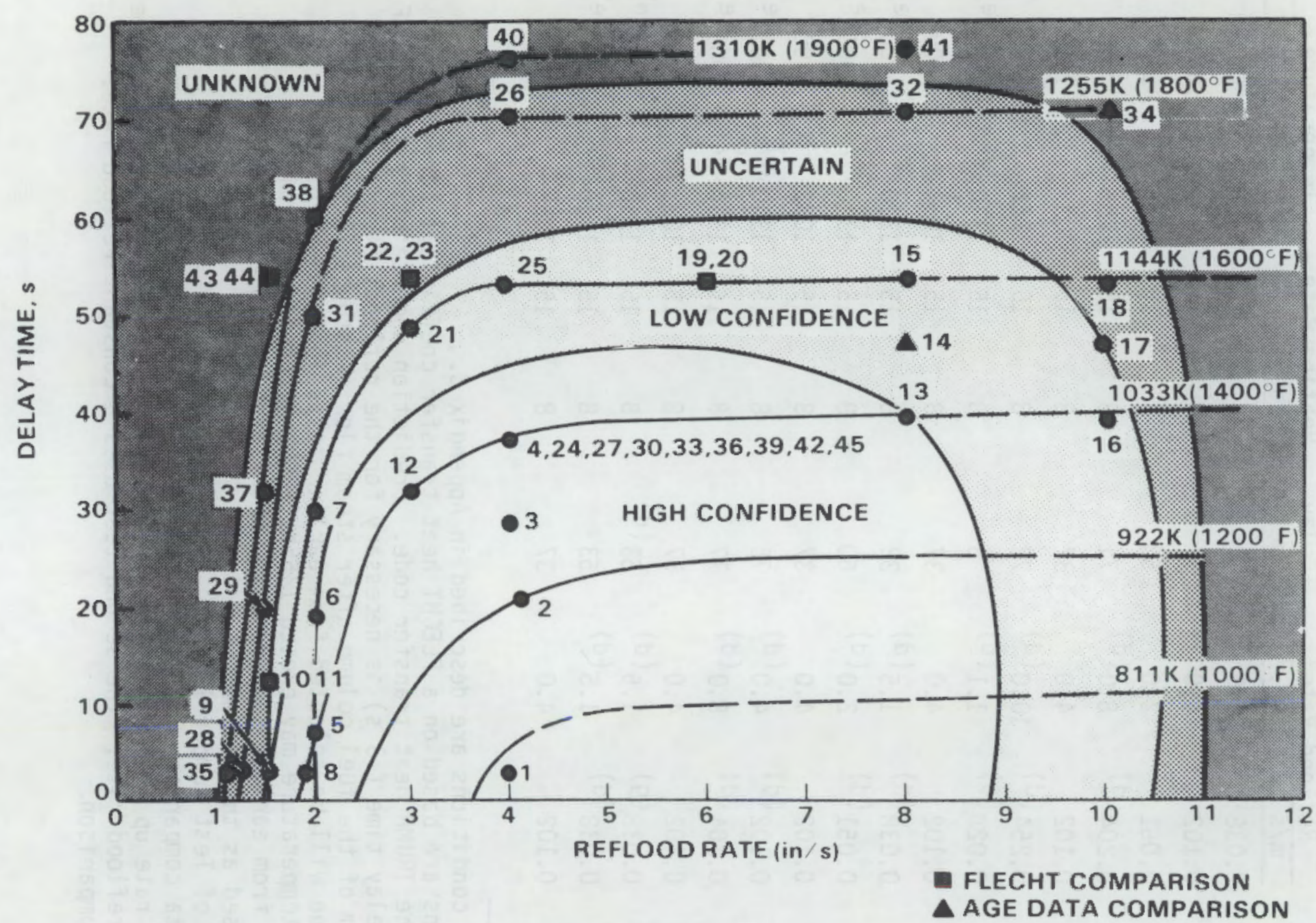

FIGURE 3.1 Schematic of test Series Operating Conditions and Uncertainty 
TABLE 3.2. Fuel Cladding Performance Tests(a)

\begin{tabular}{|c|c|c|c|c|c|c|c|}
\hline \multirow{2}{*}{$\begin{array}{c}\text { Test } \\
\text { Number } \\
\end{array}$} & \multicolumn{2}{|c|}{ Flooding Rate } & \multirow{2}{*}{$\begin{array}{l}\text { Reflood Delay } \\
\text { Time, sec }\end{array}$} & \multicolumn{2}{|c|}{ Heating Rate } & \multicolumn{2}{|c|}{$\begin{array}{l}\text { Maximum Cladding } \\
\text { Temperature } \\
\end{array}$} \\
\hline & $\mathrm{m} / \mathrm{sec}$ & in. $/ \mathrm{sec}$ & & K/sec & of $/ \mathrm{sec}$ & $K$ & ${ }^{\circ} \mathrm{F}$ \\
\hline 2 & 0.127 & 5 & $32^{(b)}$ & 8 & 15 & 1033 & 1400 \\
\hline 3 & 0.051 & 2 & ${ }_{12}(b)$ & 8 & 15 & 1033 & 1400 \\
\hline 4 & $0.025-0.036$ & $1-1.4^{(c)}$ & 0 & 8 & 15 & 1033 & 1400 \\
\hline 5 & 0.051 & 2 & $25^{(b)}$ & 8 & 15 & 1144 & 1600 \\
\hline 6 & 0.051 & 2 & $40^{(b)}$ & 8 & 25 & 1255 & 1800 \\
\hline
\end{tabular}

(a) In all six tests, peak rod power was $1.97 \mathrm{~kW} / \mathrm{m}(0.6 \mathrm{~kW} / \mathrm{ft})$, system pressure was $0.27 \mathrm{MPa}$ (40 psia), inlet subcooling temperature was $78 \mathrm{~K}$ $\left(140^{\circ} \mathrm{F}\right)$, and the initial rod pressure was $3.1 \mathrm{MPa}(450 \mathrm{psia})$. The actual value of the rod pressure will be adjusted to give an NRU hot operating pressure equivalent to that of a modern PWR. The option exists to change the rod pressures of tests 5 and 6 , depending upon results of tests 2,3 and 4 .

(b) Target, actual value selected from previous tests to obtain desired cladding temperatures.

(c) Target, lowest rate practical. 



\subsection{TEST TRAIN DESIGN SUMMARY}

Test train components were designed with the following considerations: mechanics, instrumentation, and neutronics. Each of these are discussed in enough detail to provide the most realistic boundary conditions, lead to wel1defined parameters and a clear sequence of events, and enable performance of a limited number of replicate tests that would provide well-characterized data. The bases for the test train design, the design criteria, and the general design features reflect these objectives.

\subsection{TEST TRAIN DESIGN BASES}

The mechanical design must meet the test requirements, provide a compatible interface with the NRU facility, lead to reduced assembly/disassembly costs, and facilitate poolside examination of the bundle. To meet these objectives, severa 7 key design requirements were established.

- The test train must interface with the existing reactor test loop facility, particularly the existing pressure tube design and closure stump body.

- The test train must be compatible with existing transfer procedures and equipment.

- The test train must be transported in the NRU transfer flask.

- The design must include the maximum number of instrument lead penetrations.

- After irradiation, the instrument leads must be capable of being removed and reinstalled at the pool assembly/disassembly location.

- The design must provide for continuous instrument signals to the data acquisition system, but the instrument must be able to be disconnected and clear access beyond the deck plate level must be provided.

- Fabrication steps must be simple wherever prudent.

- The test train must not impair the safe operation of the NRU reactor nor impose operating restrictions. 
- It must be relatively easy to disassemble, examine, and reassemble the test train while it is underwater and in a horizontal position.

- The design must provide for removal of a test bundle from the guard rod heater and replacement of the guard rods.

- The design must include a reusable, instrumented guide tube assently.

- The test train must have a known fuel rod position and rotation or ientation.

- An indicator must be provided to monitor the liquid level during reflood.

- The design must provide for a power level indicator in the bundle.

- The design must include a temperature distribution indicator within the bundle.

\subsection{DESIGN CRITERIA}

The mechanical design shall include:

- removable sealing hardware to keep the diameter of the portion going into the transfer flask to a maximum of $0.127 \mathrm{~m}$ ( $5 \mathrm{in.}$ )

- connectors that can be disconnected to leave one side of the connector below the deck plate level

- a pressure boundary between the pressure tube and the reactor exterior under ambient operating conditions

- construction materials selected to assure compatibility with the existing facility and to attain design life and hardware reliability

- factors to assure that yielding of components in the closure region will not compromise the safety of the NRU

- documentation showing that the fabrication history for all components of this region are traceable to the original materials of construction

- lifting attachments that will be capable of supporting the we ight of the test train 
- a rod diameter and pitch that are compatible with a PWR $17 \times 17$ assembly

- an active fuel length of $3.658 \mathrm{~m}$ (144 in.)

- a maximum of 183 penetrations for instrument leads

- commercial spacer grid designs to facilitate the manufacture of modular spacer grids

- eight spacer locations.

\subsection{GENERAL DESIGN FEATURES}

A schematic of the overall test train is depicted in Figure 4.1. Key mechanical drawings, which can be found in Appendix A, give greater detail. The total length of the test train, including both the closure region and the test region is $9.18 \mathrm{~m} \mathrm{(30} \mathrm{ft,} 1-1 / 2 \mathrm{in.}$ ).

The closure region will provide the pressure boundary between the test train and the pressure tube of the loop. It includes penetrations for 183 instrumentation leads. PNL will build a mockup of the instrument leads in the closure region for quality control leak testing.

The hanger tube is used to suspend the test bundle and shroud from the closure plug. The instrument leads will be attached to the hanger to protect them during testing and transport.

The shroud will support the fuel bundle, serve as a liner during experimental and transfer operations, and provide proper flow distribution during various stages of the experiment. The shroud will be fabricated from stainless steel and will consist of two halves clamped together at 17.78-cm (7-in.) intervals and attached at the end fittings. The split shroud design will facilitate underwater disassembly and examination. The shroud assembly will be approximately $4.27 \mathrm{~m}$ (14 ft) long and be instrumented with 22 self-powered neutron detectors (SPNDs) and 38 thermocouples. 


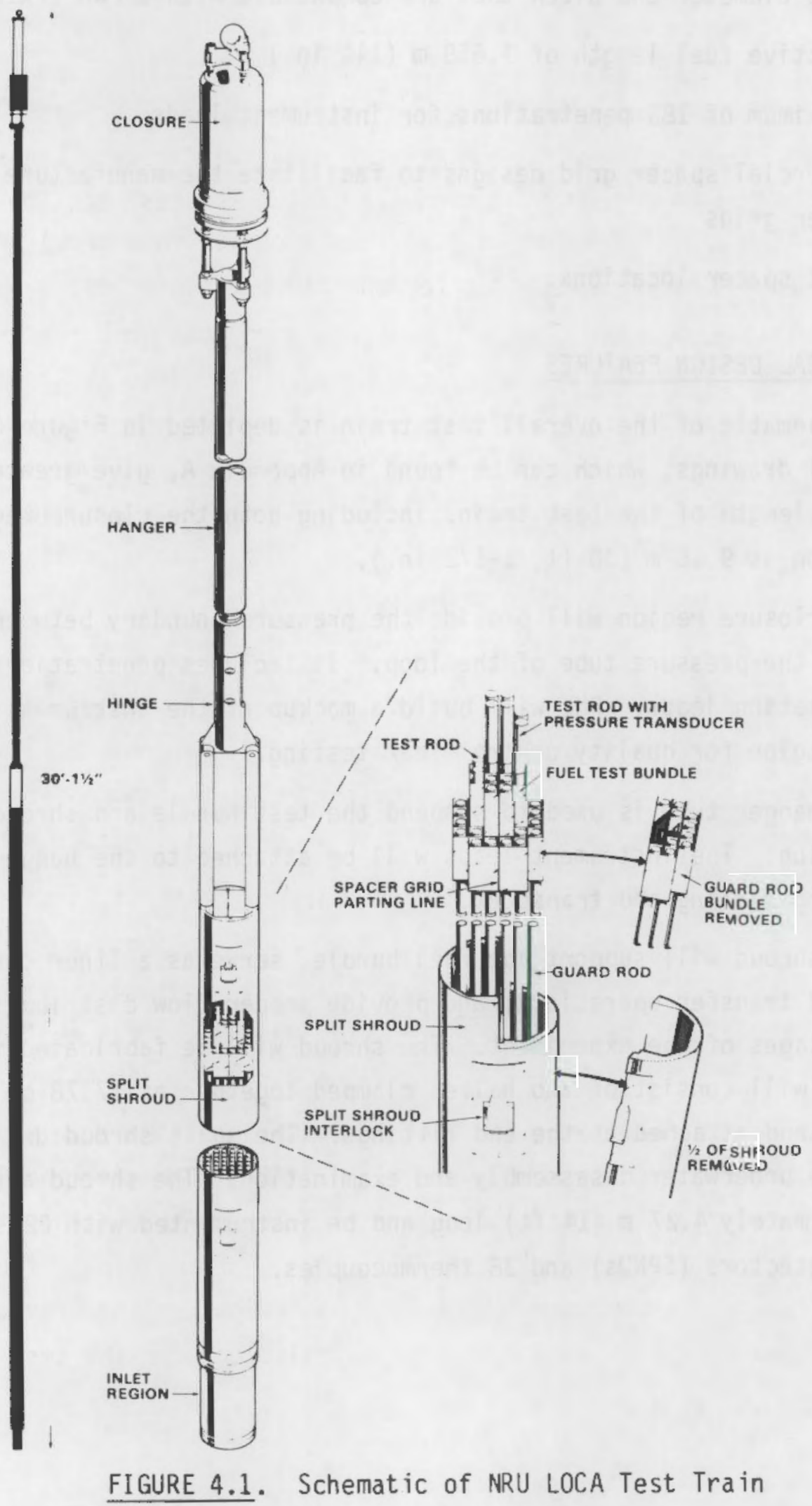


The fuel bundle consists of a $6 \times 6$ array(a) of fuel rods with the four corner rods removed for easier insertion in the shroud (see Figure 4.2). This provides a basic test array of $6 \times 6-4$ rods (or 32). The outer row of rods, including the corner rods of the next inner ring, will not be pressurized and will serve as guard rod heaters during the test. The test section consists of 11 fuel rods and one instrument thimble tube arranged in a cruciform pattern. The test rods will be unpressurized for the first test series; subsequent tests will use pressurized rods. The bundle is designed to enable reuse of the guard rod heaters, and the guard rod array can be separated into two sections (see Drawing No. SK-3-21389, p. A-5)). The cruciform array can also be divided into segments to aid poolside inspection and removal of the instrumented thimble tube. The cruciform test assembly will be replaced after each test; consequently, a high-pressure instrument connector is desirable as it would allow the test rods to be disconnected without disrupting the feed-throughs at the closure head.

There are several leak paths for coolant flow from inside the shroud to the annulus between the shroud and pressure tube. The coolant flow rate is measured upstream of the leak points, and the exact fraction of the total flow going up the annulus and bypassing the test section will not be known.

Two criteria dictate allowable bypass flow. The first is that the bypass flow must be low enough that the liquid level front in the annulus lags behind the liquid level front inside the shroud during the reflood portions of the transient tests. The second is that the flow up the annulus must provide sufficient cooling to remove the ganma heating from the pressure tube.

Preliminary calculations show that if the bypass flow were $5 \%$ of the total flow, the requirement that the bypass liquid level lag behind the level inside the shroud would be only marginally met. Other calculations show that pressure tube temperatures would be less than $505 \mathrm{~K}\left(450^{\circ} \mathrm{F}\right)$ if the bypass flow were $1 \%$ of the total flow. A design value of $1 \%$ bypass flow was therefore somewhat arbitrarily chosen and is used in design calculations for the test assembly.

(a) This is a segment of a $17 \times 17$ PWR assembly. 


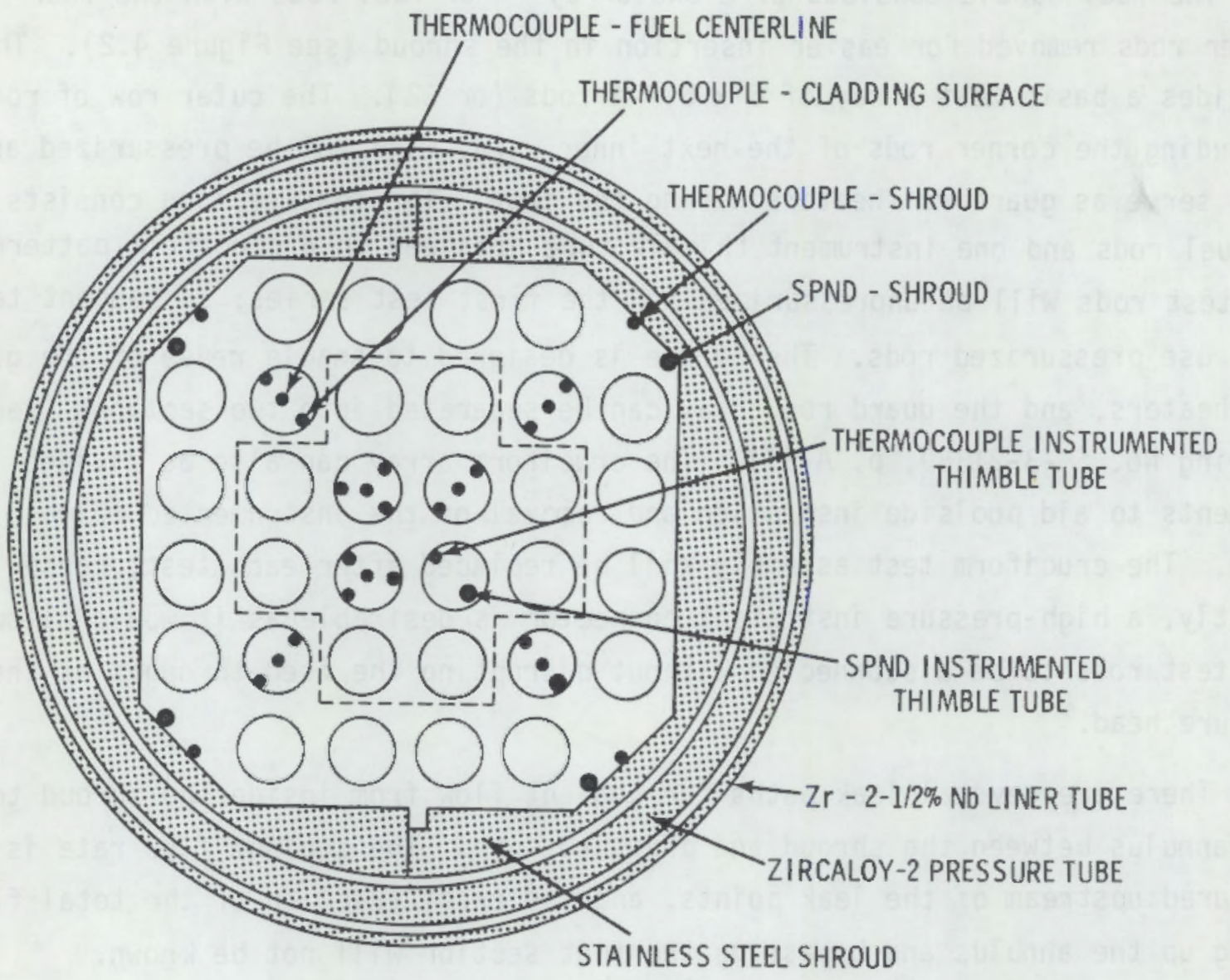

FIGURE 4.2. Schematic Cross Section of Assembly Illustrating Instrument Locations

Recent measurements ${ }^{(a)}$ have shown the bypass leak flow rate to be greater than $2.2 \%$ of the revised (higher) test assembly flow rate. An analysis ${ }^{(b)}$ using the higher test assembly flow rate and a leak flow rate of $3 \%$ predicts a peak pressure tube temperature of about $573 \mathrm{~K}\left(572^{\circ} \mathrm{F}\right)$. The recent report develops the argument that the peak pressure tube temperature would be limited to approximately the saturation temperature at the operating pressure.

(a) Quigley, M. S. August 28, 1980, Memo to G. M. Hesson. "NRU 12-ft Shroud Leak Test Results." Pacific Northwest Laboratory, Richland, Washington 99352.

(b) Hesson, G. M. September 22, 1980, Memo to G. E. Russcher. "Garma Heat Removal Adequacy for the NRU-LOCA Test Assembly." Pacific Northwest Laboratory, Richland, Washington 99352. 


\subsection{INSTRUMENTATION}

The general descriptions and locations of the various instruments included in the test train and main loop of the reactor are given here.

\subsubsection{Test Tra in Instrumentation}

Instruments included in the test train are described here. Details can be found in drawings that are included in Appendix A ( $\mathrm{H}-3-41804$, Sheets 1 and 2).

\subsubsection{Flow Measurements}

The flow rates of the pressurized water during the preconditioning phase, the steam flow rate prior to heatup, and the reflood flow rates must be measured. All of these flow rates will be measured by loop instrumentation and will not be part of the test train instrumentation.

The bundle flow rates will be calculated from the measurement of the loop flow rates taken during the test. The ratio of bundle flow rate to total loop flow rate will be measured in an out-of-reactor mockup, and the in-reactor bundle flow rate will be determined from this data.

The steam and reflood flow rates will be measured by loop instrumentation located outside the reactor core.

\subsubsection{Temperature}

All temperature measurements will be made with thermocouples that have Inconel 600 sheaths and chromel-alumel thermoelements insulated with magnesia $(\mathrm{MgO})$. The nominal diameter of all thermocouples is $1.0 \mathrm{~mm}(0.039 \mathrm{in}$.$) . Some$ of the thermocouples have dual diameters with the $1.0-\mathrm{mm}$ diameter reduced to either $0.5 \mathrm{~mm}(0.020 \mathrm{in.})$ or $0.25 \mathrm{~mm}(0.010 \mathrm{in.})$. Thermocouples will be placed in the following locations.

- cladding outside surface

- fuel centerline

- pellet-to-cladding gap

- shroud

- spacer and thimble

- coolant inlet, outlet and their difference 
- hanger tube

- test section outlet piping.

All thermocouple outputs will be monitored by the data acquisition and control system (DACS). The thermocouples attached to the hanger tube and located in the test section outlet piping will be designed so that a failure logic of 2 out of 3 can be incorporated in the reactor trip circuit.

Cladding Outside Surface Thermocouples. PNL has modified a method of attaching thermocouples to the cladding that was developed by Gesellschaft fur Kernforschung (GFK) at Karlsruhe, Federal Republic of Germany. This attachment as it applies to the low-pressure phase of a LOCA is described by Karb (1978). A platinum jacket is flattened at one end and swaged over the junction end of the thermocouple and the flattened portion is resistance-welded to the cladding. The cladding temperature as measured by the thermocouple is reported to be with in $\pm 35 \mathrm{~K}\left(63^{\circ} \mathrm{F}\right)$ of the true cladding temperature and the influence of gamma heating is smal1 $[0.5 \mathrm{~W} / \mathrm{cm}(0.015 \mathrm{~kW} / \mathrm{ft})]$, causing a temperature increase of 10K $\left(18^{\circ} \mathrm{F}\right)$ (Fischer and Osborne 1978). In the PNL version, the flattened portion is eliminated and the jacket is resistance-welded to the cladding as shown in Figure 4.3.

The thermocouples will be attached to the cladding at the hot junction end. The cable will be routed to the nearest guard rod spacer, across the spacer to the corner of the bundle, and up the space between the bundle and the shroud. The thermocouples are of dual diameter: $0.5 \mathrm{~mm}(0.020 \mathrm{in}$.) over the portion extending from the hot junction end to the corner of the bundle and $1.0 \mathrm{~mm}(0.039 \mathrm{in.})$ for that portion extending up between the bundle and the shroud.

Fuel Centerline Thermocouples. The types of sheath and thermoelements to be employed in measuring fuel centerline temperatures were selected on the basis of studies of EG\&G's (a) reported in-reactor experience in measuring fuel temperatures and on calculations made of the fuel rod center line temperatures expected in the NRU test.

(a) EG\&G, Idaho, Inc., Idaho Falls, Idaho 


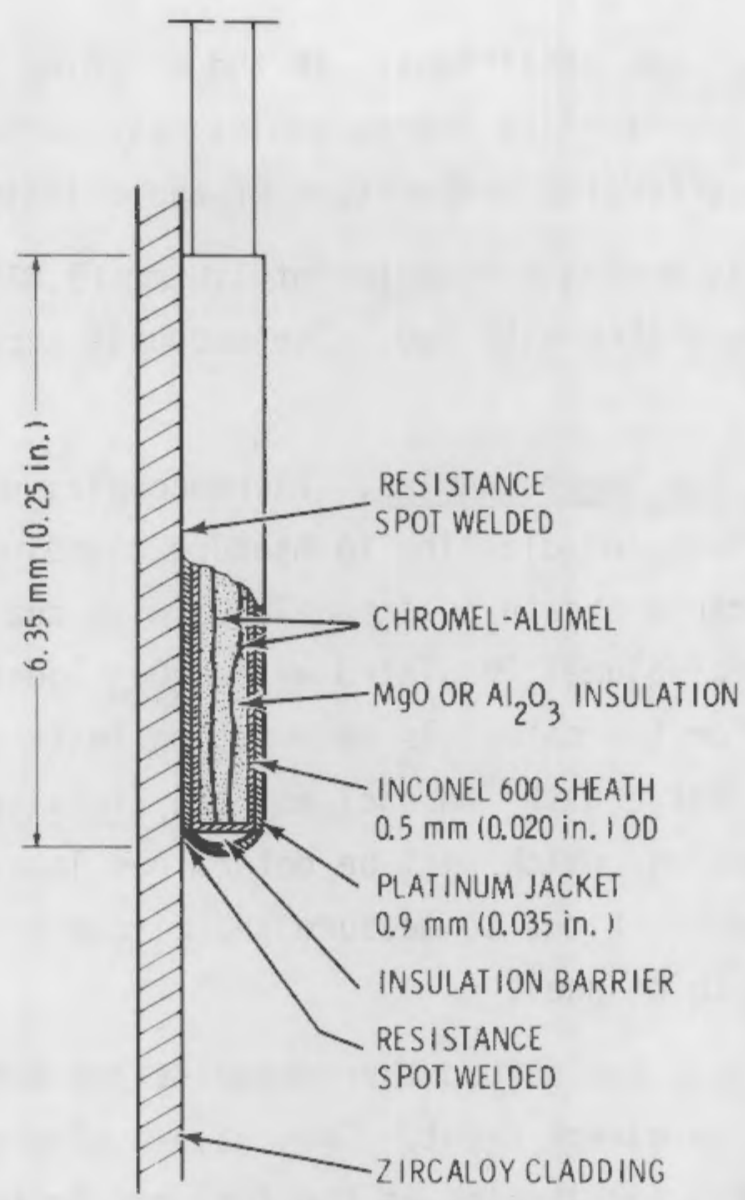

FIGURE 4.3. PNL Thermocouple as Attached to the Outside Surface of the Fuel Rod Cladding

EG\&G's experiences with Inconel 600-sheathed, chromel-alumel thermocouples for measuring off-center fuel temperatures were reviewed for gap conductance tests GC2-1, -2, and -3 (Cook 1978; Kerwin 1978; Murdock 1978). Their measurements were made with a total of 20 thermocouples. Three of the 20 thermocouples survived at $1950 \mathrm{~K}\left(3050^{\circ} \mathrm{F}\right)$ for 4 hours during steady state and power oscillations. The test was a gap conductance test with the rod power oscillating to $68 \mathrm{~kW} / \mathrm{m}$. Postirradiation examination revealed that the sheaths of these thermocouples had melted sometime during the power oscillation to the $68 \mathrm{~kW} / \mathrm{m}$ phase of the test. The remaining thermocouples operated near $1675 \mathrm{~K}\left(2555^{\circ} \mathrm{F}\right)$ and $1255 \mathrm{~K}\left(1800^{\circ} \mathrm{F}\right)$ for several hours of steady state and power oscillations.

These results and PNL's study of fuel temperatures expected in the tests demonstrate that Inconel 600-sheathed thermocouples would operate 
satisfactorily under NRU test conditions. If the cladding temperature reaches $1480 \mathrm{~K}\left(2220^{\circ} \mathrm{F}\right)$, the fuel centerline thermocouples may continue to operate at the corresponding fuel centerline temperature of approximately $1516 \mathrm{~K}\left(2270^{\circ} \mathrm{F}\right)$.

The cable sheath has a single diameter of $1.0 \mathrm{~mm}$ (0.039 in.) with chromelalumel thermoelements insulated with MgO. Thermocouple accuracy is estimated to be $\pm 3 \%$.

Pellet-to-Cladding Gap Thermocouples. Thermocouples will be located in the gap between the pellets and cladding to measure cladding inner diameter (I0) temperature. The cable sheath is Inconel 600 with dual diameters; the thermoelements are chromel-alumel insulated with $\mathrm{MgO}$. These thermocouples will be coated with niobium for the materials deformation tests to reduce the potential eutectic reactions between the Inconel and the Zircaloy at higher temperatures. At a given elevation, which will be determined later, gap thermocouples will be located at three positions to measure the circumferential temperature variations from channel to channel.

Shroud Thermocouples. The shroud thermocouples are designed to provide an axial indication of the quench front. They have a single diameter and are the same in design, except for length, as the fuel centerline thermocouples. At the hot junction end, the sheath will be resistance-welded directly to the inside surface of the ss shroud, and the cable will be routed up the corner in the space between the bundle and shroud.

Spacer and Thimble Thermocouples. The spacer and thimble thermocouples, will provide a radial indication of the quench front along with the shroud thermocouples. They have dual diameters, and the attachment to the spacer and the thimble and cable routing will be essentially the same as for the cladding outside surface thermocouples. A hole at the bottom of the thimble and at the axial locations where thermocouple hardlines exit the thimble allow the thimble to fill with coolant fluid. The remaining portion of the thimble is filled with instruments and instrument hardiines.

Loop Coolant Thermocouples. Thermocouples will be located at the inlet and outlet of the rod bundle to measure the temperature at these locations. Thermocouples connected in opposition will measure the coolant temperature increase directly and will have single diameters. 


\subsubsection{Rod Pressure}

Internal pressure of the fue 1 rod will be measured on one rod per bundle with $\operatorname{Kaman}^{(a)}$ model 1921 pressure transducers (see drawing H-3-41882, p. A-23). The transducer will be welded directly to the upper end of a transition piece that is welded to the cladding.

To detect fue 1 rod failure for the materials tests, devices will be attached to ten fuel rods per bundle in the same manner as are the pressure transducers. These devices are on/off, pressure-actuated switches and will signal the reduction in fuel rod pressure resulting from a breach in the cladding. Ten pressure detectors per cladding deformation bundle will be used to indicate fuel rod failure. A pressure sensor will be used on the remaining test rod and will also indicate fuel rod failure.

The in-reactor accuracy of the Kaman pressure transducers is difficult to predict. The out-of-reactor, least-squares linearity at temperatures above $477 \mathrm{~K}\left(400^{\circ} \mathrm{F}\right)$ is specified to be within $\pm 3 \%$ of full-scale operation. A model 1921 sensor tested out of reactor (Billeter et al. 1978) exhibited sensitivity to ambient temperatures and to temperature gradients along the sensor. The addition of a heat-conducting shield reduced the temperature gradients along the sensor. Out-of-reactor and in-reactor tests reported by Kaman (1975) on pressure transducers similar in design to the model 1921 showed error shifts resulting from changes in radiation level; these were attributed to heating by ganma radiation. Because of these temperature and radiation effects, the inreactor accuracy of the model 1921 pressure transducers cannot be confidently predicted.

The output signals from the pressure transducers and failure detectors will be monitored with the data acquisition and control system.

\subsubsection{Neutronics}

SPNDs with cobalt emitters are radially and axially distributed along the bundle to measure the neutron flux levels during steady-state and transient

(a) Kaman Science Corporation, Colorado Springs, Colorado. 
test operations. The collectors are located on the shroud (drawing H-3-41811, p. $A-10$ ) and thimble (drawing $\mathrm{H}-3-41816, \mathrm{~A}-15$ ) and are secured by straps that are spot-welded to the surface of the shroud or thimble.

During steady-state testing, the total power generated with in the loop pressure tube is obtained from the loop instrumentation. The bunde fission power is obtained by correcting the total power for the estimated gamma power component. The axial distribution of the bundle fission power is determined from the signal outputs of the axially distributed SPNDs. In addition, the linear heat rating at a given point in a single rod is calculated from measured fuel centerline and cladding surface temperatures taken at a small gap location in the rod. This local heat rating is adjusted with the outputs from the axially distributed SPNDs to provide a measure of the axial power distribution of a single fuel rod.

Thus, the axially distributed SPND outputs are calibrated for both bundle and single rod powers and can be used to signal over-power conditions. The SPNDs will have a response time, 0 to $63 \%$ of full-scale, that is $\sim 1 \mathrm{~ms}$.

The accuracy of the neutron detectors can be visualized by referring to the schematic arrangement of the detectors and signal conditioning equipment (Figure 4.4). The output from the detector is a low-level direct current. The current from the detector and background cable can follow two paths to ground: it can be shunted through the $\mathrm{MgO}$ insulation, resistance $R_{\ell}$, to ground and it can flow through the matching resistors, $R_{\ell}$, to ground. The net voltage drop

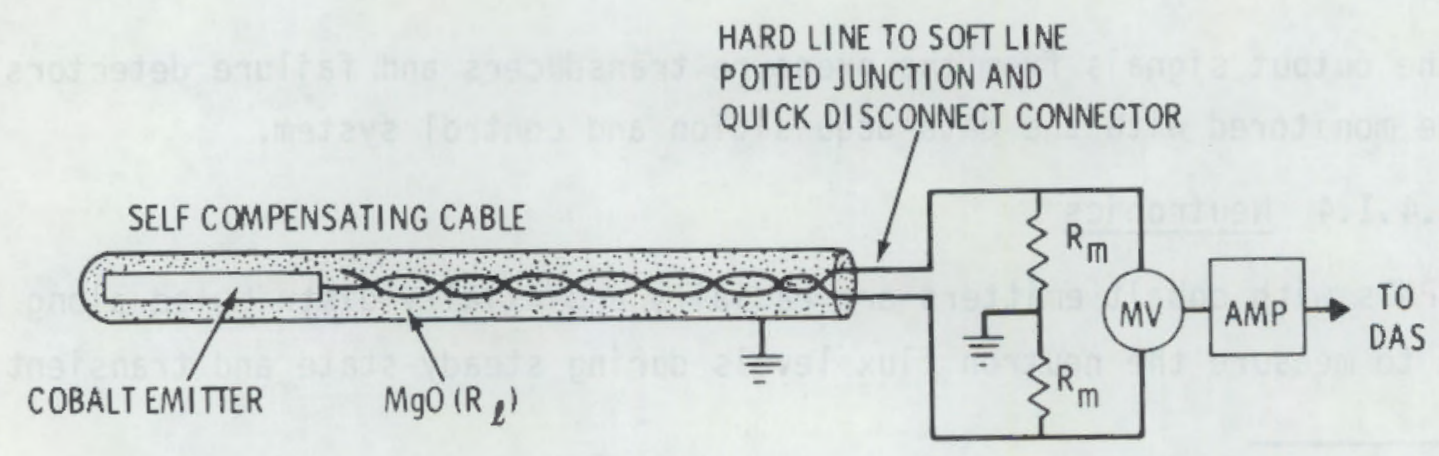

FIGURE 4.4. Schematic Arrangement of Neutron Detector and Signal Cond itioner 
across the matching resistors is amplified and becomes the input to the data acquisition and control system. High accuracy of the detectors is assured by minimizing the output current flowing through $R_{\ell}$ and maximizing the current flowing through the matching resistors. The detector output must be accurate to less than 1\%. To assure that this criterion is met, the resistance of the matching resistors must be lower than $R_{\ell}$ by a factor of 100 or more. The resistance of the $\mathrm{MgO}$ insulation, $R_{\ell}$, is a function of its temperature and decreases with increasing temperature. Accordingly, the accuracy of the detectors is a function of temperature and decreases with increasing temperature.

\subsubsection{Loop Instrumentation Measurement Requirements}

The U-2 loop instrumentation provides signals to indicators, alarms, trips, and recorders. A simplified schematic of the U-2 loop is shown in Figure 4.5. See Russcher et al (1981) for a schematic of the steam and reflood systems. To safely operate the NRU facility, loop operators require indicators, alarms and reactor trips. Researchers require indicators to run their tests properly, recorded information to analyze data, and alarms and trips to prevent damage to the test fuel.

The U-2 loop instrumentation that is connected to the data acquisition control system (DACS) is representative of that used for the preconditioning phase of the test.

\subsubsection{Pressure Sensing}

The differential pressure monitor for test section 1 uses an ITT Barton Model 368 Transmitter that shows a change in the test section flow resistance for steady-state operating conditions.

\subsubsection{Loop Instrumentation}

Instruments that are included in the U-2 10op of the reactor are described to provide an overview. Figure 4.5 shows the basic components and layout of the U-2 loop.

\subsubsection{Main Loop Flow}

Main loop flow is measured using a Venturi flowmeter at the inlet of test section 1. A Barton Differential Pressure Unit 199 with Taylor F-28T transmitter is used. 


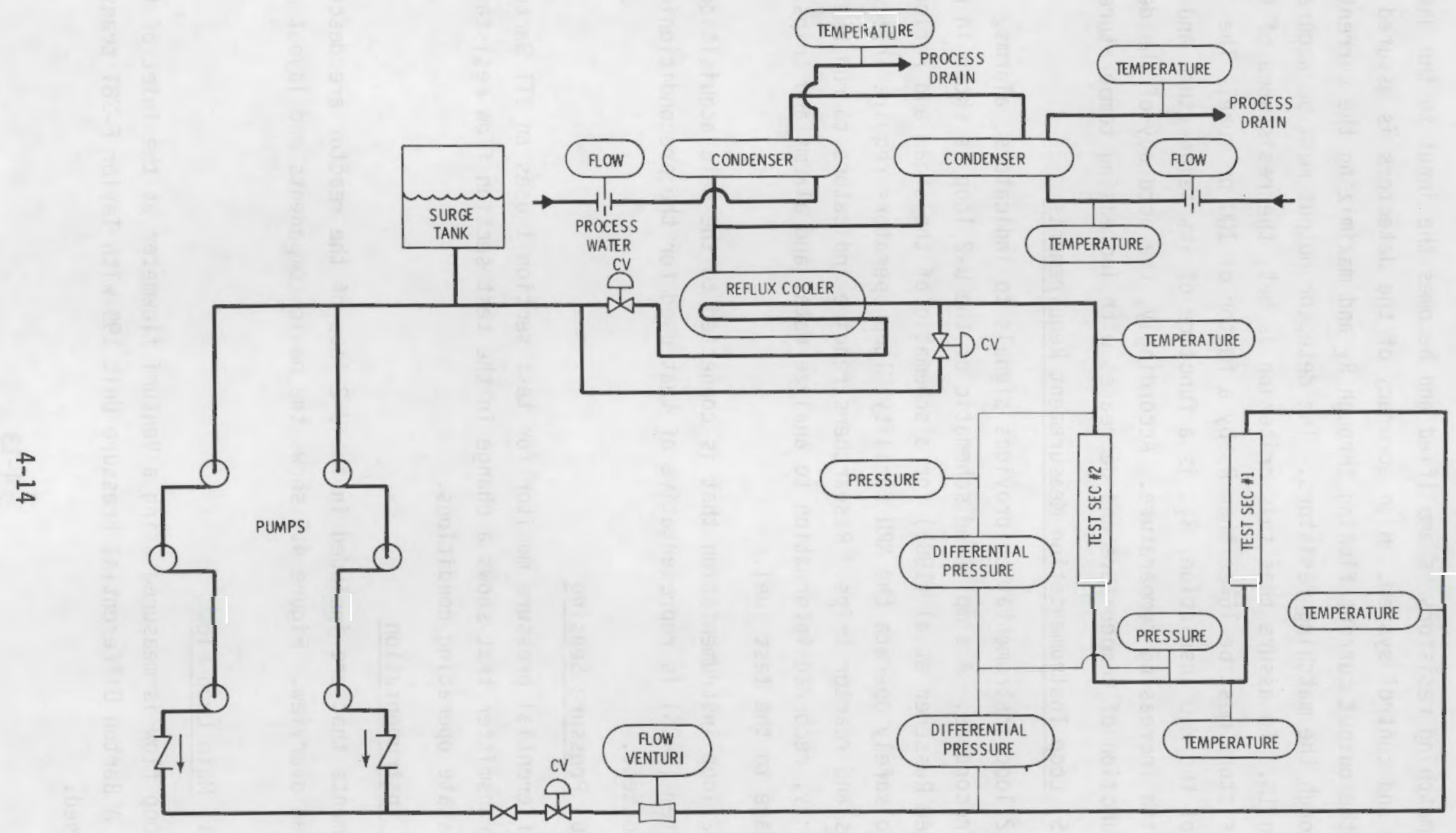

FIGURE 4.5. Simplified Schematic of U-2 Loop 


\subsubsection{Temperature Sensing}

Temperature sensing is accomplished with Rosemount Series 77 and 78 platinum temperature detectors that are typically spring-loaded in a thermowell and are used with a Rosemount bridge. The DACS uses individual detector and bridge calibration tables for improved accuracy.

Temperature sensors detect inlet and outlet temperatures of the test section and cooling water temperatures of the condenser inlet and outlet.

\subsubsection{Alarms and Trips}

\subsubsection{Preconditioning Phase}

During this phase the test section will be connected to the U-2 Loop and the following standard reactor trips will be in service.

- test section outlet temperature (high)

- pump sub-cooling delta T (low)

- test section water flow (low)

- surge tank level (low)

- surge tank pressure (high)

- manual

In addition, the following two special reactor trips will be in service.

- Hanger tube (high) temperature: Thermocouples at the bottom of the fuel hanger tube (leve1 21) will actuate the trip to protect the pressure tube from overheating.

- Outlet piping (high) temperature: Thermocouples on the outlet piping will trip the reactor to minimize thermal expansion stresses in the outlet piping.

\subsubsection{Pretransient Phase}

During this phase, the test section will be connected to the U-1 loop steam-reflood water supply and will discharge to the loop catch tanks. The following four trips will be in service:

- hanger tube (high) temperature

- outlet piping (high) temperature 
- (low) steam flow: this trip will actuate if steam flow drops below an acceptable level during the pretransient phase (the trip signal will come from the steam control circuit)

- manual.

\subsubsection{Transient Phase}

This phase will immediately follow the pretransient phase with the following seven trips in service:

- hanger tube (high) temperature

- outlet piping (high) temperature

- fuel cladding (high) temperature--The reactor will trip if the temperature of the fuel cladding at the hottest point exceeds the trip setpoint temperature. The trip signal will be computed by the DACS. Allowance will be made to compensate for the difference between the computed maximum temperature and the measured average temperature.

- reflood low flow--This trip will actuate if the normal reflood fails and the standby reflood flow is insufficient. The trip signal will be actuated from the reflood control circuit logic.

- accumulators low inventory--This trip will automatically shut the reactor down when the accumulators are nearly empty.

- transient termination time--This trip will automatically shut the reactor down at a predetermined time for each transient, if shutdown has not occurred by other means.

- manual.

All the above reactor trip circuits will be triplicated, but five of them (low steam flow, fuel cladding high temperature, reflood low flow, accumulators low inventory, transient termination time) will be single-sensor trips in that a single signal will actuate the triplicated trip. 


\subsection{CRITICALITY AND TEST FUEL MANAGEMENT}

Among the most important considerations are those of managing the supply and movement of fuels used in testing. The CRNL staff responsible for the buildings in which the material will be stored or examined will also be responsible for its handling and transfer according to the appropriate criticality regulations.

\subsection{CRITICALITY}

The test fuel assemblies will be manufactured in the United States and shipped to Chalk River where they will be assembled and installed in the test train. The storage and final assembly will take place within the NRU reactor building. After irradiation, the test assembly will be transferred to the storage bay in the NRU building for examination. Partial disassembly will take place underwater, then fresh fuel will be added and the assembly will be returned for the next test.

At the end of the test series, selected portions of the fuel will be transferred to the Universal Cell in the 234 Building for examination. A11 material from both examination sites will eventually be removed for disposal.

The total complement of fuel will be approximately 172 fuel pins. This is equivalent to about $340 \mathrm{~kg}$ of uranium dioxide; at 3 wt\% ${ }^{235} \mathrm{U}$ enrichment this is roughly $10 \mathrm{~kg}$ of ${ }^{235} \mathrm{U}$.

The test assemblies' storage in the NRU bay was analyzed on a preliminary basis. The minimum critical number of $0.8 \mathrm{~cm}-d i a, 4 \mathrm{wt} \%{ }^{235} \mathrm{U}$ enriched rods is 164. (Note: this is conservative since the expected enrichment is 3 wt\% $235_{\mathrm{U}}$.) The 40 guard heater rods, the 66 inner test rods and 66 spare rods are to be stored in the bay at least $30 \mathrm{~cm}$ from one another and from all other fissionable material in the storage basin. Guard and inner test rods can be brought together in one test assembly of 31 rods. This assembly also will be separated from all other fissionable materials by $30 \mathrm{~cm}$.

Based on these restrictions, only four groups of PNL material are allowed in the bay at any given time. Each of these is neutronically isolated (by 
$30 \mathrm{~cm}$ of light water) from other fissionable material. Each group is limited to 40 guard heater rods, $25 \%$ of the minimum critical number of rods; 66 inner test rods, $40 \%$ of the minimum critical number of rods; and 31 rods in a test assembly, $19 \%$ of the minimum critical number of rods.

\subsection{TEST FUEL MANAGEMENT}

For each of the tests, the NRU driver fue 1 will be arranged in such a manner as to minimize the variables in the flux profiles between the tests.

Different test assemblies and components within each assembly will receive different exposures. Fuel pins within a materials test assembly could see an exposure as low as 3 MWD/MT (oxide), and the maximum possible exposure would be found in the guard heater rods. If one set of rods is used in all six tests, its exposure could be 25 MND/MT (oxide). 


\subsection{OPERATING PROCEDURES AND CONDITIONS}

The basic NRU test series has been developed around relative comparisons between a set of well-characterized prototypic thermal-hydraulic tests (no cladding failure) and a series of cladding deformation or materials tests. Practical constraints on the test matrix include a time-temperature-stress limit on the NRU pressure tube, a fission product inventory with in the fuel bundle, a contractual limit of 7 days during which the NRU reactor is dedicated to these tests, and a 2- to 4-month, NRU operations-related interval between tests.

The test sequence will be standardized as much as possible for more direct comparisons between individual tests. The basic test series will consist of first, a series of prototypic thermal-hydraulic tests conducted on the same fuel assembly within a 7-day interval; and second, five separate cladding deformation tests where dilatation and failure of the cladding will occur.

The thermal-hydraulic test series will be conducted in the first of six available test periods. All of the rods will be unpressurized; consequentiy, no severe cladding deformation will occur. The thermal-hydraulic test series will provide replicate conditions for assessment of mathematical heatup and reflood models; it will also serve to calibrate the response of the system and define the boundary conditions for the pressurized rod assemblies where severe deformation and rupture will occur. The thermal-hydraulic tests will also provide a transition from well-controlled and rather benign test conditions to more severe conditions. The current design for the thermal-hydraulic tests uses one heatup rate to minimize control problems and experimental perturbations. Reflood rates and reflood delay times will be combined to reverse the temperature transient at the desired peak cladding temperature limit. The proposed number of tests and estimated peak cladding temperatures are given in Tables 3.1 and 3.2 .

The reflood delay times and reflood rates will be specially selected for each experiment before the nuclear tests begin. The exact combination of these parameters will depend upon heating rate and the design of loop modifications. These tests will provide a large amount of data on the reproducibility of 
experiments in the NRU facility and thus provide measured experimental variances that are required to adequately characterize the prototypic data.

The material deformation tests will be controlled by presetting the initial reactor conditions on the basis of information obtained from the thermalhydraulic tests. The materials deformation tests will contain prepressurized rods; consequently, it will not be possible to use the same set of test rods for replicate tests. Reflood rate, reflood delay time, and peak cladding temperature will be the primary variables considered. Performance of the materials deformation tests requires extensive information from previous tests; therefore, actual combinations of parameters will not be set until later in the program.

All cladding tubes will be precharacterized for variations in wall thickness and the location of acceptable defects. Each rod's orientation within the assembly will be controlled to ensure correct instrument placement and provide traceability to precharacterization data. The first three cladding deformation tests will be performed to investigate peak cladding temperatures less than or equal to $1033 \mathrm{~K}\left(1400^{\circ} \mathrm{F}\right)$. Dilatation and rupture of the cladding test fuel rods will depend on the internal pressure and the time-temperature relationships used in the heatup phase of the transient. Rod pressures for the first three cladding deformation tests have been established at $3.06 \mathrm{MPa}$ (450 psi). Section 9.8 addresses calculational results of cladding temperature histories for our postulated matrix of reflood rates and reflood delay times.

The rod pressure level for the first three cladding tests is typical of contemporary PWR designs. It will provide stresses sufficient to rupture a significant number of rods during the first three tests. Conditions for the last two tests will depend heavily on knowledge available at that particular point in the testing sequence.

\subsection{INSTALLATION OF ASSEMBLY}

- Installation Procedure - Thermal-Hydraulic Test Assembly

The test train will be reassembled in the horizontal attitude in the NRU reactor hall on a modified CRNL strongback. This assembly will be made 
in accordance with the applicable test assembly procedure. All instruments will be checked in accordance with applicable checkout and calibration procedures.

The test train will be reoriented to a vertical attitude by lifting the strongback with the bridge crane located in the reactor hall and by fixing the strongback to a vertical face of the reactor-elevator structure. Using the bridge crane, the test train will be removed from the strongback and inserted into a prototypic reactor pressure tube mounted alongside the strongback. This insertion will serve as a final gage for the overall test train envelope.

The test train will then be transported to the reactor location and inserted into the U-2 loop. Care should be exercised to assure correct radial orientation before installing the loop sealing rings. These rings will be installed in accordance with the appropriate installation procedure. The instrument leads to the DACS will be connected at the three multicontact cable connectors just below the test lifting ring. The test train will then be ready for final checkout procedure.

- Installation - Materials Test Assembly

For the materials test, a fresh test assembly replaces the thermalhydraulic test rods. The guard rods are used for all tests. The test assembly, guard rods, instrumented thimble tube and shroud are reassembled on the disassembly, examination, reassembly machine (DERM) in the examination. Once reassembled, the test assembly is transferred to the transfer can, carried to the bridge, and stored awaiting transfer to the loop via the J-rod flask for the next test.

- Reactivity Check and Criticality Measurements

In order that this SAR meets Atomic Energy Canada, Ltd. (AECL) requirements for the reactivity check and criticality measurement, a complete description of the fuel is included in Appendix G. Included in this fuel description will be the fissile and fertile material content and distribution in the fuel rods. With the above information, AECL will perform the criticality analys is with the test assembly in and out of the reactor to establish the worth of NRU control rods. 


\subsection{STARTUP AND OPERATING PROCEDURE}

Two types of tests are planned for these experiments. The first type will take place during the first operating period and is the "prototypic thermalhydraulic" test series. This type of test is intended to provide 1) an experimental data base of heatup-reflood information that will be available for thermal-hydraulic code verification and 2) a calibration of the test system that will be used to define the necessary operating conditions for subsequent tests. The fuel rods for these tests will be nonpressurized. Fuel rod failure is not expected and only insignificant fuel cladding deformation should occur. About 45 tests have been planned--the first under mild conditions, and successive tests under progressively more difficult conditions.

Tests of the second type are planned for the five operating periods following the first tests and are the "cladding materials deformation" tests. Their purpose is to provide information concerning the fuel failure modes and geometry. The central 11 rods will be pressurized enough to balloon and rupture during the course of the test. The outer 20 rods will be unpressurized rods that function as guard rods and are reusable for successive tests.

The startup procedure for the two types of experiments will be essentially identical, proceeding in three phases.

\subsubsection{Preconditioning Phase}

The first or preconditioning phase is designed to cause some fuel pellet cracking and relocation. The preconditioning phase, after the test assembly is installed, will occur as follows:

- With the reactor power at zero, coolant will begin to flow through the test loop, and the flow will be established to design operating conditions.

- The reactor power will then be increased, slowly, through a series of steps until the test assembly reaches design power or the reactor reaches its maximum power. (a) Physics calculations show that the design test

(a) There will not be enough time for a fuel rod shuffle. Before the test, the fuel will be arranged so that the test conditions as predicted by NRU physicists are optimized. 
assembly power of $19.6 \mathrm{~kW} / \mathrm{m}(6 \mathrm{~kW} / \mathrm{ft})$ will be reached if the test assembly is surrounded by fresh fuel and the reactor is operated at $127 \mathrm{MW}$. The test assembly design power is $23 \mathrm{~kW} / \mathrm{m}(7.0 \mathrm{~kW} / \mathrm{ft})$ average. Power calibration data will be taken at each step. The Operations Branch of NRU will set the rate of power increase.

- Once the test assembly power has been established and the necessary data recorded, the reactor power will be decreased as rapidly as possible to zero power.

The above sequence may be repeated, if time permits, during the 7-day inreactor testing window.

\subsubsection{Pretransient Phase}

The second phase of the startup is the pretransient phase, the condition occurring prior to simulated reflood. After the preconditioning phase is complete, the reactor will be shut down and the loop piping modified to provide steam coolant and reflood water to the test loop. The flow diagram for the pretransient and transient piping systems is shown in Figure 6.1 (Kendrick 1979). The pretransient phase will then occur as follows:

- Dry steam coolant at up to $1363 \mathrm{~kg} / \mathrm{hr}(3000 \mathrm{lb} / \mathrm{hr})$ will be supplied to the test loop. The loop in let pressure will be established as close to $0.28 \mathrm{MPa}$ (40 psia) as possible, but, in any case, low enough that superheated steam conditions will exist at the loop inlet instrument location. The superheat requirement is imposed so that meaningful steam temperatures can be measured.

- The reactor power will then be increased in a series of steps until the test assembly reaches design power with a peak fuel cladding temperature of $700 \mathrm{~K}\left(800^{\circ} \mathrm{F}\right)$ or the reactor reaches its maximum power. Power calibration data will be taken at each step. The rate of power increase is to be set by NRU Operations Branch.

The relative power distribution determined from the SPND array is tied to an absolute power measurement through two techniques: the first based on distributing the power determined from a thermal balance on the entire 


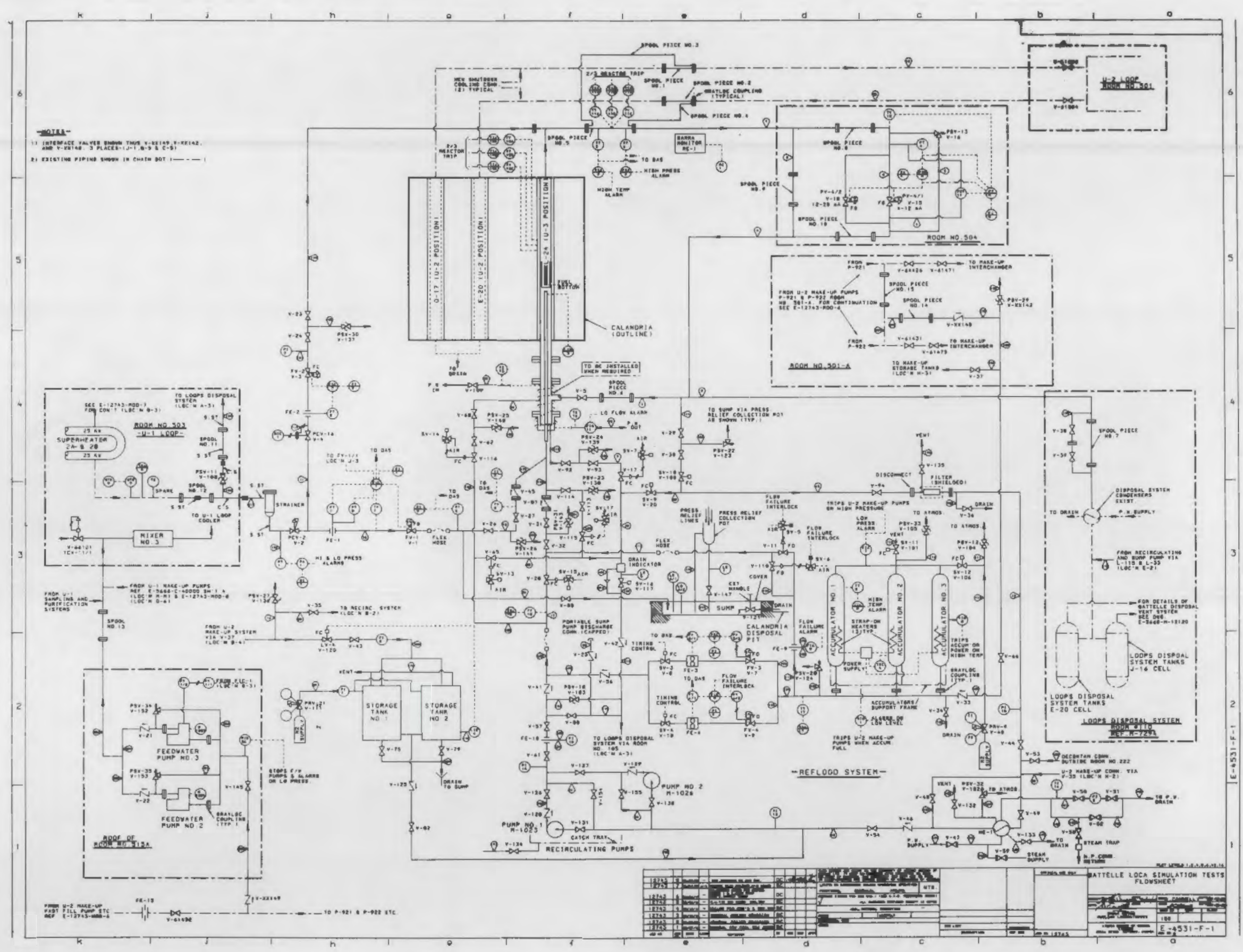

FIGURE 6.1. Pretransient and Transient Phase Piping System 

assembly during the steady-state preconditioning period in both the waterfilled and steam-filled conditions; and the second using centerline fuel thermocouples at one elevation to improve the absolute power measurements. This approach has been utilized successfully in other tests (Hann et al. 1977) and is based on the fact that the fuel rod can be one of the best power measuring instruments. By determining the fuel centerline temperature and the cladding surface temperature, the fuel rod power can be calculated from the temperature difference provided that the $\mathrm{UO}_{2}$ thermal conductivity is known. The fuel thermal conductivity of archive $\mathrm{UO}_{2}$ pellets will be determined at PNL to reduce the uncertainty associated with using values taken from the literature. Furthermore, a small fuelcladding gap will be utilized in the vicinity of the thermocouple hot junctions to produce a high gap conductance and thus minimize the uncertainties associated with the temperature gradient across the gap. The small gap will be produced by $5 \mathrm{~cm}$ of pellets slightly larger than the standard pellets.

- The reactor power will be maintained at the maximum reached in the prior step until the transient is initiated.

\subsubsection{Transient Phase}

The following procedure will be used for the third phase.

- The steam coolant flow of the steady-state, steam-cooled pretransient phase will be stopped as quickly as possible.

- At some predetermined time after the steam flow has ceased, the reflood water will be introduced. The elapsed time to reflood initiation is one of the experimental variables and can range from $0 \mathrm{sec}$ to as much as $60 \mathrm{sec}$.

- Several seconds to a few minutes after reflood has been initiated, adequate cooling of the test assembly will be reestablished and the test loop will fill with reflood water, thus terminating the test.

The first type of test, the thermal-hydraulic test, will entail several successive iterations of the pretransient and transient phases. The reflood 
rate and reflood delay time will be varied for successive tests so that the peak fuel cladding temperature reached during the transient will vary. The choice of experimental variations will be such that the first tests result in mild temperature excursions; successive tests will be tailored to result in more and more severe temperature excursions, to a peak of about $1310 \mathrm{~K}\left(1900^{\circ} \mathrm{F}\right)$. Replicate runs are planned. The total number of such runs will be as many as can be made during the allowed operating period. See Table 3.1 and Figure 3.1.

The second type of test, the materials tests, will require one sequence of the three phases since the transient phase will be designed to cause the desired rupture of the central 11 test fuel rods. See Table 3.2.

\subsection{TEST OPERATING CONDITIONS}

This section includes the operating limits for the preconditioning and pretransient phases and transient LOCA simulation.

\subsubsection{Operating Limits for Preconditioning}

The preconditioning phase is intended to provide an environment that will cause some cracking and relocation to simulate fuel pellets in a power reactor. To achieve this, the test assembly will be operated at conditions approximating those of a PWR for as short a time as possible to minimize the fission product inventory in the fuel. The test assembly will be irradiated less than an hour or just long enough to record data and determine loop power.

The latest physics calculations give average fuel rod powers of 17.1 and $19.7 \mathrm{~kW} / \mathrm{m}$ for enrichments of $2.5 \%$ and $3.0 \%{ }^{235} \mathrm{U}$, respectively, at a reactor power of $127 \mathrm{MW}$. The expected enrichment is $2.8 \%$, which gives an expected average power close to $19.7 \mathrm{~kW} / \mathrm{m}$.

The operating conditions based on a power of $23 \mathrm{~kW} / \mathrm{m}(7.0 \mathrm{~kW} / \mathrm{ft})$, somewhat above the maximum expected average power of $19.9 \mathrm{~kW} / \mathrm{m}(6.06 \mathrm{~kW} / \mathrm{ft})$, were determined using the COBRA-IV computer code. Preconditioning will be done using an outlet pressure of $8.62 \mathrm{MPa}$ (1250 psia), an outlet temperature of $564 \mathrm{~K}\left(524^{\circ} \mathrm{F}\right.$ ) and a temperature increase across the test assembly of $29 \mathrm{~K}\left(52^{\circ} \mathrm{F}\right)$. The operating conditions arising from these assumptions are given in Table 6.1. Figure 6.2 shows the radial coolant temperature distribution at the test assembly outlet. 
TABLE 6.1. Preconditioning Operation Surmary

\begin{tabular}{|c|c|c|c|c|c|c|}
\hline \multirow[b]{2}{*}{ Parameter-Units } & Low & \multirow{2}{*}{$\begin{array}{l}\text { Flow } \\
\text { AcceptabTe } \\
\text { Range }\end{array}$} & \multicolumn{2}{|c|}{ Low Pressure } & \multicolumn{2}{|c|}{ Optimum Design } \\
\hline & Values & & Values & $\begin{array}{l}\text { Acceptable } \\
\text { Range } \\
\end{array}$ & Values & $\begin{array}{l}\text { Acceptable } \\
\text { Range }\end{array}$ \\
\hline \multicolumn{7}{|l|}{ Controlled Variables } \\
\hline Coolant Flow $\underset{(\mathrm{ggm})}{\mathrm{kg} / \mathrm{s}}$ & $\begin{array}{l}10.9 \\
(213.2)\end{array}$ & $\begin{array}{l} \pm 5 \% \\
( \pm 5 \%)\end{array}$ & $\begin{array}{l}16.3 \\
(320)\end{array}$ & $\begin{array}{l} \pm 5 \Delta \\
( \pm 5 \Delta)\end{array}$ & $\begin{array}{l}16.3 \\
(320)\end{array}$ & $\begin{array}{l} \pm 5 \% \\
( \pm 5 \%)\end{array}$ \\
\hline \multicolumn{7}{|l|}{ Coolant Purity } \\
\hline Inlet Temperature $\left(\begin{array}{c}K \\
F)\end{array}\right.$ & $\begin{array}{c}503 \\
(447)\end{array}$ & $\begin{array}{l} \pm 3 \mathrm{~K} \\
\left( \pm 5^{\circ} \mathrm{F}\right)\end{array}$ & $\begin{array}{c}495 \\
(432)\end{array}$ & $\begin{array}{l} \pm 3 K \\
\left( \pm 5^{\circ} \mathrm{F}\right)\end{array}$ & $\begin{array}{c}517 \\
(472)\end{array}$ & $\begin{array}{l} \pm 3 \mathrm{~K} \\
\left( \pm 5^{\circ} \mathrm{F}\right)\end{array}$ \\
\hline Outlet Pressure $\begin{array}{c}M P a \\
\text { (psia) }\end{array}$ & $\begin{array}{l}8.62 \\
(1250)\end{array}$ & $\begin{array}{l} \pm 0.34 \\
( \pm 50)\end{array}$ & $\begin{array}{c}6.2 \\
(900)\end{array}$ & $\begin{array}{l} \pm 0.34 \\
( \pm 50)\end{array}$ & $\begin{array}{l}8.62 \\
(1250)\end{array}$ & $\begin{array}{l} \pm 0.34 \\
( \pm 50)\end{array}$ \\
\hline Reactor Power MW & 127 & \pm 5 & 127 & \pm 5 & 127 & \pm 5 \\
\hline Radial Power Skew & & $<5$ & & $<5$ & & $<5$ \\
\hline \multicolumn{7}{|l|}{ Measured Variables } \\
\hline Outlet Temperature $\underset{\left(* \frac{K}{F}\right)}{ }$ & $\begin{array}{c}547 \\
(526)\end{array}$ & $\stackrel{ \pm 6 \mathrm{~K}}{\left( \pm 10^{\circ} \mathrm{F}\right)}$ & $\begin{array}{l}505 \\
(486)\end{array}$ & $\begin{array}{c} \pm 6 K \\
\left( \pm 10^{\circ} \mathrm{F}\right)\end{array}$ & $\begin{array}{c}546 \\
(524)\end{array}$ & $\stackrel{ \pm 6 K}{\left( \pm 10^{\circ} \mathrm{F}\right)}$ \\
\hline 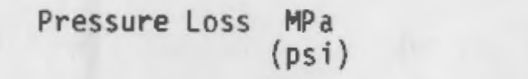 & $\begin{array}{l}0.092 \\
(13.3)\end{array}$ & $\begin{array}{l} \pm 20 \% \\
( \pm 20 \%)\end{array}$ & $\begin{array}{l}0.168 \\
(24.3)\end{array}$ & $\begin{array}{l} \pm 20 \% \\
( \pm 20 \%)\end{array}$ & $\begin{array}{l}0.165 \\
(24.0)\end{array}$ & $\begin{array}{l} \pm 20 \% \\
( \pm 20 \%)\end{array}$ \\
\hline Radial Power Skew & & $<5$ & & $<5$ & & $<5$ \\
\hline \multicolumn{7}{|l|}{ Calculated Variables } \\
\hline Total Test Assembly Power, MW & 2.23 & \pm 5 & 2.23 & $\neq 5$ & 2.23 & \pm 5 \\
\hline Peak Linear Rod Power $\begin{array}{l}\mathrm{kW} / \mathrm{m} \\
(\mathrm{kW} / \mathrm{ft})\end{array}$ & $\begin{array}{l}36.9 \\
(11.2)\end{array}$ & NA & $\begin{array}{c}36.9 \\
(11.2)\end{array}$ & NA & $\begin{array}{l}36.9 \\
(11.2)\end{array}$ & NA \\
\hline $\begin{array}{l}\text { Average Linear Rod Power } \\
\qquad(\mathrm{kw/m}) \\
\qquad(\mathrm{kW/ft})\end{array}$ & $\begin{array}{l}19.8 \\
(6)^{8}\end{array}$ & NA & $\begin{array}{l}19.8 \\
(6)\end{array}$ & NA & $\begin{array}{l}19.8 \\
(6)\end{array}$ & NA \\
\hline Min imum DNBR & 3.43 & NA & 4.08 & NA & $3.87(a)$ & NA \\
\hline Peak Clad Temperature $\left(\begin{array}{c}K \\
\text { ( } F)\end{array}\right.$ & $\begin{array}{c}576 \\
(577)\end{array}$ & $\begin{array}{l}\text { NA } \\
\text { NA }\end{array}$ & $\begin{array}{l}535 \\
(503)\end{array}$ & $\begin{array}{l}\text { NA } \\
\text { NA }\end{array}$ & $\begin{array}{c}567 \\
(561)\end{array}$ & $\begin{array}{l}\text { NA } \\
\text { NA }\end{array}$ \\
\hline
\end{tabular}

(a) ONBR minima compounded for the optimum design acceptable range of variables is 2.93 , based on a memo from W. A. Prather to G. M. Hesson, July 31, 1980, NRU-ONBR Sensitivity Analysis. 


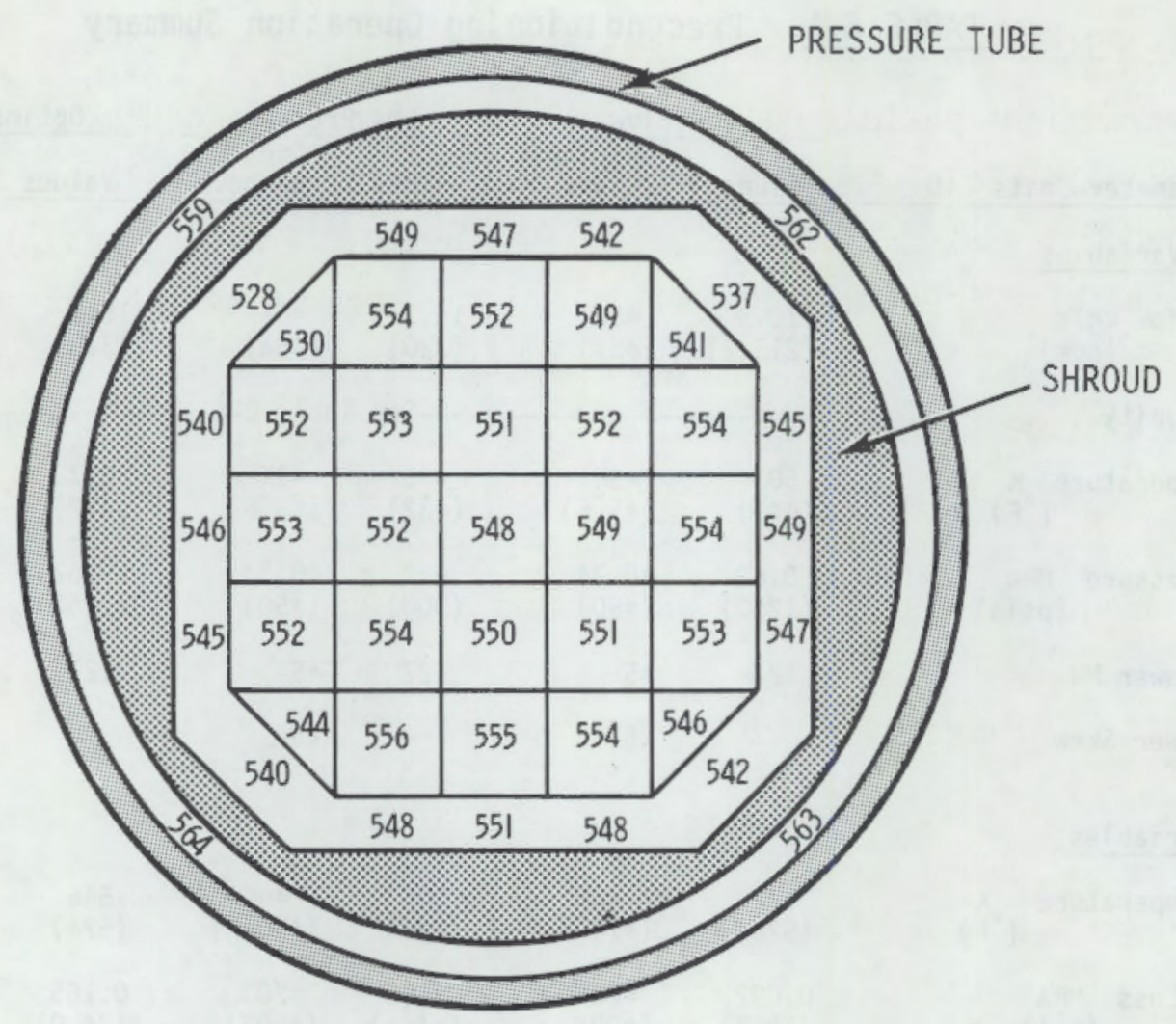

FIGURE 6.2. Out let Coolant Temperature ( $\left.{ }^{\circ} \mathrm{F}\right)$ Distribution During Preconditioning Operation

The temperature distribution is dependent on the radial power distribution and the larger flow areas in the region between the test pins and the shroud. The highest coolant temperatures occur in the annulus between the shroud and pressure tube. These temperatures reflect an assumed $1.0 \%$ bypass flow in this region and the $2 \mathrm{~W} / \mathrm{gm}$ gamma heating in the pressure tube. The peak pressure tube temperature $572 \mathrm{~K}\left(573^{\circ} \mathrm{F}\right)$ is predicted in Prather. (a)

It has been proposed that the test assembly be operated at pressures of less than $8.62 \mathrm{MPa}$ (1250 psia) outlet pressure. As a result of such operation, the corresponding temperatures in Table 6.1 and Figure 6.2 would be changed by an amount approximately equal to the decrease in saturation temperature that is associated with the pressure change. The lower pressure will result in a somewhat larger departure from nucleate boiling ratio (ONBR).

(a) Prather, W. A. July 25, 1980, Memo to G. M. Hesson. "NRU Preconditioning Operating Conditions." Pacific Northwest Laboratory, Richland, Washington 99352. 


\subsubsection{Operating Limits for Pretransient Operation}

The pretransient phase should provide the appropriate initial conditions that are needed to begin the transient tests. The operation will use $1363 \mathrm{~kg} / \mathrm{hr}(3000 \mathrm{lb} / \mathrm{hr}$ ) dry steam coolant at about $0.275 \mathrm{MPa}$ (40 psia) out let pressure and $436 \mathrm{~K}\left(325^{\circ} \mathrm{F}\right)$ in let temperature. The steam flow rate is about the maximum that pressure loss and condenser sizing allow. The exact inlet pressure and inlet temperature are not known at this time; they will depend on the piping configuration to and from the test loop and the pressure losses and heat losses of that pipe. However, the configuration will cause the steam to the in let to be dry (superheated) so that meaningful steam temperature measurements can be made. An additional criterion for the pretransient test is that the test rod cladding temperature not exceed $700 \mathrm{~K}\left(800^{\circ} \mathrm{F}\right)$.

The operating conditions based on the above criteria are also given in Table 6.2. Axial temperature distributions for test fuel cladding and test assembly coolant are given in Figure 6.3. Pressure tube temperature maxima are noted in Table 6.2, one for the tube at the test assembly location and one for

\section{TABLE 6.2. Pretransient Operating Condition Summary}

\begin{tabular}{|c|c|c|c|}
\hline Parameter-Units & \multicolumn{2}{|c|}{ Value } & $\begin{array}{l}\text { Acceptable } \\
\text { Range } \\
\end{array}$ \\
\hline Avg Coolant Flow, (a) $\mathrm{kg} / \mathrm{s}(\mathrm{lbm} / \mathrm{hr})$ & 0.378 & $(3000)$ & \pm 5 \\
\hline Coolant In let Temperature, ${ }^{(\mathrm{a})} \mathrm{K}\left({ }^{0} \mathrm{~F}\right)$ & 436 & $(325)$ & $\pm 3 K\left( \pm 5^{0} \mathrm{~F}\right)$ \\
\hline Coolant Purity & $-\ldots-$. & ee Table & $c-6^{(b)}--$ \\
\hline Total Test Assembly Power, $\mathrm{kW}$ ( $\mathrm{kW}$ ) & 141 & $(141)$ & \pm 5 \\
\hline Outlet Pressure, (a) MPa (psia) & 0.276 & $(40.0)$ & \pm 5 \\
\hline Max Test Rod Power, $\mathrm{kW} / \mathrm{m}(\mathrm{kW} / \mathrm{ft})$ & 1.80 & $(0.550)$ & NA \\
\hline Max Guard Rod Power, kW/m (kW/ft) & 2.13 & $(0.648)$ & NA \\
\hline Average Test Rod Power, kW/m $(\mathrm{kW} / \mathrm{ft})$ & 1.25 & $(0.384)$ & NA \\
\hline Max Cladd ing Surface Temperature, $\mathrm{K}\left({ }^{\circ} \mathrm{F}\right)$ & 700 & $(800)$ & NA \\
\hline Max Pressure Tube Temperature & & & \\
\hline At Test Assembly Location & $493 \mathrm{~K}$ & $428^{\circ} \mathrm{F}$ & \\
\hline Above Test Assembly & $589 \mathrm{~K}$ & $600^{\circ} \mathrm{F}$ & \\
\hline
\end{tabular}

(a) Measured values, others are derived values

(b) Russcher et al. (1981) 


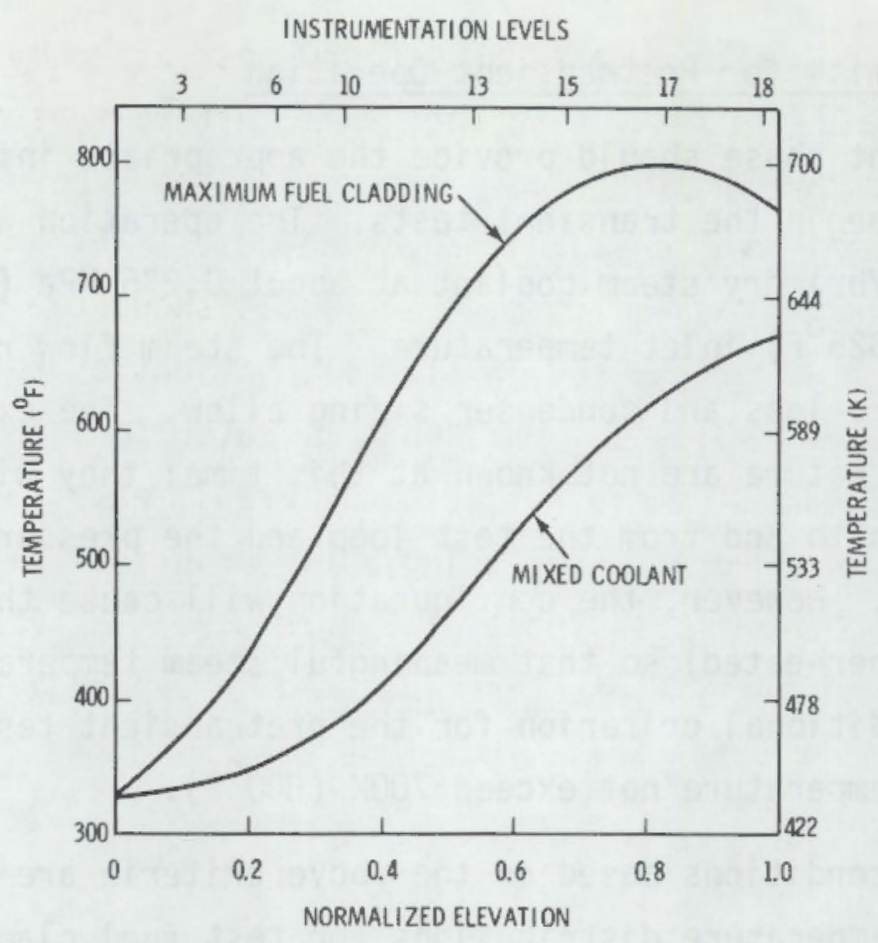

FIGURE 6.3. Axial Temperature Distribution During Pretransient Operation

the tube above the test assembly. The location above the test assembly is the hottest, primarily because it is in direct contact with the hot steam from the test assembly. The temperatures in this region will be monitored to keep the pressure tube temperature from exceeding $876 \mathrm{~K}\left(1117^{\circ} \mathrm{F}\right)$.

\subsubsection{Operating Limits for Transient LOCA Simulation (Stagnant Steam and Reflood)}

The course of events that will take place during the experimental transients is not known; in fact, the experiments are being performed to supply this information.

The transients will be initiated from the pretransient steady-state operating condition. Reflood flow is begun a few seconds after the steam coolant flow is stopped. The test assembly temperatures and coolant conditions will be measured at that time.

Hazardous conditions will be avoided by careful selection of the test sequence. The first tests will be done under mild conditions, i.e., early 
start of reflood, high reflood rates and/or low test assembly powers. The information from the early tests will be used to define subsequent test conditions to avoid hazardous temperatures. Figure 6.4 shows results of the calculations using the FLECHT correlation to provide heat transfer coefficients for input to the TRUMP heat transfer code. Figure 6.4 shows the calculated peak cladding temperatures at $\sim 2.67 \mathrm{~m}(8.75 \mathrm{ft})$ as functions of reflood rates and delay times prior to initiation of reflood. (a) Later test conditions will be chosen based on information in Figure 6.4. Preliminary results of calculations by Combustion Engineering (CE) using their proprietary THERM code are temperatures slightly lower than those of Figure 6.4. The results of these calculations were plotted by $C E$ and are included in Appendix $F$ for the axial elevations of $2.44 \mathrm{~m}(8.0 \mathrm{ft})$ and $2.74 \mathrm{~m}(9.0 \mathrm{ft})$.

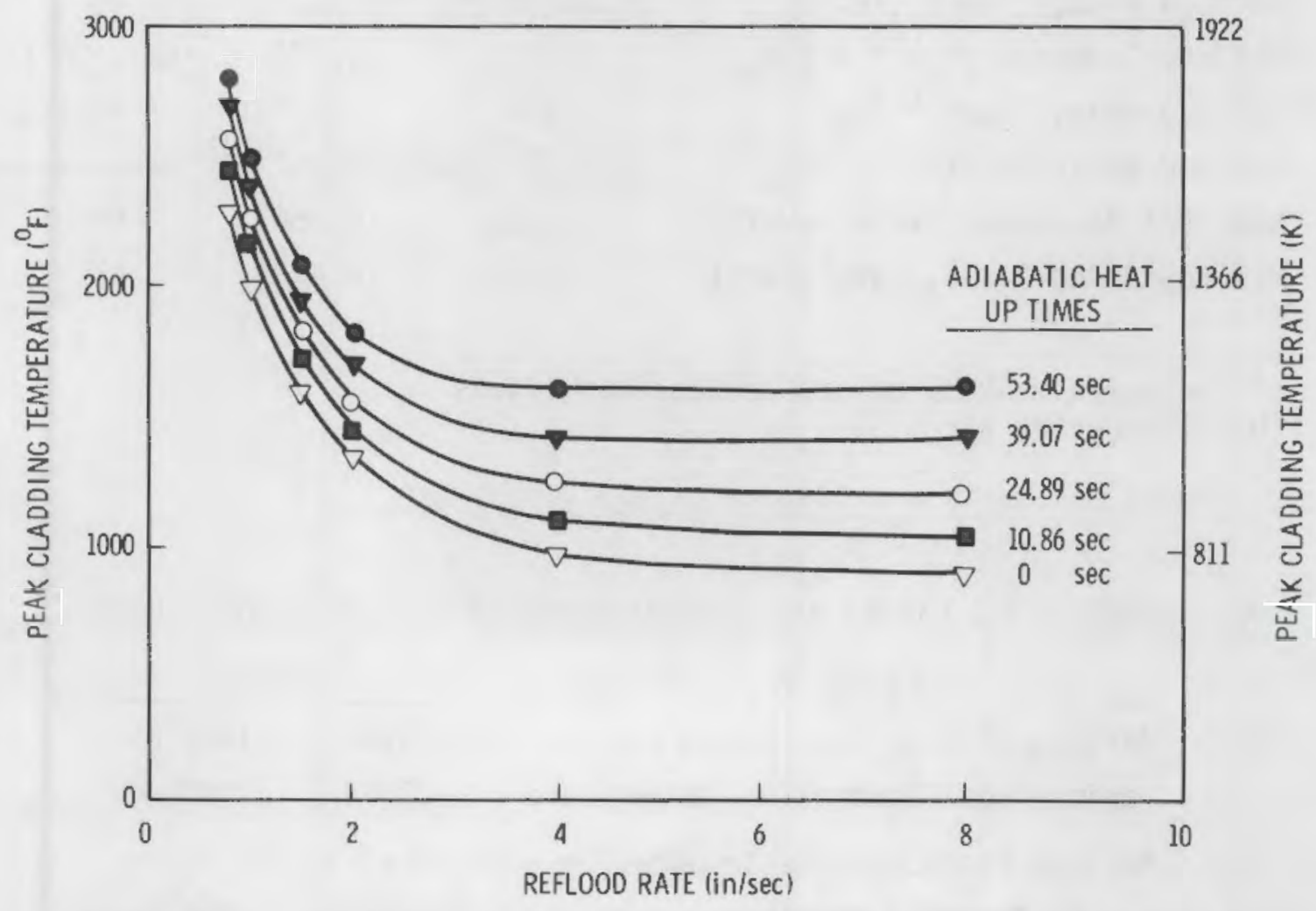

FIGURE 6.4. Predicted Peak Cladding Temperatures versus Reflood Rate for Peak Power, $1.80 \mathrm{~kW} / \mathrm{m}(0.55 \mathrm{~kW} / \mathrm{ft})$

(a) Hjelm, R. L. November 29, 1979, Memo to G. H. Hesson. "Predictions of Required NRU-LOCA Test Conditions." Pacific Northwest Laboratory, Richland, Washington 99352. 
The controlled operating conditions given in Table 6.3 will be set and maintained during the transient. When only one value is given, it is a limit. Otherwise, the values given cover the range expected to be investigated in the tests.

The values of the dependent variables, given in Table 6.4, are those that represent limits within which the tests will be confined. The testing sequence outlined above will be used to ensure that the test parameters do not exceed the limits given in Table 6.4 .

TABLE 6.3. Transient Operating Condition Sumary

\begin{tabular}{|c|c|c|c|}
\hline Parameter-Units & \multicolumn{2}{|c|}{ Value } & $\begin{array}{c}\text { Acceptab le } \\
\text { Range }\end{array}$ \\
\hline Reflood Rate, (a) $\mathrm{m} / \mathrm{s}$ (in./s) & $0.013-0.254$ & $(0.5-10)$ & \pm 5 \\
\hline Reflood Temperature, ${ }^{(\mathrm{d})} \mathrm{K}\left({ }^{\mathrm{O}} \mathrm{F}\right)$ & 326 & (127) & $\pm 6 \mathrm{~K}\left( \pm 10^{\circ} \mathrm{F}\right)$ \\
\hline Reflood Delay Times, ${ }^{(a)}$ s & $3-77$ & $(3-77)$ & $\pm 0.1 \mathrm{~s}$ \\
\hline Reflood Water Purity & ------ See & Table $\mathrm{C}-6$ & b) \\
\hline Max Test Rod Power, $\mathrm{kW} / \mathrm{m}(\mathrm{kW} / \mathrm{ft})$ & 1.80 & $(0.550)$ & NA \\
\hline Max Guard Rod Power, kW/m (kW/ft) & 2.13 & $(0.648)$ & NA \\
\hline
\end{tabular}

(a) Measured values, others are derived values

(b) Russcher et al. (1981)

TABLE 6.4. Limits for Dependent Variables During Transient

\begin{tabular}{|c|c|c|}
\hline Parameter & \multicolumn{2}{|c|}{ Value } \\
\hline Maximum $\mathrm{Cl}$ ad Surface Temperature & $1310 \mathrm{~K}$ & $1900^{\circ} \mathrm{F}$ \\
\hline Maximum Fue 1 Centerline Temperature & $1338 \mathrm{~K}$ & $19500_{\mathrm{F}}$ \\
\hline Maximum Pressure Tube Temperature & & \\
\hline At Assembly Location & $727 \mathrm{~K}$ & $850^{\circ} \mathrm{F}$ (a) \\
\hline Above Assembly & $727 \mathrm{~K}$ & $850^{\circ} \mathrm{F}(\mathrm{a})$ \\
\hline Maximum Coolant Out let Temperature & $727 \mathrm{~K}$ & $850^{\circ} \mathrm{F}^{(\mathrm{a})}$ \\
\hline
\end{tabular}

(a) Design values. 
The histories of several of the dependent variables for a severe transient experiment are shown in Figure 6.5. The information for this figure was calculated using reflood heat transfer coefficients from the FLECHT correlation (Lily 1977) as input to the TRUMP heat transfer code. The transient calculated was one for which a peak clad temperature of $1255 \mathrm{~K}\left(1800^{\circ} \mathrm{F}\right)$ was desired. For the calculations to determine the highest peak pressure tube temperature, it was conservatively assumed that conditions were not exact and that the peak cladding temperature reached $1355 \mathrm{~K}\left(1980^{\circ} \mathrm{F}\right)$. The figure gives the peak cladding temperatures of both the test and guard rods, the peak fuel centerline temperature, and the peak temperatures of the shroud and pressure tube all at the same elevation of peak cladding temperature. Calculational techniques to determine the maximum steam temperature are not available. However, the data from the FLECHT tests cover conditions that are similar to those for the NRU LOCA series. They show that steam at the test assembly outlet is superheated from 60 to $195 \mathrm{~K}\left(104^{\circ}\right.$ to $\left.350^{\circ} \mathrm{F}\right)$ above the saturation temperature of $403 \mathrm{~K}$ $\left(267^{\circ} \mathrm{F}\right)$. This superheated steam carries with it entrained water droplets. The two phases are obviously not in equilibrium. As the two-phase fluid flows

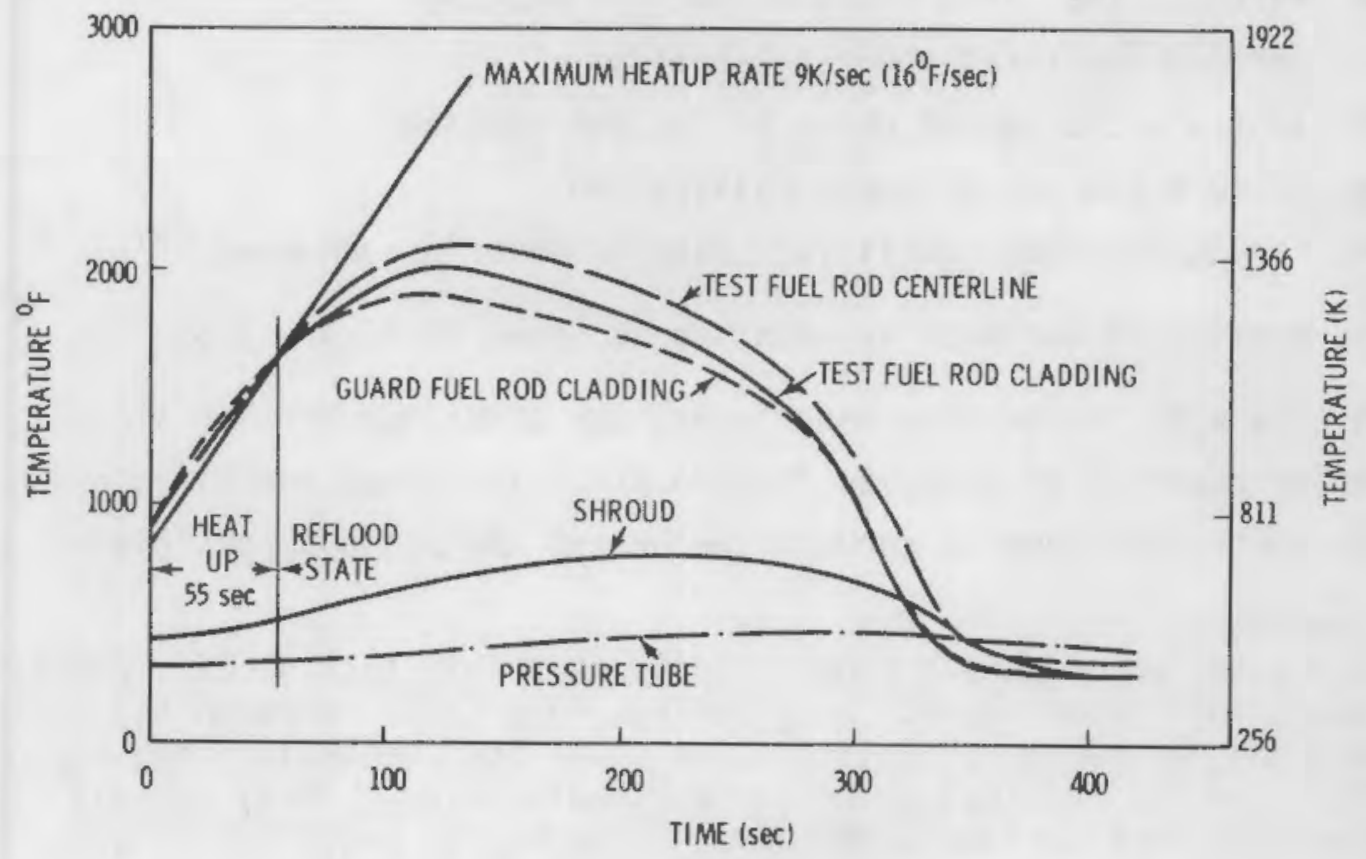

FIGURE 6.5. Nominal (worst case) Test Assembly and Pressure Tube Expected Time-Temperature Behavior 
through the system downstream of the test section it will equilibrate, causing a significant reduction in the steam temperature. Exit steam velocities are in the range of Mach 0.2 to 0.3 but are not expected to cause erosion problems.

\subsection{DURATION OF IRRADIATION}

The two phases of the test series are best explained through examination of the proposed test sequence for the basic test series.

\subsubsection{Prototypic Thermal-hydraulic Tests}

The proposed sequence for the thermal-hydraulic tests is summarized below.

1. The preconditioning period will be conducted in a water-filled loop in order to obtain power calibration data, evaluate steady-state temperature distribution, and crack the $\mathrm{UO}_{2}$ fuel to promote typical fuel relocation. The procedure followed during the proposed preconditioning period will consist of several steps:

- initiate full coolant flow in loop

- start OACS on slow scan rate

- initiate the first phase of nuclear heating

- perform the first power calibration

- initiate the second phase of nuclear heating

- perform the second power calibration

- repeat sequences until full reactor power is achieved. (a)

This portion of the test irradiation is shown in Figure 6.6.

2. The test will include preconditioning for a maximum of $1 \mathrm{hr}$ at full reactor power 1) to minimize fission product buildup and 2) to provide sufficient time to conduct the heatup and reflood portions of

(a) Full reactor power does not necessarily mean full test section power; instead, ful1 power depends upon the coupling factor between the test fuel bundle and the reactor. Full reactor power for precond it ion ing may not provide the desired fuel power for preconditioning. Thus, PNL will accept the highest test section power level $(<7.0 \mathrm{~kW} / \mathrm{ft}$, avg) that is possible and reproducible. 


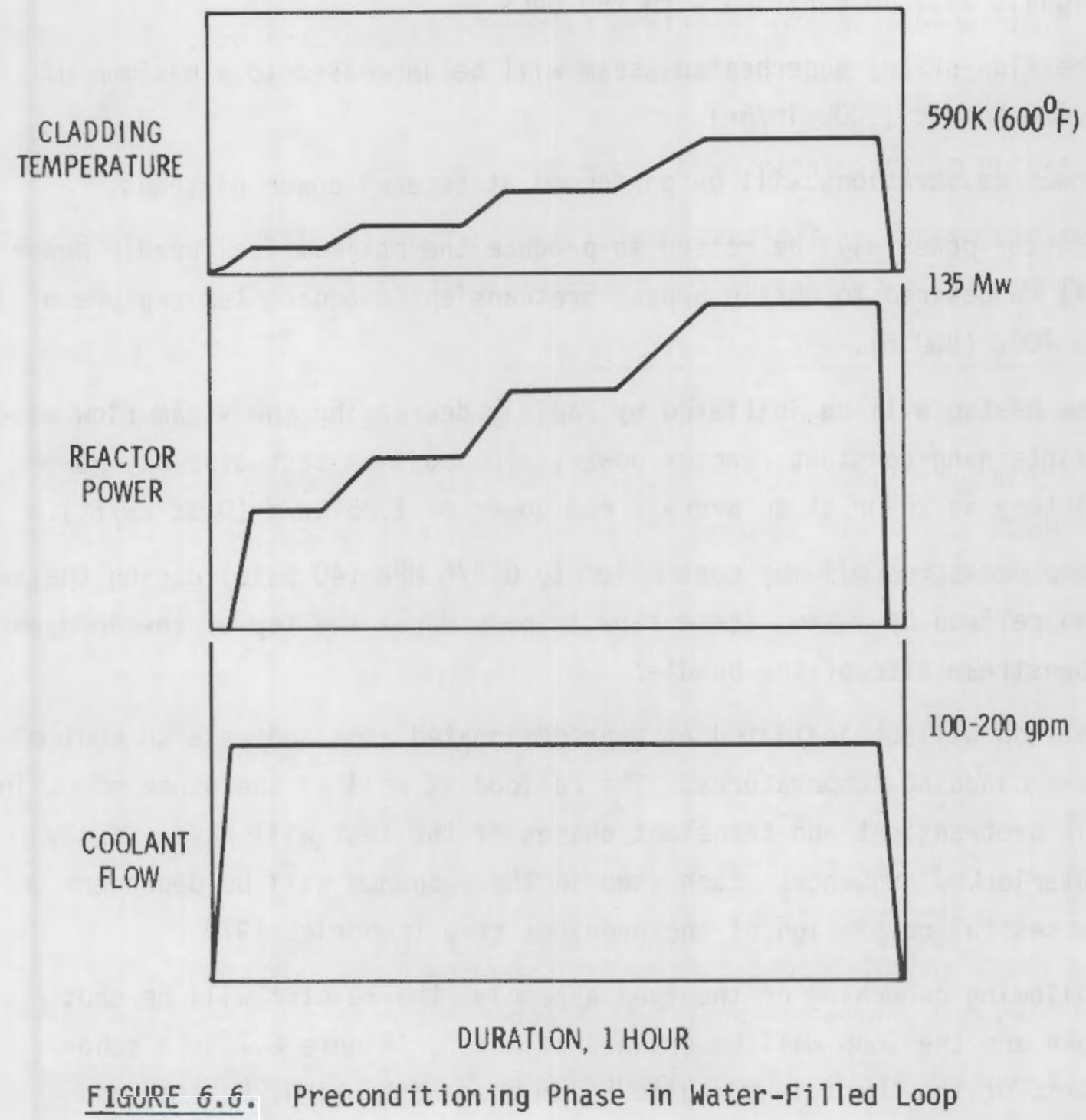

the test series within the 7-day test window. The maximum test assembly power history will be $1 \mathrm{hr}$ at an average rod power of $<23 \mathrm{~kW} / \mathrm{m}$ $(7 \mathrm{~kW} / \mathrm{ft})$.

3. The reactor will be returned to cold shutdown and the loop drained of water. The piping changes necessary for the steam-filled loop tests will be completed in an estimated 16 hours. The cooling requirements for the test assembly are included in Section 9.10.1. 
4. A low steam flow will be introduced into the loop, and the instrument signals will be verified with the DACS.

5. The flow of dry superheated steam will be increased to a maximum of $0.378 \mathrm{~kg} / \mathrm{sec}(3000 \mathrm{lb} / \mathrm{hr})$.

6. Power calibrations will be performed at several power plateaus.

7. Reactor power will be raised to produce the maximum fuel bundle power of $141 \mathrm{~kW}$ desired to obtain a peak pretransient cladding temperature of up to $700 \mathrm{~K}\left(800^{\circ} \mathrm{F}\right)$.

8. The heatup will be initiated by rapidly decreasing the steam flow while maintaining constant reactor power. The maximum test assembly power history is $20 \mathrm{hr}$ at an average rod power of $1.25 \mathrm{~kW} / \mathrm{m}(0.38 \mathrm{~kW} / \mathrm{ft})$.

9. Loop pressures will be controlled to $0.276 \mathrm{MPa}$ (40 psia) during the heatup and reflood by makeup steam flow introduced at the top of the loop on the downstream side of the bundle.

10. Reflood will be initiated at a predesignated time and rate to control peak cladding temperatures. The reflood as well as the other steps in the pretransient and transient phases of the test will have a fully interlocked sequence. Each step in the sequence will be dependent on the successful completion of the previous step (Kendrick 1979).

11. Following quenching of the fuel assembly, the reactor will be shut down and the loop will be drained of water. Figure 6.7 is a schematic of the thermal-hydraulic steam preconditioning, heatup, and reflood tests. Cooling requirements are given in Section 9.10.2.

12. Steps 4 through 11 will be repeated using different values for reflood rate and reflood initiation time to produce the requisite conditions for the maximum number of heatup and reflood tests possible within the 7-day interval available for the test series.

The sequence of tests will be such that the benign tests (low peak cladding temperatures and short times to quench) will be done first. They will provide the information needed to define subsequent tests to prevent excessive temperatures. 


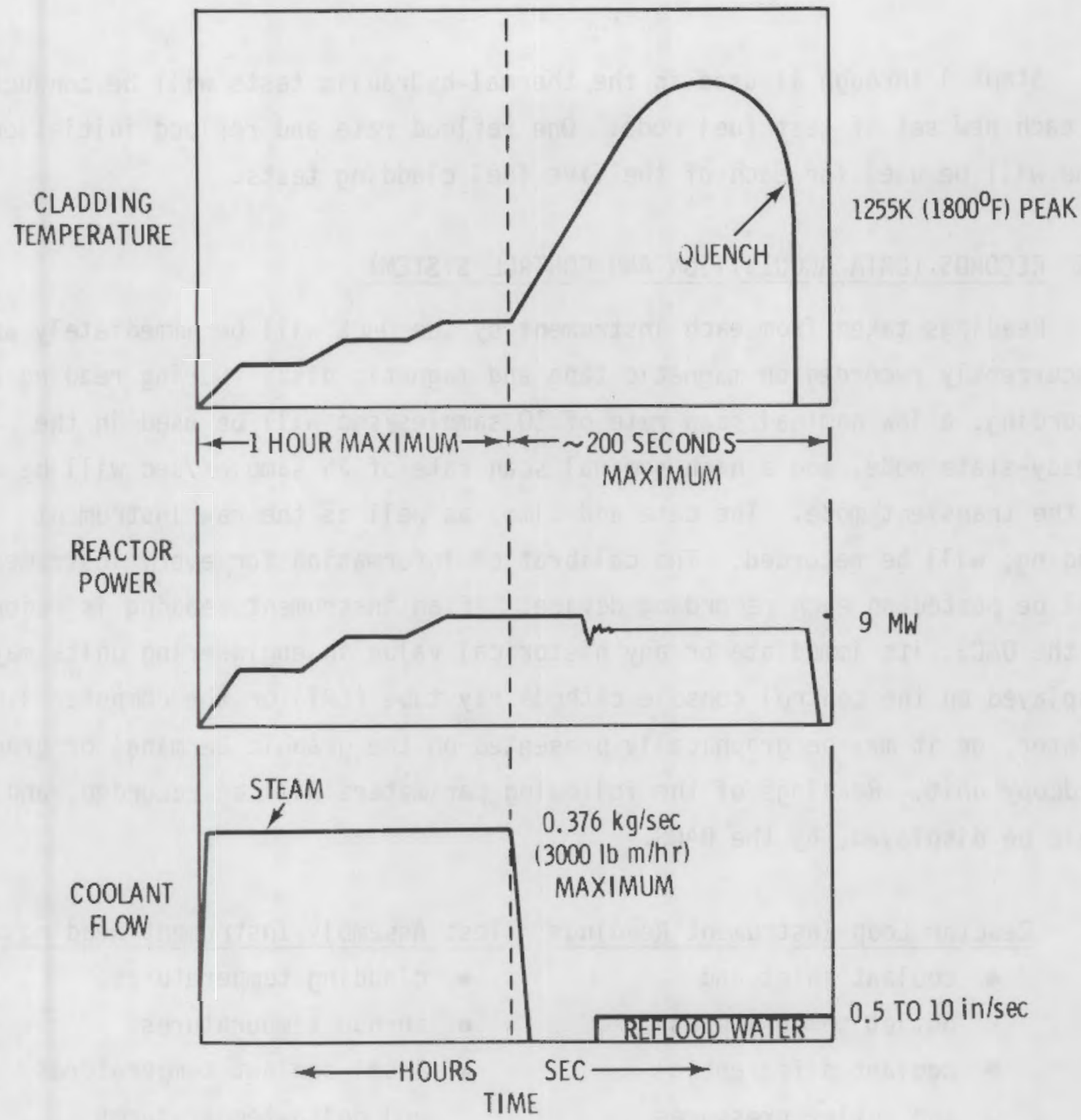

FIGURE 6.7. Heatup/Reflood Test Phase

\subsubsection{Cladding Material Deformation Tests}

The preconditioning test sequences used for the thermal-hydraulic tests (Steps 1 through 3) will be repeated for the cladding deformation tests. The thermal-hydraulic tests included on ly one water flow preconditioning phase. However, since the prepressurized fuel rods will be used in the fuel cladding tests, the test rods cannot be used for more than one test. Therefore, a water flow preconditioning phase will be required for each of the five sets of new test fuel rods (5 total). 
Steps 4 through 11 used in the thermal-hydraulic tests will be conducted on each new set of test fuel rods. One reflood rate and reflood initiation time will be used for each of the five fuel cladding tests.

\subsection{RECORDS (DATA ACQUISITION AND CONTROL SYSTEM)}

Readings taken from each instrument by the DACS will be immediately and concurrentiy recorded on magnetic tape and magnetic disk. During reading and recording, a low nominal scan rate of 10 samples/sec will be used in the steady-state mode, and a high nominal scan rate of 25 samples/sec will be used in the transient mode. The date and time, as well as the raw instrument reading, will be recorded. The calibration information for every instrument will be posted on each recording device. If an instrument reading is recorded by the DACS, its immediate or any historical value in engineering units may be displayed on the control console cathode ray tube (CRT) or the computer line printer, or it may be graphically presented on the graphic terminal or graphic hardcopy unit. Readings of the following parameters will be recorded, and could be displayed, by the DACS.

\begin{tabular}{ll} 
Reactor Loop Instrument Readings & Test Assembly Instrument Readings \\
\cline { 2 - 3 } - coolant inlet and & - cladding temperatures \\
outlet temperatures & - shroud temperatures \\
- coolant differential & - local coolant temperatures \\
and outlet pressures & and delta temperatures \\
- main loop coolant flow rate & - local neutron fluxes \\
- steam flow rate & - fuel centerline temperatures \\
- steam pressure & - internal fuel rod pressures \\
- steam temperature & - thimble tube temperatures \\
- reflood flow rate & - hanger tube temperature \\
&
\end{tabular}

\subsection{REACTOR CONTROL AND TRIPS}

In the NRU reactor, 18 control rods are used to control reactor power, and four adjuster rods are used to adjust the neutron flux. For normal 
reactor startup, the control rods are lifted in numbered sequence until the reactor reaches critical level. The reactor power is then raised to a constant power level of $20 \%$ above critical. The reactor can be automatically set to maintain a constant neutron power (as measured by ion chambers). Currentiy, reactor trips are set so that, at a $5-\mathrm{MW} / \mathrm{sec}$ increase in linear power, $110 \%$ over power, and $5 \% / \mathrm{sec}$ change in the log rate meter, these trips will cause all the control rods to drop.

\subsubsection{Reactor Control}

As the reactor reactivity changes because of xenon burnout or an adjuster rod being moved, the main control rod moves in or out to maintain the neutron power. Recent tests at NRU show that the reactor can safely operate at a constant neutron power below 20\%, as required for the LOCA test. For the test discussed here, thermal reactor power was kept constant even though xenon was decaying and the controlling rod was moving. Thus, the average neutron flux in the reactor could change even while the ion chamber used for control of the reactor observed a constant flux. These flux changes can affect the thermal power so that it changes relative to the neutron power.

There are two convenient ways to monitor thermal power. If the reactor heavy water coolant flow is held constant, the heavy water outlet temperature indicates the reactor power. It responds to a change in power within 20 to $60 \mathrm{sec}$. Another instrument automatically converts reactor flow and temperature to thermal power. The thermal power indicators' response time for a change in power is much slower than the response time of the heavy water outlet temperature: about 4 or 5 minutes.

The flux in the L-24 test section can change, even though the neutron power for the whole reactor is held constant. Controlling the neutron power with an ion chamber close to the test section by moving a control rod remote from the test section could give the most constant flux for the LOCA test.

Neutron power can also drift as a result of noise from voiding, boiling, etc., that could cause uncontrollable changes in reactor power. Since the control system cannot immediately compensate for such changes, the neutron power will change. 


\subsubsection{Reactor Trips}

There are currently three types of reactor trips: linear-rate trips, lograte trips, and overpower trips. These trips cause all the control rods to drop. There are four linear rate trip channels. Channel $A$ is set to trip at $5 \mathrm{MW} / \mathrm{sec}$ increase in reactor power and channels $B, C$ and $D$ are set to trip at $5.5 \mathrm{MW} / \mathrm{sec}$. When two of these four channels trip, the reactor drops all of its control rods. There are also four log-rate trip channels. All channels are set to trip at $5 \%$ power increase/sec. When two of these four channels trip, the reactor drops all control rods. There are three channels for the overpower trip. One channel is set to trip at a $6 \%$ overpower and the other two channels are set to trip at $10 \%$ overpower. When two of these three channels trip, the reactor drops all the control rods.

For the LOCA test, trips for the U-2 10op, steam system, and reflood system can be set as required. In contrast, other trips associated with the reactor normally cannot be altered.

There are two trip-setting limitations: the upper and lower trip settings cannot be set inside the normal noise range of the instrumentation; and the accuracy of the trip setting is dependent on the sensitivity of the instrument used for the trip.

Trips should be adjusted so that noise does not set them off. Injection of reflood water could cause voiding, boiling and slug flow that could, in turn, cause a significant reactivity change. This reactivity change could be large enough to set off log-rate trips. The reactor power levels for the test are low enough to affect on ly the log-rate trips, not the linear-rate trips. If reflooding is determined to cause rate trips for the existing rate-trip settings, it may be necessary to increase the rate-trip setting levels. If this is the case, the new required trip settings will be reviewed by CRNL. Before new trip settings are acceptable, CRNL must justify the safe use of the new settings to the Nuclear Safety Advisory Committee. 


\subsection{TEST TRAIN REMOVAL AND TRANSPORT}

Following the conclusion of a heatup and reflood transient test, the experimental assembly should be allowed to cool in the reactor at least an hour. The test train would then be removed from the loop and transported to the examination and storage bay for disassembly and inspection. Requirements for shutdown cooling and wet removal are included in Section 9.10.

The instrument leads connected to the DACS will be disconnected at the three multicontact cable connectors just below the test lifting ring and above the loop closure plug. Water-tight caps will be installed to cover the exposed contacts on the test train side of the connectors. Loop sealing rings will then be loosened and removed.

The J-rod flask fuel handling machine ${ }^{(a)}$ will be indexed into position over the loop, and the test train drawn upward into the flask barrel. During test operation, thermal anomalies may exist that could induce some degree of longitudinal bow into the shroud. This bow may cause the shroud to contact the pressure tube wall, hampering extraction of the experimental assembly. The net result could be an increase in the force required to remove the assembly from the pressure tube.

The maximum lifting capability of the J-rod flask hoist is 3,000 pounds. All load-carrying components of the test train are designed to withstand extractive loads of this magnitude. In the unlikely event that the hoist would be unable to remove the assembly, the entire reactor pressure tube containing the test assembly could be removed in accordance with CRNL procedures.

When the test assembly has been withdrawn and totally contained and sealed within the flask, it will be transported by the J-rod flask to the elevator position. At this location the flask will be indexed into position over the elevator receptacle, which for this operation is equipped with an integral full-length transfer can. The test train will be lowered, still in the vertical attitude, into the full-length transfer can until the loop closure plug

(a) This light-water-cooled flask shall be supplied by Chalk River Nuclear Laboratory. 
rests in the elevator receptacle. The elevator, containing the transfer can and test assembly, will then descend to the examination bay canal.

At the point it enters this canal, the transfer can must pass under a concrete baffle. The upper end of the test train will therefore be approximately $1 \mathrm{ft}$ below the pool surface. After passing under the baffle, the upper end of the test assembly will emerge above the pool surface and the transfer can containing the test assembly will proceed to the entrance of the examination bay.

Where the test train enters the bay, it will be removed from the transfer can and will be transferred to a support strongback. The support strongback will be hinged. This hinge will allow it to be rigidly fixed to support the test assembly after the hanger rod is loosened. The hinge also will permit the test section to assume a horizontal attitude where necessary, then allow its return to the original attitude to prevent submersion of the seal area and connectors for extended periods.

The strongback/test train unit will be transported to a position adjacent to the DERM. The test train will then be transferred from the strongback to the DERM. 


\subsection{POSTIRRADIATION EXAMINATION}

After irradiation, the fuel bundle will undergo destructive and nondestructive examination to obtain bay information, universal cell information and metallurgical information:

- The shroud will be characterized to determine its shape.

- The fuel bundle will be inspected, channel blockages located, and its shape and open channels characterized.

- The inner test bundle will be photographed, its shape and open channels characterized and exterior rod diameters described.

- Single rods will undergo profilometry, and their surfaces characterized and examined for cladding strain or failure.

- Rod regions that contain ballooned or burst configuration will be removed and samples taken for metallurgical examination.

\subsection{BAY EXAMINATION}

Nondestructive examination and partial disassembly of the fuel bundle will be done on and with the DERM in the examination bay.

\subsubsection{Shroud}

When the test assembly is transferred from the transfer can to the DERM, the shroud will be located on the end supports, which are an integral part of the DERM. These end supports form the three base data planes to which all dimensional information is related. At this point, the shroud will be characterized to determine its "free state" cross-sectional and longitudinal shape. Th is information will be obtained using state-of-the-art inspection equipment and the DACS.

Following this characterization, the shroud halves will be clamped to retain their free-state shape, which will facilitate later reassembly of the shroud. Then the shroud will be opened longitudinally, under machine control, to expose the fuel bundle. 


\subsubsection{Fuel Bund le}

The fuel bundle will be positioned in the pool for underwater TV scanning at any longitudinal location, both for general inspection purposes and to ascertain locations of channel blockages. The fuel bundle will be characterized for overall cross-sectional and longitudinal shape; all open channels will be characterized in two orthogonal planes and exterior rods for diameter. This information will be obtained with the same inspection equipment as is used for the shroud and the DACS.

Following characterization of the total bundle, the guard rod units will be separated along the bundle parting plane to expose the inner test bundle. The fue 1 bundle will then be positioned for inspection. Another underwater TV scan will be performed for general inspection purposes, and a photographic record of the areas of interest can be made. This bundle will be characterized for overall cross-sectional and longitudinal shape. All open channels are to be characterized in two orthogonal planes and exterior rods are to be characterized for diameter. State-of-the-art inspection equipment and techniques will be used here, and the data recorded by the DACS. Following characterization of the test bundle, the test rod bundle halves will be separated to expose the remaining three interior rods and the instrumented thimble

tube. (a) The instrumented thimble tube will be removed then from a test bundle half, stored, and eventually installed in the next test bundle.

The halves of the test bundle in place on the DERM will then be reassembled without the thimble tube. The instrument leads of the bundle will be disconnected and the bundle will be moved to a storage location.

\subsubsection{Assembly of Replacement Test Bundle}

The next test bundle will be located on the DERM and opened along the longitudinal parting plane. The instrumented thimble tube that was set aside will be inserted and the test bundle reassembled. The new test bundle instrument leads will be installed at the gland seal. Reassembly is done in the

(a) At this point further TV scanning and underwater photography may be appropriate. 
reverse order from disassembly. Once reassembled, the test train will be transferred to the transfer can, carried to the bridge, straightened, and stored until transferred to the loop for the next test.

\subsubsection{Single-Rod Examination}

After the test train is removed from the DERM, the equipment will be available for single-rod profilometry. At this time any rod remaining in stored test bundles can be removed by cutting the grid spacers, the rod can be indexed into the OERM, and its surface can be characterized. At this point, particular attention will be given to areas exhibiting excessive cladding strain or failure. Data will be obtained using NDT techniques such as profilometry and photography, and the data will be recorded. At this time single-rod gamma scan data can also be obtained and recorded to confirm axial flux profiles within the test. The rods will be stored in protective cans until all bundles have been through the planned heatup/reflood simulation and pool examinations are complete.

\subsection{UNIVERSAL CELL EXAMINATION}

Fuel rod regions in the universal cell containing ballooned and burst configurations will be sectioned to remove them from the rest of the rod. Waste will be packaged, and the rod sections of interest marked to show their orientation in the bundle and placed in cans for transfer to the metallurgical cell. CRNL procedures will be used for moving burst configurations of fuel to the cells.

\subsection{METALLURGICAL EXAMINATION}

The fuel cross sections in some of the test samples will be examined to assure proper fracturing of the fuel during the preconditioning phase. Ballooned portions of the rods, which may have too complex a shape to be characterized by photography or profilometry, will be examined using equipment developed specifically for that purpose. The burst configurations will be studied in a similar manner. Some of the burst fuel rods that reached high temperatures will be sectioned longitudinally through the burst, the fuel 
removed, and the oxide thickness on the inside of the tube characterized as a function of axial or aximuthal distance from the opening.

other sections are to be taken and examinations conducted as the need arises. There is no plan to do extensive ceramography of the fuel; there will be fewer than 25 metallographic samples per test.

Fission gas studies on unruptured rods will be done only to the extent necessary to confirm in-pile instrument readings. The upper limit is 11 gas samples per test. 


\subsection{WASTE DISPOSAL}

Four sources of waste will be generated as a result of the tests and subsequent examinations:

1. The more severe transients, those leading to cladding rupture, are expected to release a small number of fuel fragments to the coolant. These will be retained in the strainer at the bottom of the test train. Any release of fuel fragments would occur during the reflood and quench portions of the transient phase of the test. At this time, water or twophase steam flow through the coolant channel is relatively slow, and most fuel fragments would settle to the bottom of the test assembly. A negligible amount of fission gas may also be released. Special loop cleanup procedures are used when necessary to decontaminate loop piping. Most of the solid fuel material debris will be carried over into the canal and rod bay. Manipulation of the bundle is likely to release some material into the basin where routine underwater vacuum cleaning ${ }^{(a)}$ will retrieve it.

2. When the grids are cut to free individual rods from the cruciform section of the material test bundles, fine chips or turnings of low-level, activated Inconel-718 will be released into the basin. Provision can be made to capture this material as it is generated, or it can be left for routine cleanup.

3. Transverse sectioning of the rod in the universal cell to separate ballooned and burst regions of cladding for detailed examination will release fuel fragments. After sectioning, the fuel contained in the rod must be removed. Similarly, sectioning fuel to verify the effectiveness of preconditioning will generate waste. In all cases, the samples not retained in archive will require disposal.

4. Instruments, equipment, and hardware that are furnished by PNL will be removed from the site unless PNL and AECL agree otherwise.

(a) To be furnished by AECL. 
Within 2 years of the completion of the six tests described in the appendix of the PNL/AECL Contract, 1978, PNL will transport back to the United States all fuel and samples associated with these tests. However, AECL has expressed willingness, subject to signing a mutually satisfactory separate contract, to dispose of the fuel. 


\subsection{HAZARDS ANALYSIS}

This section summarizes the characterized behavior of the test train during both normal and accident conditions. Included are estimates of maximum temperature, time to rupture, transient temperature history for the pressure tube and upper hanger region along with cool-down information pertaining to removal of the assembly from the U-2 100p. The effects of changes in reactivity or redispersal of the fuel are treated, and the structural integrity of the bundle under maximum loading conditions is evaluated. Sensor reliability for both the loop and test train measurements is also reviewed. Possible reactor trip conditions are identified for protection of both the reactor and the test train. Finally, decay heat information for the test assembly is included. This information will be used for cooling requirements to enable safe removal of the test assembly from the U-2 loop.

\subsection{ESTIMATES OF REACTIVITY}

The reactivity effects of heavy water, light water, and steam are compared. For this comparison, it is assumed that the reactor is critical and that the test assembly contains heavy water, $3.0 \mathrm{wt} \%{ }^{235} \mathrm{U}$-enriched fuel, and a stainless steel shroud. If light water were used, the reactivity would be $0.3 \mathrm{mk}$ lower than in an assembly cooled with $\mathrm{D}_{2} \mathrm{O}$. (a) If steam were used, the reactivity would be $2.3 \mathrm{mk}$ higher than a $\mathrm{D}_{2} \mathrm{O}-\mathrm{fill}$ ed assembly.

Four assembly failure types have been considered: test fuel relocation, NRU driver fuel relocation, test fuel dispersal outside the test loop, and test fuel dispersal within the test loop.

In order for the test fuel to relocate, it is necessary for it to fracture; however, this is not a credible accident. Relocation of NRU driver fuel is also highly unlikely. Neutron flux in the region around the test assembly is fairly uniform and the flux in the test loop somewhat lower than most surrounding 10 ations. Therefore, if $\mathrm{NRU}$ fuel were to relocate into the test site,

(a) Here, apparently the poisoning effect of the light water and stainless steel overrides the positive effect of the fuel material. 
the NRU fuel would probably see a lower flux or, at worst, only a sma11 increase. This would cause a decrease or a very small increase in reactivity.

Dispersal of test fuel outside the loop would not be possible without test loop fracture. However, such a fracture is not credible.

Significant dispersal of fuel with in the test loop is not likely to occur during the tests. If dispersal did take place, the limiting case for calculational purposes would involve a compaction of the fuel within the shroud. If the shroud were to be completely packed with $3.0 \mathrm{wt} \%{ }^{235} \mathrm{U}$ enriched fuel, this would result in a reactivity of $5.8 \mathrm{mk}$ above the $3.0 \mathrm{wt} \%$, steam-cooled cond it ion.

Under normal conditions two reactivity insertions related to the test assembly can be expected. A $0.3-\mathrm{mk}$ decrease (over a $\mathrm{D}_{2} \mathrm{O}-\mathrm{fill}$ led loop) is estimated with installation of the test. Upon draining the light water (hot water density at $0.65 \mathrm{~g} / \mathrm{cm}^{3}$ ) from the test loop, the reactivity gain is estimated to be $2.6 \mathrm{mk}$ from the water-cooled state. If light water were accidentally voided from the test, a ramp reactivity increase would result. The reactivity change associated with th is release has been estimated at $2.6 \mathrm{mk}$ as mentioned above. The $2.6 \mathrm{mk}$ reactivity change is we 11 within the range of reactivity increases that can safely be handled by the NRU reactor.

To conservatively assess the transient associated with loop voiding, the following situation was modeled. A 45 \&eactivity insertion over $1 \mathrm{sec}$ at a linear rate was assumed. The reactor control system was modeled as inserting a maximum negative reactivity of $\$ 4.50$ in $2 \mathrm{sec}$ with a cosine-shaped insertion. A 3/10-sec delay time was allowed between the detector response and the initiation of control rod motion. The reactor was modeled to scram on any one of three different events: $110 \%$ of steady-state (135 MW) power; $5 \% / \mathrm{sec}$ rate change in the log power measurement; or $5 \mathrm{MW} / \mathrm{sec}$ rate change in the linear power measurement. No time lag existed between the actual occurrence of an event in core and its detection. The calculations indicate the resultant transient generates a reactor power increase, peaking at $117 \%$ of the pretransient power and decaying to $100 \%$ pretransient power about $1 \mathrm{sec}$ after voiding begins. 
The normalized reactor power occurring after a positive reactivity insertion of 45 in $1 \mathrm{sec}$ is shown in Table 9.1. The power rise in the first $0.1 \mathrm{sec}$ is shown to be rapid enough to trip two of three trip settings (5\%/sec rate change in log power measurement; or a $5 \mathrm{MW} / \mathrm{sec}$ rate change in linear power.)

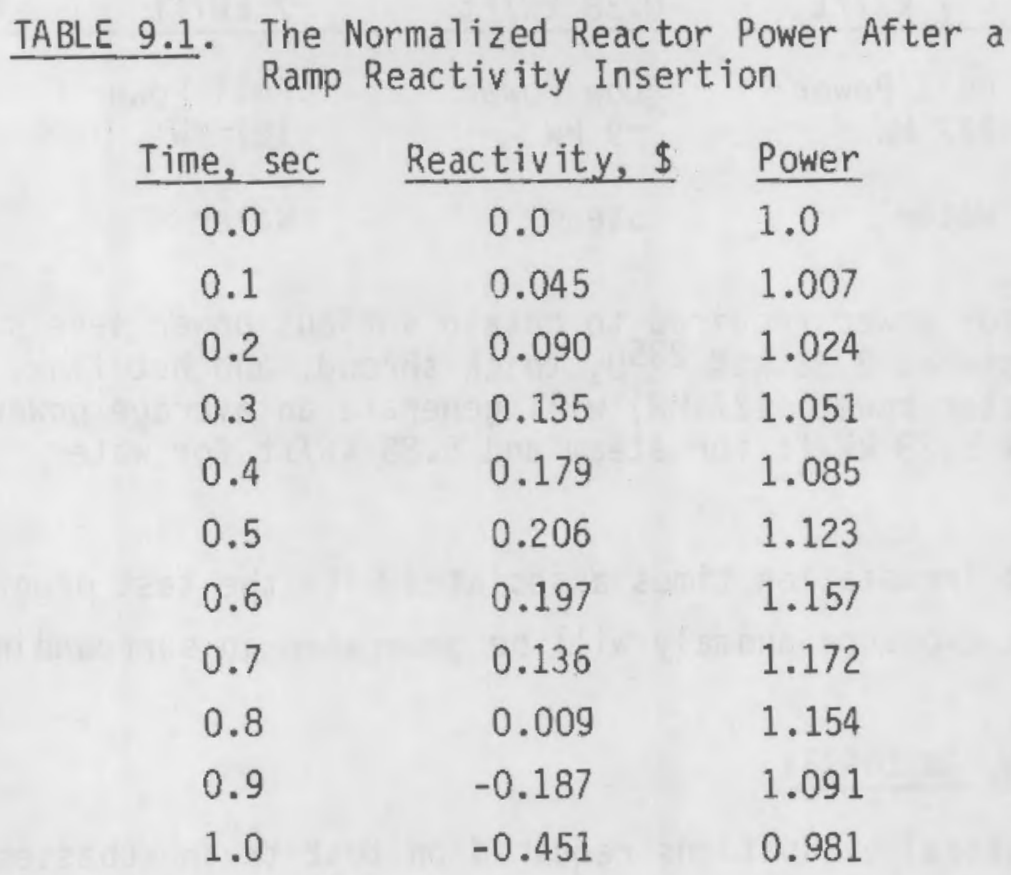

9.2 ESTIMATE OF NEUTRON FLUX AND TEST ASSEMBLY-REACTOR POWER COUPLING

Preliminary calculations indicate the neutron flux profile across the reactor will not be greatly disturbed by the test. Since the reactor neutron flux profile is a function of loading, it will be examined again when the reactor loading for the test has been set.

The reactor powers required to obtain the test assembly power levels in the test bundles are shown in Table 9.2. The power coupling between the test assembly and the reactor is shown for both steam and water cooling for a hot flux, (a) 2.88 wt\% fue 1 enrichment and a thick shroud.

(a) Hot flux means that the NRU fuel immediately surrounding the test section is fresh or relatively unirradiated fuel. 
TABLE 9.2. Reactor Powers Required to Obta in Power Levels In The Test Bundle as Specified in LOCA Tests

\begin{tabular}{|c|c|c|c|c|}
\hline & $\begin{array}{r}\text { Therma T-Hyc } \\
\text { Test }\end{array}$ & $\frac{\text { Specified Powe }}{\text { rautics }}$ & $\frac{\text { in Test Bundle }}{\text { Mate }}$ & rials \\
\hline & $\begin{array}{c}\text { Preconditioning } \\
7 \mathrm{~kW} / \mathrm{ft} \\
\end{array}$ & $\begin{array}{c}\text { Pretransient } \\
0.38 \mathrm{~kW} / \mathrm{ft} \\
\end{array}$ & $\begin{array}{c}\text { Preconditioning } \\
7 \mathrm{~kW} / \mathrm{ft} \\
\end{array}$ & $\begin{array}{c}\text { Pretransient } \\
0.38 \mathrm{~kW} / \mathrm{ft} \\
\end{array}$ \\
\hline $\begin{array}{l}\text { Reactor } \\
\text { Power (b) }\end{array}$ & $\begin{array}{l}\text { Ful1 Power } \\
127 \mathrm{MW}\end{array}$ & $\begin{array}{l}\text { Low Power } \\
\sim g \text { MW }\end{array}$ & $\begin{array}{l}\text { Ful1 Power } \\
127 \mathrm{MW}\end{array}$ & $\begin{array}{l}\text { Low Power } \\
\sim 9 \mathrm{MW}\end{array}$ \\
\hline Coolant & Water & Steam & Water & Steam \\
\hline
\end{tabular}

(a) The reactor power required to obtain various power levels in the test bundle assumes 2.88 wt\% $235 \mathrm{U}$, thick shroud, and hot flux.

(b) Full reactor power (127 MW) will generate an average power in the test bundle of $5.28 \mathrm{~kW} / \mathrm{ft}$ for steam and $5.85 \mathrm{~kW} / \mathrm{ft}$ for water.

The short irradiation times associated with the test program suggest that no significant exposure anomaly will be generated in surrounding fuel.

\subsection{STRUCTURAL INTEGRITY}

The analytical evaluations required on test train subassemblies and components are indicated in Table 9.3.

Handling stresses are loads generated by movement of the assembly either in the vertical or horizontal position. Handing stresses occur during shipping or transfer by crane in air or water, and at the point of support on the strongback or DERM or should the assembly be dropped outside the loop.

Mechanical stresses are those caused by shock, pressure, restraint (including preload), weight and flow. They are steady (or in quasi equilibrium) during the given operational phase of the experiment, or are caused by a single postulated loading (e.g., water hammer or assembly dropped in the loop).

Thermal stresses not included in this category are thermal stresses or loads caused by thermal expansion. These are handled in the subsection pertaining to thermal expansion. Also considered in the latter category is the softening, weakening effect of operation at high temperature. 
TABLE 9.3. Required Structural Integrity Evaluation

\begin{tabular}{|c|c|c|c|c|c|c|c|c|c|c|c|c|c|c|c|c|}
\hline \multirow[b]{4}{*}{$\begin{array}{l}\text { COMPONENTS, } \\
\text { SUBASSEMBLIES }\end{array}$} & \multicolumn{7}{|c|}{ STRESS } & \multirow{3}{*}{\multicolumn{3}{|c|}{$\begin{array}{l}\text { VIBRATION - } \\
\text { HIGH CYCLF FATIGUE }\end{array}$}} & \multirow[b]{4}{*}{$\begin{array}{c}\text { LOW } \\
\text { CYCLE } \\
\text { FATIGUE }\end{array}$} & \multirow[b]{4}{*}{ OXIDATION } & \multirow[b]{4}{*}{ EROSION } & \multirow[b]{4}{*}{$\begin{array}{c}\text { THERMAL } \\
\text { EXPANSION }\end{array}$} & \multirow[b]{4}{*}{ FIT-UP } & \multirow[b]{4}{*}{$\begin{array}{l}\text { LOAD } \\
\text { LIMITS }\end{array}$} \\
\hline & \multirow[b]{3}{*}{ HANDLING } & \multirow{2}{*}{\multicolumn{6}{|c|}{ MECHANICAL }} & & & & & & & & & \\
\hline & & & & & & & & & & & & & & & & \\
\hline & & $\begin{array}{l}\text { PRE- } \\
\text { COND.* }\end{array}$ & \begin{tabular}{|l|} 
PRE- \\
TRANS.***
\end{tabular} & $\begin{array}{c}\text { TANSIENT } \\
\text { A IND } \\
\text { REROOD }\end{array}$ & $\begin{array}{l}\text { PRE- } \\
\text { COND. }\end{array}$ & \begin{tabular}{|l|} 
PRE- \\
TRANS.
\end{tabular} & $\begin{array}{c}\text { TRANSIENT } \\
\text { AND } \\
\text { RELOOD }\end{array}$ & $\begin{array}{l}\text { PRE- } \\
\text { COND. }\end{array}$ & $\begin{array}{l}\text { PRE- } \\
\text { TRANS. }\end{array}$ & \begin{tabular}{|c|} 
TRANSIENT \\
AND \\
RERLOD
\end{tabular} & & & & & & \\
\hline $\begin{array}{l}\text { TOTAL TEST } \\
\text { TRAIN ASSEMBLY }\end{array}$ & - & & & & & & & & & & & & & - & - & - \\
\hline $\begin{array}{l}\text { CLOSURE } \\
\text { REGION }\end{array}$ & & - & - & - & 0 & - & - & & - & & - & & & - & - & - \\
\hline $\begin{array}{l}\text { INLET } \\
\text { REGION }\end{array}$ & & & & & & & & 0 & - & & & & & 0 & - & \\
\hline HANGER & 0 & - & 0 & 0 & & & - & - & 0 & & - & 0 & & 0 & 0 & 0 \\
\hline SHROUD & 0 & 0 & & & & & 0 & & 0 & & 0 & 0 & & 0 & 0 & 0 \\
\hline $\begin{array}{l}\text { SPACER } \\
\text { GRIDS }\end{array}$ & - & & & 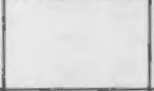 & & & & & - & $=$ & - & & & - & 0 & \\
\hline FUEL RODS & 0 & & & - & & & 0 & & 0 & & & 0 & & - & 0 & 0 \\
\hline FEED THRUS & & 0 & & & 0 & 0 & - & & & & 0 & & & 0 & 0 & \\
\hline $\begin{array}{l}\text { BUNDLE } \\
\text { REGION }\end{array}$ & 0 & & & & & & & & 0 & & & - & & - & 0 & 0 \\
\hline $\begin{array}{l}\text { INSTRUMENATS } \\
\text { (THERMOCOUPLE } \\
\text { PROBES, SPNO'S) }\end{array}$ & & & & & - & - & - & - & - & - & & - & - & - & & \\
\hline
\end{tabular}

* preconditioning

** PRETRANSIENT 
Both mechanical and thermal stresses will be evaluated in each of the three principal phases of the experiment:

1. Preconditioning: Water flow, high power.

2. Pretransient: High velocity dry steam flow, relatively low power.

3. Transient and reflood: Negligible flow during heatup at relatively low power followed by water/steam mixture at low flow. An important aspect is time at temperature, cumulative from test to test. The objective of this portion of the analysis is to show that the test train is not damaged during Phases 1 and 2 and that damage is confined to the test rod cladding during Phase 3.

The vibration/high-cycle fatigue analysis is mainly concerned with the high velocity steam flow of Phase 2, although checks are made on Phase 1 water flow for subassemblies that may be susceptible to flow instabilities. In general, vibration amplitudes are low enough to be a concern only if flow instability criteria are exceeded. Special attention is given to the flow baffle in the closure region, the shroud, and the fuel rods.

Low-cycle fatigue is due to thermal, pressure, and preload cycling. As long as the stresses are in the elastic range, the few cycles experienced should not lead to distortion or weakening of the vital components. The purpose of the analysis is to be sure this is the case.

Oxidation, principally by corrosion in steam during the transient heatup, can lead to weakening of structural members and significant distortion of close-fitting components.

Erosion, mainly of junctions between thermocouple and cladding, is important during the pretransient flow of high-velocity steam.

Thermal expansion evaluations are made to assure that component buckling or other localized damage does not occur, that clearances are adequate to accomodate differential thermal expansion, that parameters such as bypass flow are not changed from their design values, and that seal preloads are within acceptable limits. 
Fitup is concerned with ease of assembly, disassembiy, and the use of interchangeable components. This is a physical confirmation as well as a drawing layout check.

The load limits category of analysis is to set lifting load limits for the test train and certain critical components. Should the assembly become jammed in the tube, it is important to know which components will fail and at what lifting loads.

The analytical evaluations designated in Table 9.3 were conducted on each component subassembly as design information became available. When the design package on the test train was completed, a stress report was compiled. Results of the evaluation of the subassemblies have been sumarized in table form.

\subsection{TEST ASSEMBLY SENSOR RELIABILITY}

Instrumentation in the test assembly must be reliable. Instrument reliability insures that the required test data will be obtained and that the data will be accurate.

\subsubsection{Thermocouples}

The chromel-alumel thermocouples will have voltage characteristics that will be within the ANSI special limits of error of 0.375 over the temperature range of interest. The reference junction temperature is specified to be maintained to within $\pm 0.15^{\circ} \mathrm{F}$ of $66^{\circ} \mathrm{C}\left(150^{\circ} \mathrm{F}\right)$. The DACS overal1 accuracy specification is 0.2 for full scale. These errors accumulate to an overall error of $\pm 0.6 \%$.

The thermoelement conductors from the hot junction to the reference junction are chromel and alumel, except for the pins and sockets in the quick disconnects that are located in the hole below the top deck plate. These are made from a gold-plated copper alloy. An axial temperature gradient along the pins and sockets could introduce an additional error into the temperature measurements. It is assumed that this temperature gradient will not be appreciable, so errors from this source are not included in the above overall error est imate. 
Based on experimental thermocouple response time data from Meservey (1976) and Billeter et al. (1978), a 0-63\% response time of less than $100 \mathrm{~m} / \mathrm{sec}$ is predicted for all thermocouples in the NRU tests.

\subsubsection{Cladding, Shroud, Thimble, Pressure Tube, and Coolant Thermocouples}

Experiments performed at the GfK's Nuclear Research Center Karlsruhe (Karb 1978 and Fischer and Osborne 1978), which concentrated on the simulation of the cladding temperature history during the low-pressure phase of a LOCA, were similar in nature to the NRU tests. Although Karb and Fischer did not state the number of cladding thermocouples that failed, their reported data indicate that the failure rate was low. Because the PNL methods of attaching thermocouples to the outside surface of the cladding is similar to GfK's method, we are presuming a failure rate of less than $10 \%$ for the cladding, shroud, and thimble thermocouples. The failure rate for the spring-loaded pressure tube and coolant thermocouples is also expected to be less than $10 \%$.

\subsubsection{Fuel Centerline and Pellet-Cladding Gap Thermocouples}

Three reports on EG\&G's experience with off-center fuel thermocouples (Murdock 1978, Kerwin 1978, Cook 1978) showed that out of 20 thermocouples, two failed under conditions that were more severe than those anticipated for the NRU tests. Thus, we are presuming a failure rate of less than $10 \%$ for the fuel centerline thermocouples.

The pellet-cladding gap thermocouples will have dual diameters: the smaller diameter inside the fuel rod and the larger diameter outside the fuel rod. Because of this design, a low failure rate for these thermocouples is expected.

Corrosion and erosion effects on the thermocouples have not been evaluated as yet.

\subsubsection{Test Assembly Flow Measurement}

The flow rates of the pressurized water during the preconditioning phase, the steam flow rate prior to heat up, and the reflood flow rates are required. None of these flow rates will be measured in the test assembly. 
The bundle flow rates will be determined from the measurement of the loop flow rates taken during the test. The ratio of bundle flow rate to total loop flow rate will be measured in an out-of-reactor mockup, and from these data the in-reactor bundle flow rate will be predicted. The bypass flow will be between $1 \%$ and $5 \%$ of the tota 1 flow, and it is expected to be approximately $4 \%$ based on the out-of-reactor mockup tests. The flow through the test section, therefore, should be known to within $1 \%$.

The steam and reflood flow rates will be measured by loop instrumentation located outside the reactor core.

\subsubsection{Test Assembly Power Measurement}

The power distribution within the assembly will be determined by an array of SPNDs with cobalt emitters located on the shroud and within the guide tube. A typical planar array is shown in Figure 9.1. The four SPNDs on the shroud define the edge of the power surface at that elevation and thus assist the interpretation of the degree of flux tilt across the bundle. The SPNDs contained in the guide tube assist in defining the contours of the power surface within the bundle. A series of SPND arrays at other elevations provides a means of coupling the radial power distribution to the axial distribution. Provision is also made for a limited number of SPNDs at grid spacer locations. These are needed to define the localized power depression.

The relative power distribution determined from the SPND array is tied to an absolute power measurement through two techniques: 1) the first is based on distributing the power determined from a thermal balance on the entire assembly during the steady-state preconditioning period in both the water-filled and steam-filled conditions; 2 ) in the second, centerline fuel thermocouples are used at one elevation to improve the absolute power measurements. This approach has been utilized successfully in other tests and is based on the fact that the fuel rod can be one of the best power measuring instruments. By determining the fuel centerline temperature and the cladding surface temperature, the fuel rod power can be calculated from the temperature difference, provided that the $\mathrm{UO}_{2}$ thermal conductivity is known. The fuel thermal conductivity of archive $\mathrm{UO}_{2}$ pellets will be determined at PNL to reduce the 


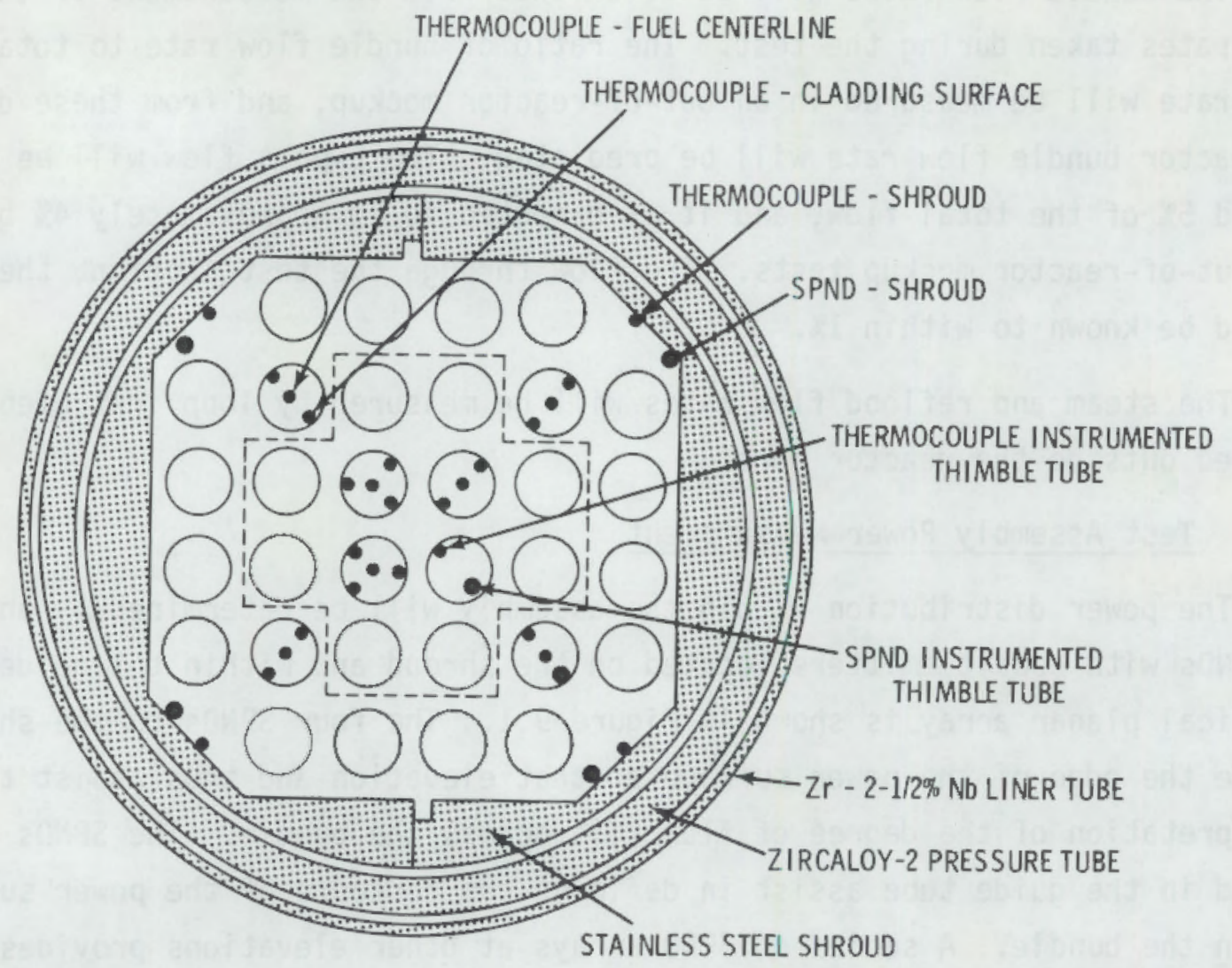

FIGURE 9.1. Cross Section of Assembly Illustrating Fuel Bundle Array, SPND and Thermocouple Locations

uncertainty associated with using literature values. Furthermore, a small fuel-cladding gap will be utilized in the vicinity of the thermocouple hot junctions to produce a high gap conductance and thus minimize the uncertainties associated with the temperature gradient across the gap. The small gap will be produced by a $5-\mathrm{cm}$ column of pellets, which are slightly larger than the standard pellets.

The schematic arrangement of the detectors and signal conditioning equipment is indicated in Figure 9.2.

An accuracy criterion of less than $1 \%$ is set for the detector output. To assure that this criterion is met, the measuring resistance $R_{m}$ must be lower 


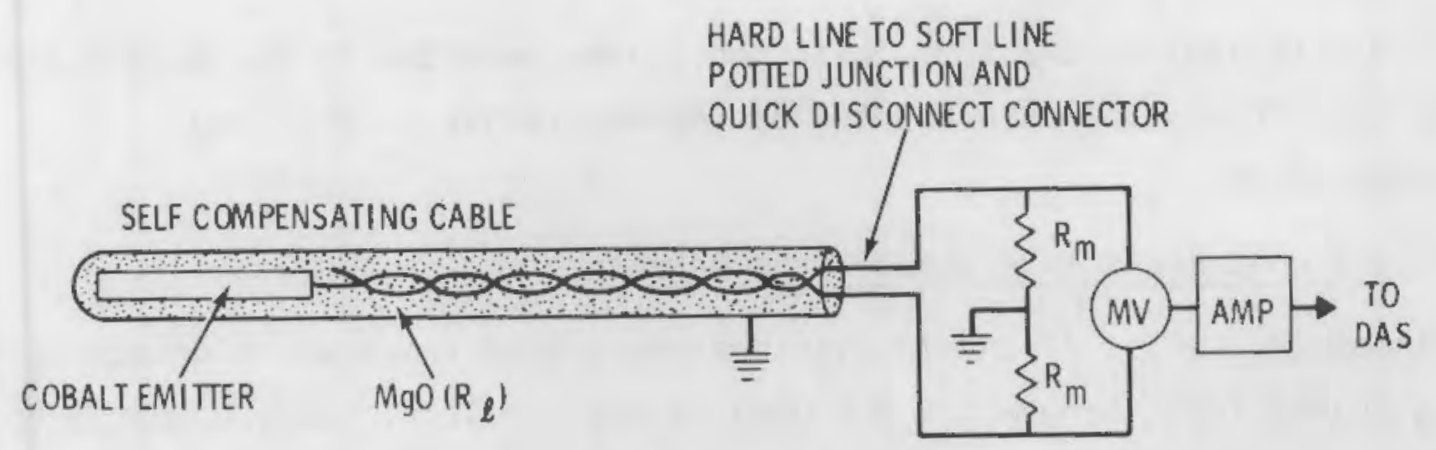

FIGURE 9.2. Schematic Arrangement of Neutron Detector and Signal Conditioner

than $R_{\ell}$ by a factor of 100 or greater. $R_{\ell}$, the resistance of the Mg0 insulation, is a function of its temperature; the resistance decreases with increasing temperature. Thus, the accuracy of the detectors is a function of temperature and decreases with increasing temperature.

The resistance of the $\mathrm{MgO}\left(\mathrm{R}_{\ell}\right)$ will be maintained at a level greater than $10^{8}$ ohms during the tests. To assure that the accuracy criterion of less than $1 \%$ is met, the resistance of $R_{m}$ will be set at $10^{6}$ ohms.

The accuracy of the neutron detector amplifier is $\pm 1 \%$ and that of the DACS is $\pm 0.2 \%$. Applying propagation of errors to the detector, amplifier, and DACS errors, the overall error is less than $1.4 \%$.

The use of measurement resistors having a resistance of $10^{6}$ ohms will give a $63 \%$ response in $\sim 1 \mathrm{~ms}$ for the SPNDS.

\subsection{NRU U-2 LOOP SENSOR REL IABILITY}

Reliability can be looked at in terms of instrumentation for control of the reactor (in which case there is a lot of redundancy in the system) or in terms of instrumentation for recorded information such as with the data acquisition and control system. Control of the reactor and loop involves much redundancy. If one instrument fails, the operator can switch over to a spare instrument insuring the reliability of instrumentation required for safe operation of the reactor. NRU facility U-2 loop instrumentation is time tested and 
relatively reliable. U-2 loop instrumentation connected to the REDACE data logger computer system is presented as representative of U-2 loop instrumentation.

\subsubsection{U-2 Loop Resistance Temperature Detector}

Rosemount series 77 and 78 platinum resistance temperature detectors spring loaded into thermowells are used in the U-2 loop. They output 0 to $50 \mathrm{mV}$ and are accurate to $\pm 0.1 \%$ full scale. Their response time is typically 15 to $20 \mathrm{sec}$.

\subsubsection{U-2 Loop Flow Measurement}

Main U-2 loop flow is measured using a Venturi flow element with a Barton Differential Pressure Unit 199 that has a Taylor F-28T transmitter. The input range is 0 to $500 \mathrm{in}$. water with a transmitter accuracy of $\pm 0.5 \%$. The response time of flow instrumentation is difficult to determine because of the dependence of response time on the length of the tubing that is used to connect them to the U-2 loop.

\subsubsection{U-2 Loop Power Measurement}

Power measurement in the $\mathrm{U}-2$ loop is done by calorimetry using test section flow rate, and inlet and outlet temperature. Thus the power measurement accuracy, response times and reliability are dependent upon the flow and temperature instrumentation.

\subsection{FUEL FAILURE DETECTION EQUIPMENT}

The U-2 loop has a gamma detector and a sample point for a gamma spectrometer that should be available for the preconditioning phase of the LOCA test. $A E C L$ is in the process of putting in a delayed neutron detector. For the steam and reflood portions of the test, a gamma detector will be installed on the steam line to the condenser on the outside of the piping. Also, fuel rod failure detector devices will be attached to fuel rods in the same manner as the pressure transducers. These devices are on-off, pressure actuated switches and will signal the reduction in fuel rod pressure resulting from a breach in the cladding. 


\subsection{REACTOR TRIP CONDITIONS AND REQUIREMENTS}

There are two types of trips used for tripping the reactor: conditional and absolute trips. Trips in the U-2 loop and trips in the steam and reflood system of the LOCA test can be conditional trips. For a conditional trip, all the control rods, except the first eight to be withdrawn, are caused to drop and shut down the reactor. An absolute trip causes all the control rods in the reactor to drop. All trips associated with the reactor plant protective system must be absolute trips. Although absolute trips shut down the reactor faster, it takes longer to start the reactor up again. Figures 9.3, 9.4 and 9.5 show the decay in neutron power level for the three NRU U-2 loop, high temperature conditional trips. The curves reflect the time necessary for the trip relays. Normalized decay power versus time is shown, where Po is the original power and $P$ is the power at a given time. Differences in the decay curves could be attributed to the initial power and the number of rods dropped. The figures show that when more control rods are dropped, the reactor power tends to decay faster.

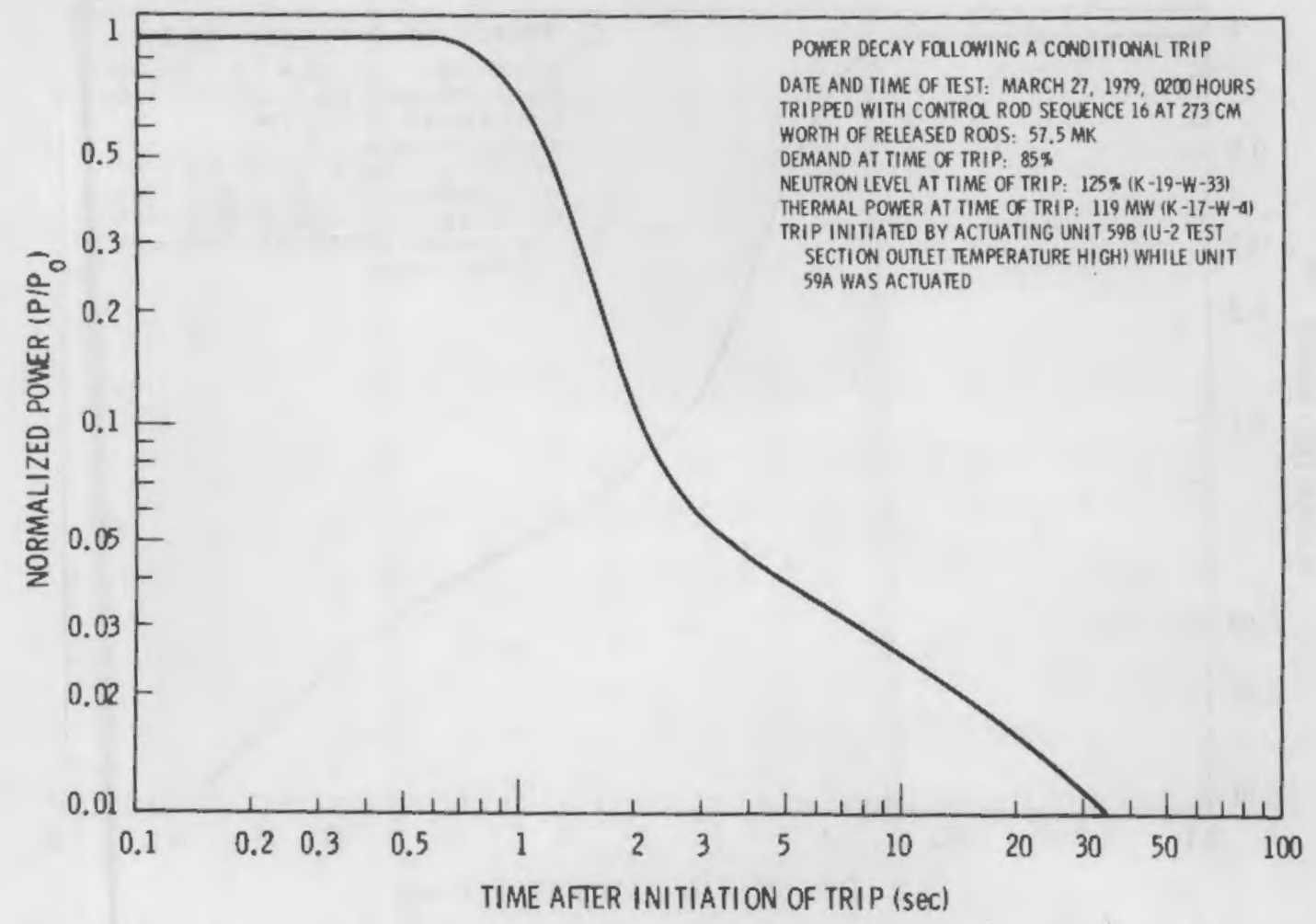

FIGURE 9.3. Neutron Power Decay Following a Conditional Trip on Rod 16 


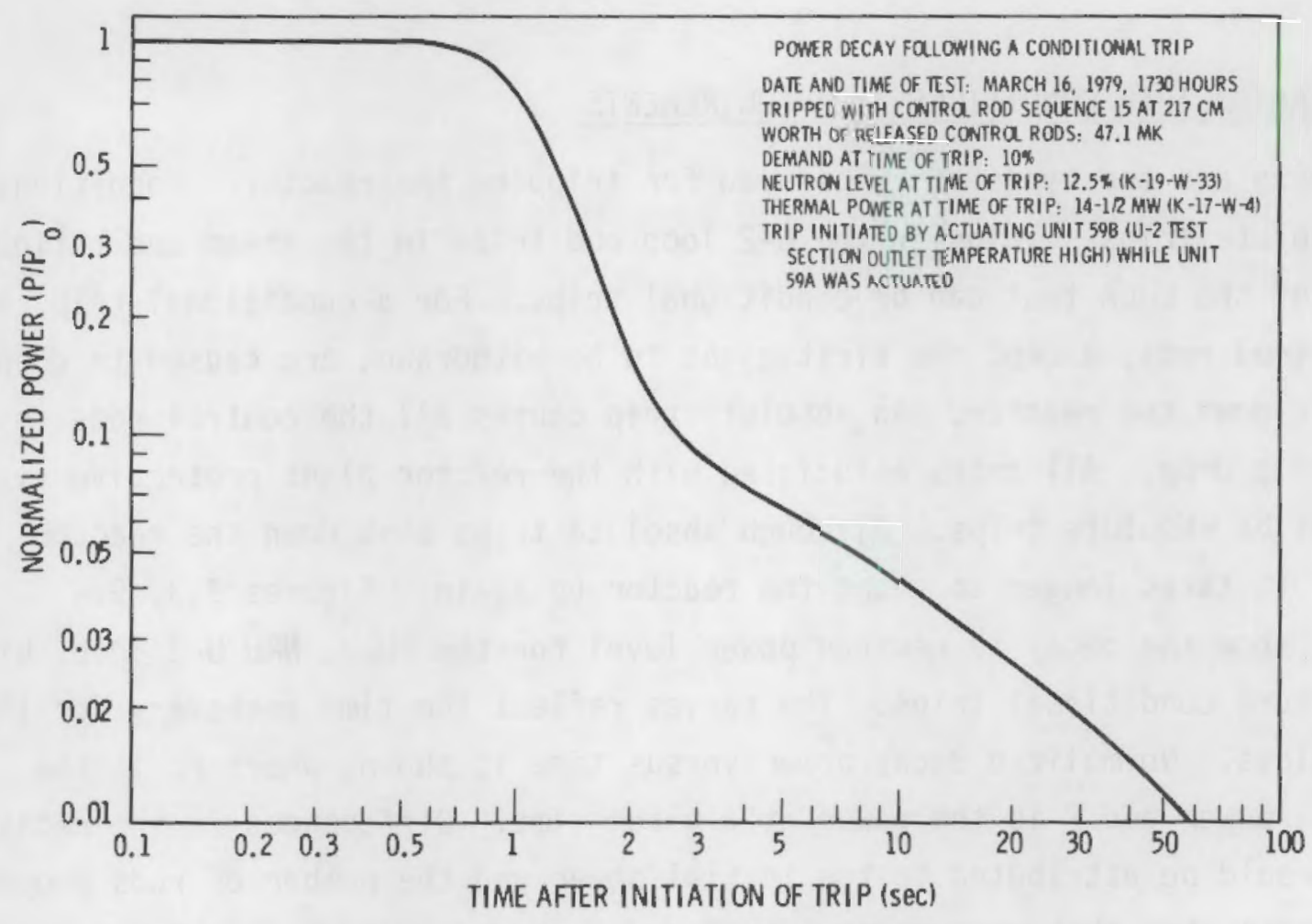

\section{FIGURE 9.4. Power Decay Following a Conditional Trip on Rod 15}

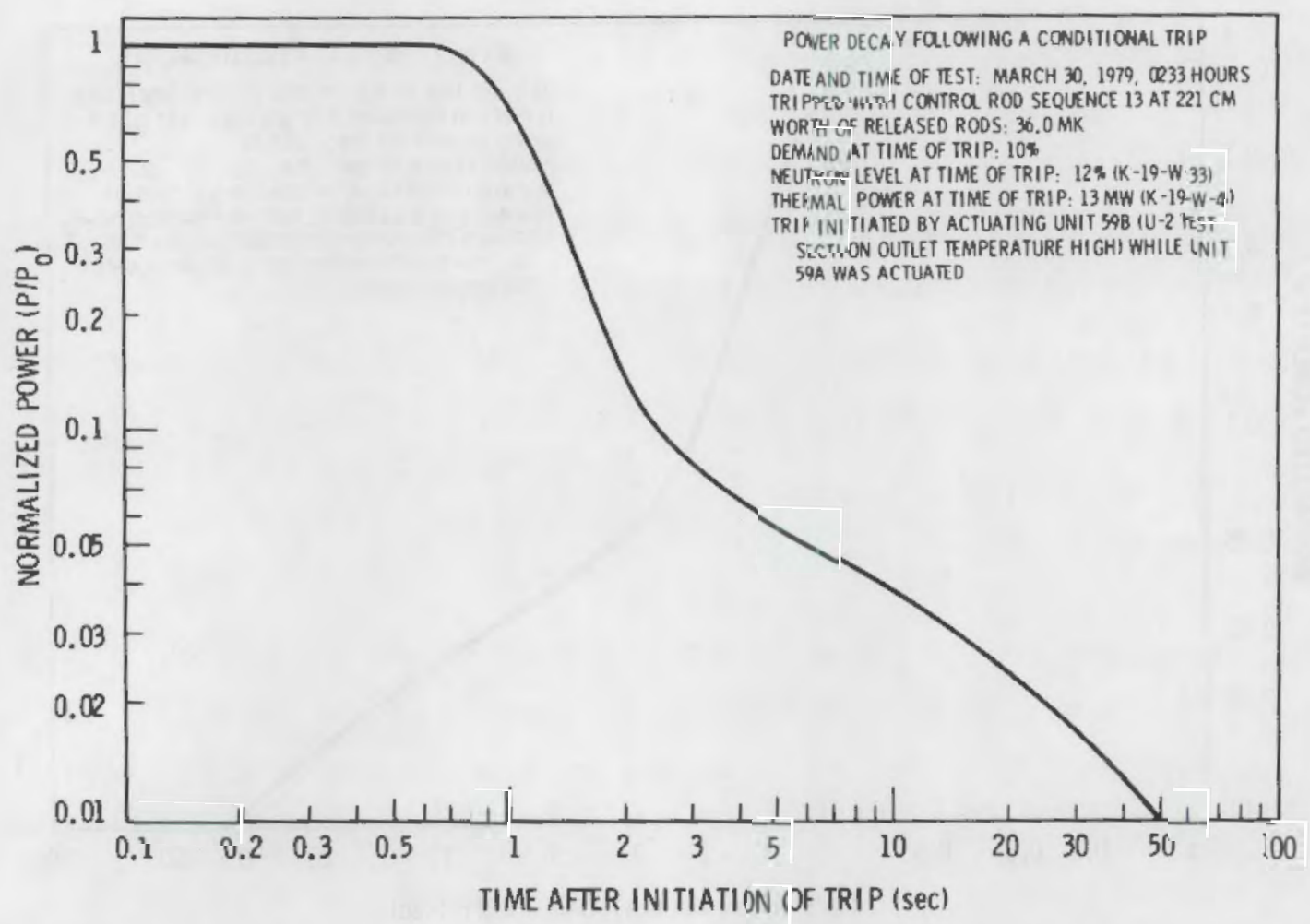

FIGURE 9.5. Power Decay Following a Conditional Trip on Rod 13 


\subsubsection{Preconditioning Phase Trips}

During this phase, the test section will be connected to the U-2 loop and the following standard $U-2$ reactor trips will be in service:

- test section outlet temperature (high)

- pump subcooling de1ta T (low)

- test section water flow (low)

- surge tank level (low)

- surge tank pressure (high)

- manual.

In addition, the following two reactor trips will be in service:

- Hanger tube (high) temperature: thermocouples at the bottom of the fuel hanger tube (level 21) will actuate the trip to protect the pressure tube from overheating.

- Outlet piping (high) temperature: thermocouples on the outlet piping will trip the reactor to minimize thermal expansion stresses in the outlet piping.

\subsubsection{Pretransient Phase Trips}

The pretransient trips will be:

- Hanger tube high temperature trip where 2 of 3 thermocouples must reach a high set point temperature to cause the trip.

- Outlet piping high steam temperature trip where 2 of 3 thermocouples must reach a high set point temperature to cause the trip.

- Loss of steam flow trip.

- Manuar trip.

The steam control system determines steam flow at the outlet of the test assembly. Steam pressure, temperature, and control valve positions for test assembly bypass and total steam flows are used to determine steam flow through the test assembly. When test assembly steam flow drops below a set point, the reactor will trip. 


\subsubsection{Transient Phase Trips}

The transient phase trips will be:

- Hanger tube high temperature trip (same as pretransient).

- Outlet piping high temperature trip (same as pretransient).

- Low reflood flow standby trip.

- High fuel cladding temperature trip.

- Manuar trip.

The standby reflood flow would operate if the normal reflood did not operate. If the standby reflood water flow rate is low, the reactor will trip.

Fuel cladding temperature will be measured at instrument levels 13, 15, and 17 (see drawing $\mathrm{H}-3-41804$, Appendix A). The cladding high-temperature trip will trip the reactor if the pseudo (averaged) cladding temperature at any one of the 13,15, or 17 instrument levels should exceed a pre-determined set point as outlined below.

Average thermocouple readings at a level will be used for the trip. The average of several thermocouples is called a pseudo sensor. For example, the pseudo sensor at level 13 to be used for a trip includes an average of 4 ID thermocouples. The DACS will sample this pseudo sensor 10 times for a second, average these ten readings, and store the average. This will be done for the next $g$ seconds so that 10 averages are obtained. These 10 averages are then averaged and this final result is used for comparison with the trip setpoint. Each second a new average of 10 pseudo readings is included with this average, and the oldest reading is deleted from the 10 -second average. The reactor will trip when the average temperature at any one of the three levels reaches the trip setting. The pseudo sensors to be used are as follows:

Level 13: $4 \mathrm{cladding}$ ID thermocouples on 4 outer guard fuel rods.

Level 15: 4 cladding ID thermocouples on 4 outer guard fuel rods.

Level 17: $8 \mathrm{cladding}$ ID thermocouples on 4 inner guard fuel rods.

A minimum of two operating thermocouples is required for each of the three trip circuit instrumentation levels $(13,15$ and 17$)$. Less than six operating thermocouples will result in the reactor trip, or will require an alternate 
trip scheme. An alternate scheme would require a pseudo trip signal from two of any three levels $(13,15$ and 17), or from level 15 or 17 alone. Alternate trip schemes require more conservative trip set points than are required for the full complement of trip sensor thermocouples (greater than or equal to 2 at each of the three levels).

During the transient phase of the test, the reactor will also trip on failure of the normal reflood water. That is, if the reflood water flow rate is significantiy less than the reflood water flow rate setting, the reactor will trip.

\subsection{FUEL BEHAVIOR - NORMAL OPERATION}

This section covers three kinds of tests that will be performed to examine the behavior of fuel under normal operating conditions.

\subsubsection{Thermal-Hydraulic Tests}

The thermal-hydraulic and fuel cladding tests will be conducted as described in Section 6.0 of this SAR. All of the rods in the thermal-hydraulic tests will be unpressurized and no severe cladding deformation will occur. For the thermal-hydraulic tests, no cladding failures are expected to occur and therefore no fission products are expected to be released from the test bundle to the test loop.

Figures 9.6 through 9.11 present the expected peak temperature histories for both the cladding and fuel for the matrix of test parameters presently planned for the NRU tests. Figure 9.6 presents the CE/THERM Code results and Figures 9.7 through 9.11 present the GAPCON T-3 computer code results. One heatup rate was examined for reflood rates varying between 5.08 and $25.4 \mathrm{~cm} / \mathrm{s}$ $(2.0$ and $10 \mathrm{in.} / \mathrm{s})$ with reflood initiation delay times from 0.0 to $20.0 \mathrm{sec}$. In all cases, the peak pretransient steady-state cladding temperature is $726 \mathrm{~K}$ $\left(848^{\circ} \mathrm{F}\right)$. The analysis is conservative since the maximum allowed peak pretransient cladding temperature is $700 \mathrm{~K}\left(800^{\circ} \mathrm{F}\right)$.

Table 9.4 shows the cladding materials deformation test results calculated by GAPCON T-3 computer code (Lanning et al. 1978). Also included in the table 


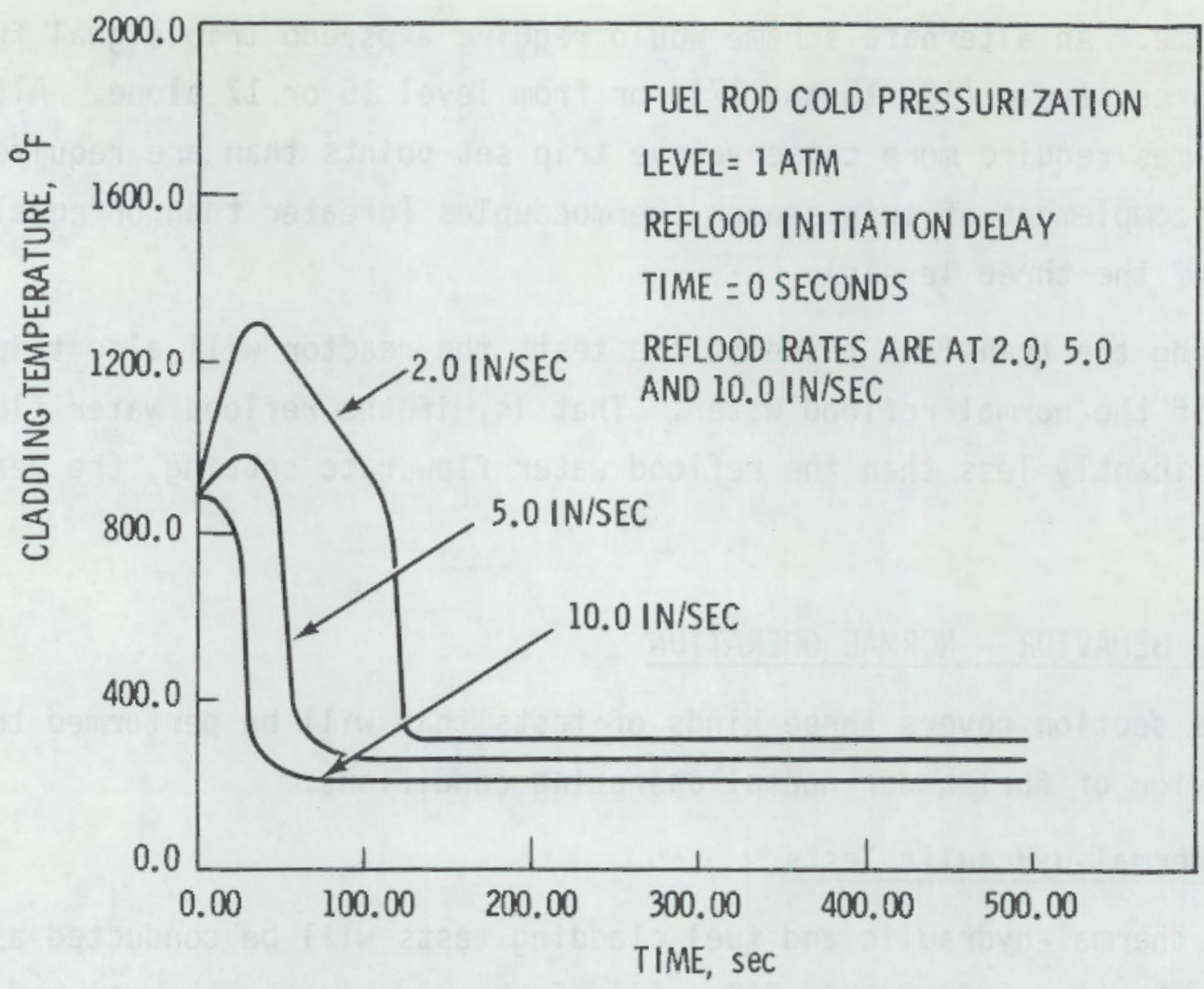

FIGURE 9.6. Cladding Temperature for Thermal-Hydraulic Tests 0 -Second Reflood Initiation Delay Time (based on CE/THERM Code results)

of results is the peak rod internal gas pressure during the transients. It should be noted that Table 9.4 details the results of the cladding deformation calculations for the thermal-hydraulic assembly with a cold rod prepressurization level of $0.10 \mathrm{MPa}$ (14.7 psia).

Fission product content for the thermal-hydraulic tests has been estimated using the ORIGEN computer code (Bell 1973). The ORIGEN code is used to calculate the quantity of radioactive isotopes in the fuel at the time of cladding rupture and at various times following the cladding failure. All of the thermal-hydraulic tests will be conducted using the same fuel assembly (guard heater rods and test rods) within a seven-day interval. The total fission product content of all rods in the fuel assembly was calculated for the condition of the fuel rods following completion of all possible thermal-hydraulic tests. No cladding failure is expected during any of these tests. 


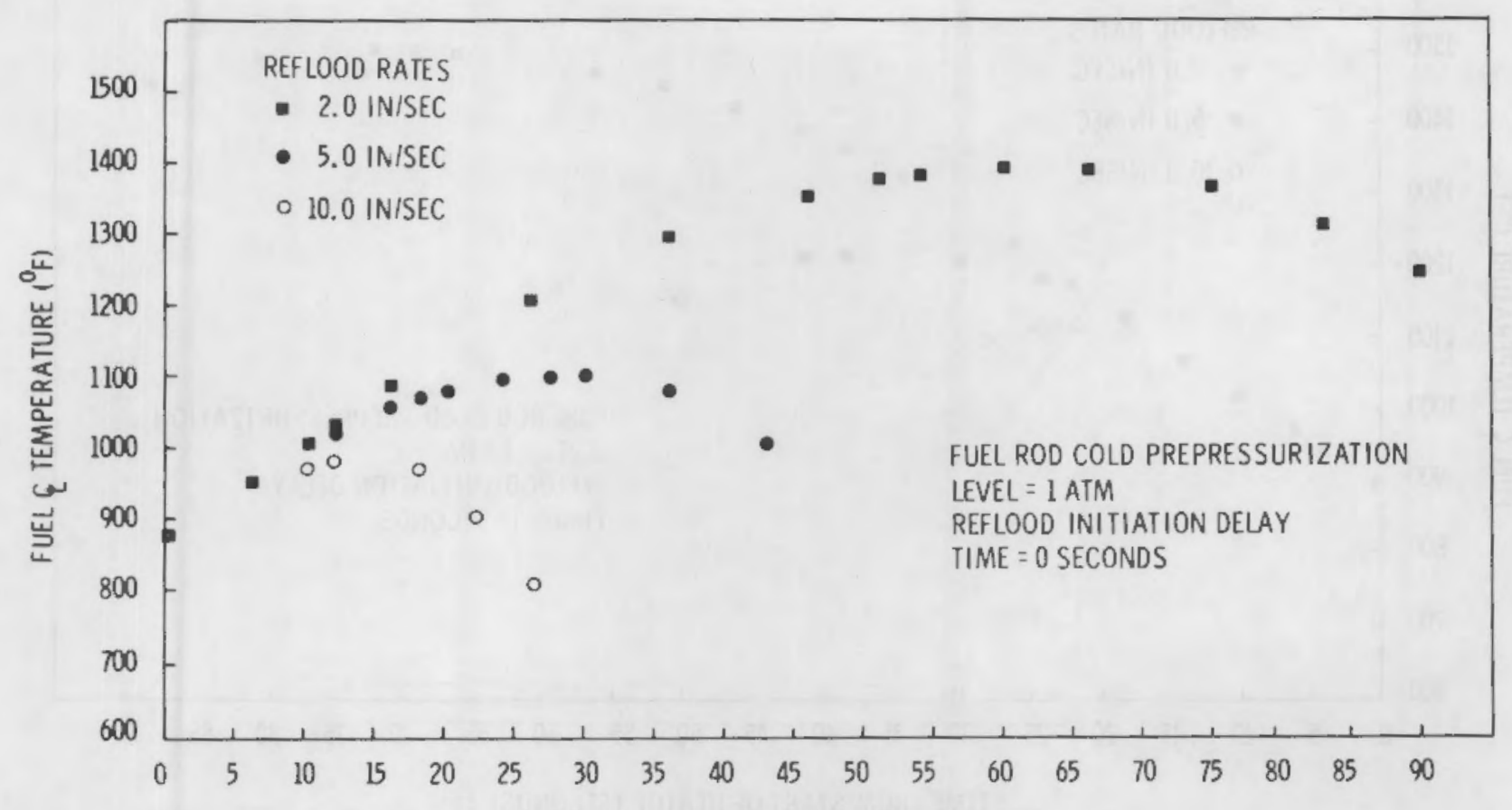

IIME FROM START OF HEATUP (SECONDS)

FIGURE 9.7. Fuel Centerline Temperature for Thermal-Hydraulic Tests - 0-Second Refiood Initiation Delay Time

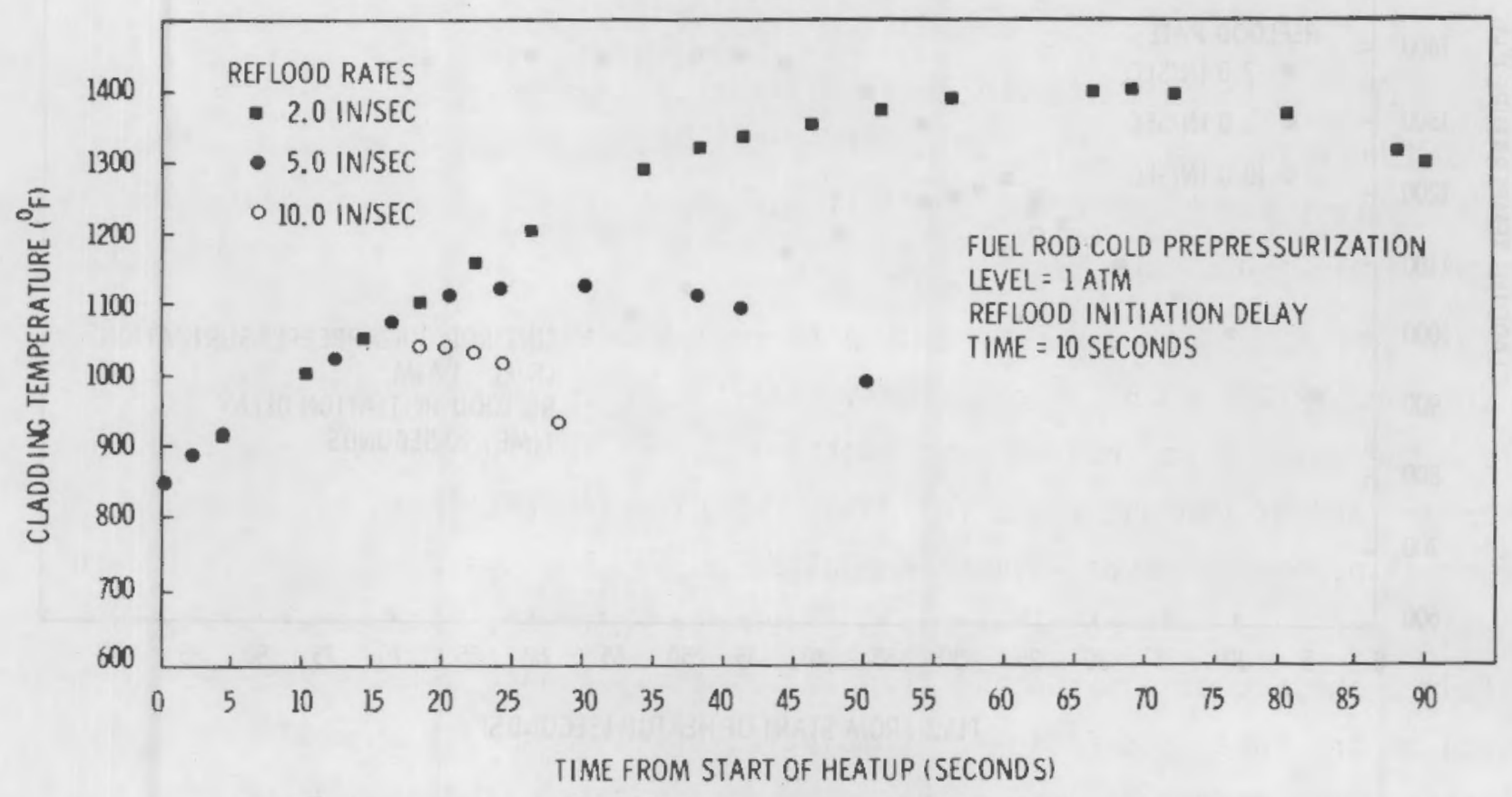

FIGURE 9.8. Cladding Temperature for Thermal-Hydraulic Tests 10-Second Reflood Initiation Delay Time 


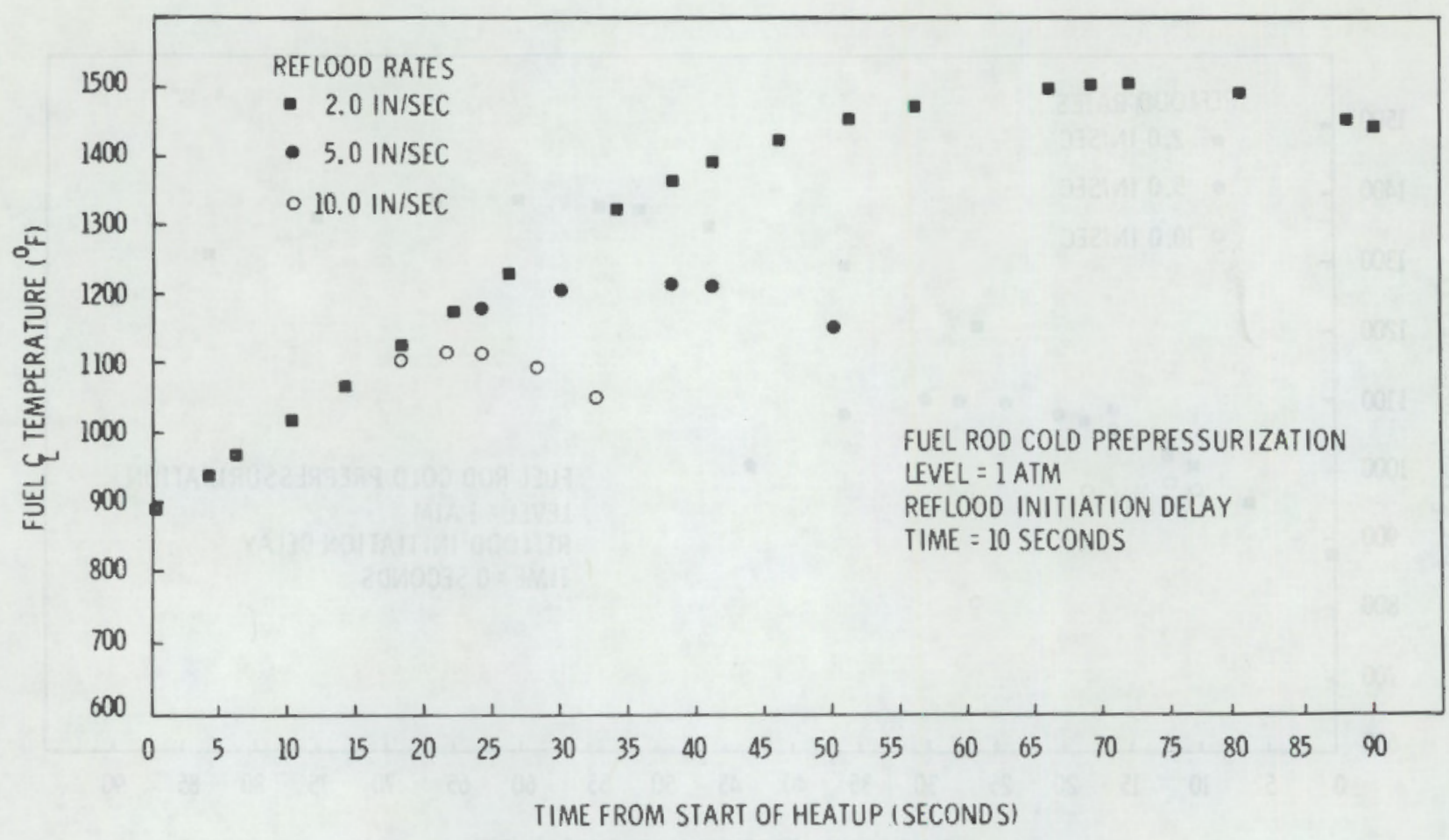

FIGURE 9.9. Fuel Centerline Temperature for Thermal-Hyaraulic Tests - 10-Second Reflood Initiation Delay Time

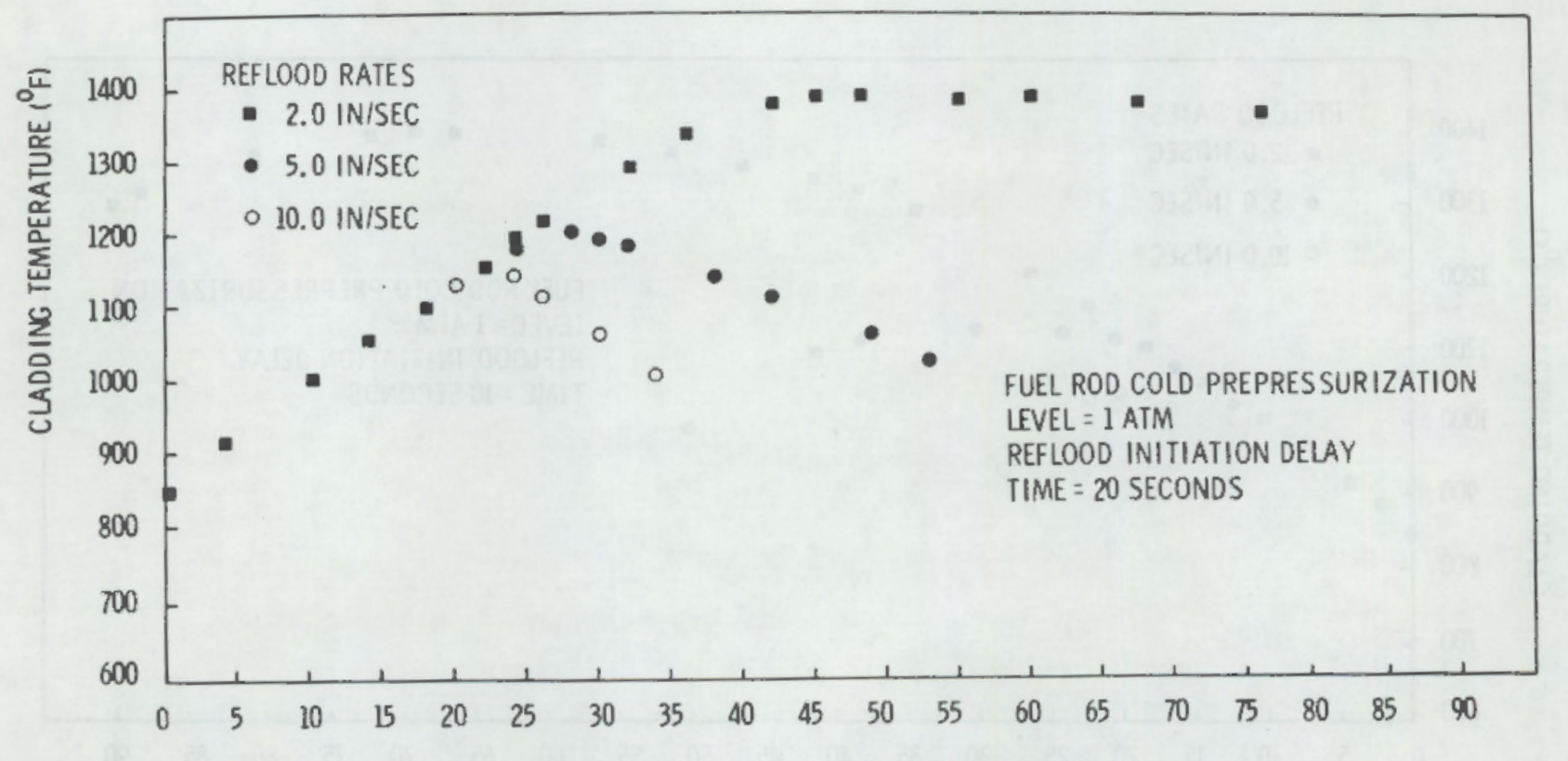

TIME FROM START OF HEATUP (SECONDS)

FIGURE 9.10. Ciladding Temperature for Thermal-Hydraulic Tests 20-Second Reflood Initiation Delay Time 


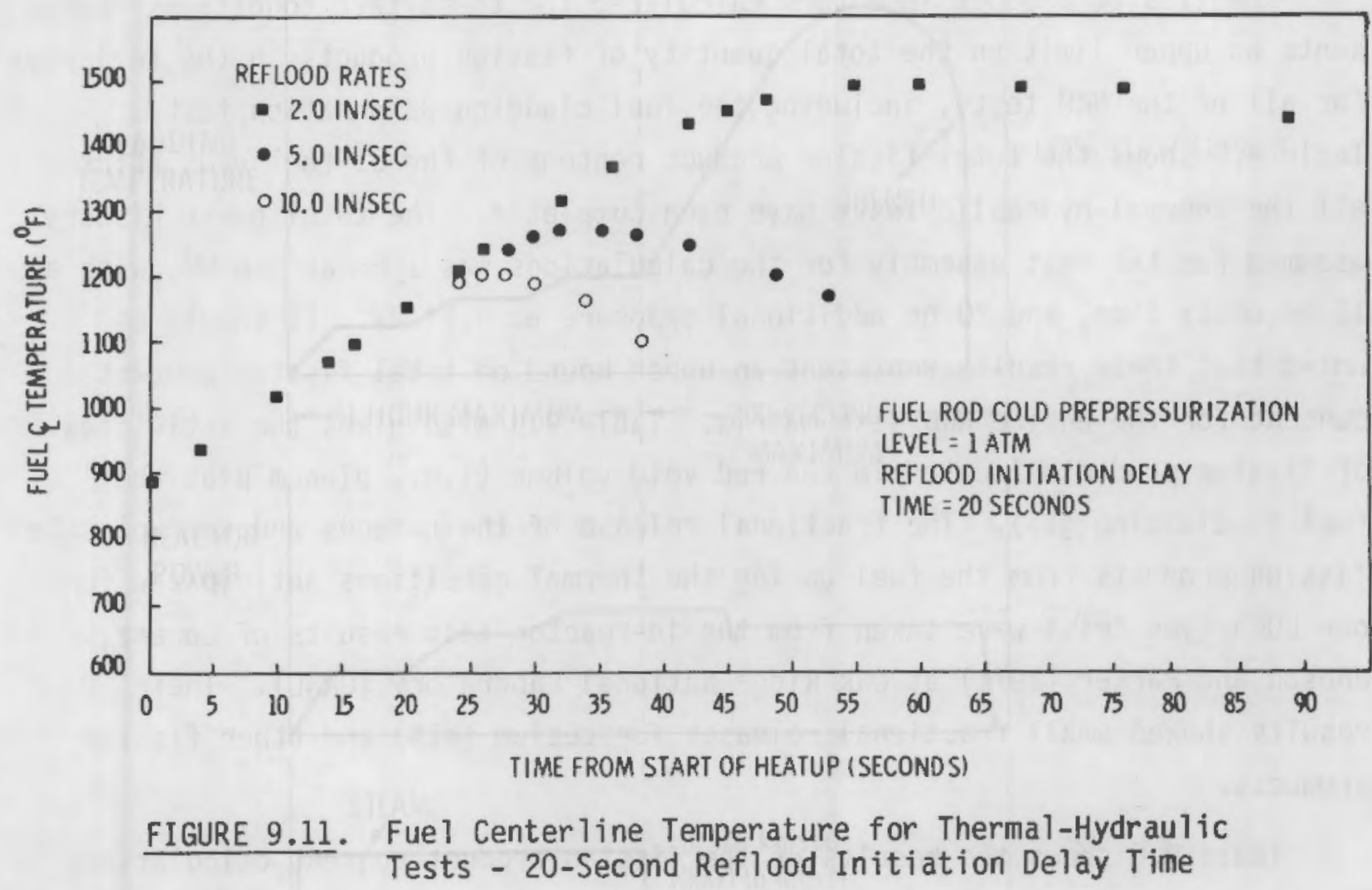

TABLE 9.4. GAPCON T-3 Code TH Tests Predictions

\begin{tabular}{|c|c|c|c|c|c|c|}
\hline $\begin{array}{l}\text { Reflood } \\
\text { Rate }\end{array}$ & $\begin{array}{c}\text { Delay } \\
\text { Time, } \\
\text { sec }\end{array}$ & $\begin{array}{l}\text { Elastic Change } \\
\text { in Cladding } \\
\text { Radius, in. } \\
\end{array}$ & $\begin{array}{c}\text { Creep-Plastic } \\
\text { Change In Cladding } \\
\text { Radius, in. } \\
\end{array}$ & $\begin{array}{l}\text { Total Change } \\
\text { In Cladding } \\
\text { Radius, in. } \\
\end{array}$ & $\begin{array}{l}\text { Peak Rod } \\
\text { Internal Gas } \\
\text { Pressure, psi } \\
\end{array}$ & $\begin{array}{l}\text { Cladding Rupture } \\
\text { Predicted and } \\
\text { Number of Rods } \\
\text { Expected to } \\
\text { Rupture } \\
\end{array}$ \\
\hline 2.0 & 0 & 0.000607 & - & 0.000607 & 43 & No, none \\
\hline 5.0 & 0 & 0.000488 & -- & 0.000488 & 40 & No, none \\
\hline 10.0 & 0 & 0.00445 & -- & 0.000445 & 38 & No, none \\
\hline 2.0 & 10 & 0.000647 & - & 0.000647 & 44 & No, none \\
\hline 5.0 & 10 & 0.00534 & -- & 0.000534 & 41 & No, none \\
\hline 10.0 & 10 & 0.000503 & $\cdots$ & 0.000503 & 40 & No, none \\
\hline 2.0 & 20 & 0.00607 & - & 0.00607 & 43 & No, none \\
\hline 5.0 & 20 & 0.000488 & - & 0.000488 & 40 & Ho, none \\
\hline 10.0 & 20 & 0.000446 & - & 0.000446 & 39 & No, none \\
\hline
\end{tabular}


The fission product inventory calculated for these test conditions represents an upper limit on the total quantity of fission products in the fuel rods for all of the NRU tests, including the fuel cladding deformation tests. Table 9.5 shows the total fission product content of the 31 fuel rods after all the thermal-hydraulic tests have been completed. The total power history assumed for the test assembly for the calculations was $1 \mathrm{hr}$ at $2.6 \mathrm{MW}$, with a 16-hr decay time, and $20 \mathrm{hr}$ additional exposure at $0.14 \mathrm{MW}$. It should be noted that these results represent an upper bound on total fission product content for the entire NRU test matrix. Table 9.5 also gives the activities of fission products located in the rod void volume (i.e., plenum plus the fuel-to-cladding gap). The fractional release of the gaseous and semivolatile fission products from the fuel during the thermal conditions anticipated for our LOCA-type tests were taken from the in-reactor test results of Lorenz, Hobson and Parker (1971) at Oak Ridge National Laboratory (ORNL). Their results showed small fractional releases for cesium $(<1 \%)$ and other fission products.

Table 9.6 shows the results of the fission product content calculations for the period after preconditioning. For these calculations, it was assumed that the total power history of the test assembly was $1 \mathrm{hr}$ at $2.6 \mathrm{MW}$. Table 9.6 also gives the activities of fission products located in the rod void volume. The fractional release of the gaseous and semivolatile fission products to the gap and plenum void volume is assumed to be $1 \%$.

\subsubsection{Cladding Oeformation Tests}

In the fuel cladding materials deformation tests the inner eleven test positions will contain prepressurized rods, and dilatation and rupture of the cladding of the inner test rods will depend on the cold internal pressure and the cladding time-temperature relationships experienced during the transients.

Figures 9.12 through 9.20 present the expected temperature transients for both the cladding and fuel for the matrix of test parameters presently planned for the NRU cladding deformation tests. Figure 9.12 presents the CE/THERM Code results and Figures 9.13 through 9.20 present the GAPCON-FLECHT Computer Code 


\section{TABLE 9.5. Fission Product Inventory for Post Thermal-Hydraulic Tests (total for 31 fuel rods)}

Gaseous Fission Product Inventory, curies-Cs, I, Xe, Kr

\begin{tabular}{l} 
Time After \\
Test, da \\
\hline Isotope \\
\hline I-131 \\
I-132 \\
I-133 \\
l-134 \\
I-135 \\
Kr-85 \\
Kr-85M \\
Kr-87 \\
Kr-88 \\
Kr-89 \\
Xe-131M \\
Xe-133 \\
Xe-135 \\
Cs-135M \\
Cs-136 \\
Cs-137 \\
Cs-138 \\
Cs-135 \\
Total
\end{tabular}

\begin{tabular}{|c|c|c|c|c|c|c|}
\hline 0 & 0.01 & 0.10 & 0.5 & 1.0 & 2 & 5 \\
\hline $3.90 \times 10^{2}$ & $3.93 \times 10^{2}$ & $4.02 \times 10^{2}$ & $3.97 \times 10^{2}$ & $3.89 \times 10^{2}$ & $3.67 \times 10^{2}$ & $2.94 \times 10^{2}$ \\
\hline $1.47 \times 10^{3}$ & $1.47 \times 10^{3}$ & $1.44 \times 10^{3}$ & $1.31 \times 10^{3}$ & $1.18 \times 10^{3}$ & $9.55 \times 10^{2}$ & $5.03 \times 10^{2}$ \\
\hline $50.8 \times 10^{3}$ & $5.10 \times 10^{3}$ & $4.92 \times 10^{3}$ & $3.61 \times 10^{3}$ & $2.43 \times 10^{3}$ & $1.10 \times 10^{3}$ & $1.02 \times 10^{2}$ \\
\hline $9.27 \times 10^{3}$ & $8.93 \times 10^{3}$ & $3.26 \times 10^{3}$ & $3.0 \times 10^{0}$ & $3 \times 10^{4}$ & $2 \times 10^{12}$ & 0 \\
\hline $6.64 \times 10^{3}$ & $6.48 \times 10^{3}$ & $5.18 \times 10^{3}$ & $1.92 \times 10^{3}$ & $5.55 \times 10^{2}$ & $4.63 \times 10^{1}$ & $2.7 \times 10^{-2}$ \\
\hline $9.94 \times 10^{2}$ & $1.00 \times 10^{1}$ & $1.04 \times 10^{-1}$ & $1.12 \times 10^{-1}$ & $1.14 \times 10^{-1}$ & $1.15 \times 10^{1}$ & $1.15 \times 10^{-1}$ \\
\hline $1.42 \times 10^{3}$ & $1.39 \times 10^{3}$ & $9.88 \times 10^{2}$ & $2.18 \times 10^{2}$ & $32.9 \times 10^{r}$ & $7.5 \times 10^{-1}$ & $9 \times 10^{-6}$ \\
\hline $2.96 \times 10^{3}$ & $2.63 \times 10^{3}$ & $8.06 \times 10^{2}$ & $4.2 \times 10^{0}$ & $5.9 \times 10^{-3}$ & $1 \times 10^{-8}$ & $9 \times 10^{-26}$ \\
\hline $4.21 \times 10^{-3}$ & $3.98 \times 10^{3}$ & $2.33 \times 10^{3}$ & $2.16 \times 10^{2}$ & $1.11 \times 10^{1}$ & $2.92 \times 10^{-2}$ & $5 \times 10^{-10}$ \\
\hline $5.46 \times 10^{2}$ & $2.47 \times 10^{2}$ & $2 \times 10^{-10}$ & 0 & 0 & 0 & 0 \\
\hline $1.70 \times 10^{-1}$ & $1.72 \times 10^{-1}$ & $1.88 \times 10^{-1}$ & $2.58 \times 10^{-1}$ & $3.41 \times 10^{-1}$ & $4.95 \times 10^{-1}$ & $8.41 \times 10^{-1}$ \\
\hline $7.01 \times 10^{2}$ & $7.07 \times 10^{2}$ & $7.57 \times 10^{2}$ & $9.32 \times 10^{2}$ & $1.06 \times 10^{3}$ & $1.14 \times 10^{3}$ & $9.01 \times 10^{2}$ \\
\hline $4.59 \times 10^{3}$ & $4.63 \times 10^{3}$ & $4.81 \times 10^{3}$ & $3.94 \times 10^{3}$ & $2.20 \times 10^{3}$ & $4.80 \times 10^{2}$ & $2.6 \times 10^{\circ}$ \\
\hline $5 \times 10^{-8}$ & $4 \times 10^{-8}$ & $8 \times 10^{-9}$ & $4 \times 10^{-12}$ & $3 \times 10^{-16}$ & $2 \times 10^{-24}$ & 0 \\
\hline $6.6 \times 10^{-1}$ & $6.6 \times 10^{-1}$ & $6.5 \times 10^{-1}$ & $6.4 \times 10^{-1}$ & $6.2 \times 10^{-1}$ & $5.9 \times 10^{-1}$ & $5.0 \times 10^{\prime}$ \\
\hline $7.4 \times 10^{-1}$ & $7.4 \times 10^{-1}$ & $7.4 \times 10^{-1}$ & $7.4 \times 10^{-1}$ & $7.4 \times 10^{-1}$ & $7.4 \times 10^{-1}$ & $7.4 \times 10^{-1}$ \\
\hline $6.83 \times 10^{3}$ & $6.37 \times 10^{3}$ & $6.32 \times 10^{2}$ & $3 \times 10^{-3}$ & $5 \times 10^{-10}$ & $2 \times 10^{-23}$ & 0 \\
\hline $4 \times 10^{-6}$ & $4 \times 10^{-6}$ & $4 \times 10^{-6}$ & $5 \times 10^{-8}$ & $6 \times 10^{-6}$ & $7 \times 10^{-6}$ & $7 \times 10^{-0}$ \\
\hline $4.90 \times 10^{4}$ & $4.23 \times 10^{4}$ & $2.55 \times 10^{4}$ & $1.26 \times 10^{4}$ & $7.86 \times 10^{3}$ & $4.09 \times 10^{3}$ & $1.81 \times 10^{3}$ \\
\hline
\end{tabular}

Amount of gaseous fission products free in the fuel rod void volume (plenum plus fuel-cladding gap) for all 31 fuel rods at the time of cladding rupture $=4.90 \times 10^{2}$ Curies

Semi.Volarile Fission Product Inventory, curies-Sr, Ba, Te, Se, Sb

\begin{tabular}{|c|c|c|c|c|c|c|c|}
\hline $\begin{array}{l}\text { Time After Last } \\
\text { Test, da }\end{array}$ & 0 & 0.01 & 0.10 & 0.5 & 1.0 & 2 & 5 \\
\hline \multicolumn{8}{|l|}{ Isotope } \\
\hline Sr & $3.14 \times 10^{2}$ & $1.40 \times 10^{4}$ & $8.51 \times 10^{3}$ & $2.92 \times 10^{3}$ & $1.20 \times 10^{3}$ & $3.08 \times 10^{2}$ & $1.14 \times 10^{2}$ \\
\hline $\mathrm{Ba}$ & $2.83 \times 10^{4}$ & $1.52 \times 10^{4}$ & $3.31 \times 10^{3}$ & $6.28 \times 10^{2}$ & $5.90 \times 10^{2}$ & $5.59 \times 10^{2}$ & $4.76 \times 10^{2}$ \\
\hline $\mathrm{Te}$ & $2.91 \times 10^{4}$ & $1.87 \times 10^{4}$ & $4.63 \times 10^{3}$ & $1.81 \times 10^{3}$ & $1.42 \times 10^{3}$ & $1.07 \times 10^{3}$ & $5.34 \times 10^{2}$ \\
\hline Se & $3.25 \times 10^{3}$ & $3.73 \times 10^{2}$ & $9.9 \times 10^{0}$ & $1.5 \times 10^{2}$ & $1.0 \times 10^{-2}$ & $7 \times 10^{3}$ & $2 \times 10^{-3}$ \\
\hline Sb & $2.53 \times 10^{4}$ & $5.86 \times 10^{3}$ & $1.15 \times 10^{3}$ & $2.63 \times 10^{2}$ & $7.04 \times 10^{\prime}$ & $2.88 \times 10^{\prime}$ & $1.57 \times 10^{1}$ \\
\hline Total & $1.17 \times 10^{5}$ & $5.41 \times 10^{4}$ & $1.76 \times 10^{4}$ & $5.62 \times 10^{3}$ & $3.28 \times 10^{3}$ & $1.97 \times 10^{3}$ & $1.14 \times 10^{3}$ \\
\hline
\end{tabular}

Amount of semi-volatile fission products free in the fuel rod void volume (plenum plus fuel-cladding gap) for all 31 fuel rods at the time of cladding cupture $=1.17 \times 10^{3}$ Curies.

Total fission product inventory (Gaseous plus Semi-Volatite) free in the fuel void volume (plenum plus fuel-cladding gap) for all 31 fuel rods at the time of cladding rupture $=1.66 \times 10^{3}$ Curies. 
TABLE 9.6. Fission Product Inventory for Post-Preconditioning (total for 31 fuel rods)

Gaseous Fission Product Inventory, curies-Cs, I, Xe, Kr

\begin{tabular}{|c|c|c|c|c|c|c|c|c|c|c|c|}
\hline conditioning, $\mathrm{hr}$ & 0 & 1 & 3 & 5 & 7 & 9 & 11 & 13 & 15 & 17 & 19 \\
\hline \multicolumn{12}{|l|}{ Isotope } \\
\hline $\mid-131$ & $4.09 \times 10^{1}$ & $1.39 \times 10^{2}$ & $1.96 \times 10^{2}$ & $1.99 \times 10^{2}$ & $2.00 \times 10^{2}$ & $1.99 \times 10^{2}$ & $1.99 \times 10^{2}$ & $1.99 \times 10^{2}$ & $1.99 \times 10^{2}$ & $1.99 \times 10^{2}$ & $1.98 \times 10^{2}$ \\
\hline 1.132 & $9.01 \times 10^{2}$ & $8.80 \times 10^{2}$ & $8.48 \times 10^{2}$ & $8.24 \times 10^{2}$ & $8.04 \times 10^{2}$ & $7.87 \times 10^{2}$ & $7.72 \times 10^{2}$ & $7.57 \times 10^{2}$ & $7.44 \times 10^{2}$ & $7.30 \times 10^{2}$ & $7.17 \times 10^{2}$ \\
\hline $1-133$ & $1.89 \times 10^{3}$ & $3.56 \times 10^{3}$ & $4.24 \times 10^{3}$ & $4.14 \times 10^{20}$ & $3.91 \times 10^{3}$ & $3.67 \times 10^{3}$ & $3.43 \times 10^{3}$ & $3.21 \times 10^{5}$ & $3.01 \times 10^{3}$ & $2.82 \times 10^{3}$ & $2.64 \times 10^{3}$ \\
\hline $1-134$ & $4.42 \times 10^{-5}$ & $5.10 \times 10^{4}$ & $2.00 \times 10^{4}$ & $5.46 \times 10^{3}$ & $1.31 \times 10^{3}$ & $2.96 \times 10^{2}$ & $6.47 \times 10^{1}$ & $1.39 \times 10^{1}$ & $2.93 \times 10^{0}$ & $6.16 \times 10^{-1}$ & $1.29 \times 10^{1}$ \\
\hline 1.135 & $1.30 \times 10^{4}$ & $1.19 \times 10^{4}$ & $9.64 \times 10^{3}$ & $7.84 \times 10^{3}$ & $6.37 \times 10^{3}$ & $5.18 \times 10^{3}$ & $4.21 \times 10^{3}$ & $3.43 \times 10^{3}$ & $2.79 \times 10^{3}$ & $2.27 \times 10^{3}$ & $1.84 \times 10^{3}$ \\
\hline $\mathrm{Kr}-85 \mathrm{M}$ & $3.67 \times 10^{3}$ & $3.42 \times 10^{3}$ & $2.50 \times 10^{3}$ & $1.82 \times 10^{0}$ & $1.33 \times 10^{3}$ & $9.71 \times 10^{2}$ & $7.08 \times 10^{2}$ & $5.17 \times 10^{2}$ & $3.77 \times 10^{2}$ & $2.75 \times 10^{2}$ & $2.01 \times 10^{2}$ \\
\hline$K_{r}-85$ & $1.23 \times 10^{-2}$ & $1.86 \times 10^{2}$ & $2.85 \times 10^{2}$ & $3.57 \times 10^{2}$ & $4.09 \times 10^{2}$ & $4.48 \times 10^{2}$ & $4.76 \times 10^{2}$ & $4.96 \times 10^{2}$ & $5.11 \times 10^{2}$ & $5.22 \times 10^{2}$ & $5.30 \times 10^{2}$ \\
\hline $\mathrm{Kr}-87$ & $2.25 \times 10^{4}$ & $1.34 \times 10^{4}$ & $4.49 \times 10^{3}$ & $1.50 \times 10^{3}$ & $5.03 \times 10^{2}$ & $1.69 \times 10^{2}$ & $5.64 \times 10^{1}$ & $1.89 \times 10^{1}$ & $6.32 \times 10^{\circ}$ & $2.12 \times 10^{0}$ & $7.08 \times 10^{1}$ \\
\hline$k_{r}-88$ & $1.71 \times 10^{4}$ & $1.34 \times 10^{\circ}$ & $8.19 \times 10^{3}$ & $4.99 \times 10^{0}$ & $3.04 \times 10^{3}$ & $1.85 \times 10^{3}$ & $1.13 \times 10^{3}$ & $6.89 \times 10^{2}$ & $4.20 \times 10^{2}$ & $2.56 \times 10^{2}$ & $1.56 \times 10^{2}$ \\
\hline Kr-89 & $1.01 \times 10^{5}$ & $2.34 \times 10^{\prime}$ & $1.21 \times 10^{.2}$ & $6.21 \times 10^{24}$ & 0 & 0 & 0 & 0 & 0 & 0 & 0 \\
\hline $\mathrm{Xe}-131 \mathrm{M}$ & $2.34 \times 10^{4}$ & $2.05 \times 10^{-3}$ & $9.00 \times 10^{3}$ & $1.67 \times 10^{2}$ & $2.44 \times 10^{2}$ & $3.21 \times 10^{2}$ & $3.97 \times 10^{2}$ & $4.73 \times 10^{-2}$ & $5.49 \times 10^{-2}$ & $6.24 \times 10^{2}$ & $6.98 \times 10^{2}$ \\
\hline$x e \cdot 133$ & $3.97 \times 10^{0}$ & $1.94 \times 10$ & $6.21 \times 10^{1}$ & $1.06 \times 10^{2}$ & $1.48 \times 10^{2}$ & $1.87 \times 10^{2}$ & $2.23 \times 10^{2}$ & $2.56 \times 10^{2}$ & $2.86 \times 10^{2}$ & $3.14 \times 10^{2}$ & $3.40 \times 10^{2}$ \\
\hline Xe-135 & $7.73 \times 10^{2}$ & $1.60 \times 10^{3}$ & $2.88 \times 10^{0}$ & $3.71 \times 10^{3}$ & $4.19 \times 10^{3}$ & $4.42 \times 10^{3}$ & $4.46 \times 10^{3}$ & $4.37 \times 10^{3}$ & $4.20 \times 10^{3}$ & $3.97 \times 10^{3}$ & $3.70 \times 10^{3}$ \\
\hline Cs-135M & $3.65 \times 10^{12}$ & $1.67 \times 10^{12}$ & $3.47 \times 10^{13}$ & $7.20 \times 10^{14}$ & $1.53 \times 10^{14}$ & $2.92 \times 10^{15}$ & $7.91 \times 10^{-16}$ & $1.42 \times 10^{17}$ & $1.42 \times 10^{17}$ & $1.42 \times 10^{17}$ & $1.42 \times 10^{17}$ \\
\hline Cs-135 & $9.13 \times 10^{-9}$ & $4.05 \times 10^{8}$ & $1.61 \times 10^{7}$ & $3.36 \times 10^{7}$ & $5.46 \times 10^{7}$ & $7.74 \times 10^{7}$ & $1.01 \times 10^{-6}$ & $1.24 \times 10^{-6}$ & $1.47 \times 10^{-8}$ & $1.68 \times 10^{-6}$ & $1.89 \times 10^{-6}$ \\
\hline Cs-136 & $3.31 \times 10^{-1}$ & $3.31 \times 10^{-1}$ & $3.29 \times 10^{1}$ & $3.28 \times 10^{1}$ & $3.26 \times 10^{1}$ & $3.25 \times 10^{1}$ & $3.23 \times 10^{1}$ & $3.22 \times 10^{1}$ & $3.20 \times 10^{-1}$ & $3.19 \times 10^{1}$ & $3.18 \times 10^{1}$ \\
\hline Cs-137 & $320 \times 10^{1}$ & $3.56 \times 10^{1}$ & $3.56 \times 10^{1}$ & $3.56 \times 10^{1}$ & $3.56 \times 10^{1}$ & $3.56 \times 10^{1}$ & $3.56 \times 10^{1}$ & $3.56 \times 10^{1}$ & $3.56 \times 10^{1}$ & $3.56 \times 10^{1}$ & $3.56 \times 10^{1}$ \\
\hline Cs-138 & $6.47 \times 10^{4}$ & $4.21 \times 10^{4}$ & $3.94 \times 10^{3}$ & $3.04 \times 10^{2}$ & $2.30 \times 10^{1}$ & $1.74 \times 10^{\circ}$ & $1.31 \times 10^{1}$ & $9.91 \times 10^{3}$ & $7.48 \times 10^{4}$ & $5.65 \times 10^{5}$ & $4.27 \times 10^{6}$ \\
\hline Total & $2.70 \times 10^{5}$ & $1.41 \times 10^{5}$ & $5.70 \times 10^{4}$ & $3.09 \times 10^{-4}$ & $2.18 \times 10^{4}$ & $7.87 \times 10^{3}$ & $1.53 \times 10^{4}$ & $1.35 \times 10^{4}$ & $1.20 \times 10^{5}$ & $1.98 \times 10^{2}$ & $9.79 \times 100$ \\
\hline
\end{tabular}

Amount of gaseous fission products free in the fuel rod void volume (plenum plus fuel-cladding gap) for all 31 fuel rods at the time of ciadding rupture $=2.70 \times 10^{3}$ Curies

Semı. Volatile Fission Product Inventory, curies - Sr, Ba, Te, Se, Sb

\begin{tabular}{|c|c|c|c|c|c|c|c|c|c|c|c|}
\hline $\begin{array}{l}\text { Time After } \\
\text { Preconditioning, hr }\end{array}$ & 0 & 1 & 3 & 5 & 7 & 9 & 11 & 13 & 15 & 17 & 19 \\
\hline \multicolumn{12}{|l|}{ Isotope } \\
\hline $\mathrm{Sr}$ & $3.86 \times 10^{5}$ & $2.94 \times 10^{4}$ & $1.94 \times 10^{4}$ & $1.35 \times 10^{4}$ & $9.79 \times 10^{3}$ & $7.32 \times 10^{3}$ & $5.65 \times 10^{3}$ & $4.48 \times 10^{3}$ & $3.64 \times 10^{3}$ & $3.01 \times 10^{3}$ & $2.53 \times 10^{3}$ \\
\hline Ba & $3.96 \times 10^{5}$ & $5.43 \times 10^{4}$ & $1.47 \times 10^{4}$ & $5.55 \times 100$ & $2.23 \times 10^{3}$ & $1.01 \times 10^{3}$ & $5.65 \times 10^{2}$ & $4.00 \times 10^{2}$ & $3.39 \times 10^{2}$ & $3.15 \times 10^{2}$ & $3.06 \times 10^{2}$ \\
\hline Te & $3.41 \times 10^{5}$ & $9.10 \times 10^{4}$ & $1.53 \times 10^{5}$ & $4.58 \times 10^{3}$ & $2.71 \times 10^{3}$ & $2.12 \times 10^{3}$ & $1.78 \times 10^{3}$ & $1.54 \times 10^{3}$ & $1.36 \times 10^{3}$ & $1.22 \times 10^{3}$ & $1.11 \times 10^{3}$ \\
\hline Se & $5.86 \times 10^{4}$ & $1.15 \times 10^{3}$ & $5.64 \times 10^{\prime}$ & $7.21 \times 10^{0}$ & $1.49 \times 10^{\circ}$ & $3.44 \times 10^{1}$ & $8.47 \times 10^{2}$ & $2.47 \times 10^{2}$ & $1.08 \times 10^{2}$ & $7.45 \times 10^{3}$ & $6.62 \times 10^{3}$ \\
\hline $\mathrm{Sb}$ & $4.23 \times 10^{5}$ & $1.55 \times 10^{4}$ & $3.22 \times 10^{3}$ & $2.03 \times 10^{3}$ & $1.46 \times 10^{3}$ & $1.06 \times 10^{3}$ & $7.79 \times 10^{2}$ & $5.74 \times 10^{2}$ & $4.25 \times 10^{2}$ & $3.17 \times 10^{2}$ & $2.37 \times 10^{2}$ \\
\hline Total & $1.60 \times 10^{6}$ & $1.91 \times 10^{5}$ & $5.27 \times 10^{4}$ & $2.57 \times 10^{4}$ & $1.62 \times 10^{4}$ & $1.15 \times 10^{4}$ & $8.77 \times 10^{3}$ & $6.99 \times 10^{3}$ & $5.76 \times 10^{3}$ & $4.86 \times 10^{3}$ & $4.18 \times 10^{3}$ \\
\hline
\end{tabular}

Amount of semi-volatile fission products tree in the fuel rod void volume (plenum plus fuel-cladding gap) for all 31 fuel rods at the time of cladding rupture $=1.60 \times 10^{4}$ Curies.

Total fission product inventory (Gaseous plus Semi-Volatile) free in the fuel void volume (plenum plus fuel-cladding gap) for all 31 fuel rods at the time of cladding rupture $=1.87 \times 10^{-}$Curies 


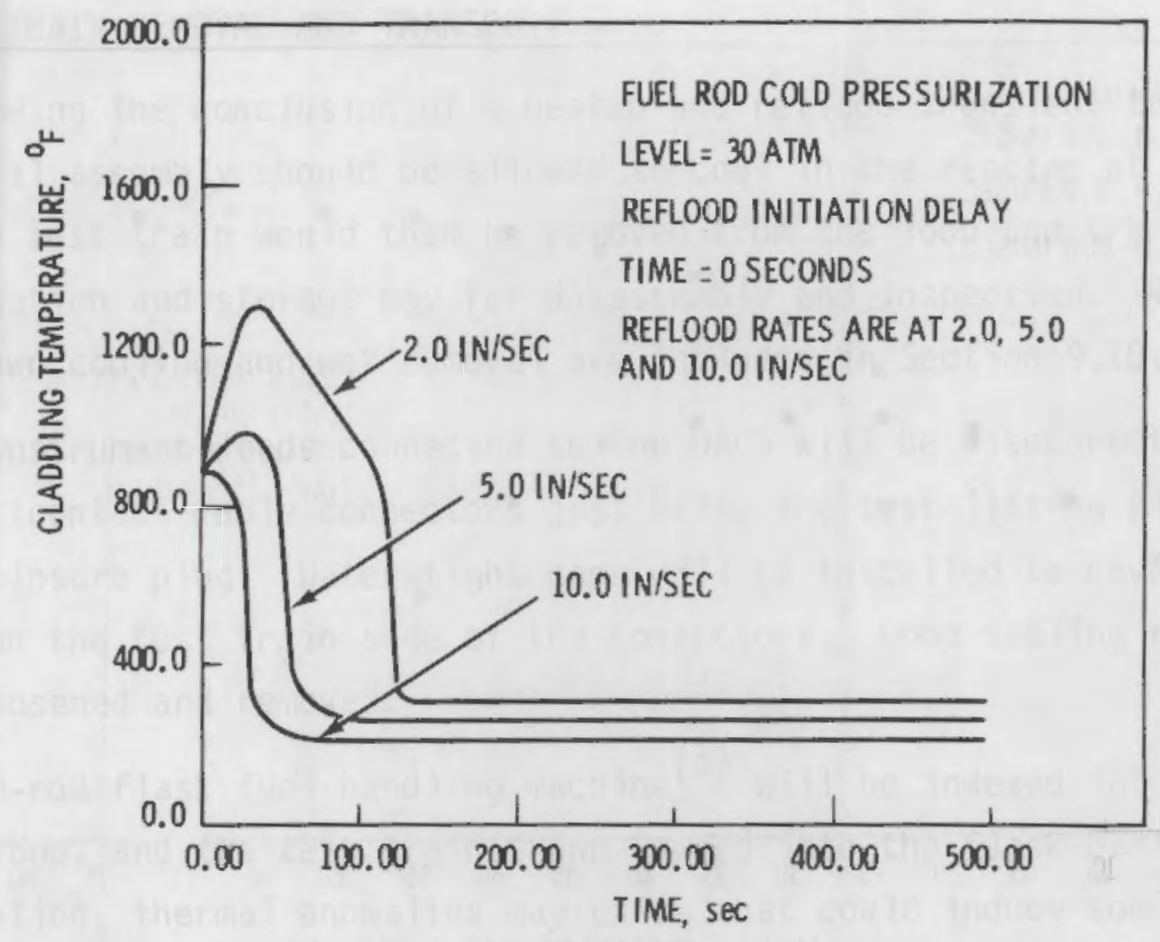

FIGURE 9.12. Cladding Temperature for Cladding Deformation Tests 0 -Second Reflood Initiation Delay Time (based on CE/THERM Code results)

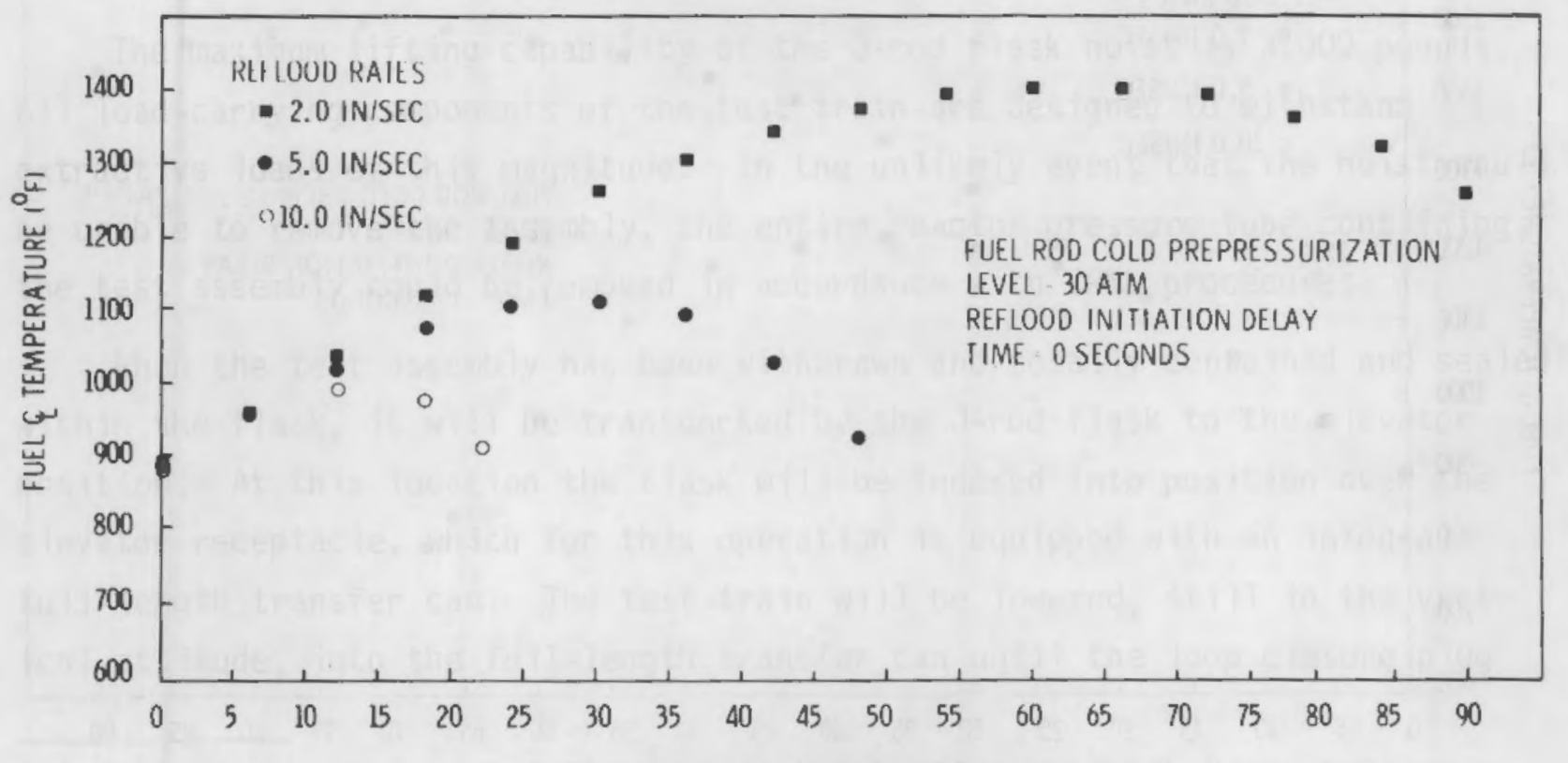

TIME FROM START OF HEATUP (SECONDS)

FIGURE 9.13. Fuel Centerline Temperature for Cladding Deformation Tests - 0-Second Reflood Initiation Delay Time 


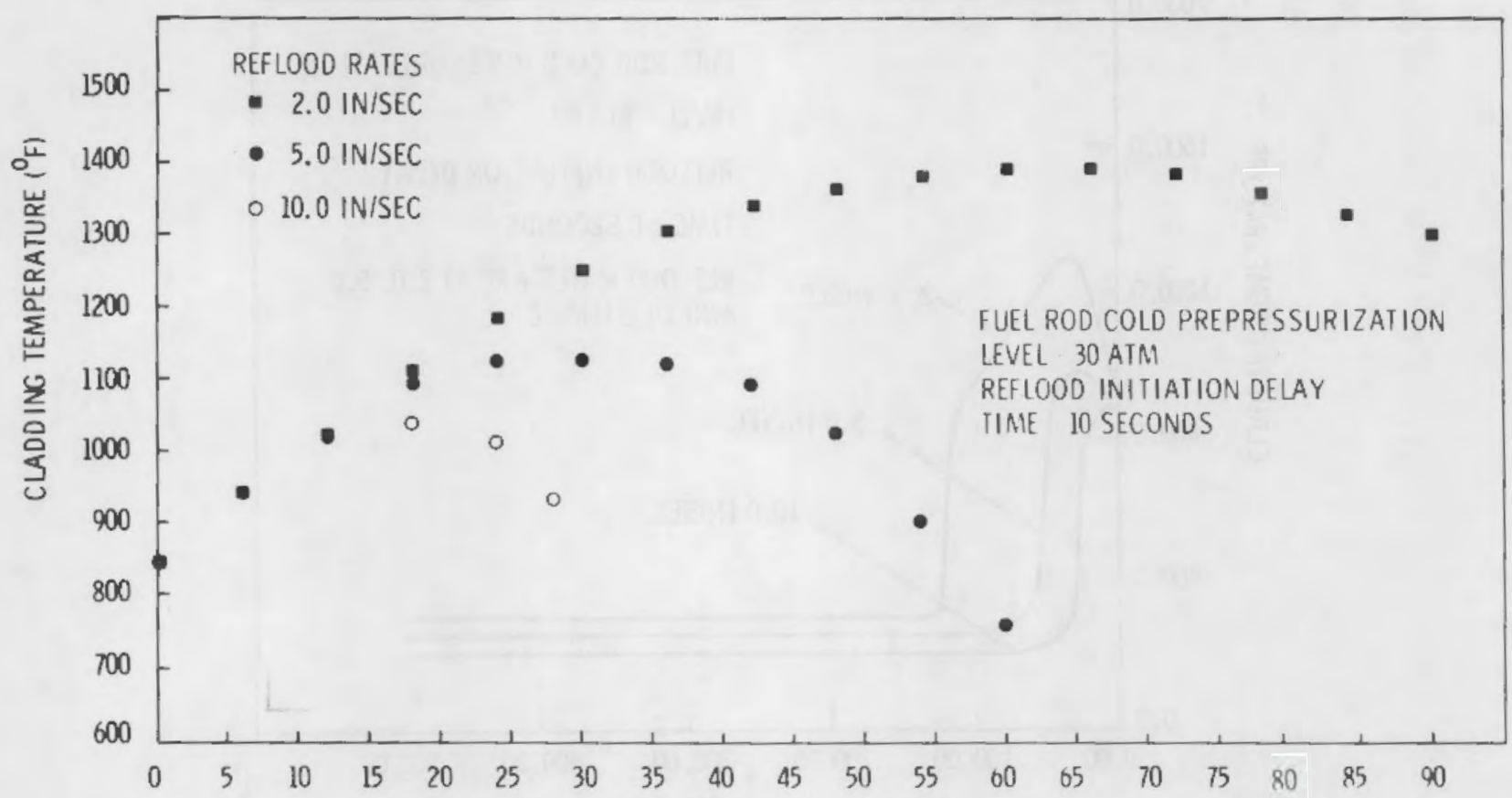

IIME FROM START OF HEATUP ISECONDSI

FIGURE 9.14. Cladding Temperature for Cladding Deformation Tests10-Second Reflood Initiation Delay Time

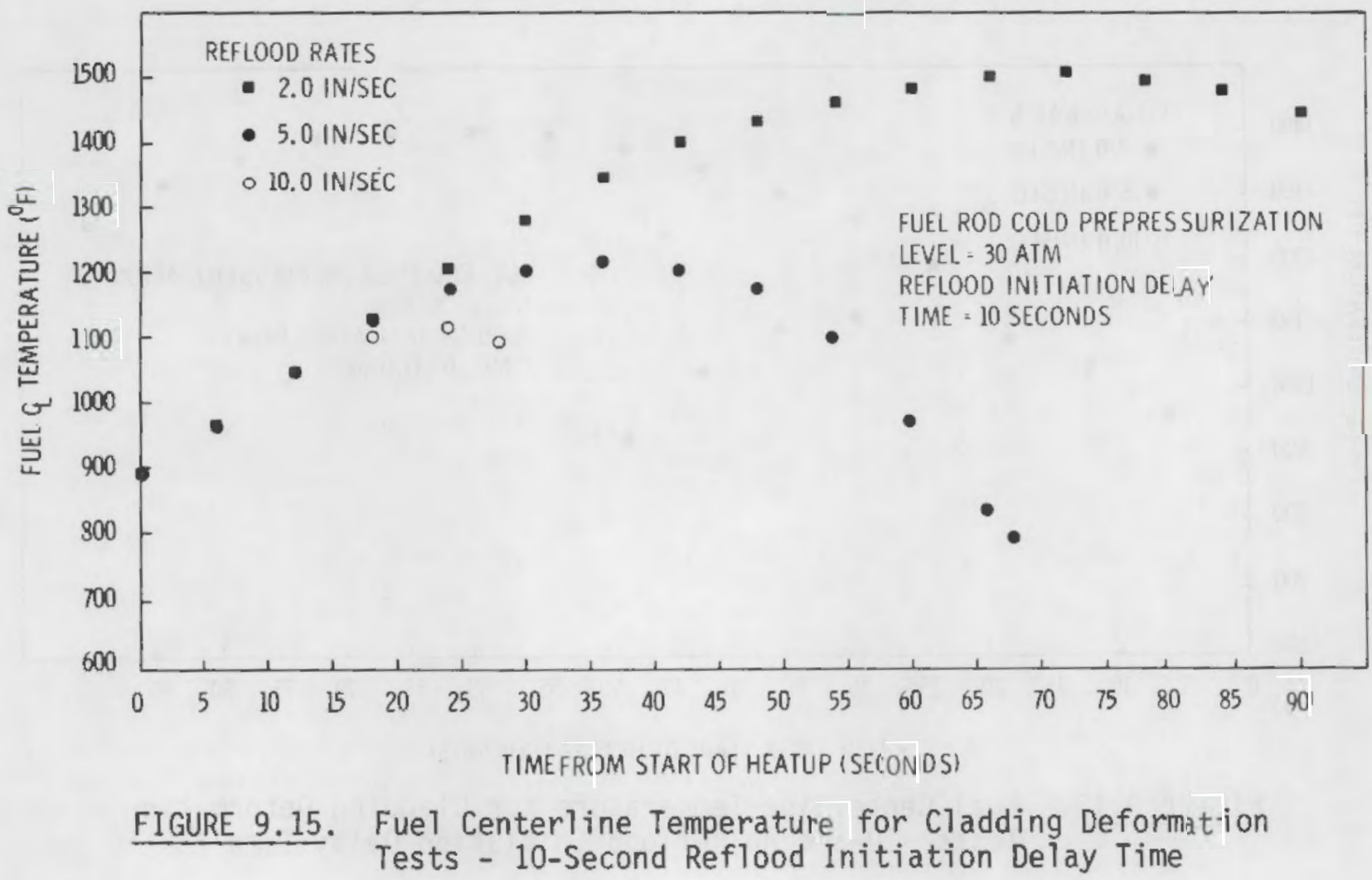




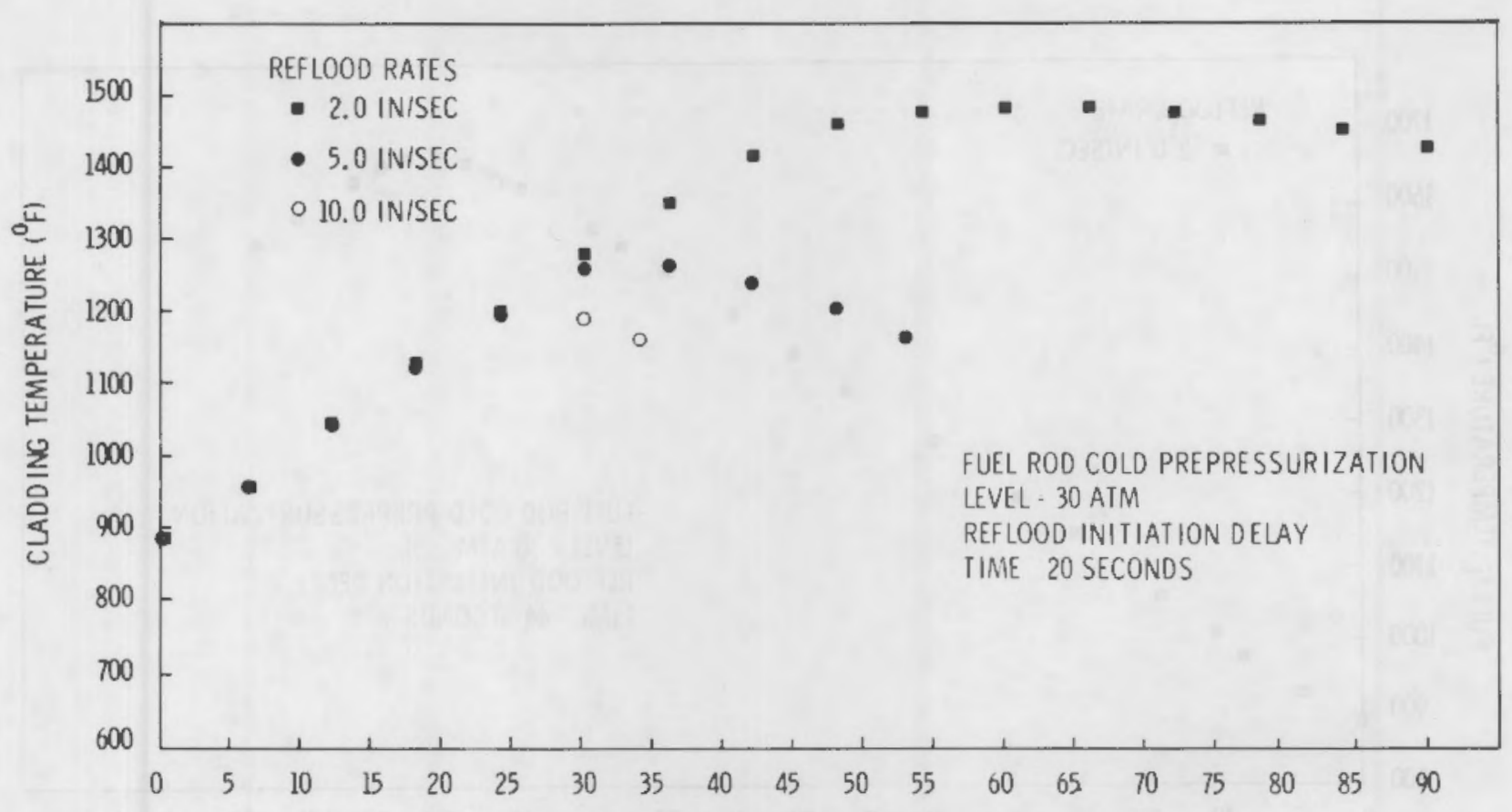

TIME FROM START OF HEATUP (SECONDS)

FIGURE 9.16. Cladding Temperature for Cladding Deformation Tests 20-Second Reflood Initiation Delay Time

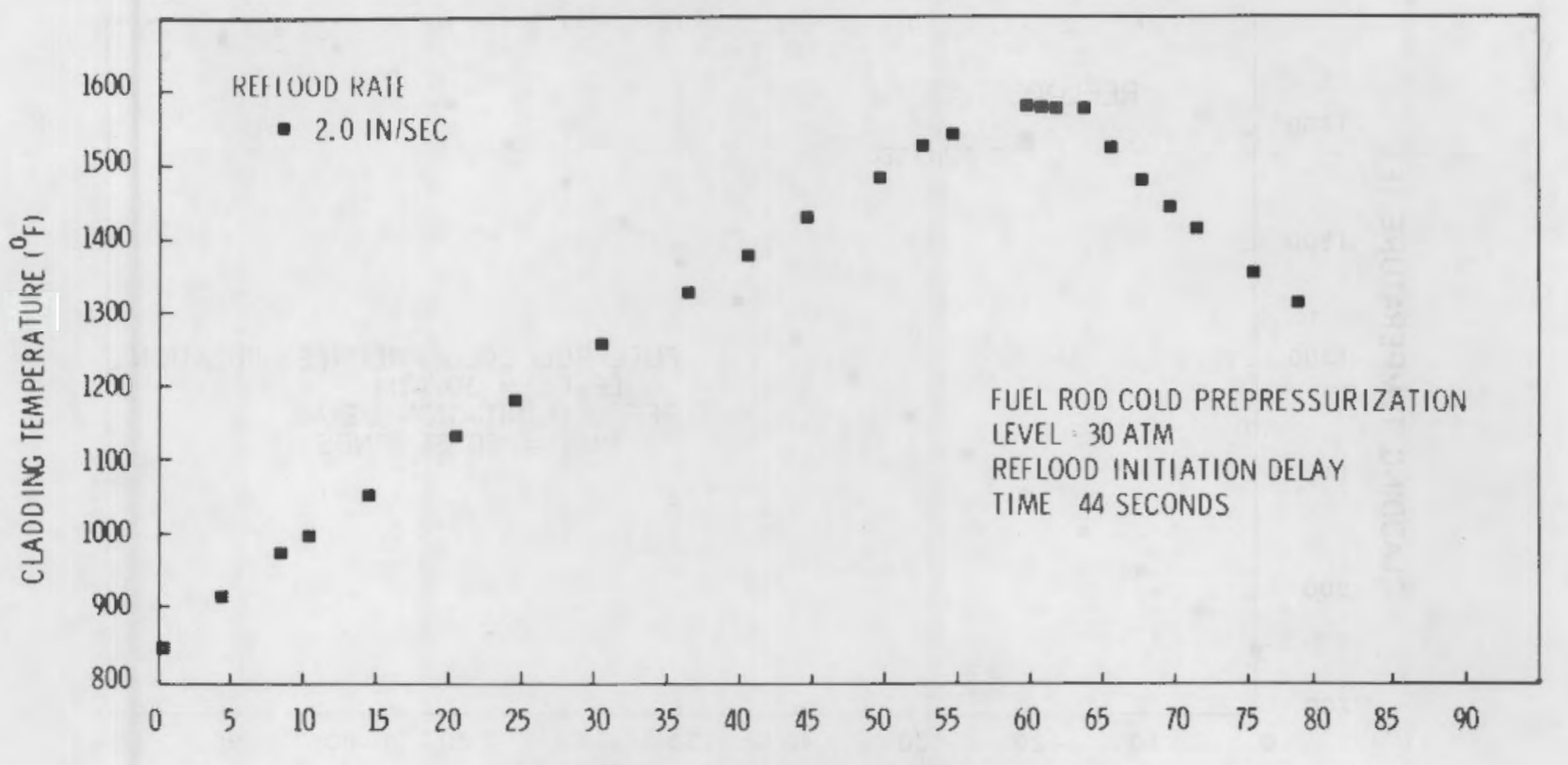

TIME FROM START OF HEATUP (SECONDS)

FIGURE 9.17. Cladding Temperature for Cladding Deformation Tests 44-Second Relfood Initiation Delay Time 


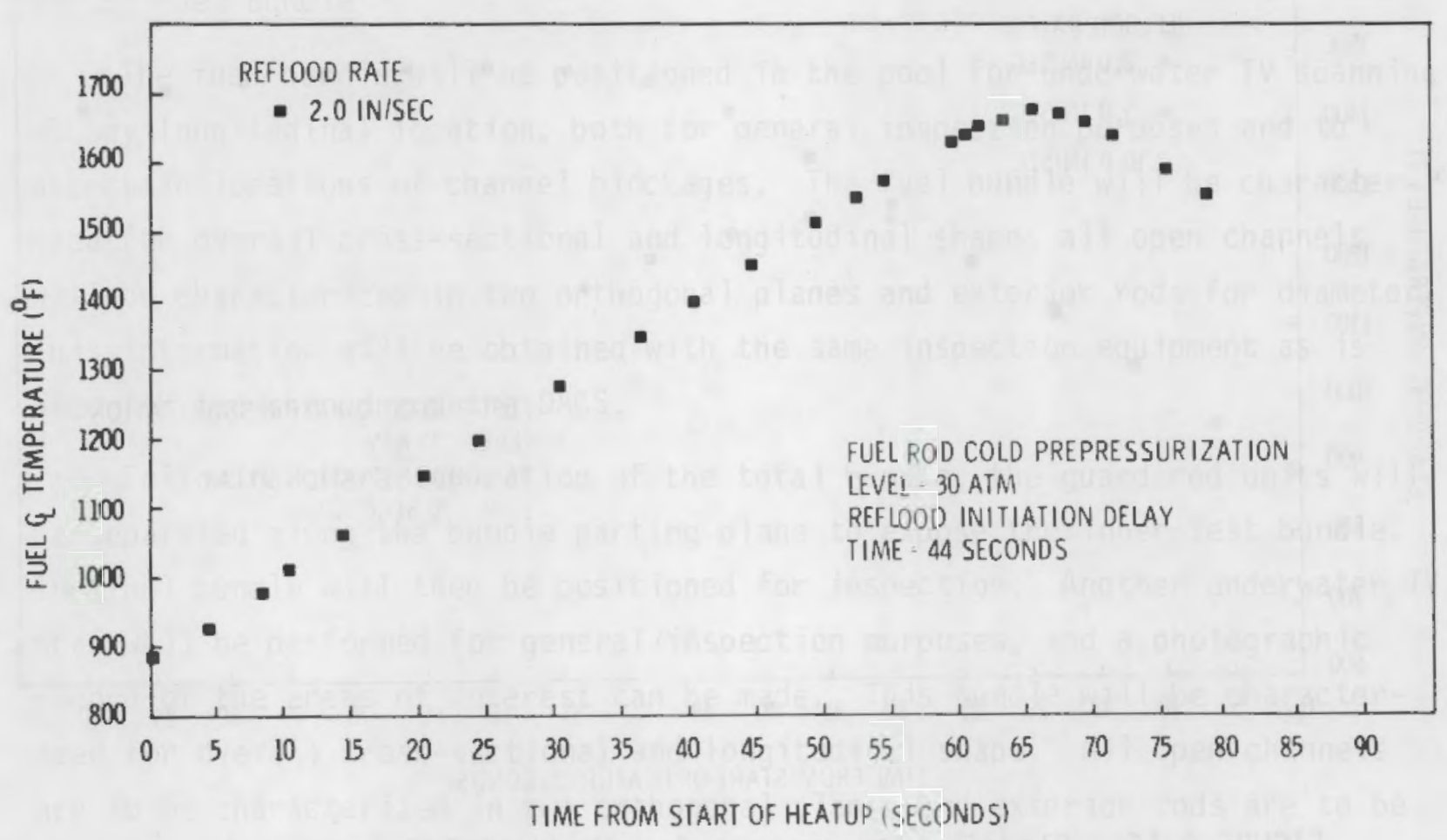

FIGURE 9.18. Fuel Centerline Temperature for Cladding Deformation Tests - 44-Second Reflood Initiation Delay Time

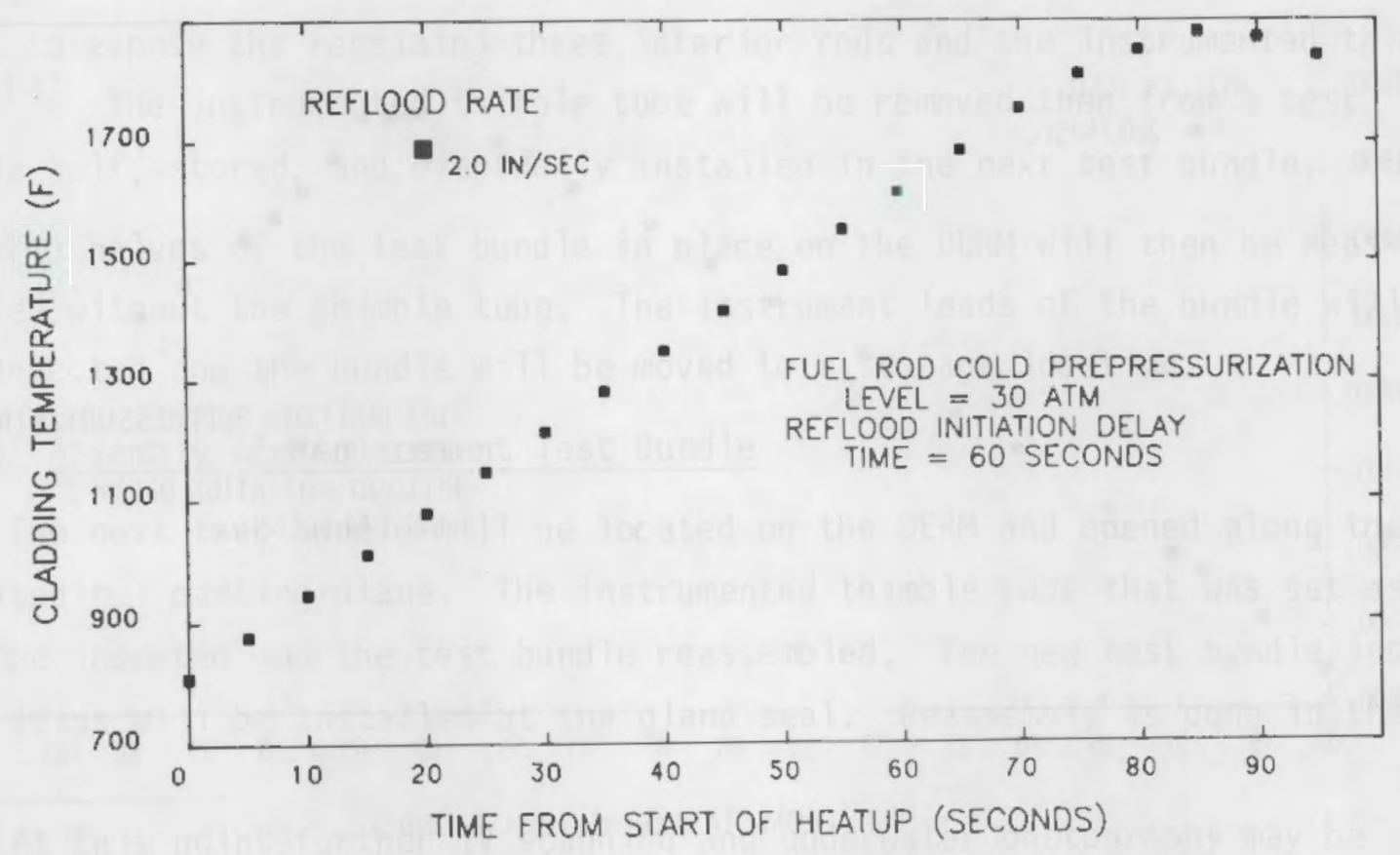

FIGURE 9.19. Cladding Temperature for Cladding Deformation Tests 60-Second Reflood Initiation Delay Time 


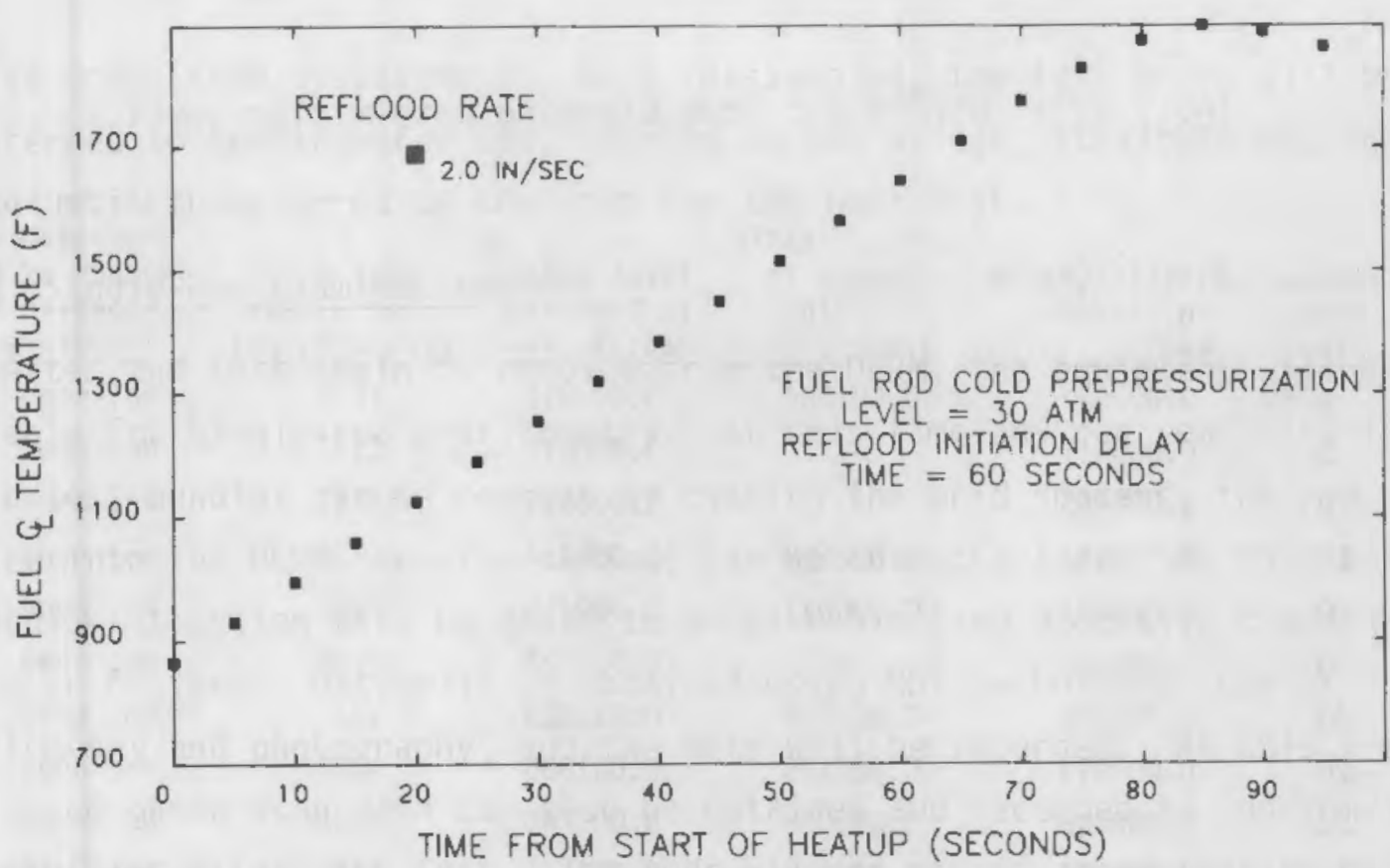

FIGURE 9.20. Fuel Centerline Temperature for Cladding Deformation Tests - 60-Second Reflood Initiation Delay Time

results. (a) One heatup rate was used for reflood rates varying between 5.08 and $25.4 \mathrm{~cm} / \mathrm{s}(2.0$ and $10.0 \mathrm{in.} / \mathrm{s})$ with reflood initiation delay times of 0.0 to $60.0 \mathrm{~s}$. As in the case of the thermal-hydraulic tests, the peak pretransient, steady-state cladding temperature is $700 \mathrm{~K}\left(800^{\circ} \mathrm{F}\right)$. Some of the calculations were initiated at temperatures as high as $750 \mathrm{~K}\left(890^{\circ} \mathrm{F}\right)$, so these predictions are concervatively high.

Table 9.7 presents the results of the cladding deformations calculated by the GAPCON-FLECHT computer code (Lanning et al. 1978). Also included in the table of results is the peak fuel rod internal gas pressure during the transient. It should be noted that the cladding deformation results given in Table 9.7 are for test rods with an initial cold prepressurization level of $3.06 \mathrm{MPa}(450 \mathrm{psi})$. The transients where rod failure was calculated to take place as well as the failure mechanisms and the number of test rods expected to fail are noted in the tables.

(a) The GAPCON-FLECHT computer code is a combination of the GAPCON-T3 code with the FLECHT heat transfer correlation and the OILATE Code Materials data base (Mohr et al. 1979). 
TABLE 9.7. GAPCON T-3 Code Cladding Deformation Results

\begin{tabular}{|c|c|c|c|c|c|c|}
\hline $\begin{array}{l}\text { Ref lood } \\
\text { Rate } \\
\end{array}$ & $\begin{array}{l}\text { Delay } \\
\text { Time, } \\
\text { sec } \\
\end{array}$ & $\begin{array}{l}\text { Elastic Change } \\
\text { in Cladding } \\
\text { Radius, in. } \\
\end{array}$ & $\begin{array}{c}\text { Creep-Plast ic } \\
\text { Change In } \\
\text { Cladding } \\
\text { Radius, in. } \\
\end{array}$ & $\begin{array}{l}\text { Total Change } \\
\text { In Cladding } \\
\text { Radius, in. } \\
\end{array}$ & $\begin{array}{c}\text { Peak Rod } \\
\text { Internal Gas } \\
\text { Pressure, psi } \\
\end{array}$ & $\begin{array}{l}\text { Cladding Rupture } \\
\text { Predicted and } \\
\text { Number of Rods } \\
\text { Expected to } \\
\text { Rupture } \\
\end{array}$ \\
\hline 2.0 & 0 & 0.002827 & 0.001084 & 0.003911 & 1231 & No, none \\
\hline 5.0 & 0 & 0.000611 & -- & 0.000611 & 1174 & No, none \\
\hline 10.0 & 0 & 0.000565 & - & 0.000565 & 1141 & No, none \\
\hline 2.0 & 10 & 0.005856 & 0.002598 & 0.008454 & 1238 & No, none \\
\hline 5.0 & 10 & 0.000697 & 0.000021 & 0.000718 & 1206 & No, none \\
\hline 10.0 & 10 & 0.000622 & -- & 0.000622 & 1180 & No, none \\
\hline 2.0 & 20 & 0.005688 & 0.002516 & 0.011829 & 1217 & No, none \\
\hline 5.0 & 20 & 0.000910 & 0.000125 & 0.001035 & 1223 & No, none \\
\hline 10.0 & 20 & 0.000748 & 0.000025 & 0.000748 & 1209 & No, none \\
\hline 2.0 & 44 & 0.009346 & 0.004315 & 0.013661 & 1246 & $\begin{array}{l}\text { Yes, eleven } \\
\text { inner test } \\
\text { rods }\end{array}$ \\
\hline 2.0 & 60 & -- & - & -- & 1248 & $\begin{array}{l}\text { Yes, eleven } \\
\text { inner test } \\
\text { rods }\end{array}$ \\
\hline
\end{tabular}

Fission product content for the cladding deformation tests has been estimated using the ORIGEN computer code. The version of the ORIGEN code used for these calculations is the same as the version used in the thermal-hydraulic fission product calculations. Table 9.8 shows the results of the fission product content calculations for a typical single cladding deformation test. The total power history assumed for the test assembly for the calculations was $1 \mathrm{hr}$ at $2.6 \mathrm{MW}$, with $16 \mathrm{hr}$ decay time and $65 \mathrm{~min}$ additional exposure at $0.14 \mathrm{MW}$. Table 9.8 also lists the fission products free in the rod void volume (i.e., plenum plus the fuel-to-cladding gap). The fractional release of the gaseous and semivolatile fission products at cladding rupture is assumed to be $1 \%$. The table gives the fission product inventory for 31 fuel rods. Since the inner 11 test rods will be pressurized, and the surrounding guard rods operate at a high power, the expected fractional release is $11 / 31$ of that shown in the table. 
TABLE 9.8. Fission Product Inventory for Post Materials Test (total for 31 fuel rods)

\begin{tabular}{|c|c|c|c|c|c|}
\hline \multirow[b]{2}{*}{ Time After Tesi. da } & \multicolumn{5}{|c|}{ Gaseous Fission Product Inventory, curies-Cs, I, Xe, $\mathrm{Kr}$} \\
\hline & 0 & 0.5 & 1.0 & 2 & 5 \\
\hline \multicolumn{6}{|l|}{ Isotope } \\
\hline $\mid-131$ & $1.99 \times 10^{2}$ & $2.05 \times 10^{2}$ & $2.01 \times 10^{2}$ & $1.90 \times 10^{2}$ & $1.53 \times 10^{2}$ \\
\hline $1-132$ & $7.83 \times 10^{2}$ & $7.01 \times 10^{2}$ & $6.3 \times 10^{2}$ & $5.09 \times 10^{2}$ & $2.68 \times 10^{2}$ \\
\hline $1-133$ & $2.89 \times 10^{3}$ & $2.06 \times 10^{3}$ & $1.39 \times 10^{3}$ & $6.28 \times 10^{2}$ & $5.84 \times 10^{\prime}$ \\
\hline $1-134$ & $2.63 \times 10^{3}$ & $1.71 \times 10^{0}$ & $1.45 \times 10^{4}$ & $8.99 \times 10^{13}$ & 0 \\
\hline 1.135 & $3.01 \times 10^{3}$ & $8.72 \times 10^{2}$ & $2.52 \times 10^{2}$ & $2.1 \times 10^{\prime}$ & $1.22 \times 10^{2}$ \\
\hline Kr-85M & $487 \times 10^{2}$ & $7.63 \times 10^{\prime}$ & $1.15 \times 10^{\prime}$ & $2.63 \times 10^{-1}$ & $3.12 \times 10^{0}$ \\
\hline $\mathrm{Kr}-85$ & $5.3 \times 10^{2}$ & $5.76 \times 10^{-2}$ & $5.83 \times 10^{2}$ & $5.84 \times 10^{-2}$ & $5.84 \times 10^{2}$ \\
\hline$K_{r}-87$ & $1.3 \times 10^{3}$ & $1.87 \times 10^{\infty}$ & $2.64 \times 10^{-3}$ & $5.21 \times 10^{9}$ & $1.22 \times 10^{16}$ \\
\hline $\mathrm{Kr}-88$ & $1.24 \times 10^{3}$ & $6.4 \times 10^{1}$ & $3.28 \times 10^{\circ}$ & $8.62 \times 10^{3}$ & $1.57 \times 10^{10}$ \\
\hline$K_{r}-89$ & $5.46 \times 10^{3}$ & 0 & 0 & 0 & 0 \\
\hline$X \mathrm{e}-131 \mathrm{M}$ & $6.47 \times 10^{2}$ & $1.11 \times 10^{1}$ & $1.54 \times 10^{1}$ & $2.35 \times 10^{-1}$ & $4.18 \times 10^{-1}$ \\
\hline Xe-133 & $3.29 \times 10^{2}$ & $4.66 \times 10^{2}$ & $5.43 \times 10^{2}$ & $5.94 \times 10^{2}$ & $4.77 \times 10^{2}$ \\
\hline$X e-135$ & $3.9 \times 10^{3}$ & $2.52 \times 10^{3}$ & $1.29 \times 100$ & $2.67 \times 10^{2}$ & $1.39 \times 10^{0}$ \\
\hline Cs-135M & $3.54 \times 10^{-10}$ & $2.88 \times 10^{14}$ & $2.35 \times 10^{-18}$ & 0 & 0 \\
\hline Cs.135 & $1.7 \times 10^{6}$ & $2.73 \times 10^{6}$ & $3.32 \times 10^{-6}$ & $3.74 \times 10^{-6}$ & $3.84 \times 10^{5}$ \\
\hline Cs-136 & $3.39 \times 10^{1}$ & $3.30 \times 10^{1}$ & $3.21 \times 10^{-1}$ & $3.04 \times 10^{-1}$ & $2.59 \times 10^{1}$ \\
\hline Cs.137 & $3.75 \times 10^{1}$ & $3.77 \times 10^{-1}$ & $3.77 \times 10^{-1}$ & $3.77 \times 10^{-1}$ & $3.77 \times 10^{1}$ \\
\hline Cs-138 & $3.78 \times 10^{3}$ & $2.02 \times 10^{-3}$ & $3.76 \times 10^{-10}$ & $1.3 \times 10^{-23}$ & 0 \\
\hline Total & $2.60 \times 10^{4}$ & $6.97 \times 10^{3}$ & $4.32 \times 10^{3}$ & $2.21 \times 10^{3}$ & $9.58 \times 10^{2}$ \\
\hline
\end{tabular}

Amount of gaseous fission producets free in the fuel rod void volume (plenum plus fuelcladding gap) for all 31 fuel rods at the time of cladding rupture $=2.60 \times 10^{2}$ Curies.

\begin{tabular}{|c|c|c|c|c|c|}
\hline \multirow{3}{*}{$\begin{array}{l}\text { Time After Last } \\
\text { Test, da }\end{array}$} & \multicolumn{5}{|c|}{ Semi-Volatile Fission Product Inventory, curies-Sr, Ba, Te, Se, Sb } \\
\hline & & & & & \\
\hline & 0 & 0.5 & 1.0 & 2 & 5 \\
\hline \multicolumn{6}{|l|}{ isotope } \\
\hline Si & $2.41 \times 10^{4}$ & $1.47 \times 10^{3}$ & $6.23 \times 10^{2}$ & $1.60 \times 10^{2}$ & $5.83 \times 10^{\prime}$ \\
\hline $\mathbf{B a}$ & $2.21 \times 10^{4}$ & $3.22 \times 10^{2}$ & $3.04 \times 10^{2}$ & $2.88 \times 10^{2}$ & $2.45 \times 10^{2}$ \\
\hline Te & $2.03 \times 10^{4}$ & $9.33 \times 10^{2}$ & $7.55 \times 10^{2}$ & $5.76 \times 10^{2}$ & $2.86 \times 10^{2}$ \\
\hline Se & $3.18 \times 10^{3}$ & $8.35 \times 10^{-3}$ & $5.34 \times 10^{-3}$ & $3.68 \times 10^{-3}$ & $1.04 \times 10^{3}$ \\
\hline Sb & $2.33 \times 10^{4}$ & $1.05 \times 10^{2}$ & $3.22 \times 10^{1}$ & $1.52 \times 10^{1}$ & $8.34 \times 10^{\circ}$ \\
\hline Total & $930 \times 104$ & $283 \times 10^{3}$ & $171 \times 10^{3}$ & $1.04 \times 10^{3}$ & $5.98 \times 10^{2}$ \\
\hline
\end{tabular}

Amount of semivolatile fission products free in the fuel rod void volume iplenum plus fuelcladding gap) for all 31 fuel rods at the time of cladding rupture $=9.30 \times 10^{2}$ Curies.

Total fission product inventory (Gaseous plus Semi-Volatile) free in the fuel void volume (plenum plus fuel-ciadding gap) for all 31 fuel rods at the time of cladding rupture = $1.19 \times 10^{3}$ Curies.

\subsubsection{Effectiveness of Fuel Rewetting}

The largest body of information bearing on fuel rewetting or quench is that of the Westinghouse FLECHT experimental series. Cadek (1972) and Rosal (1978) have written reports that describe the experiments and results and cover the same range of reflood rates as in the tests proposed for NRU. 
The FLECHT tests used a $10 \times 10$ array of $12-\mathrm{ft}$ long electrically heated rods. The assembly represents a part of a Westinghouse $15 \times 15$-rod bundle; therefore, its rod power distribution was similar to the Westinghouse fuel assembly, including the thimble tubes. The axial power peaking was 1.66 with the peak at the axial centerline.

Qualitatively, the tests show a brief adiabatic period after reflood was initiated. This was followed by a period wherein sufficient quantities of the reflood were vaporized in the lower sections to cause a convective cooling mode in the upper regions and the rate of temperature rise was decreased. As the reflood level rose in the assembly the lower sections quenched (rewet). At the same time, boiling in the lower section became more vigorous and the steam in the upper sections increased in velocity and carried more entrained water. This high-velocity mist flow enhanced the convective cooling and the rod surface temperature rise rate decreased until the temperature peaked and decreased. At this point the rod surface began to cool. Somewhat later the quench front arrived at the upper sections and the rod surface temperature rapidly dropped to saturation temperature. The tests showed the adequacy of the rewetting to cool the fuel rods. They also provided the basis of correlations that quantitatively describe its occurrence.

The NRU LOCA test will be quite similar to that of the FLECHT tests, with the following major exceptions:

- NRU LOCA has nuclear-heated rods; FLECHT has electrically-heated rods.

- NRU has zircaloy-clad rods; FLECHT has stainless steel-clad rods.

- NRU has peak-to-average axial power distribution of 1.51; FLECHT's peakto-average axial power distribution is $\mathbf{1 . 6 6}$.

- The NRU test has 32 rods. The tests have different rod surface-toshroud surface ratios.

- Pretransient steam cooling in the NRU tests distorts the initial axial temperature distribution.

- The fuel rods in the materials tests are expected to distort to a significant degree. 
The FLECHT tests showed the effectiveness of rewetting. The NRU LOCA tests will also show effective rewetting as the FLECHT tests did; however, the timing of the temperature increase, turnaround, and quench may be different. By rising the stepwise approach to the performance of the tests, the problem of excessive temperatures up to the time quench occurs will be avoided.

The maximum credible temperatures expected in the NRU LOCA tests are shown in Figure 9.21. These temperatures were determined for conditions that would give peak cladding temperatures somewhat higher than the maximum planned [ $1255 \mathrm{~K}$ $\left.\left(1800^{\circ} \mathrm{F}\right)\right]$.

\subsection{FUEL BEHAVIOR--WORST-CASE CONDITIONS}

Three cases of fuel behavior during accidents have been assumed and examined as worst-case conditions. For each of the three cases examined, the peak cladding temperature for the inner 11 test rods was calculated to be equal to

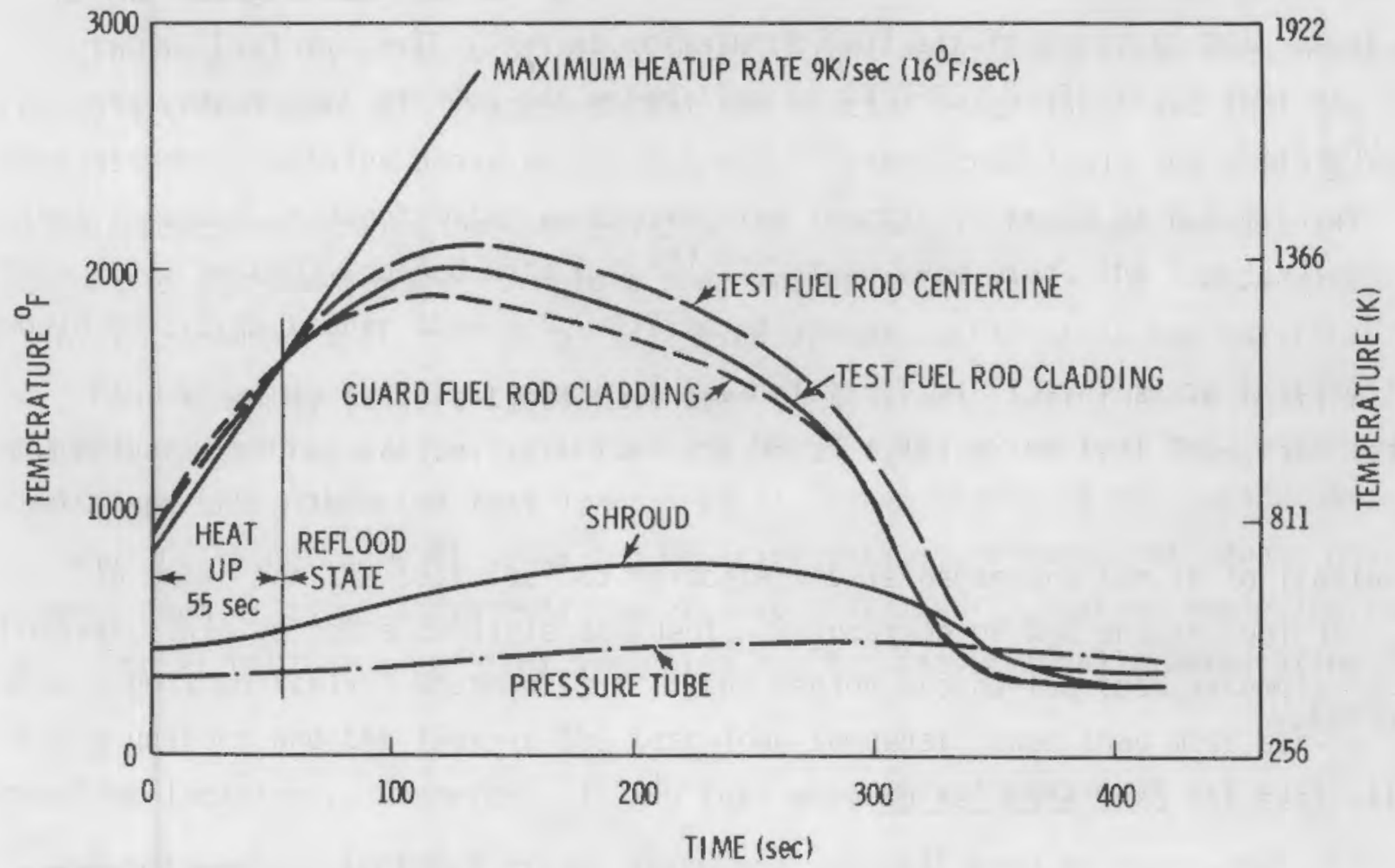

FIGURE 9-21. Maximum Credible Temperatures Expected in the Test Train Assembly 
or greater than $1255 \mathrm{~K}\left(1800^{\circ} \mathrm{F}\right)$. For each of the accident cases, it can be assumed that all of these inner test rods, which have a pressurization level of $3.06 \mathrm{MPa}$ (450 psi), will rupture during the accident transient. GAPCON FLECHT calculations for the cladding materials deformation fuel rods show that failure occurs when peak cladding temperatures exceed $1144 \mathrm{~K}\left(1600^{\circ} \mathrm{F}\right)$. The maximum fission product content for 31 rods for the thermal-hydraulic tests and the materials test will be as given in Tables 9.5 and 9.8. (Both tables can be found in subsection 9.8.2.) The amount of gaseous fission products free in the fuel rod volume (plenum plus fuel-cladding gap) for the inner 11 test rods at the time of cladding rupture is 92 curies.

The respective amount of semivolatile fission products is 330 curies. Therefore, the total fission product inventory (gaseous plus semivolatile) free in the fuel rod void volume for the 11 inner high-pressure test rods at the time of cladding rupture is 422 curies.

Peak temperatures calculated for both the cladding and the fuel for each of the three accident cases show that there will be no fuel melting for any of the tests that are part of the LOCA Simulation in NRU. The peak fuel centerline temperature of $1561 \mathrm{~K}\left(2350^{\circ} \mathrm{F}\right)$ is well below the melting temperature of the $\mathrm{UO}_{2}$ fuel.

The thermal-hydraulic response to the three assumed worst-case conditions was calculated. All three cases assume that a high cladding temperature test was initiated and that reflood was to have started $60 \mathrm{sec}$ after termination of pretransient steam flow. The first two cases assume that reflood failed to come on and that another $20 \mathrm{sec}$ elapsed before any corrective action was taken. In other words, for these two cases, it is assumed that no action will be taken to turn around the temperature rise until $80 \mathrm{sec}$ after termination of the pretransient steam coolant. The third case assumes the reflood rate is much lower than anticipated after a 55-sec reflood delay and that the condition is not detected.

\subsubsection{Case 1: 80-Second Scram}

The first case assumes that reflood never occurs but that the reactor was scrammed $80 \mathrm{sec}$ after initiation of the transient. The power then drops in 
accord with the calculated decay for the accumulated power history of the fuel. This decay is conservatively shown in Figure 9.22 .

Test assembly temperatures calculated for this case are shown in Figure 9.23. The clad temperature stops increasing about $20 \mathrm{sec}$ after the SCRAM occurs and a peak of less than $1366 \mathrm{~K}\left(2000^{\circ} \mathrm{F}\right)$ is reached. Heat is removed through the shroud, pressure tube, and then to the $\mathrm{D}_{2} \mathrm{O}$ moderator. The shroud and pressure tube temperatures continue to increase for 8 to $10 \mathrm{~min}$ before the clad temperature levels off. Their peak values are $800 \mathrm{~K}\left(995^{\circ} \mathrm{F}\right)$ and $533 \mathrm{~K}$ $\left(500^{\circ} \mathrm{F}\right)$, respectively. The fuel centerline temperatures will be less than $14 \mathrm{~K}$ $\left(26^{\circ} \mathrm{F}\right)$ higher than the cladding temperature.

Since there is no reflood, there will be no steam exiting from the test assembly. Therefore, there will also be no energy transfer to the pressure tube above the test assembly, and thus, the pressure tube temperature will drop. The rate of temperature decrease was calculated and is shown in Figure 9.24. An initial pressure tube temperature of $644 \mathrm{~K}\left(700^{\circ} \mathrm{F}\right)$ at the test assembly outlet was used for this calculation. This temperature corresponds to an average rod power of $1.64 \mathrm{~kW} / \mathrm{m}(0.5 \mathrm{~kW} / \mathrm{ft})$. Since the actual test will use $1.25 \mathrm{~kW} / \mathrm{m}(0.38 \mathrm{~kW} / \mathrm{ft})$, the initial pressure tube temperature for the test is less than $644 \mathrm{~K}\left(700^{\circ} \mathrm{F}\right)$. Thus, the initial pressure tube temperature used for this analysis is conservatively high.

\subsubsection{Case 2: 80-Second Reflood}

The second case assumes that there is no reactor scram but standby reflood coolant is initiated after $80 \mathrm{sec}$ at a rate of $10 \mathrm{~cm} / \mathrm{s}(3.94 \mathrm{in.} / \mathrm{sec})$. Figure 9.25 is a graph from FLECHT tests (Cadek 1972) that shows peak cladding temperature rise as a function of reflood rate. This curve shows that the peak cladding temperature rise will be in the range of 55 to $80 \mathrm{~K}\left(99^{\circ}\right.$ to $\left.144^{\circ} \mathrm{F}\right)$. If this temperature $r$ ise is added to the temperature shown in Figure 9.22 at $80 \mathrm{sec}$, a peak clad temperature of about $1388 \mathrm{~K}\left(2040^{\circ} \mathrm{F}\right)$ will be reached. The corresponding fuel centerline temperature will be about $1400 \mathrm{~K}\left(2060^{\circ} \mathrm{F}\right)$.

The FLECHT test data shows that for the higher reflood rates, such as the one used here, the steam exiting from the test assembly has a temperature not much greater than saturation temperature. Thus, as the steam passes up the 


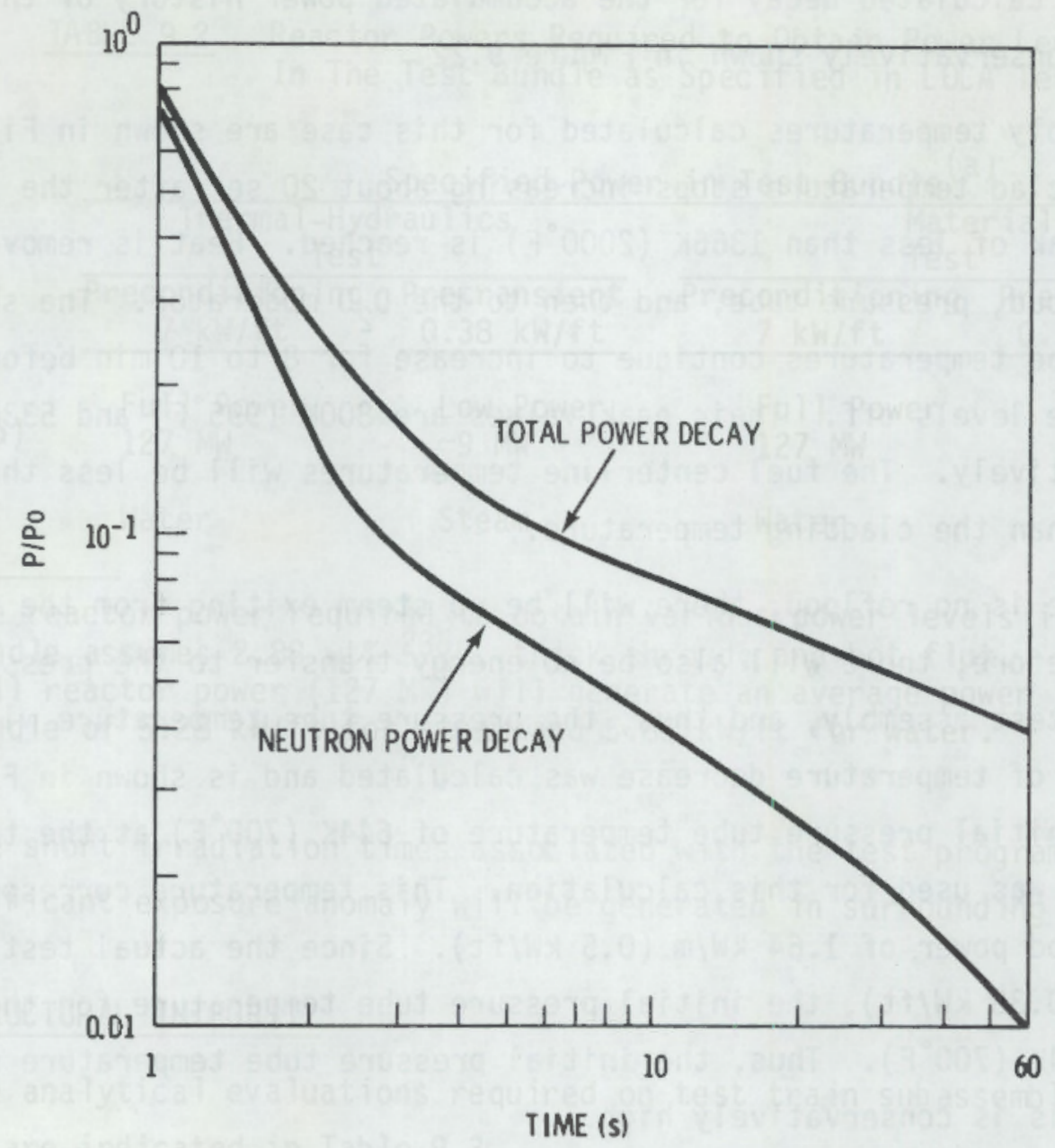

FIGURE 9.22. NRU Power Decay After Trip

pressure tube above the test assembly, it cools the tube. The temperature drop of the pressure tube above the assembly for this case will be even faster than that shown in Figure 9.24.

\subsubsection{Case 3: Partial Reflood}

The third worst-case condition being considered arises from the fact that a few FLECHT experiments at the very low reflood rates of about $1.2 \mathrm{~cm} / \mathrm{s}$ $(0.5 \mathrm{in.} / \mathrm{sec})$ give high steam exit temperatures in excess of $972 \mathrm{~K}\left(1290^{\circ} \mathrm{F}\right)$ even though cladding temperatures peaked and decreased and quench was achieved. 


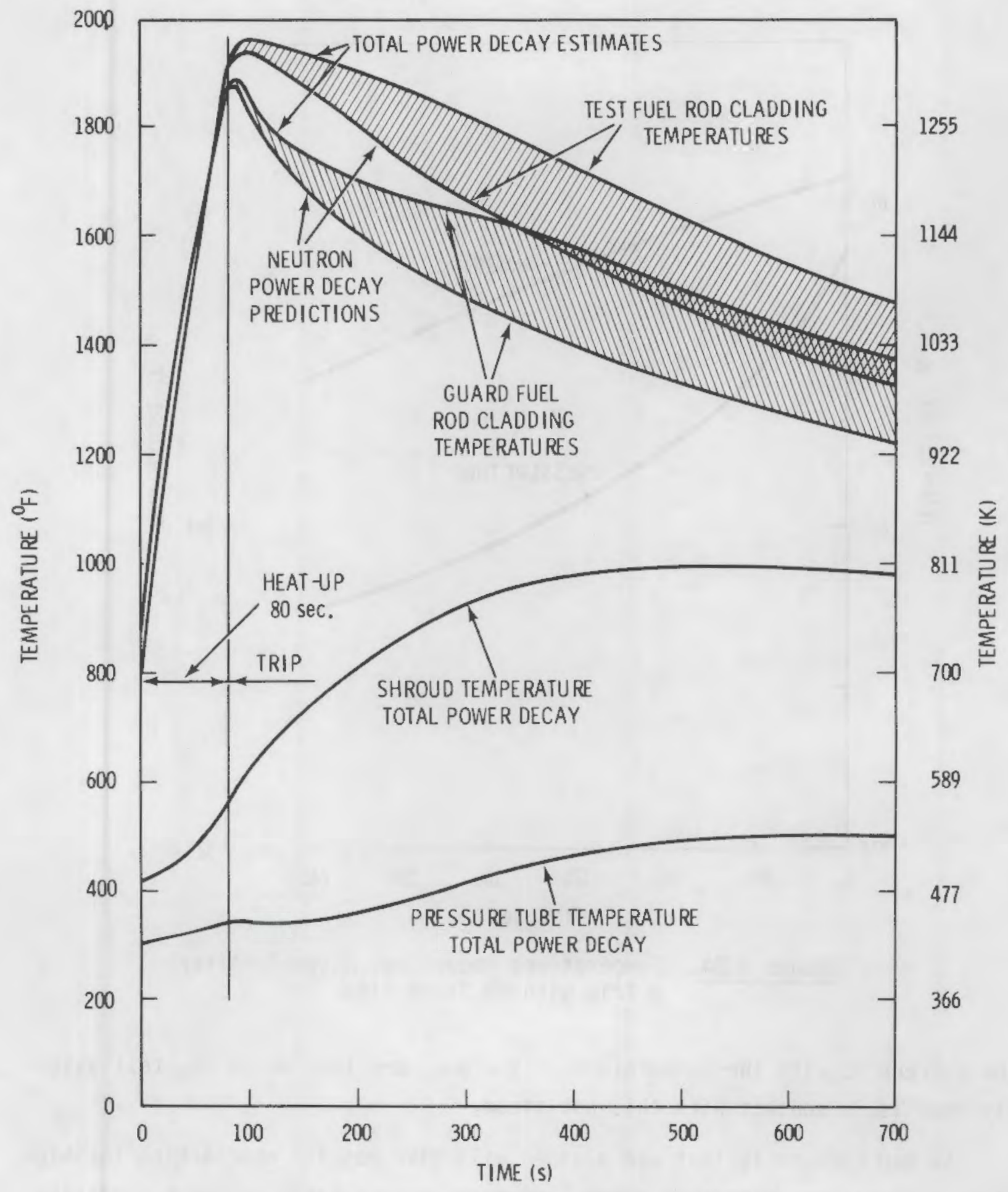

FIGURE 9.23. Test Assembly Temperatures After a Trip 


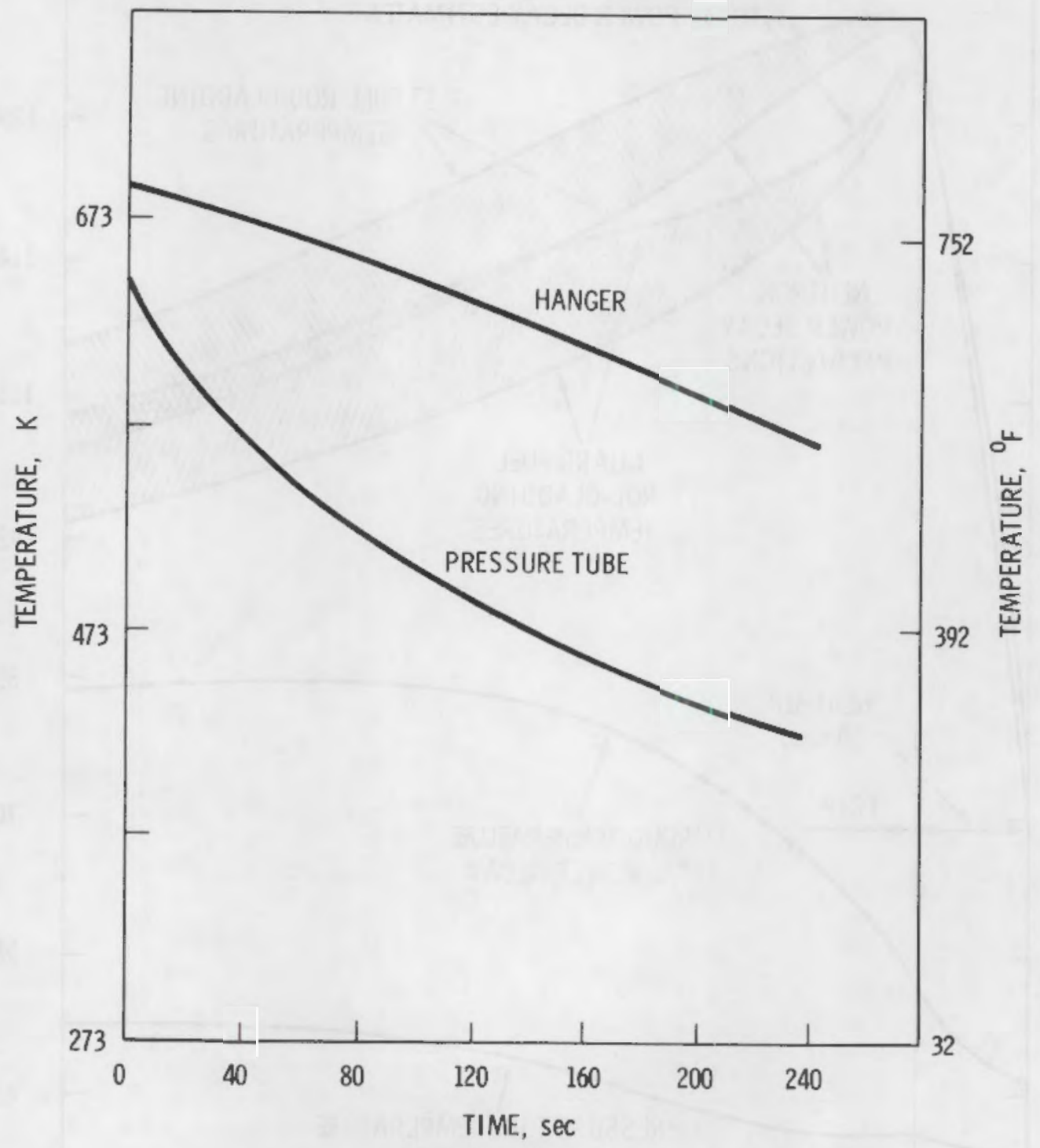

FIGURE 9.24. Temperatures Above Test Assembly After a Trip with No Steam Flow

The concern is with the temperature of the pressure tube above the test assembly that is in contact with this hot steam.

No NRU LOCA tests that are planned will give results approaching the high steam temperatures discussed above. However, a postulated accident condition that could result in the high steam temperatures proceeds as follows. A high temperature $\left[1255 \mathrm{~K}\left(1800^{\circ} \mathrm{F}\right)\right]$ run is planned. In order to achieve it, the reflood will not begin until $55 \mathrm{sec}$ after pretransient steam cooling is stopped. 


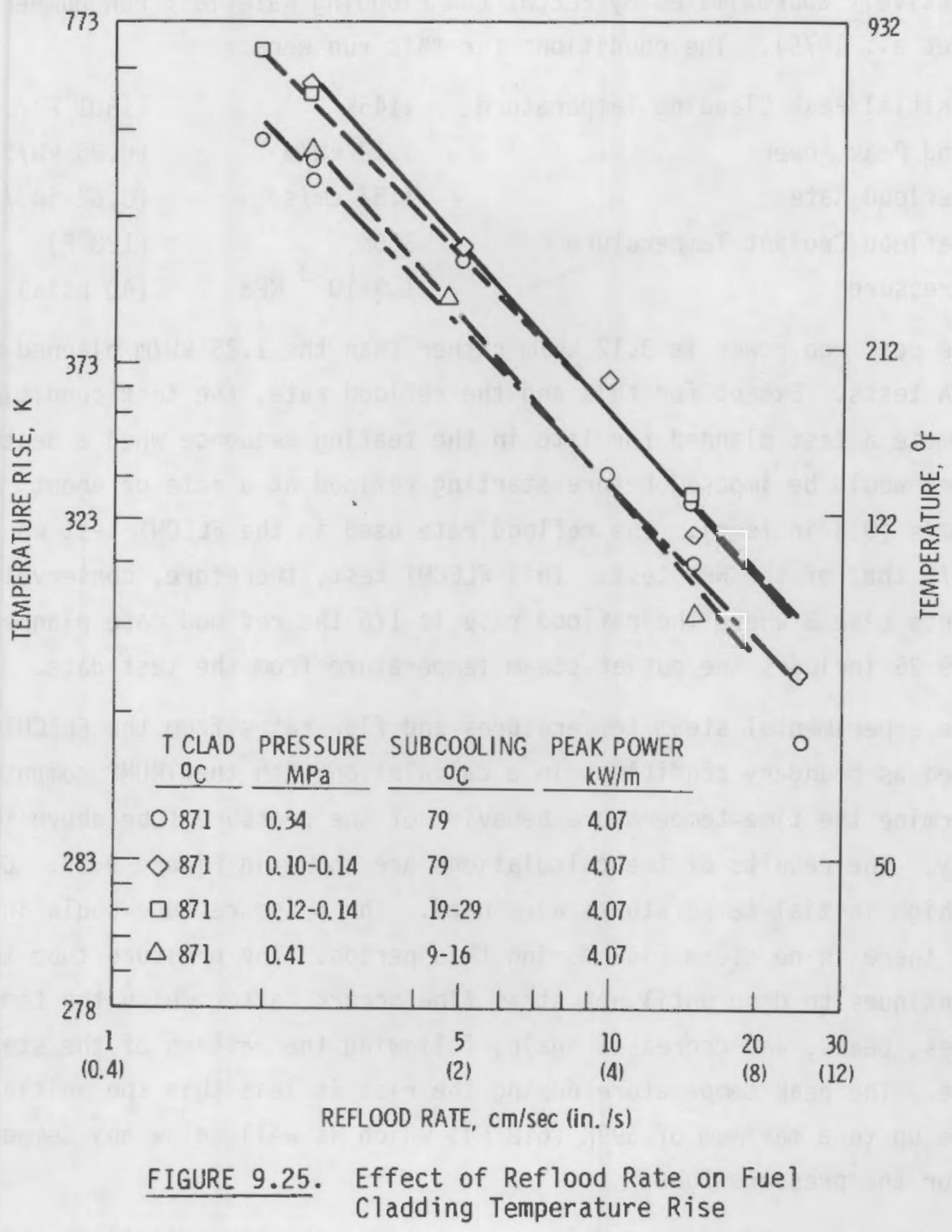

However, if for some accidental condition the reflood rates were much lower than planned, the low reflood and high steam temperature case described above could occur. This analysis further assumes that this low reflood rate condition is not recognized and no corrective action is taken.

Calculational techniques to determine the exit steam temperature and flow rates for this particular case are not available. However, this case can be 
conservatively approximated by FLECHT Low Flooding Rate Test run number 07934 (Rosal et al. 1975). The conditions for this run were:

$\begin{array}{lll}\text { Initial Peak Cladding Temperature } & 1145 \mathrm{~K} & \left(1601^{\circ} \mathrm{F}\right) \\ \text { Rod Peak Power } & 3.12 \mathrm{~kW} / \mathrm{m} & (0.95 \mathrm{~kW} / \mathrm{ft}) \\ \text { Reflood Rate } & 1.57 \mathrm{~cm} / \mathrm{s} & (0.62 \mathrm{in} . / \mathrm{sec}) \\ \text { Reflood Coolant Temperature } & 326 \mathrm{~K} & \left(128^{\circ} \mathrm{F}\right) \\ \text { Pressure } & 1.9 \times 10^{-3} \mathrm{MPa} & (40 \mathrm{psia})\end{array}$

The peak rod power is $3.12 \mathrm{~kW} / \mathrm{m}$ rather than the $1.25 \mathrm{~kW} / \mathrm{m}$ planned for the NRU LOCA tests. Except for this and the reflood rate, the test conditions approximate a test planned for late in the testing sequence when a heatup time of $55 \mathrm{sec}$ would be imposed before starting reflood at a rate of about $1.016 \mathrm{~cm} / \mathrm{s}(0.4 \mathrm{in} . / \mathrm{sec})$. The reflood rate used in the FLECHT test would be about $1 / 6$ that of the NRU test. This FLECHT test, therefore, conservatively represents Case 3 where the reflood rate is $1 / 6$ the reflood rate planned. Figure 9.26 includes the outlet steam temperature from the test data.

The experimental steam temperatures and flow rates from the FLECHT run were used as boundary conditions in a calculation with the TRUMP computer code to determine the time-temperature behavior of the pressure tube above the test assembly. The results of the calculations are shown in Figure 9.27. Conservatively high initial temperatures were used. The pressure tube cools initially because there is no steam flow during this period. The pressure tube temperature continues to drop until hot steam flow occurs, after which the temperature increases, peaks, and decreases again, following the pattern of the steam temperature. The peak temperature during the rise is less than the initial temperature up to a maximum of $599 \mathrm{~K}\left(618^{\circ} \mathrm{F}\right)$, which is well below any temperature limit for the pressure tube.

There is one significant difference between the NRU LOCA tests and the FLECHT tests that will impact this analysis: the metal-water reaction. At high cladding temperatures the steam will react with the zircaloy cladding as given by:

$$
\mathrm{Zr}+2 \mathrm{H}_{2} \longrightarrow \mathrm{ZrO}_{2}+2 \mathrm{H}_{2}
$$




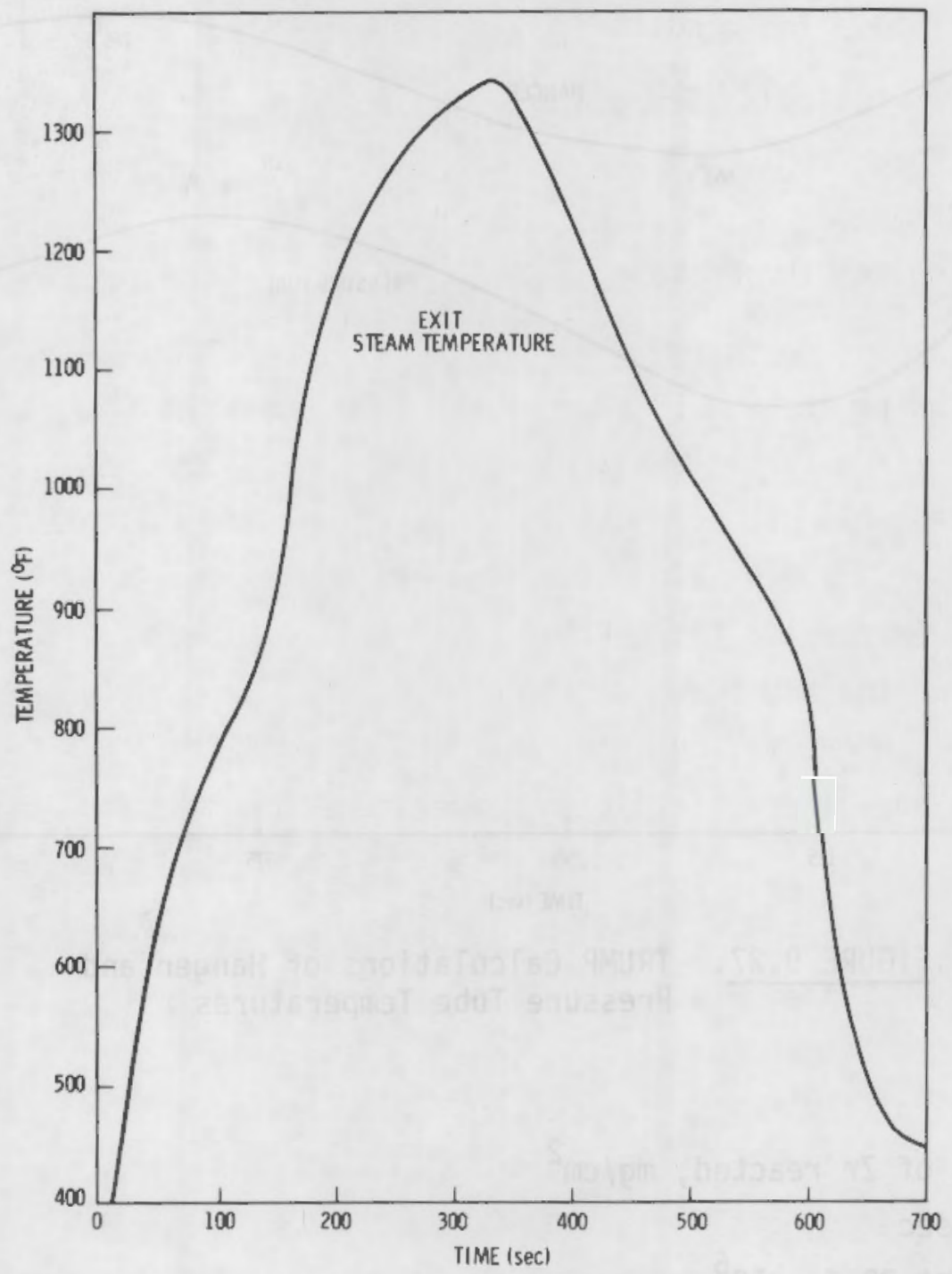

FIGURE 9.26. Upper Steam Exit Temperature from FLECHT Data

The reaction is exothermic producing a heat of $559 \mathrm{~kJ}$ (143 kcal) per mole $\mathrm{Zr}$. The conventional description of the kinetics of this reaction is given by Baker-Just (1962) as follows:

$$
\frac{d W}{d \theta}=\frac{1}{2} \frac{1}{\theta 1 T 2}\left(A \operatorname{Exp} \frac{B}{R T}\right)^{1 / 2}
$$




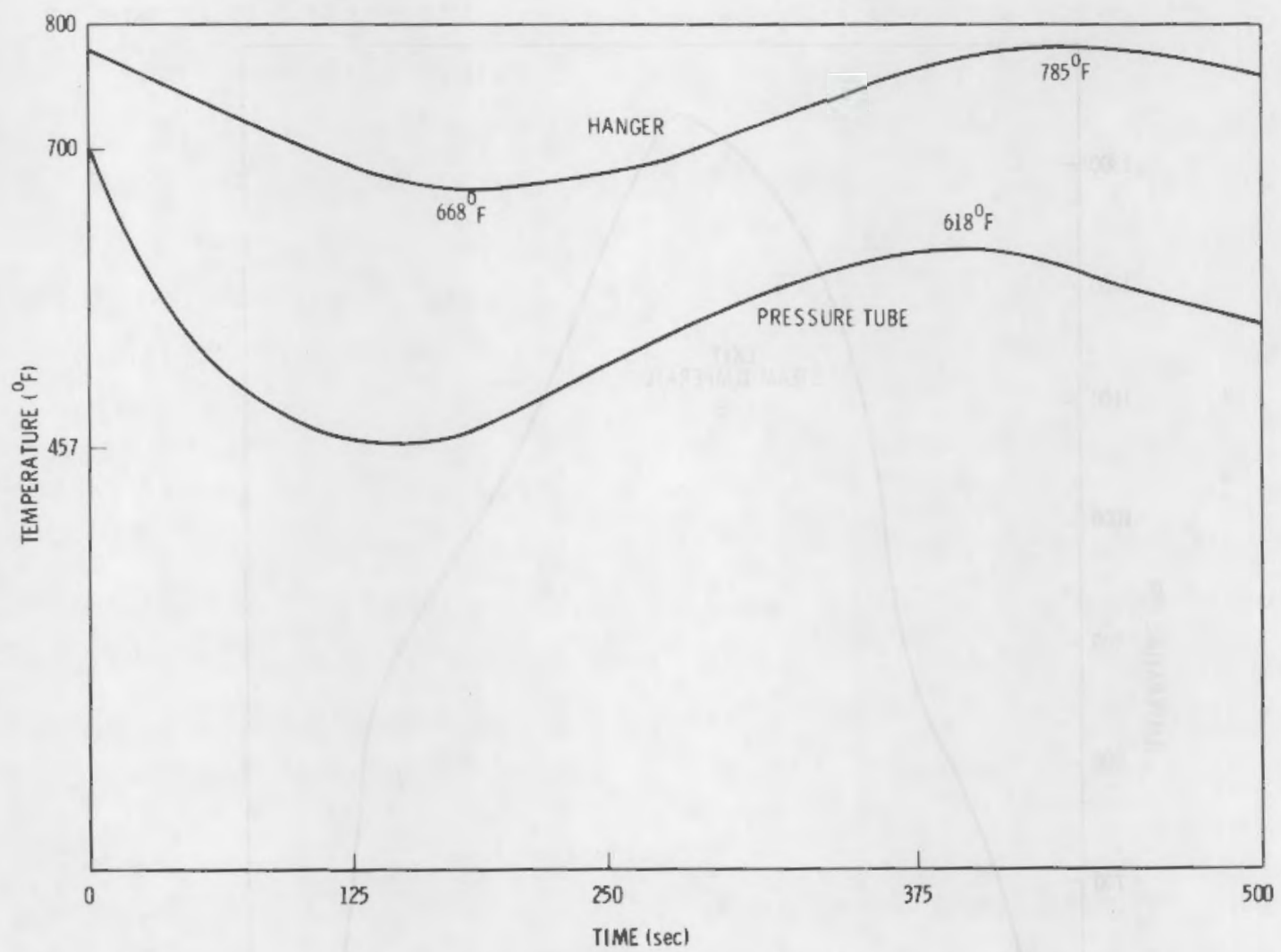

FIGURE 9.27. TRUMP Calculations of Hanger and Pressure Tube Temperatures

where

$w=$ weight of $\mathrm{Zr}$ reacted, $\mathrm{mg} / \mathrm{cm}^{2}$

$\theta=$ time, $\sec$

$A=$ constant $33.6 \times 10^{6}$

$B=$ activation energy $-45,500 \mathrm{cal} / \mathrm{mole}$

$R$ = gas constant, 1.987 mole $K$

$T=$ temperature, $K$.

Since the Baker-Just correlation was developed, much experimental data has been accumulated showing reaction rates lower by as much as a factor of two (Westerman 1977).

The Baker-Just correlation and a more recent one (Cathcart 1976) were incorporated in the GAPCON computer code. Two accident cases were then examined. The first assumed that an experiment had a planned reflood rate of 
$2.5 \mathrm{~cm} / \mathrm{sec}$ (1.0 in./ $/ \mathrm{sec}$ ), but during the accident the reflood rate was half of that planned, just above the reflood rate trip point. The case also assumed that the accident continued until the reactor was scrammed and that the SCRAM became effective when the peak cladding temperature reached $1478 \mathrm{~K}\left(2200^{\circ} \mathrm{F}\right)$. The second case was identical except that the planned and achieved reflood rates were assumed to be $5.1 \mathrm{~cm} / \mathrm{sec}(2 \mathrm{in.} / \mathrm{sec})$ and $2.54 \mathrm{~cm} / \mathrm{sec}(1.0 \mathrm{in} . / \mathrm{sec})$, respectively. The first accident case, which gave the most pessimistic answers, is reported here.

The GAPCON results gave the rod power contributed by the energy release from the metal-water reaction. These values are given in Figure 9.28 for the two correlations. These energy contributions were added to the nuclear energy and used as input to the TRUMP computer code to calculate test assembly temperatures for the accident. The results are plotted in Figure 9.29, which shows quite a prompt turn-around of the temperatures for both metal-water reaction models.

The results were incorporated into input to the TRUMP computer code to calculate test assembly temperatures during the accident. The results are illustrated in Figure 9.29 .

As is indicated, the peak clad temperature rises only slightly above $1478 \mathrm{~K}$ $\left(2200^{\circ} \mathrm{F}\right.$ ) (the temperature at which the trip occurs) before turning around. The shroud and pressure tube temperatures continue to increase for a short period of time before turning around at a level well below any problem temperatures. Subsequent calculations (a) evaluated fuel cladding temperatures of $1644 \mathrm{~K}$ $\left(2500^{\circ} \mathrm{F}\right)$, which showed that a predictable, stable termination of the accident occurred, based on the high temperature validated correlation (Cathcart 1976).

A second effect of the zirconium/water reaction has also been evaluated (b) to determine the maximum cladding oxidation wastage, and to estimate the maximum $\mathrm{H}_{2}$ production that could be anticipated for a postulated test accident

(a) Letter from R. L. Hjelm to G. M. Hesson, "Effect of Energy Release from $\mathrm{ZrH}_{2} \mathrm{O}$ Reaction on NRU Assembly Temperatures-High Temperature SCRAM Case," March 10, 1980.

(b) Letter from G. M. Hesson to G. E. Russcher, "Total Hydrogen Evolution from NRU Test (Accident)," June 25, 1980. 


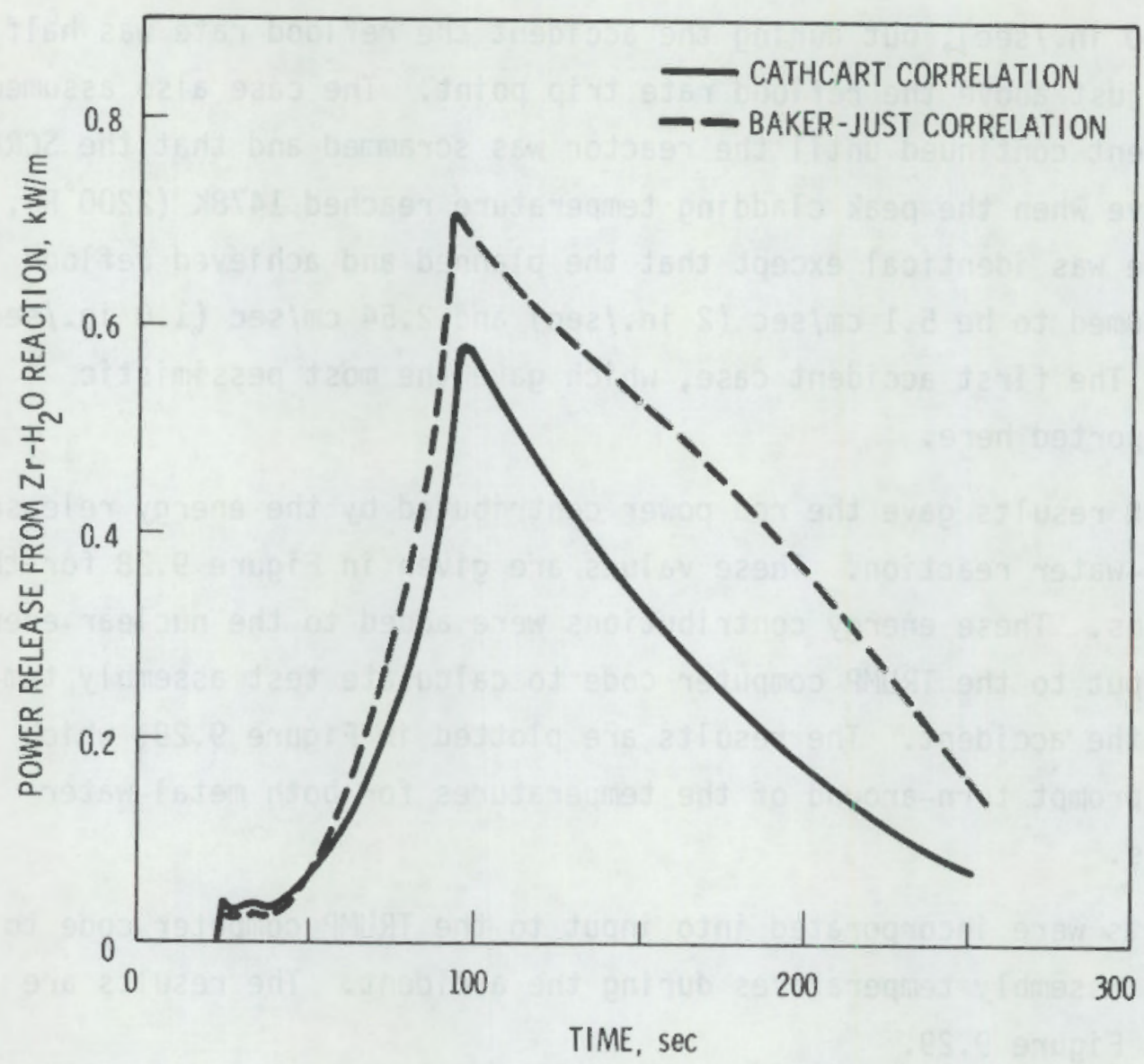

FIGURE 9.28. Contribution of Metal-Water Reaction to Rod Power

in which cladding temperatures of $1478 \mathrm{~K}\left(2200^{\circ} \mathrm{F}\right)$ could be reached. A THERM calculation of an accident terminated at $1444 \mathrm{~K}\left(2140^{\circ} \mathrm{F}\right)$ provided the temperature distribution and time history that conservatively represented such an accident. No reactor trip was assumed, so the time at the peak temperature was extended as the reactor was powered down, and the bundle fuel cladding was reflooded and quenched. The zirconium/water reaction was integrated over all 31 fuel pins, both in time and axial temperature distribution. Using the correlation of Baker and Just (1962) provided the most conservative integrated estimate of $0.133 \mathrm{~m}^{3}\left(4.70 \mathrm{ft}^{3}\right)$ hydrogen production (at STP), with a peak cladding wastage of $0.0028 \mathrm{~cm}(0.0011 \mathrm{in.})$. Similarly, using the more realistic Cathcart (1976) correlation provided integrated estimates of $0.081 \mathrm{~m}^{3}$ $\left(4.02 \mathrm{ft}^{3}\right.$ ) hydrogen production (at STP) with a peak cladding wastage of $0.0015 \mathrm{~cm}(0.0006$ in.). See Figure 9.28. With the receiver catch tank less 


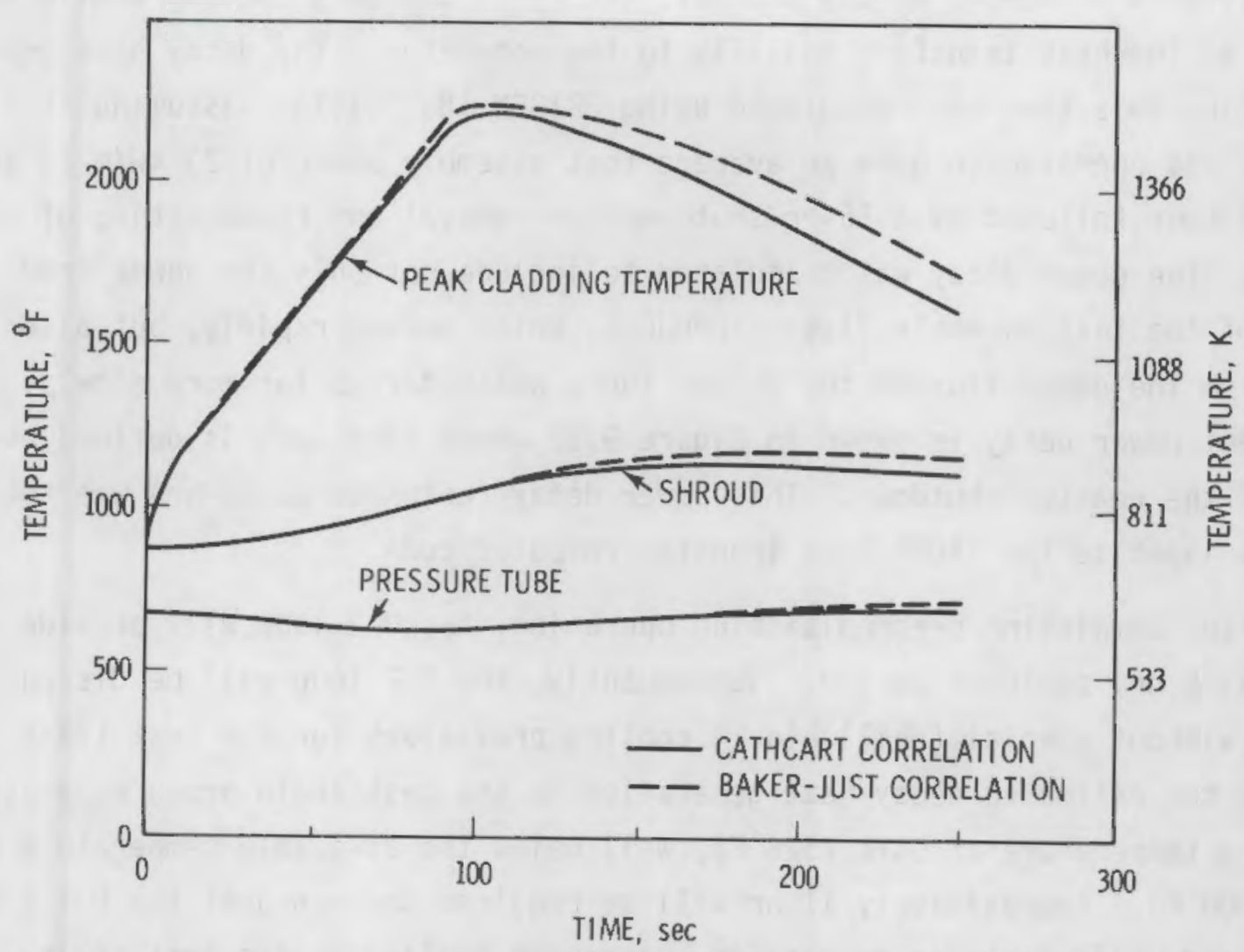

FIGURE 9.29. Shroud, Pressure Tube, and Test Fuel Cladding Temperatures for 21-s Heatup (to $1800^{\circ} \mathrm{F}$ ), Slow Reflood $(0.5 \mathrm{in} / \mathrm{s}$ ) and Reactor Trip at $1478 \mathrm{~K}\left(2200^{\circ} \mathrm{F}\right)$

than one-half full, the conservative estimate of $0.133 \mathrm{~m}^{3}\left(4.70 \mathrm{ft}^{3}\right)$ would result in an $\mathrm{H}_{2}$ concentration of less than the $4 \%$ flammable limit.

\subsection{COOLING REQUIREMENTS FOR THE TEST ASSEMBLY}

As has been mentioned, an experimental assembly must cool in the reactor following transient testing. This section gives the cooling requirements for the test assembly during these periods: after preconditioning, between transients, and following the test.

\subsubsection{Requirement for Cooling After Preconditioning}

The cooling problems for the period after the preconditioning operation result from the piping to the test assembly being removed and then being replaced by the transient piping. During the replacement period the test 
assembly will be devoid of any coolant; therefore the only cooling available occurs as the heat transfers radially to the moderator. The decay heat generated during this time was calculated using ORIGEN (Be11 1973), assuming that the reactor was operated to give an average test assembly power of $23 \mathrm{~kW} / \mathrm{m}(7 \mathrm{~kW} / \mathrm{ft}$ ) for one hour followed by a 16-hr shutdown for removal and reconnecting of the piping. The power decay was calculated to include not only the power from decay of the test assembly fission product, which decays rapidly, but also the heat from the gamma flux of the driver fuel, which decays far more slowly. The resuitant power decay is shown in Figure 9.22 where time zero is defined as the time of the reactor shutdown. This power decay (extended to $16 \mathrm{hr}$ ) was then used as input to the TRUMP heat transfer computer code.

After completing preconditioning operation, the U-2 loop will provide a (nominal $5 \mathrm{hr}$ ) cooldown period. Subsequently, the U-2 loop will be disconnected without special (chill block) cooling provisions for the test train because the estimated decay heat generation in the test train produces a peak cladding temperature of $547 \mathrm{~K}\left(526^{\circ} \mathrm{F}\right)$, well below the allowable temperature of $700 \mathrm{~K}\left(800^{\circ} \mathrm{F}\right)$. Approximately $11 \mathrm{hr}$ will be required to reconnect the U-1 steam supply and reflood piping to provide subsequent cooling to the test train. During that period, no coolant is assumed to be available (only radiation). The maximum pressure tube temperature reached, $489 \mathrm{~K}\left(420^{\circ} \mathrm{F}\right)$, is relatively low and poses no hazards.

\subsubsection{Requirement for Cooling Between Transients}

This cooling requirement is for the period occurring between the several thermal-hydraulic tests when the loop has been drained of reflood water from one test, but the steam cooling has not been established for the subsequent test. A conservative power history for this case is one in which the test assembly is operated for one hour at an average rod power of $23.0 \mathrm{~kW} / \mathrm{m}$ $(7 \mathrm{~kW} / \mathrm{ft})$, the reactor is shut down for $16 \mathrm{hr}$, and then the reactor is operated for $20 \mathrm{hr}$ at an average rod power of $1.25 \mathrm{~kW} / \mathrm{m}(0.38 \mathrm{~kW} / \mathrm{ft})$. The decay heat for this case was calculated in a manner identical to that for the post preconditioning case with results also shown in Figure 9.30. The peak cladding temperatures calculated with the TRUMP computer code are shown in Figure 9.31. The time required to drain the loop and reestablish steam cooling is estimated 


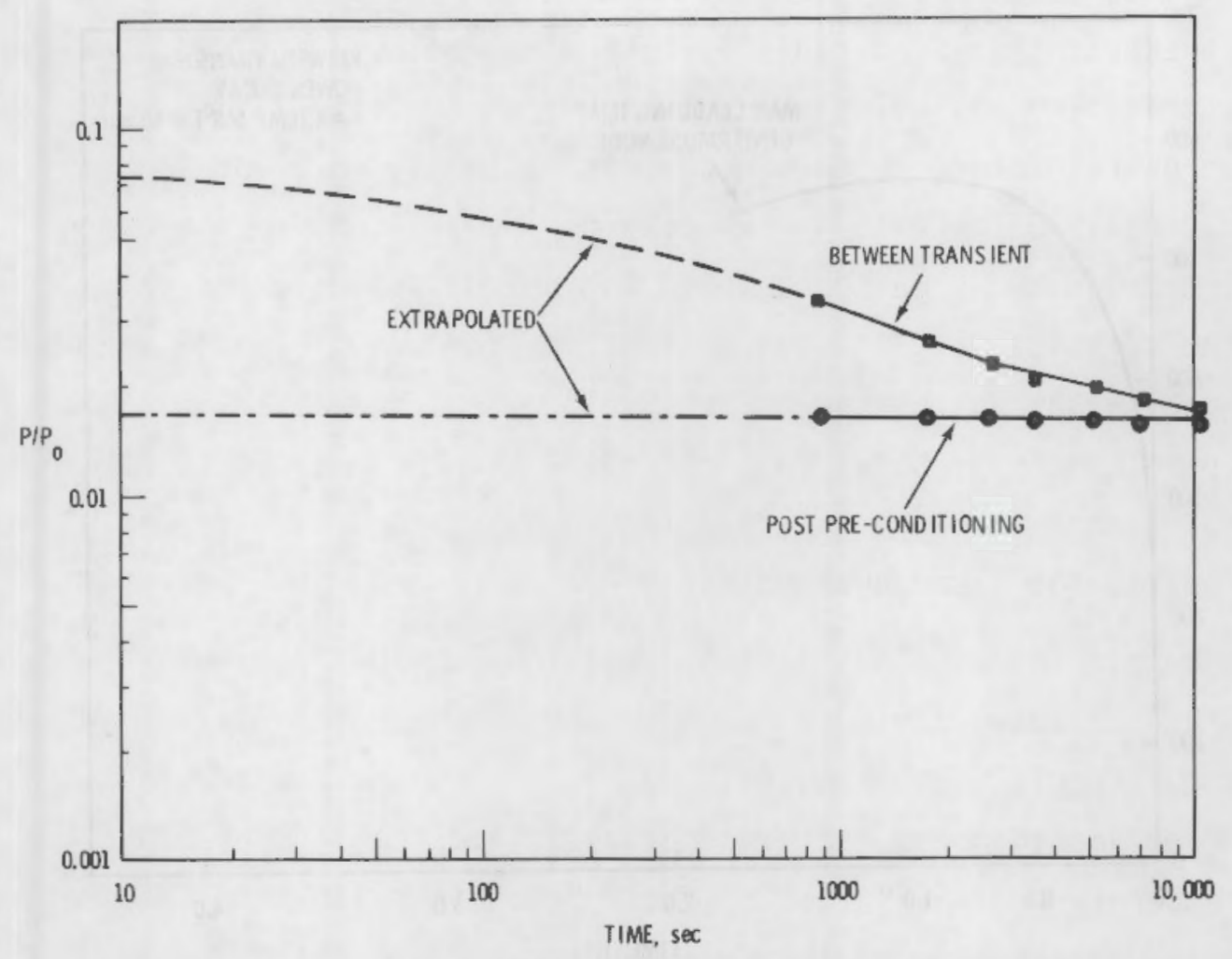

FIGURE 9.30. Power Decay Curve Normalized to $0.38 \mathrm{~kW} / \mathrm{ft}$

to be less than one-half hour. Figure 9.31 shows that the peak cladding temperature at one-half hour is $558 \mathrm{~K}\left(545^{\circ} \mathrm{F}\right)$. Even if the steam cooling is not reestablished in that period, the peak cladding temperature reached is only $573 \mathrm{~K}\left(570^{\circ} \mathrm{F}\right)$, which causes no hazards.

\subsubsection{Requirement for Post-Test Cooling}

Previous experience at NRU shows that by the time the loop is shut down, the test assembly will be cool enough to handle for removal. 


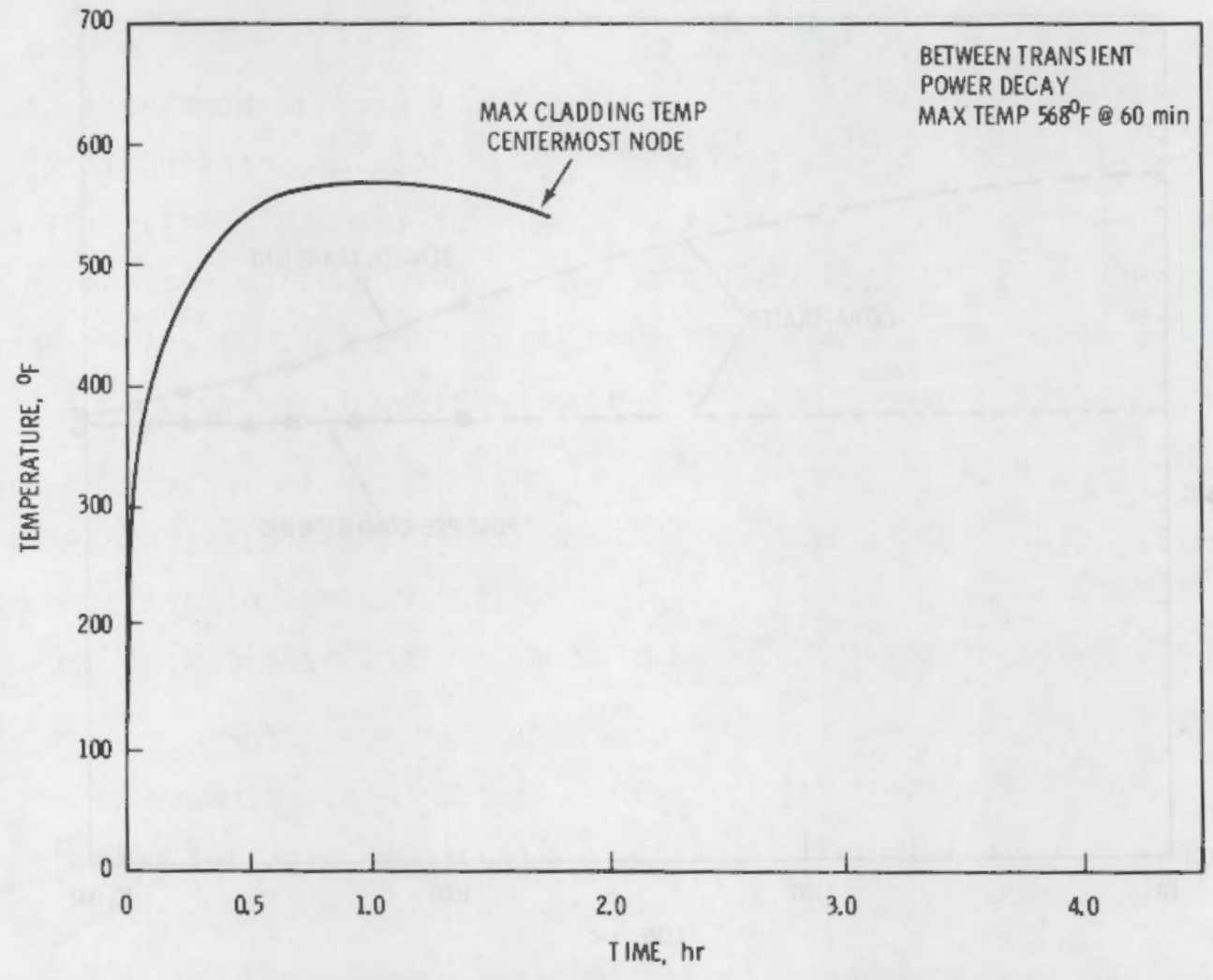

FIGURE 9.31. Maximum Cladding Temperature Between Transient Operation 


\subsection{QUALITY ASSURANCE}

The Quality Control Plan (QCP) implemented by Pacific Northwest Laboratory will be used during the design, procurement, fabrication, construction, and assembly of each test train that will be tested at the NRU facility by AECL. This plan governs all activities that affect product quality commencing with design and development and continuing through procurement, materials handling, fabrication, testing, inspection, storage, and shipment.

Detailed specifications and procedures covering these activities are contained in material, product, welding/brazing, special processes, fabrication, and assembly documents. Clear, concise, approved drawings of all assemblies and components will be provided for ease of machining, fabrication, or assembly.

A central records-keeping source will be established for material specifications, product specifications, drawings, procurement documents, inspection logs and other information deemed necessary for traceability of materials or components for each project.

The project manager shall appoint a project quality control representative (PQCR) who shall implement this plan. The manager or PQCR, whoever is responsible, shall have the organizational freedom to make independent assessments of quality and direct the attention of others to any quality problem, and its causes and to recommend corrections. A quality assurance engineer assigned to the Materials Department of PNL shall provide assistance in implementing the quality control elements contained within this QCP and conduct independent audits of all projects. A materials review board shall be established to process all nonconformance reports or discrepancies of materials or components.

\subsection{ELEMENTS DF QUALITY ASSURANCE}

Quality Assurance Plan: The purpose of a Project Quality Assurance Plan is to assist in planning Quality Control activities for the project and to identify special Quality Assurance requirements specified by PNL's Quality Assurance Organization (QAO) or sponsor. 
Design Control and Method Review: The purpose of this element is to assure that the design requirements are formally documented in design drawings, specifications and procedures.

Procurement: The purpose of this element will be to provide documented records of all procurement activities, and to establish a central file of all purchased materials and components.

Instructions, Procedures and Drawings: The purpose of this element is to assure that activities affecting quality are accomplished in accordance with documented instructions, procedures, or drawings.

Document Control: The purpose of this element is to assure that documents affecting quality are properly prepared, identified, reviewed, approved, distributed to the affected work location, and maintained current.

Material Identification and Controls: The purpose of this element is to assure that only acceptable materials or components are used and that these meet special requirements for identification, storage and use.

Key Fabrication and Special Processes: The purpose of this element is to provide documented verification of the control of key fabrication processes which affect the quality.

Inspection and Testing: The purpose of this element will be to assure that items requiring inspection and testing conform to specifications and design requirements.

Calibration: The purpose of this element is to assure that all measuring and test equipment used are suitable for the intended purpose and are maintained in accordance with specified calibration and service procedures.

Handling, Storage and Shipping: The purpose of this element is to assure that all materials or components requiring special instructions are handled, stored or shipped to reduce unnecessary damage, deterioration, or loss.

Nonconformance and Corrective Action: Regulations concerning nonconformance and corrective action must be applied to all components and materials. 
Project Records: Drawings, specifications, procedures, and other documents affecting quality must be generated and maintained as evidence of conformance to all requirements. Copies of all pertinent documents shall be maintained in the project file. Documents shall include but not be limited to the following:

- Purchase Orders

- Engineering Drawings

- Material Specifications

- Product Specifications

- Receiving Reports

- Inspection Reports

- Special Process Procedures

- Key Fabrication Procedures

- Nonconformance Reports

- Calibration Reports and Records

- Audits

- Testing Reports

- Design Analysis

- Qualification Prodecures

- Personal Qualifications

- Shop Travelers

- Accept Tags

\subsection{SPECIFICATIDNS AND PROCEDURES}

The specifications that will be developed and implemented during the procurement and fabrication phases of this project are listed on the following pages. The specifications, themselves, can be found in these appendices:

$\begin{array}{lll}\text { Material Specifications } & \text { Appendix B } & \text { B-1 } \\ \text { Product Specifications } & \text { Appendix C } & \text { C-1 } \\ \text { Welding/Brazing Specifications } & \text { Appendix D } & \text { D-1 } \\ \text { Heat Treatment Specifications } & \text { Appendix E } & \text { E-1 }\end{array}$





\section{REFERENCES}

AECL/PNL Contract for LOCA Simulation Testing and Evaluation Conducted in the NRU Program, Agreement B-68724-A-P. 1978. Pacific Northwest Laboratory, Richland, Washington 99352.

American Society of Mechanical Engineers Boiler and Pressure Vessel Code, Section III, Division 1, Subsection NB, (1977) ASME, 345 East 47th, New York, New York 10017.

ANS 5.1 Committee. 1977. Proposed Revised ANS Standard (ANS 5.1). Decay Heat Power in Light Water Reactors for Shutdown Times Less than 10 Seconds. American Nuclear Society, 244 E. Ogden Ave., Hillsdale, Illino is 60521.

ASME BPV Code, Section III, Division 1, Appendices (1977).

Baker, L. and L. C. Just. 1962. Studies of Metal Water Reactions at High Temperatures. III. Experimental and Theoretical Studies of the Zirconium Water Reaction. ANL-6548, Argonne National Laboratory, Chicago, I11inois.

Be11, M. J. 1973. "ORIGEN - The ORNL Isotope Generation and Depletion Code." ORNL-4628, Oak Ridge National Laboratory, Oak Ridge, Tennessee.

Billeter, T. J. et al. 1978. "LOFT Advanced Fuel Rod Instrumentation Development." Paper presented at the Sixth Water Reactor Safety Research Information Meeting, November 6-9, 1978, Gaithersburg, Maryland.

Cadek, F. F. et al. 1972. PWR FLECHT Final Report Supplement. WCAP-7931, Westinghouse Electric Corporation.

Cathcart, J. V. 1976. Quarterly Progress Report on the Zirconium Metal-Water Oxidation Kinetics Program Sponsored by the NRC Division of Reactor Safety Research for April-June 1976. ORNL/NUREG/TM-41, Oak Ridge National Laboratory, Oak Ridge, Tennessee.

Cook, B. A. 1978. Postirradiation Examination Data Report for Gap Conductance Test Series, Test GC 2-3. NUREG/CR-0253*, EG\&G Idaho, Inc., Idaho Fa11s, Idaho.

Den Hartog, J. P. 1952. Advanced Strength of Materials. McGraw Hill Book Company, New York, New York.

Fischer, M. and M. F. Osborne. 1978. "LWR Fuel Behavior Research in the Federal Republic of Germany." Nuclear Safety 1978 Bimonthly Technical Progress Review 9(2):184.

Garner, R. W. et al. 1977. Gap Conductance Test Series - 2, Test GC 2-1, 2-2, and 2-3 Draft Test Results Report. TFBP-TR-230, EG\&G Idaho, Inc., Idaho Falls, Idaho. 
Hann, C. R. et al. 1977. A Method for Determining the Uncertainty of Gap Conductance Deduced from Measured Fuel Centerline Temperatures. BNWL-2091, Pacific Northwest Laboratory, Richland, Washington 99352.

Hann, C. R. 1979. Program Plan LOCA Simulations in the National Research University (NRU) Reactor. PNL-3056, Pacific Northwest Laboratory, Richland, Washington 99352.

Kaman Science Corporation. 1975. "Radiation Sensitivity, Kaman Extreme Environment Pressure Transducers." Application Note 206, Revision A, Colorado Springs, Colorado.

Karb, E. H. 1978. Results of the FR2 Nuclear Tests on the Behavior of Zircaloy Clad Fuel Rods. Paper presented at Sixth Water Reactor Safety Research Information Meeting, November 6-9, 1978, Gaithersburg, Maryland.

Kendrick, S. H. 1979. Control Systems for the NRC Transient Tests. Process Systems Design Branch, Chalk River Nuclear Laboratories, Chalk River, Ontario, Canada.

Kerwin, D. K. 1978. Postirradiation Examination Data Report for Gap Conductance Test Series, Test GC 2-2. NUREG/CR-0211,* EG\&G Idaho, Inc., Idaho Fa17s, Idaho.

Lanning, D. D. et a7. 1978. GAPCDN-THERMAL-3 Code Description. PNL-2434, Pacific Northwest Laboratory, Richland, Washington 99352.

Lilly, G. P. et al. 1977. PWR FLECHT Cosine Low Flooding Rate Test Series

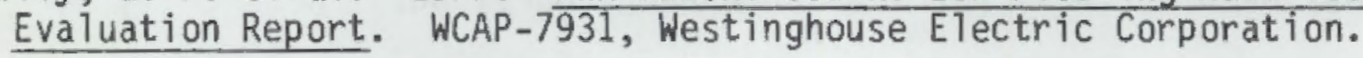

Lorenz, R. A., D. D. Hobson and G. W. Parker. 1971. "Final Report on the First Fuel Rod Failure Transient Test of a Zircaloy-Clad Fuel Rod Cluster in TREAT." ORNL-4635, Oak Ridge National Laboratory, Oak Ridge, Tennessee.

Meservey, R. H. 1976. Temperature Measurement on Zircaloy-Clad Fuel Pins During High Temperature Excursions. ANCR-NUREG-1303, Aerojet Nuclear Company, Idaho Falls, Idaho.

Mohr, C. L. et al. 1979. GAPCON THERMAL-3: A Technique for Evaluation of Transient Gap Conductance and Stored Energy. PNL-SA-7712, Pacific Northwest Laboratory, Richland, Washington 99352.

Murdock, B. A. 1978. Postirradiation Examination Data Report for Gap Conductance Test Series, Test GC 2-1. NUREG/CR-1204; EG\&G Idaho, Inc., Idaho Falls, Idaho.

Osborne, M. F. and G. W. Parker. 1971. "Rupture Tests of Irradiated Fuel Rods." In Nuclear Safety Program Annual Progress Report, for period ending December 31, 1970, ORNL-4647. 
Roark, R. J. 1965. Formulas for Stress and Strain. 4th Ed, Chap 13, McGraw-Hill Book Company, New York, New York.

Rosal, E. R. et a7. 1975. FLECHT Low Flooding Rate Cosine Test Series Data Report. WCAP-8651, Westinghouse Electric Corporation.

Russcher, G. E. et a1. January 1981. Experiment Operations Plan for a Lossof-Coolant Accident Simulation in the National Research Universal Reactor.

PNL 3551, NUREG/CR-1735. Pacific Northwest Laboratory, Rich7and, WA 99352.

Trapp, T. J. 1978. "The Effects of Buildup and Depletion on LWR Decay Power." NUREG/CR-0404* Nuc lear Regulatory Commission, Washington, D.C.

Westerman, R. E. and G. M. Hesson. 1977. Zircaloy Cladding ID/OD Oxidation Studies. EPRI-NP-525, Pac if ic Northwest Laboratory, Richland, WA 99352.

*Available for purchase from the NRC/GPO Sales Program, U.S. Nuclear Regulatory Commission, Washington, D.C. 20555, and/or National Technical Information Service, Springfield, VA. 22161 

APPENDIX A

DESIGN DRAWINGS 


\section{DESIGN DRAWINGS}

This appendix contains copies of 4 conceptual layout drawings and mechanical drawings that are representative of the entire drawing package to be used in the fabrication of the test assemblies.

Copies of the other drawings in the design package are available upon request.

The following list can be used to locate specific drawings in this appendix.

\section{Drawing Title}

Closure Region Layout

Outlet Region

Inlet Region Layout

Major Assembly \& Disassembly Schematic

Reactor Test Train Interface

Loop Closure Assembly

Test Train Arrangement

Test Train Instrumentation Array

Shroud Assembly

Guard Bundle Assembly (Side 1)

Guard Bundle Assembly (Side 6)

Thermal Hydraulic \& Materials

Test Bundle Assembly (Side 1)

Test Bundle Assembly (Side 6)

Thimble Assembly

Thimble Tube Assembly

Guard Rod Spacer Assembly

Test Bundle Spacer (Side 1 Assy)

Test Bundle Spacer (Side 6 Assy)

Carrier Assembly ( $1 F, 6 A$ )

Carrier Assembly (1A, 6F)

Rod Type I

Instrumented Rod Type XIII

Materials Test Bundle

Twelve-Pin Connector Assembly
Drawing Number

SK-3-21397

SK-3-21393

SK-3-21392

SK-3-21389

$\mathrm{H}-3-41801$

$\mathrm{H}-3-41802$

$\mathrm{H}-3-41803$

$\mathrm{H}-3-41804$

$\mathrm{H}-3-41811$

$\mathrm{H}-3-41812$

H-3-41813

$\mathrm{H}-3-41814$

$\mathrm{H}-3-41815$

$\mathrm{H}-3-41816$

$\mathrm{H}-3-41817$

H-3-41819

$\mathrm{H}-3-41820$

$\mathrm{H}-3-41821$

$\mathrm{H}-3-41847$

$\mathrm{H}-3-41846$

$\mathrm{H}-3-41832$

$\mathrm{H}-3-41882$

$\mathrm{H}-3-41778$
Page Number

A-2

A-3

A-4

A-5

A-6

A-7

A-8

A- 10

A- 11

A-12

A-13

A-14

A- 15

A-16

A-18

A-19

A-20

A-22

A-23

A-24

A-25

A-26

A-27 


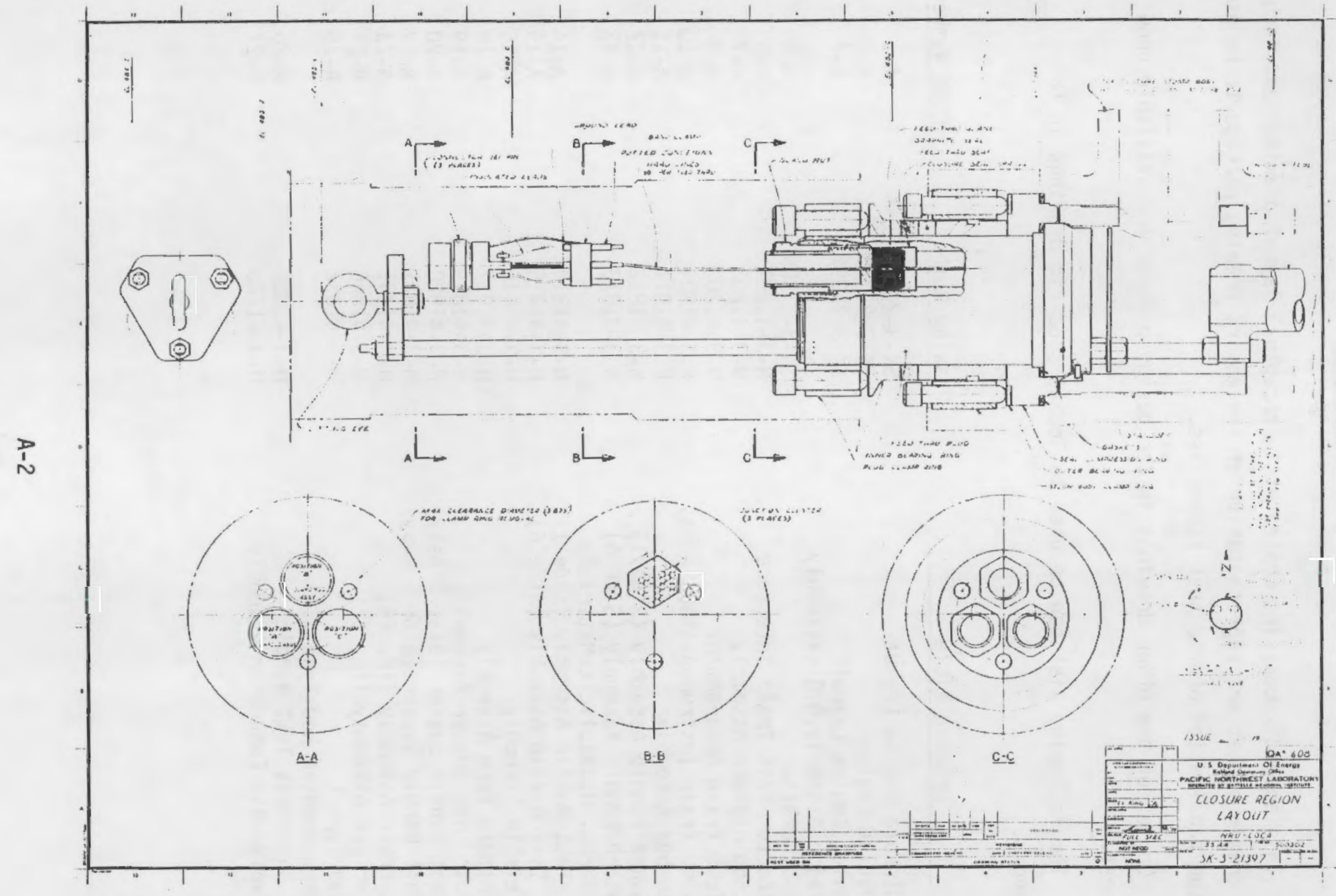




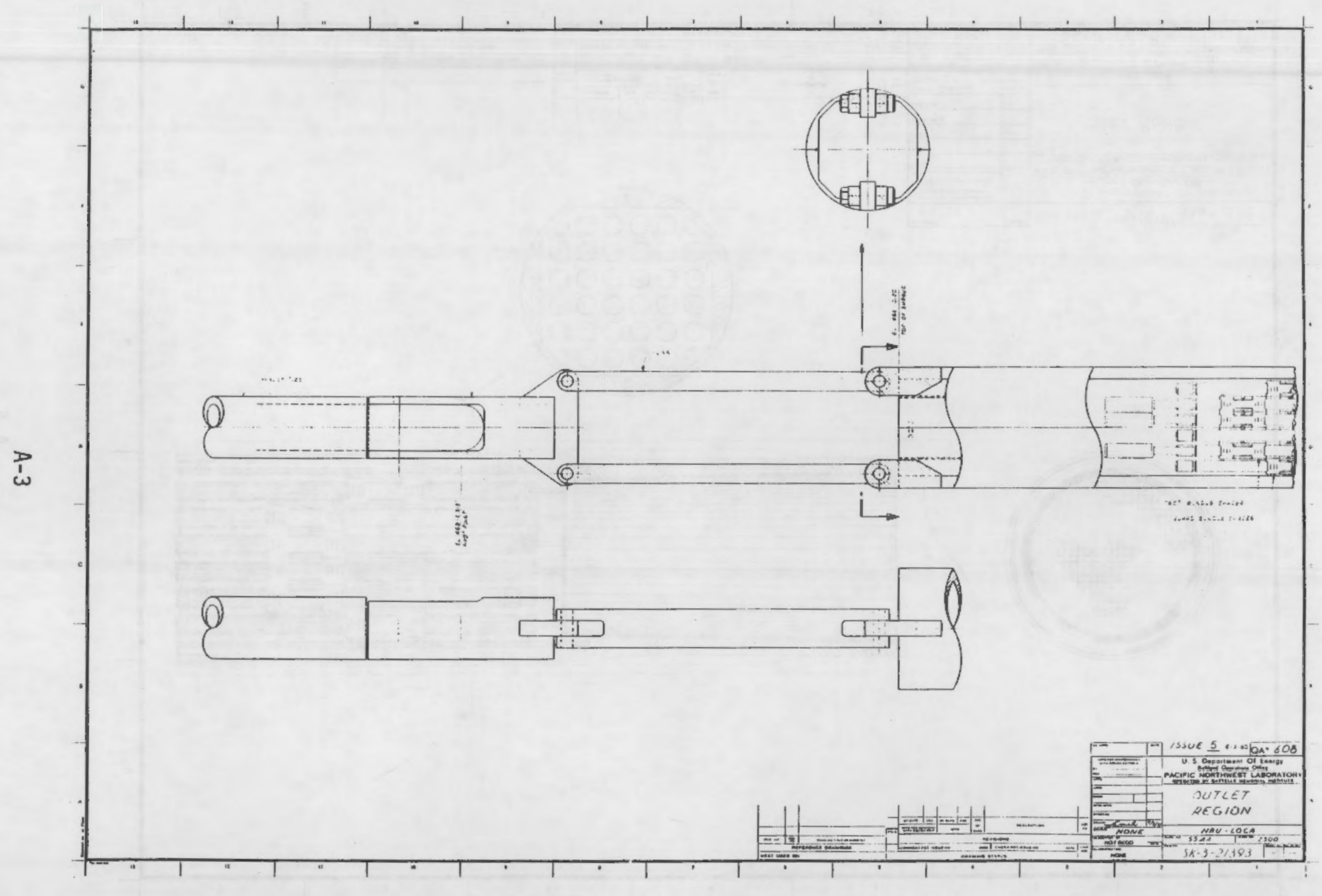




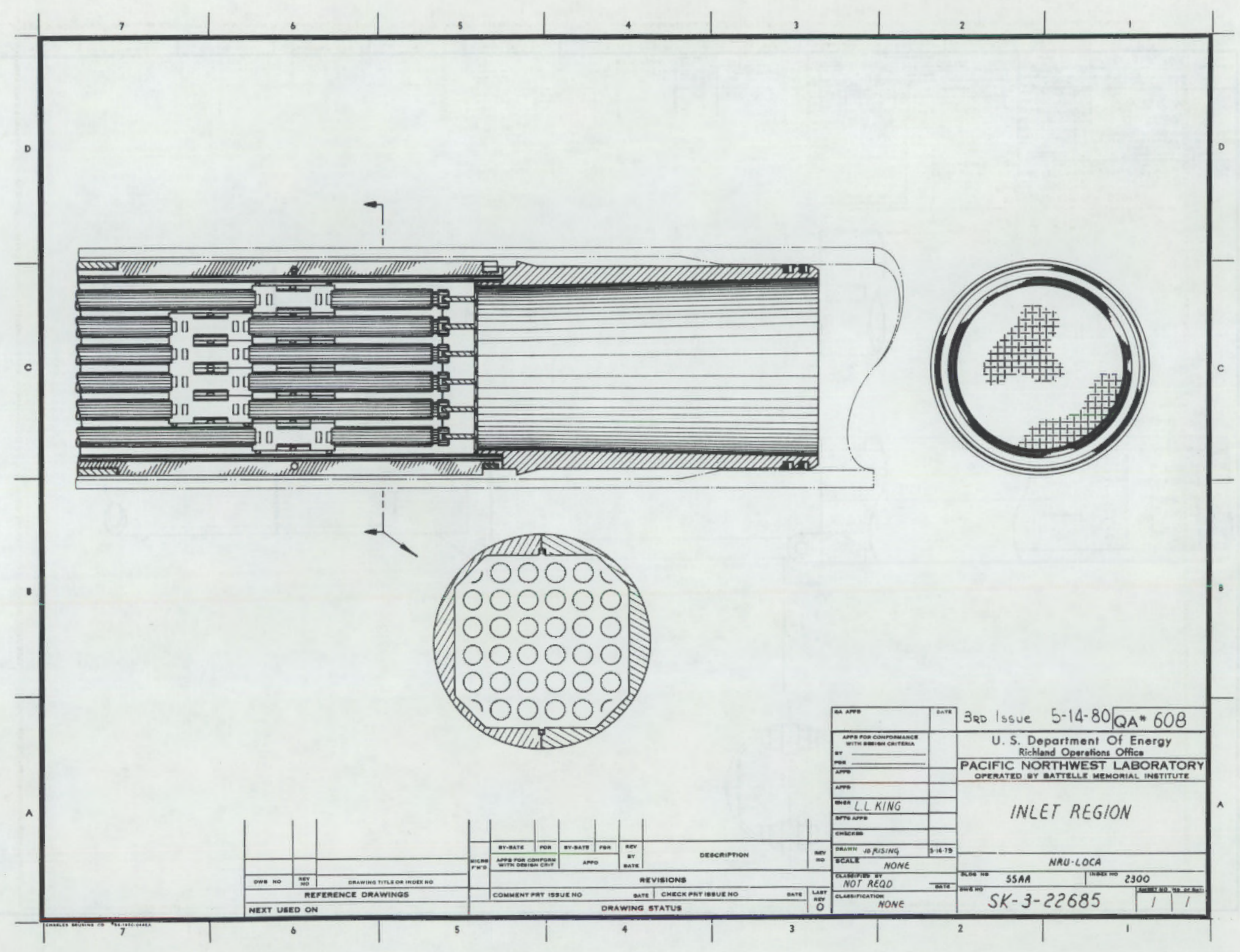




$$
\text { E }
$$




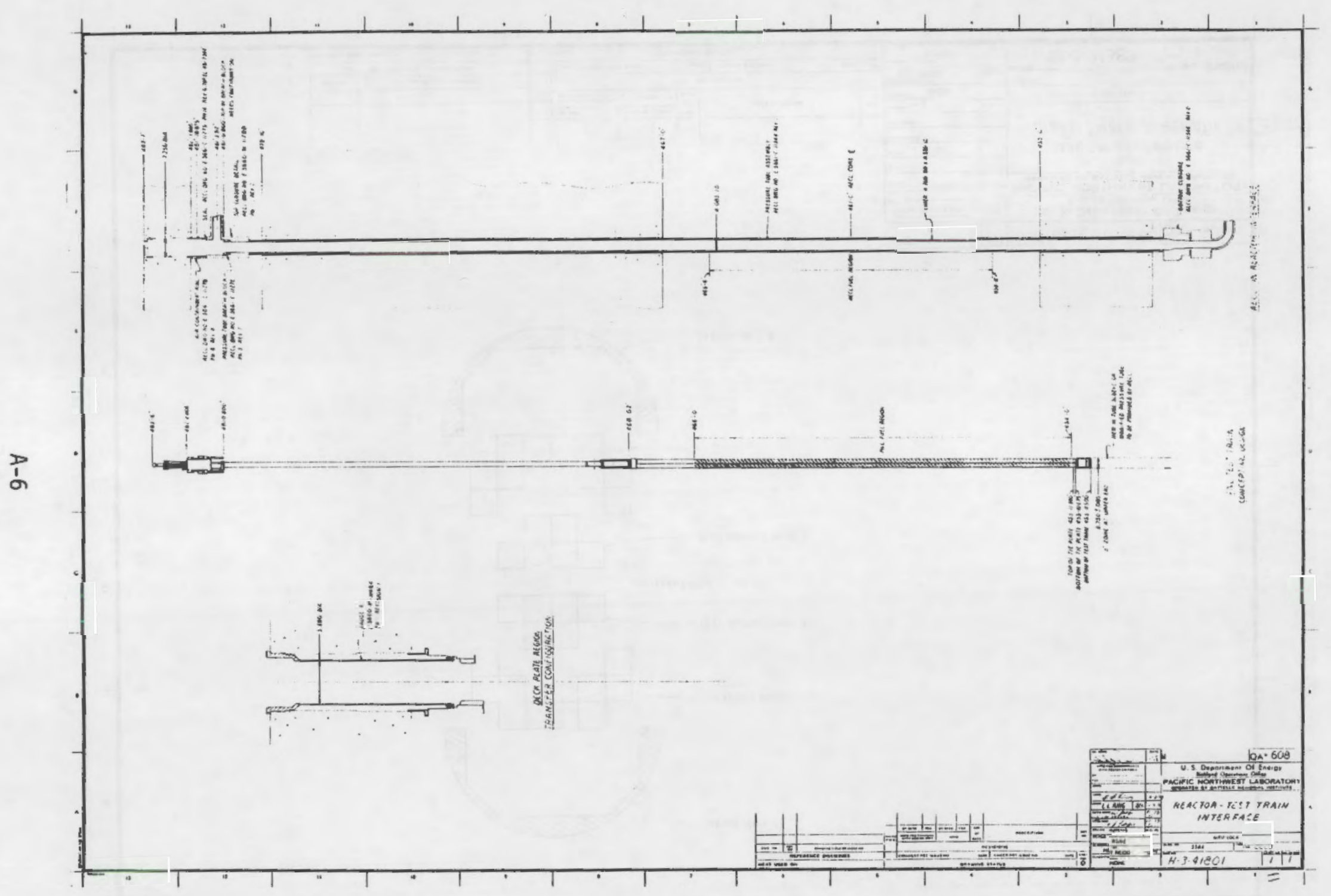




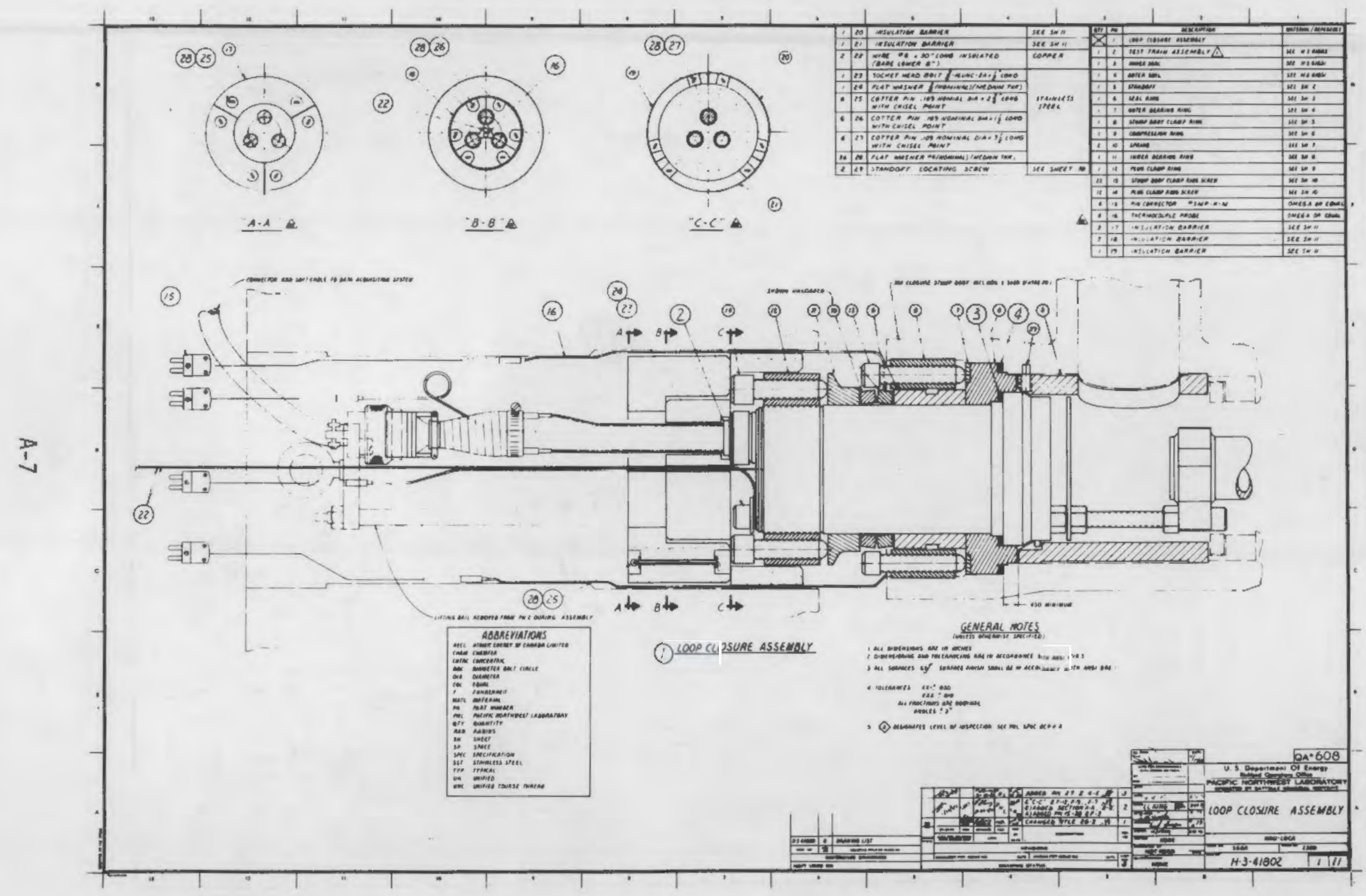




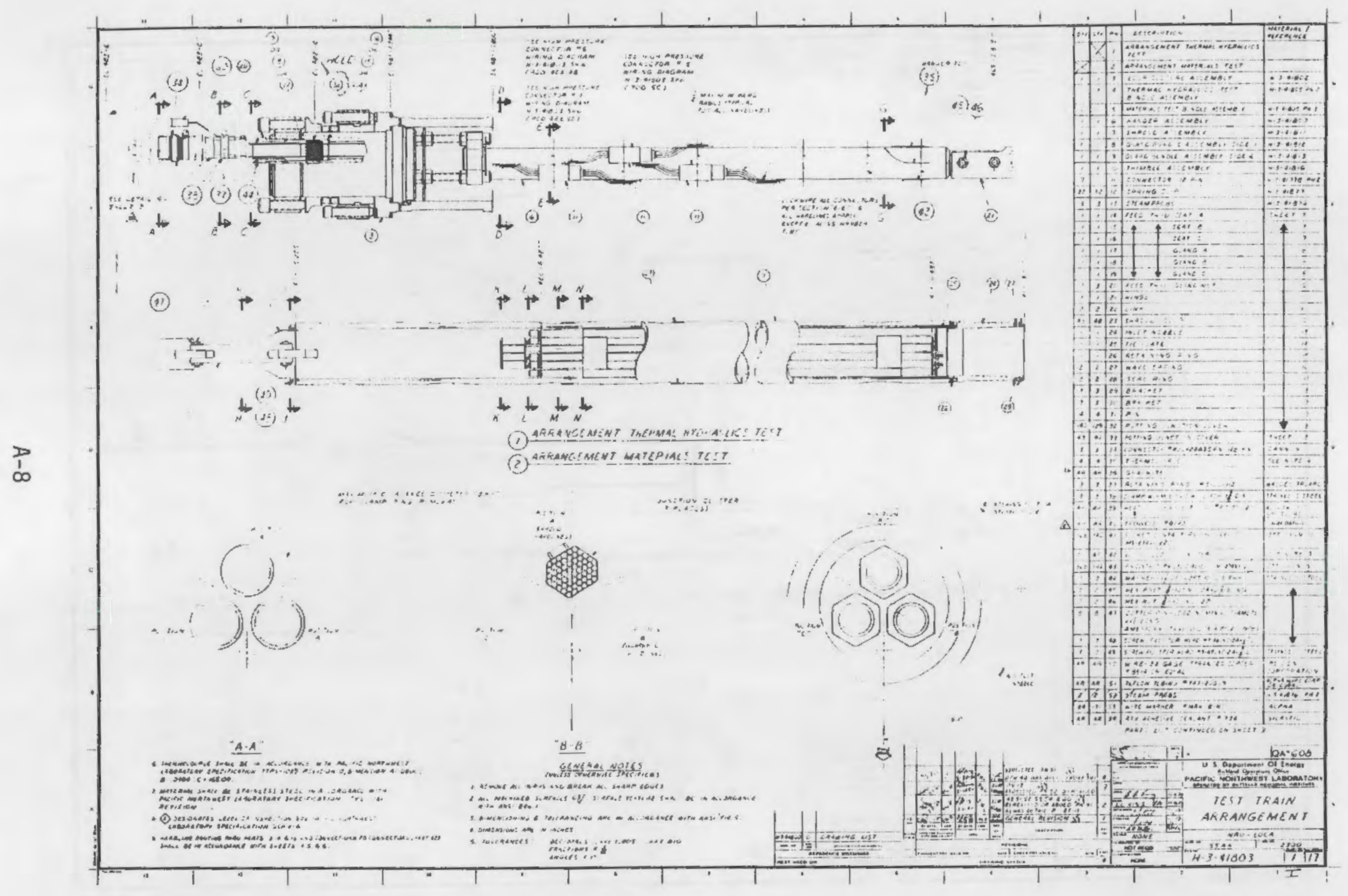




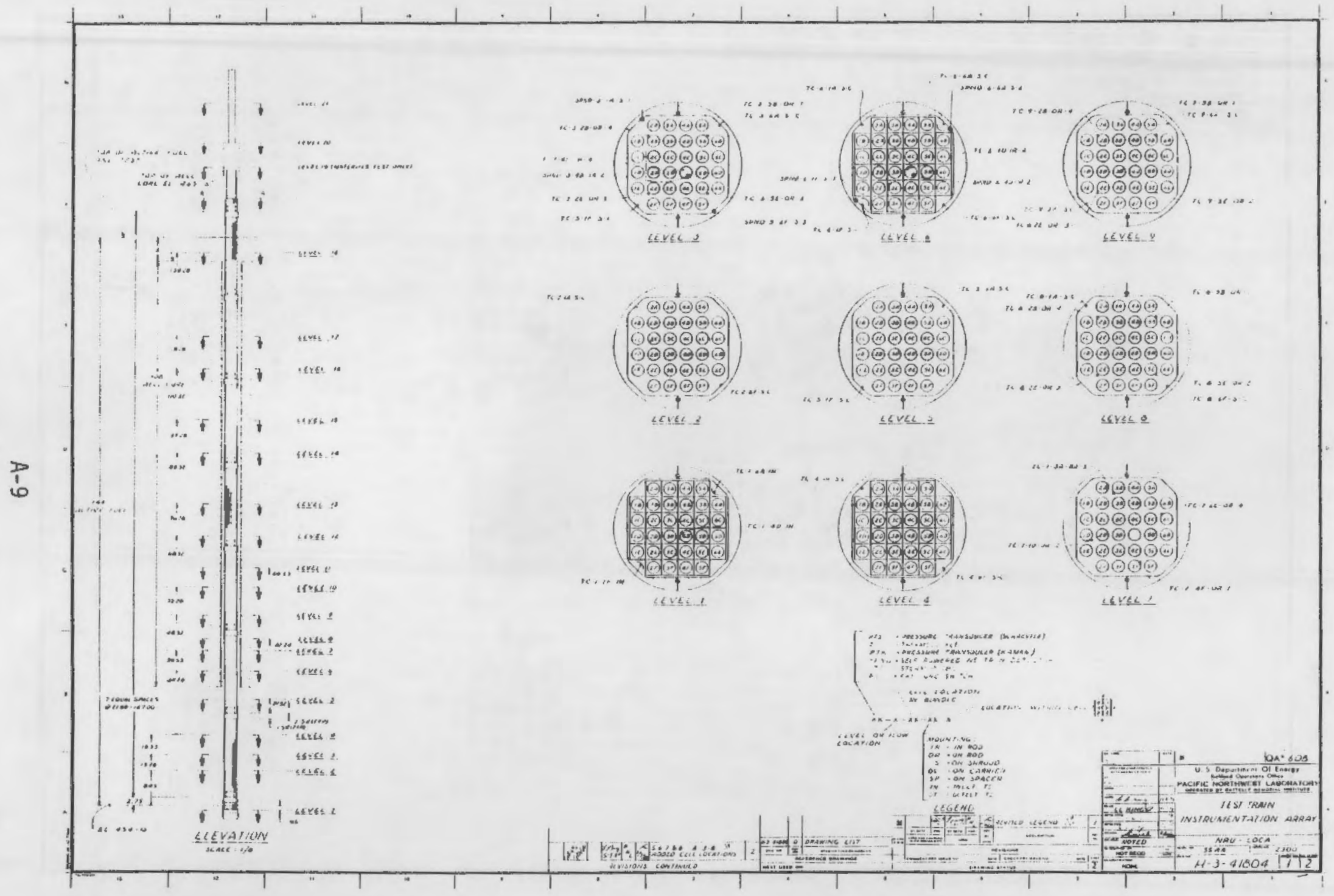




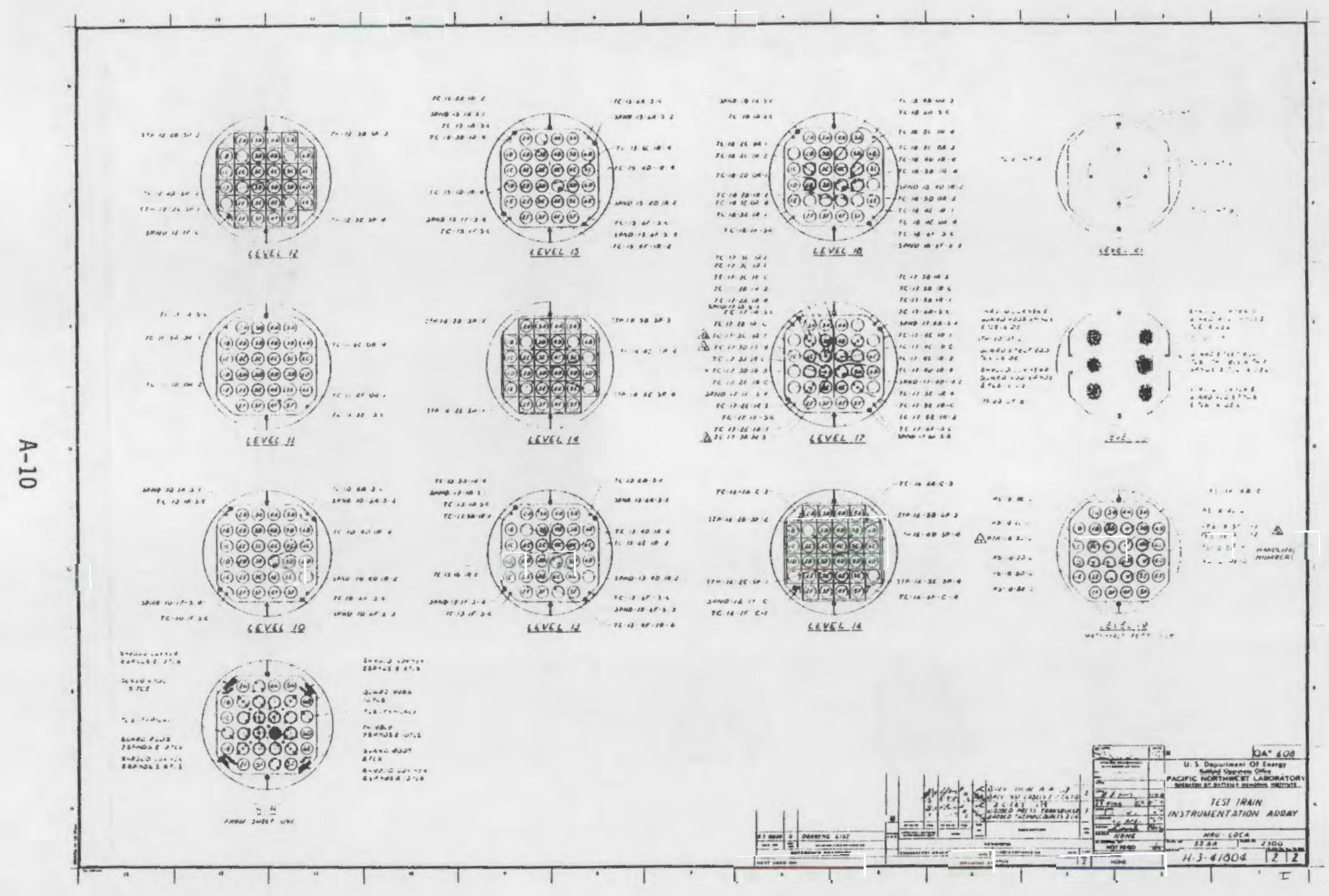




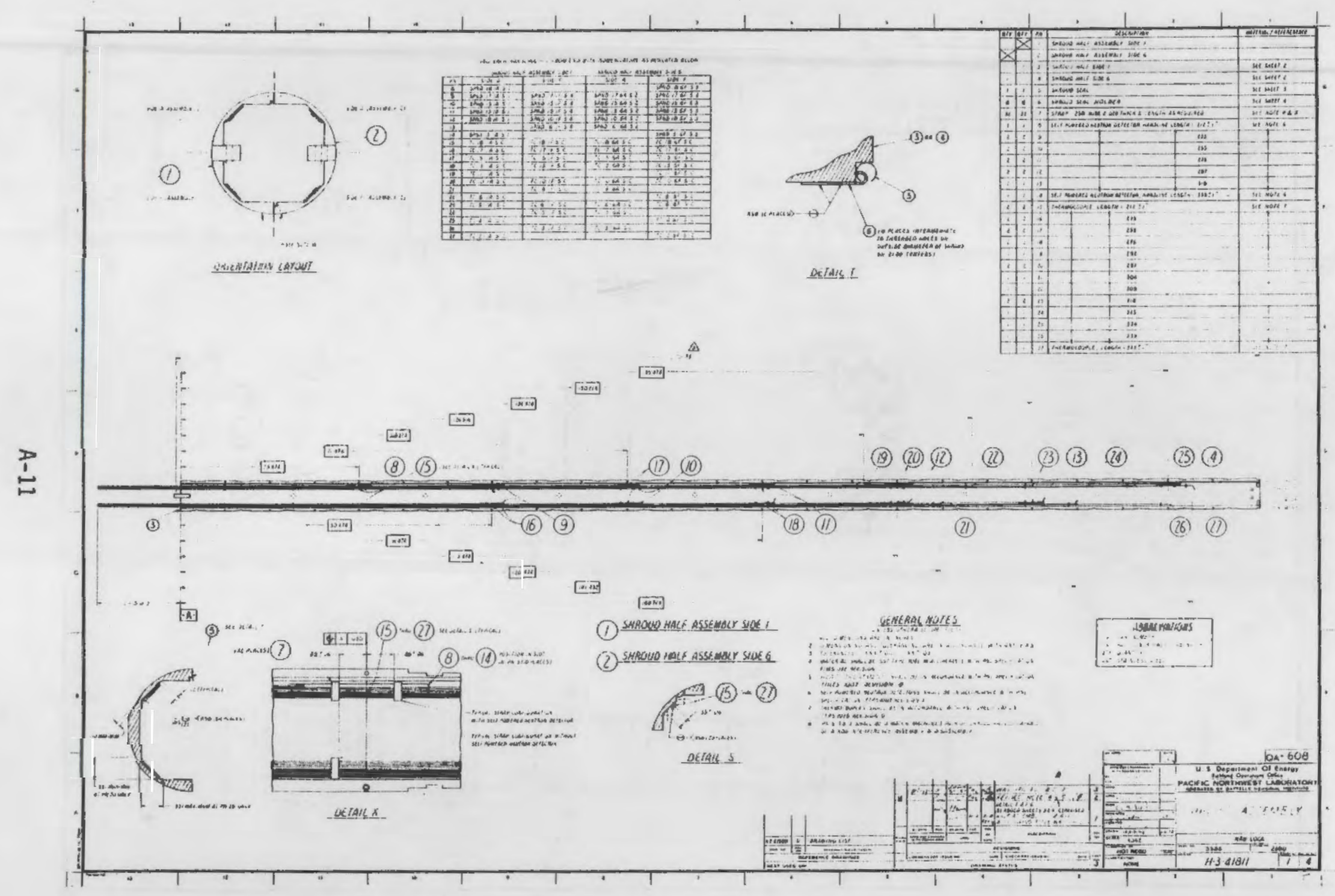




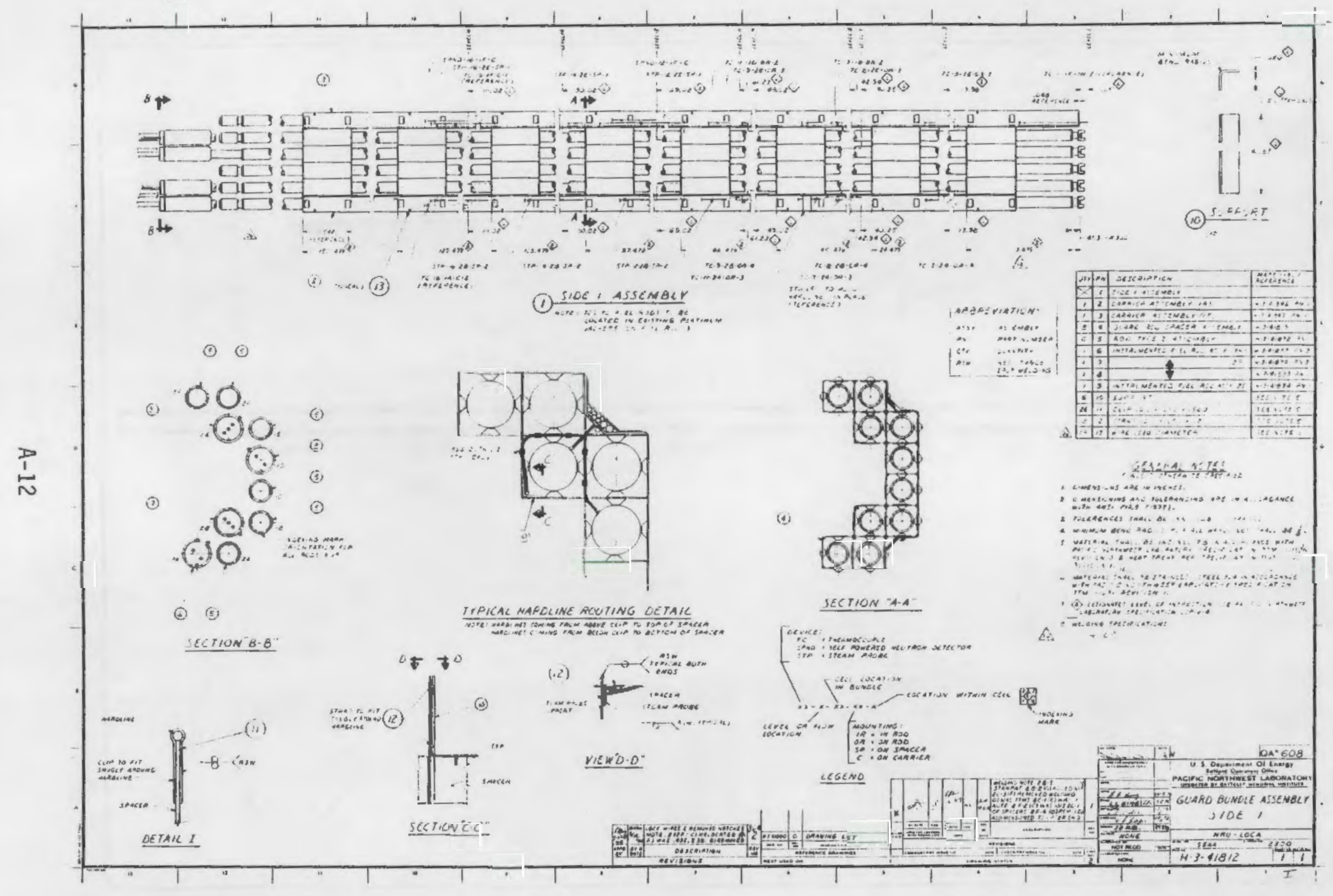




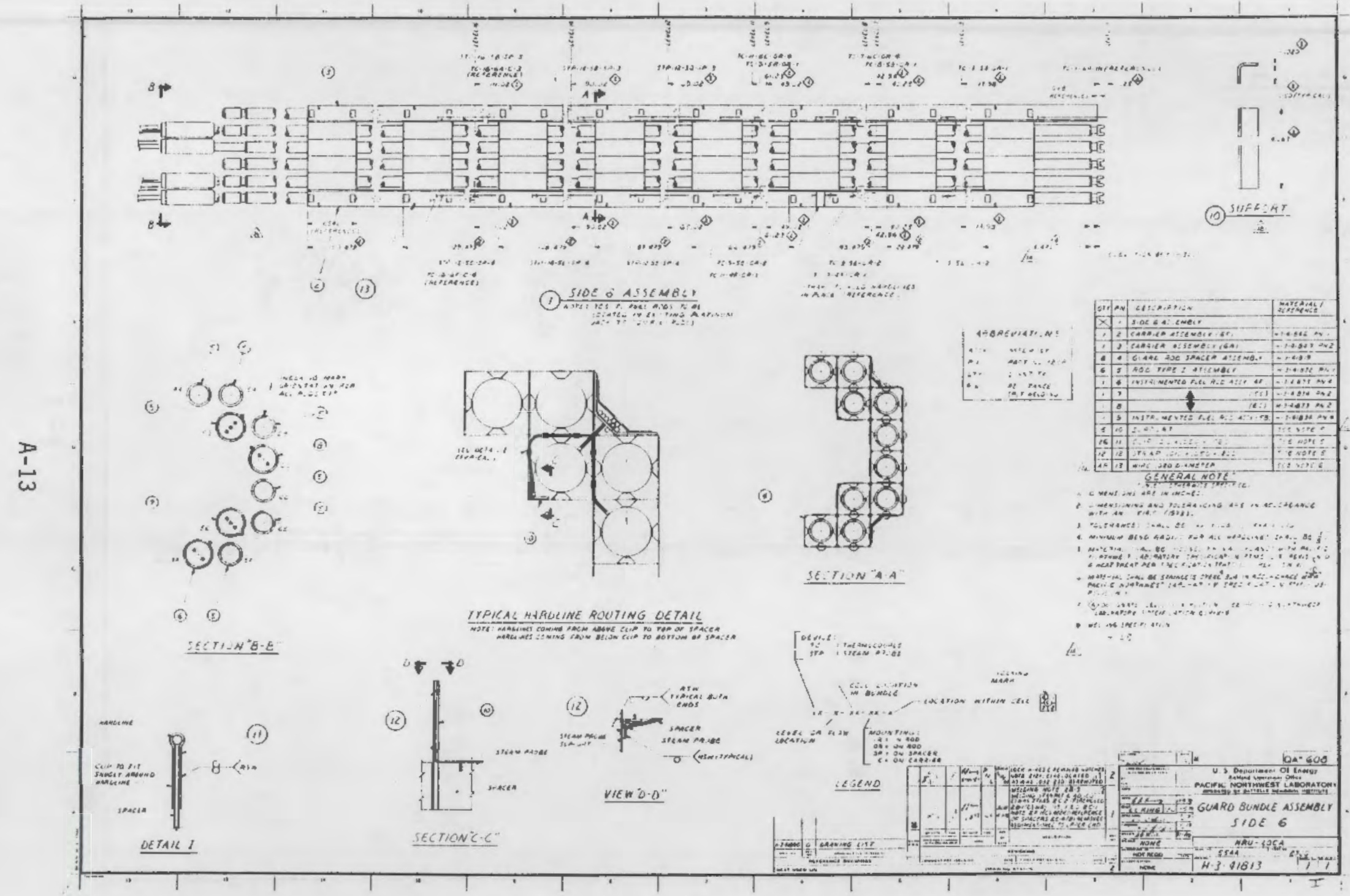




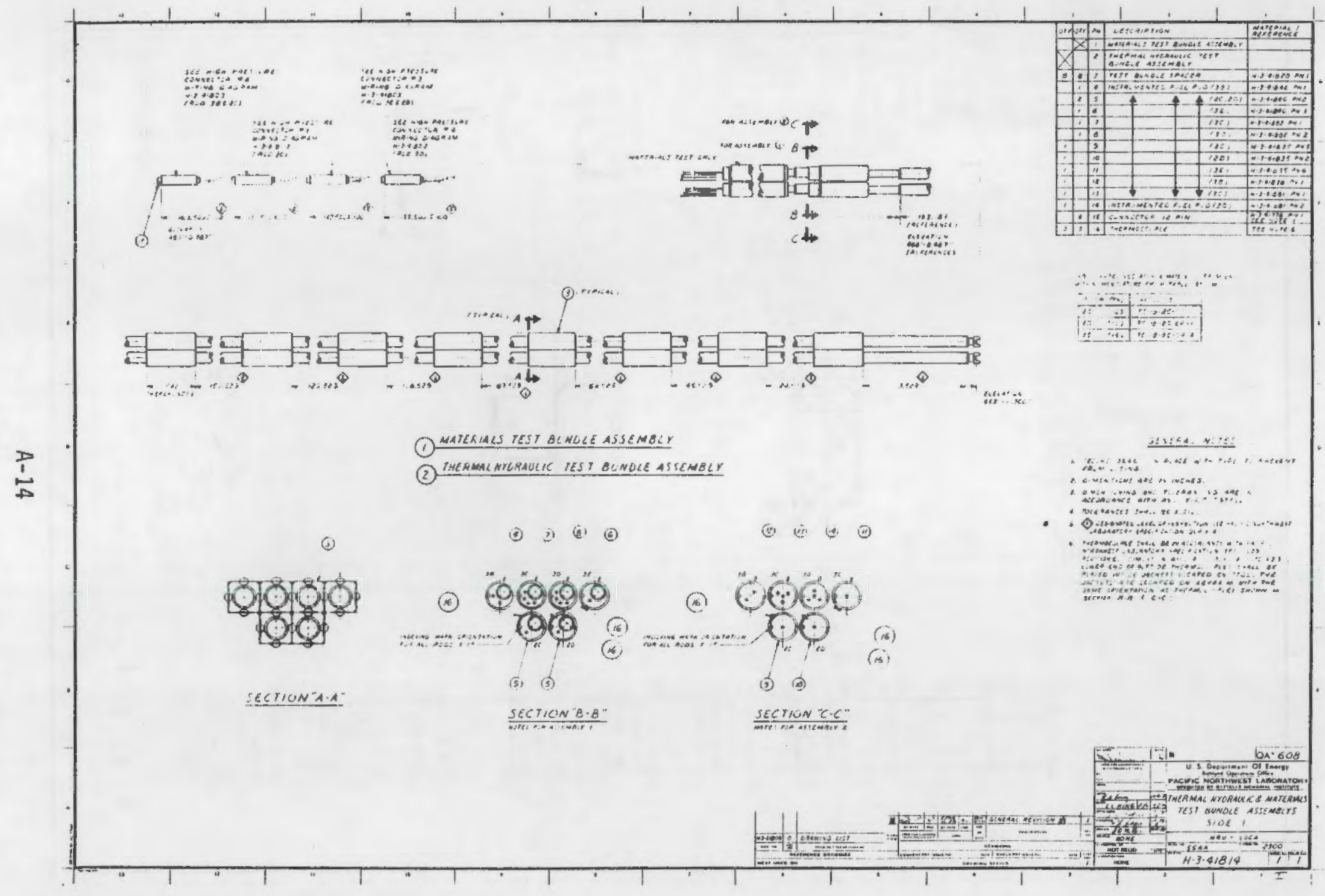




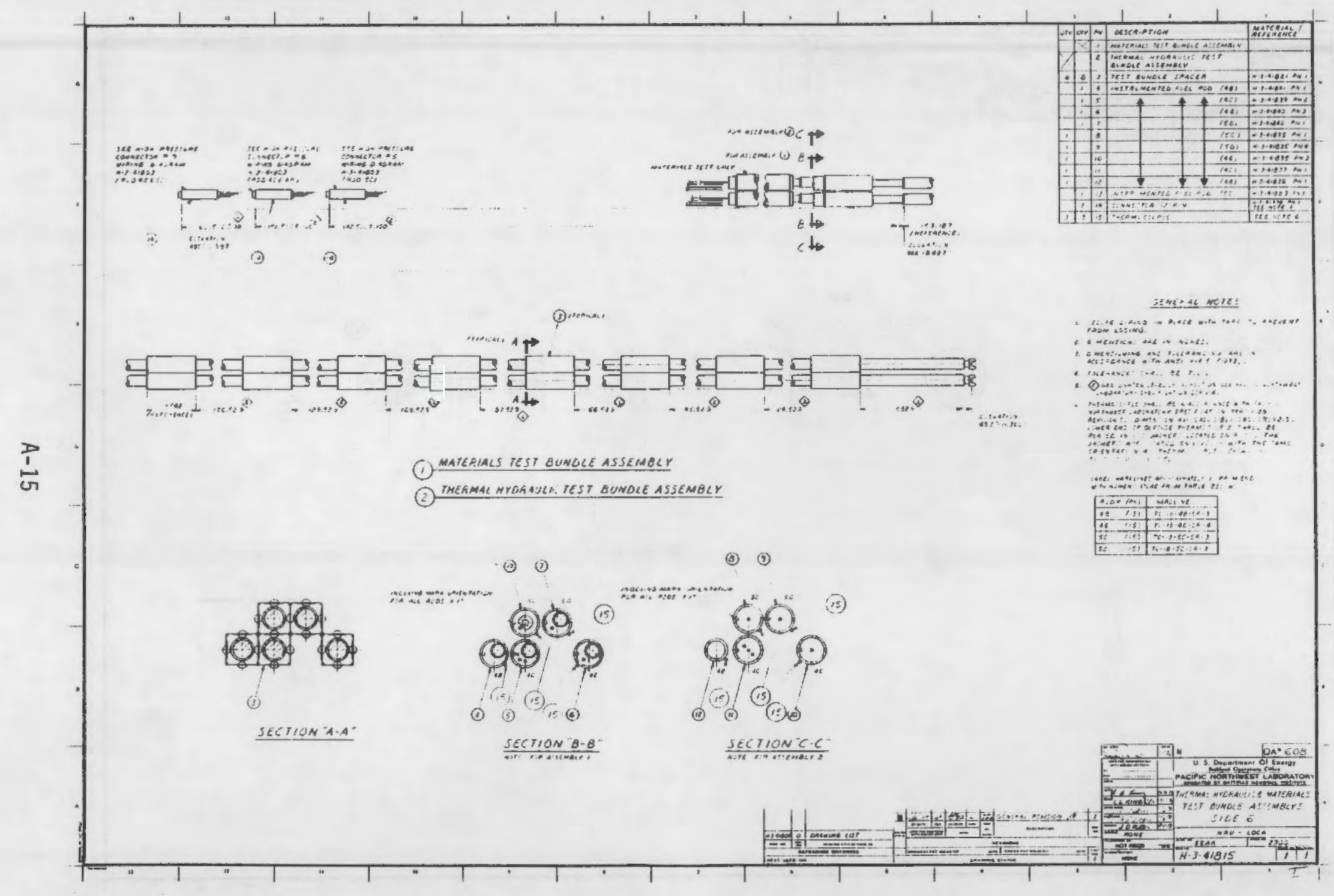




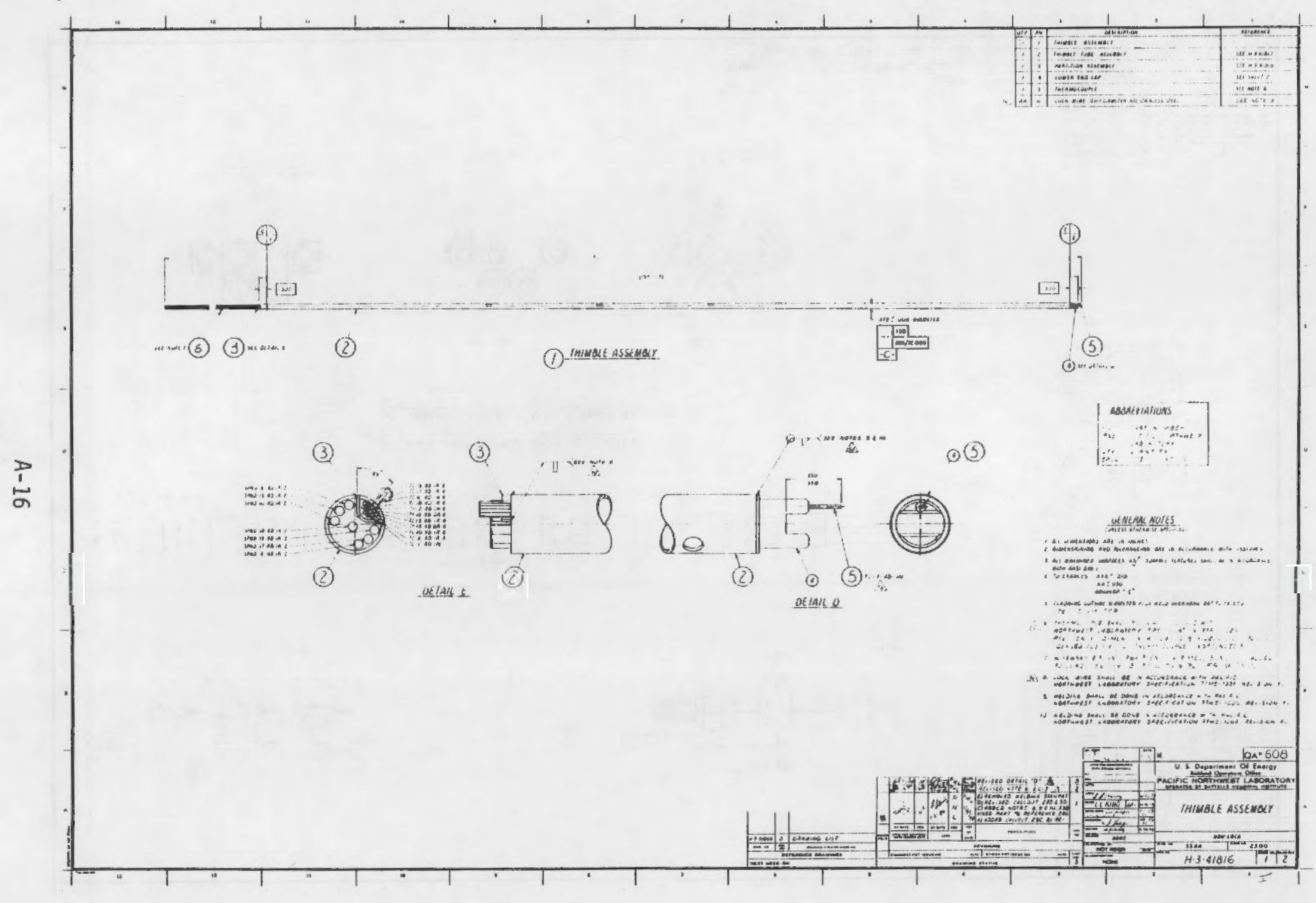




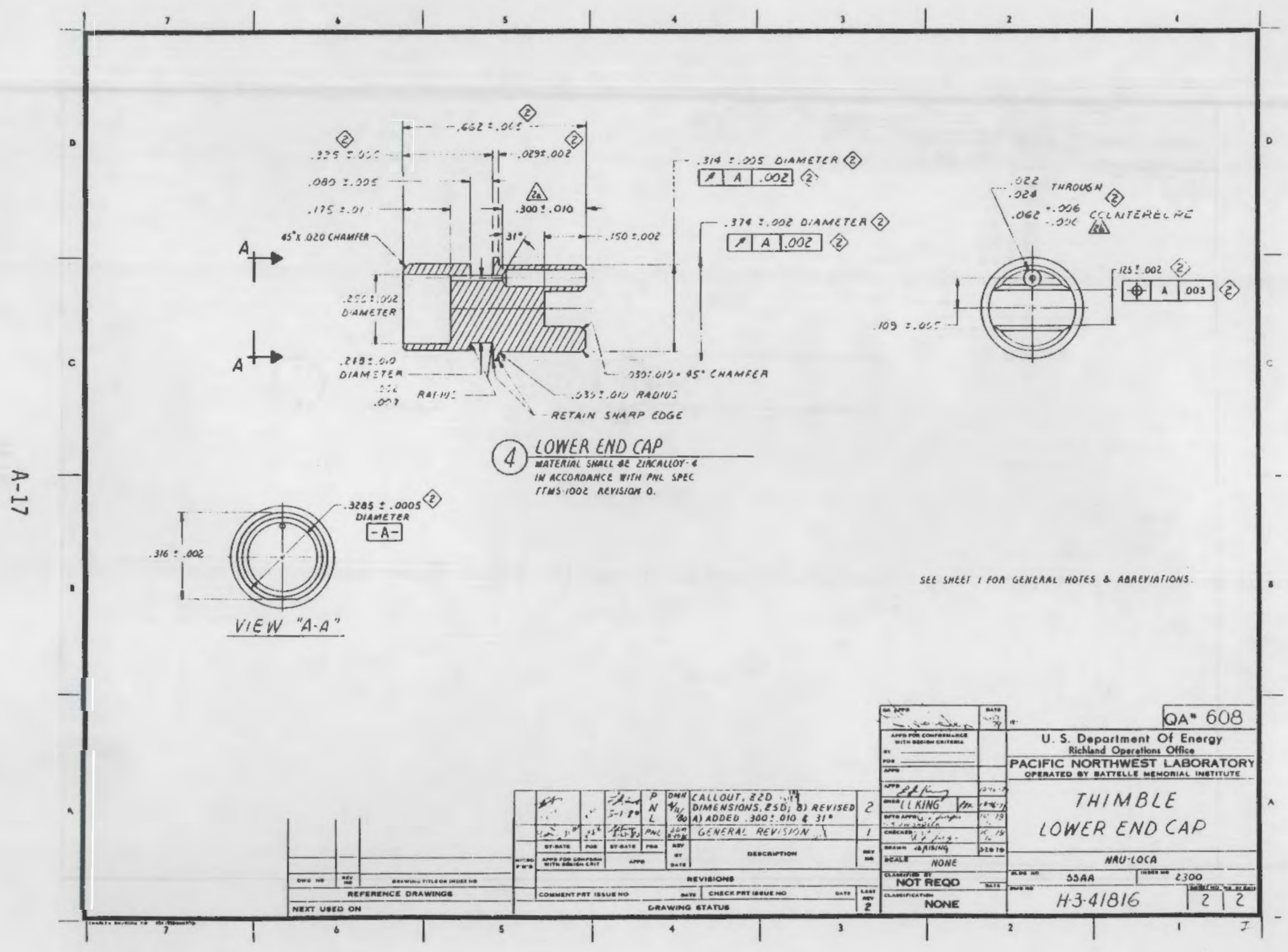




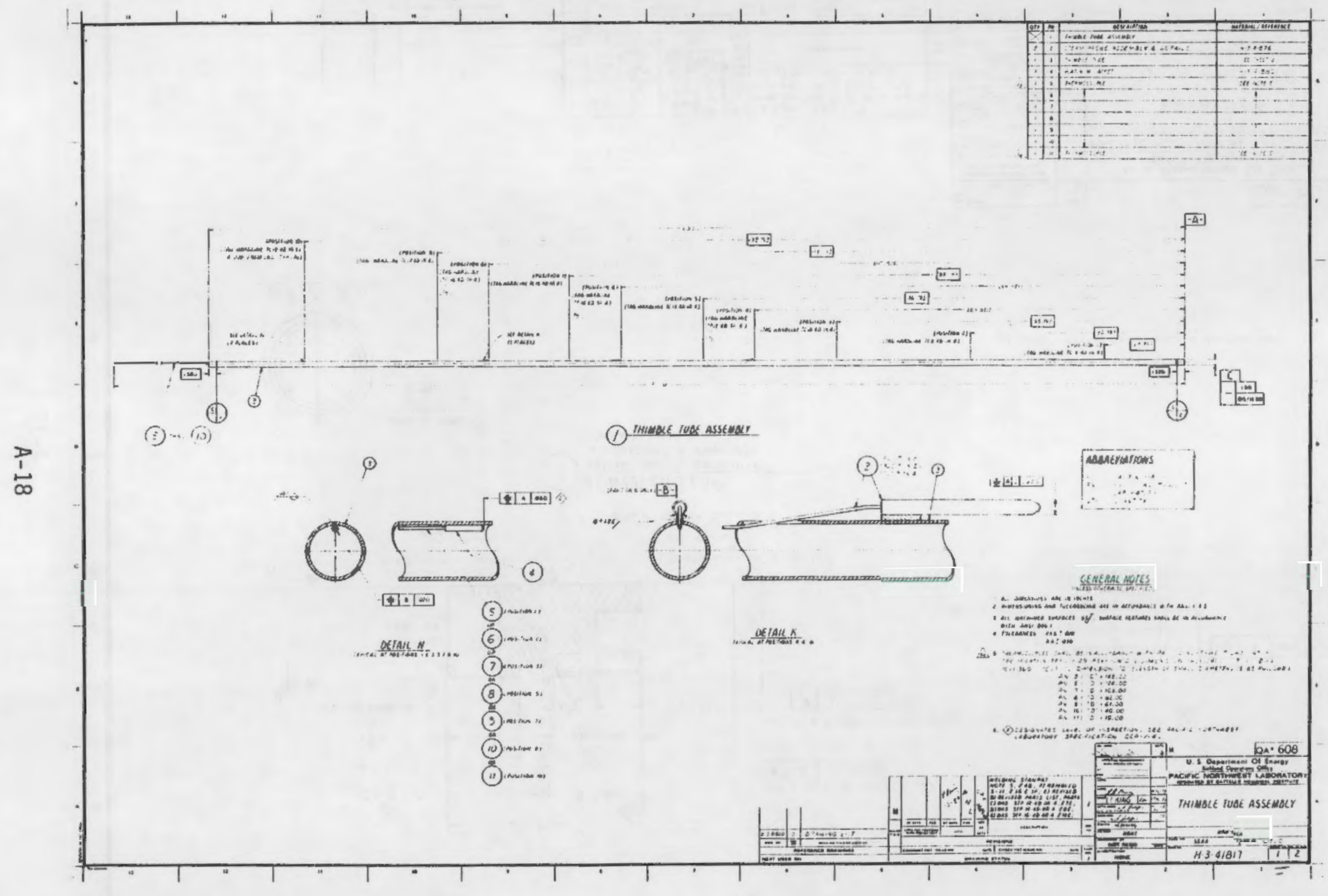




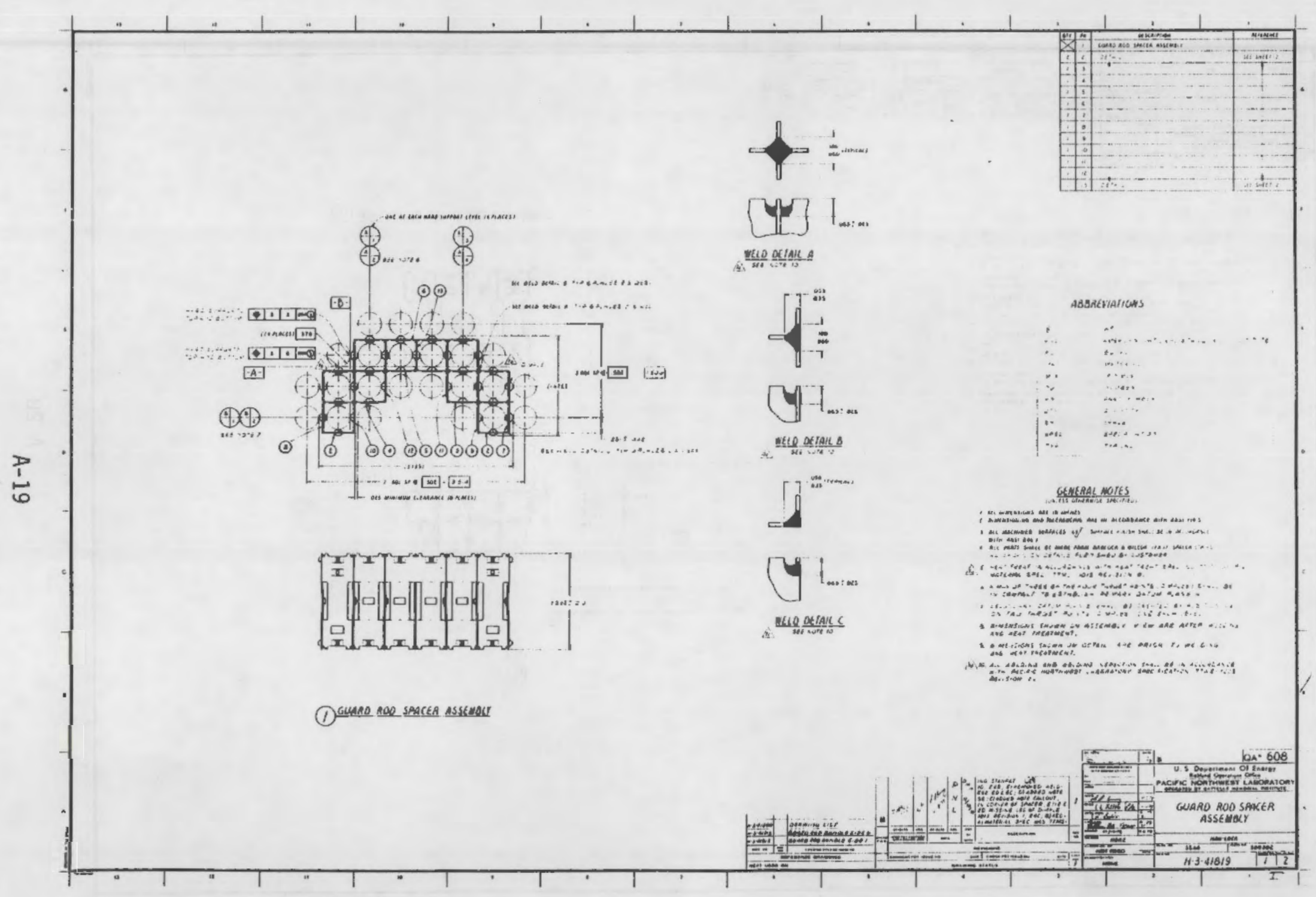




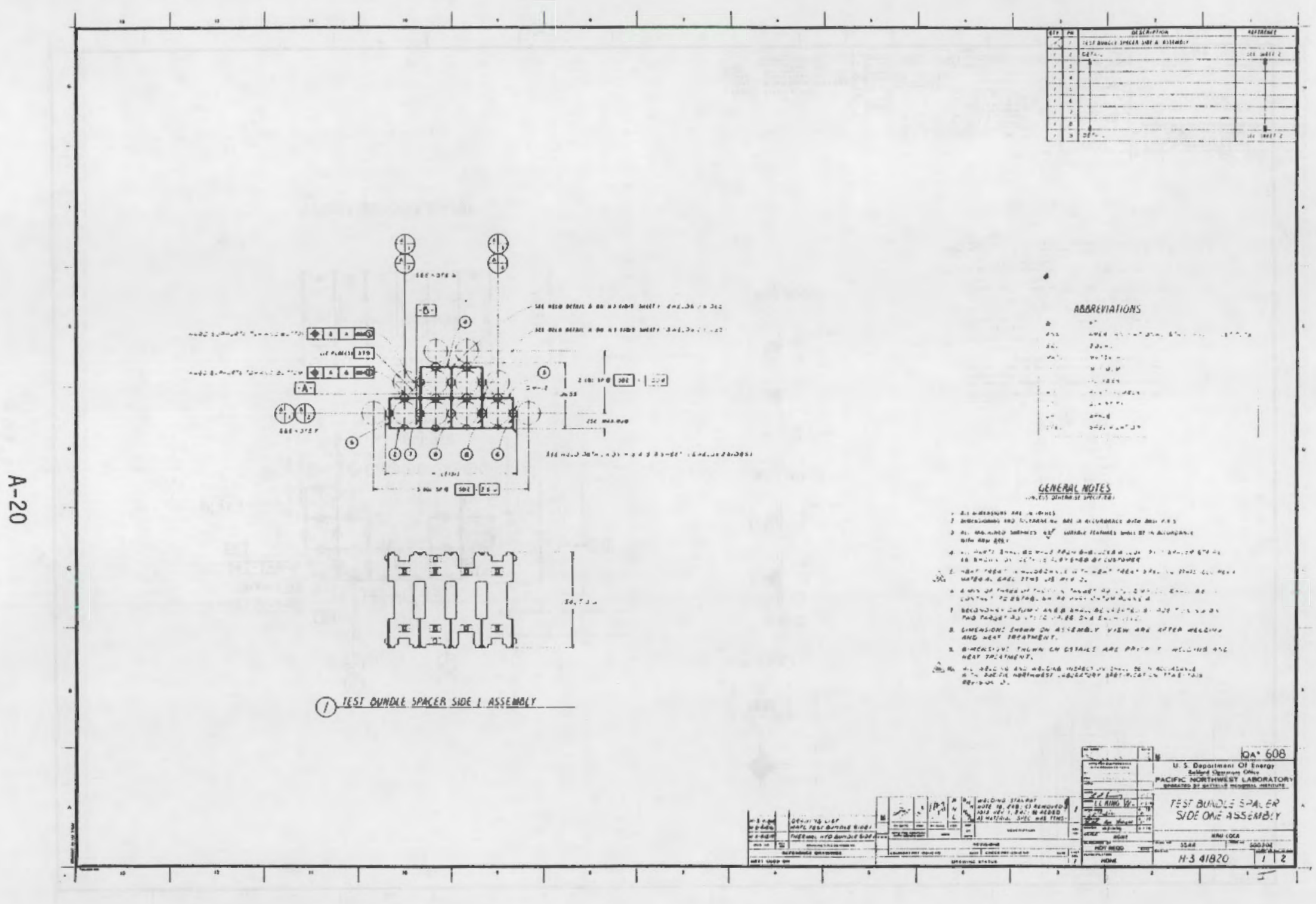




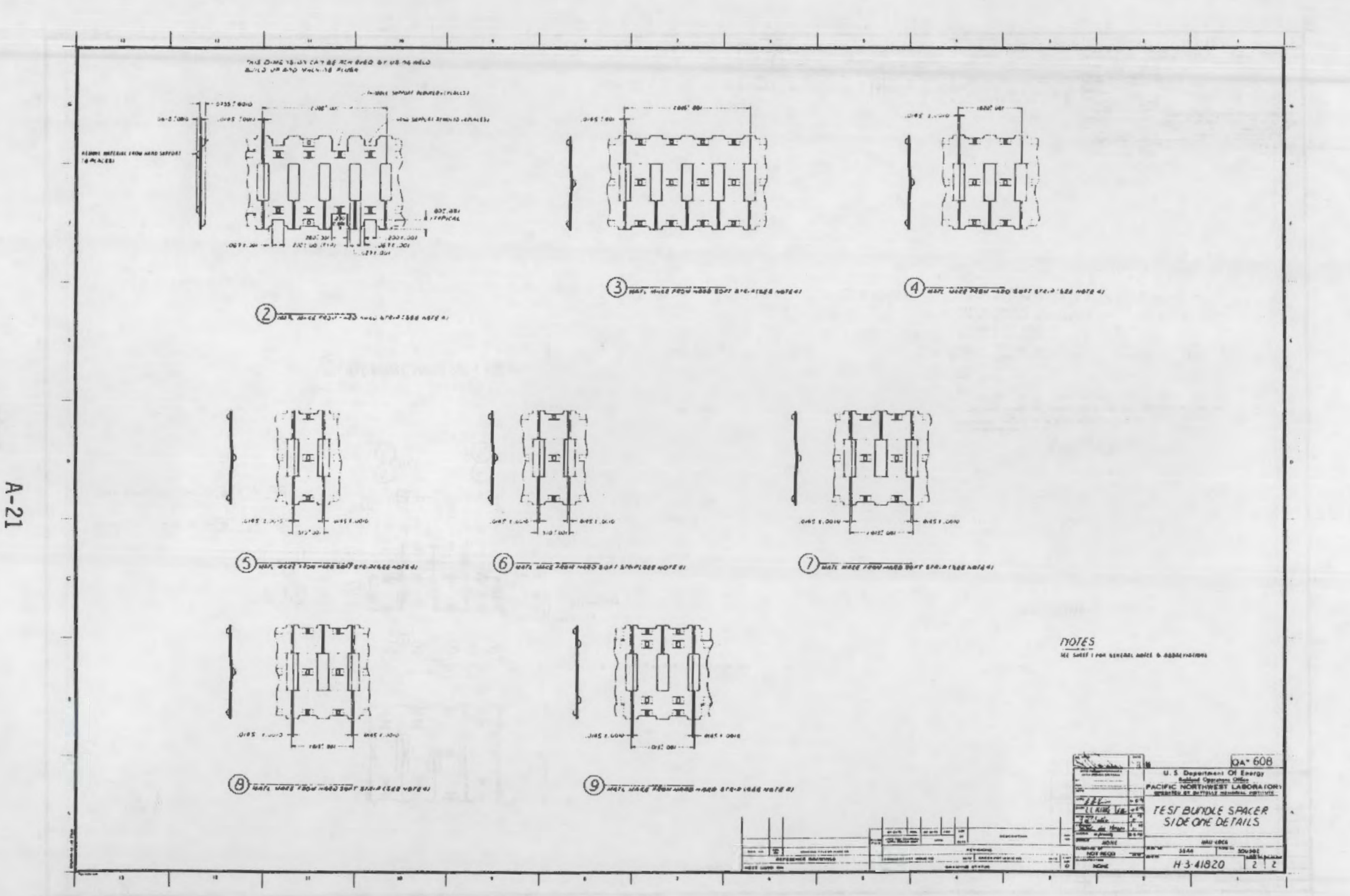




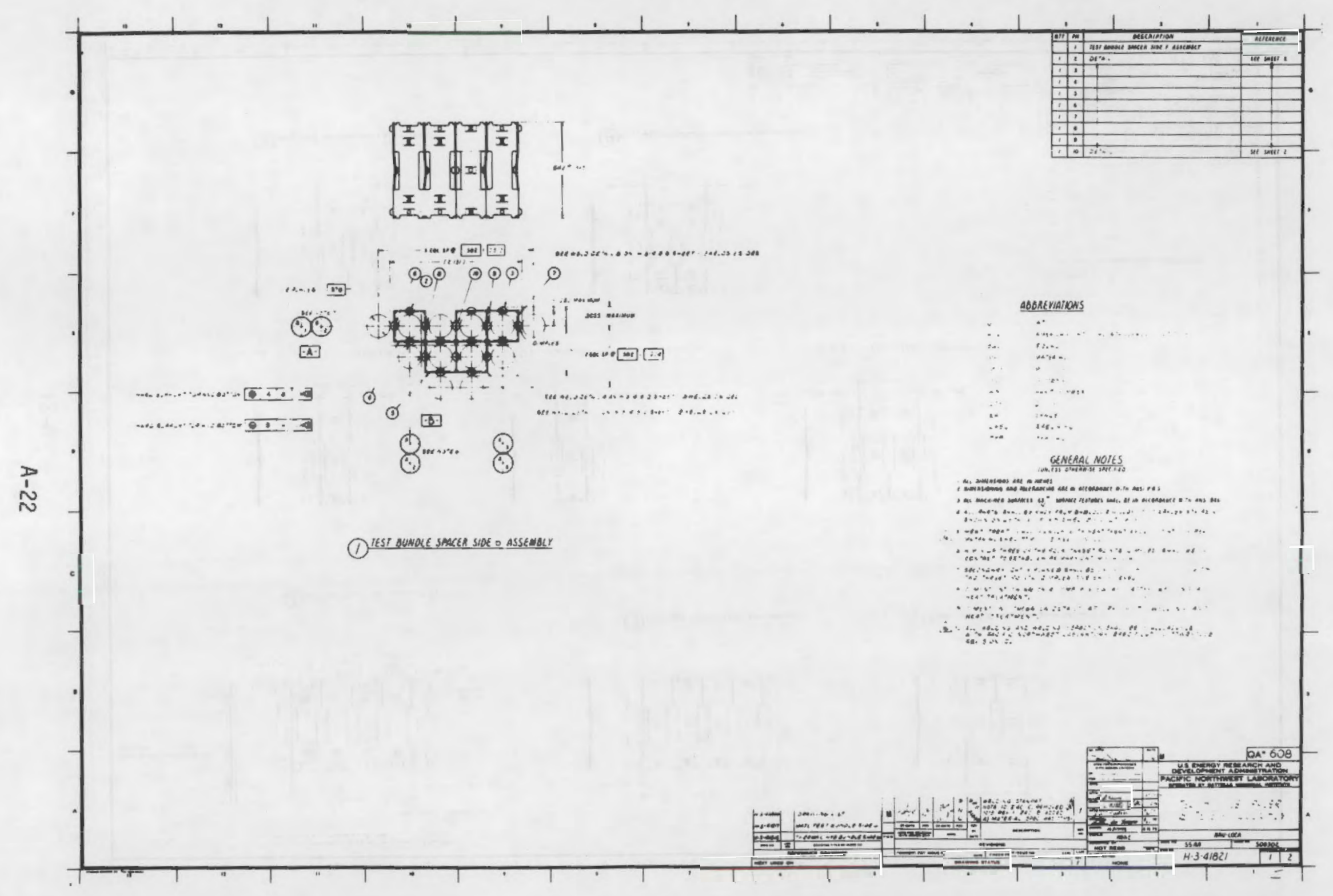




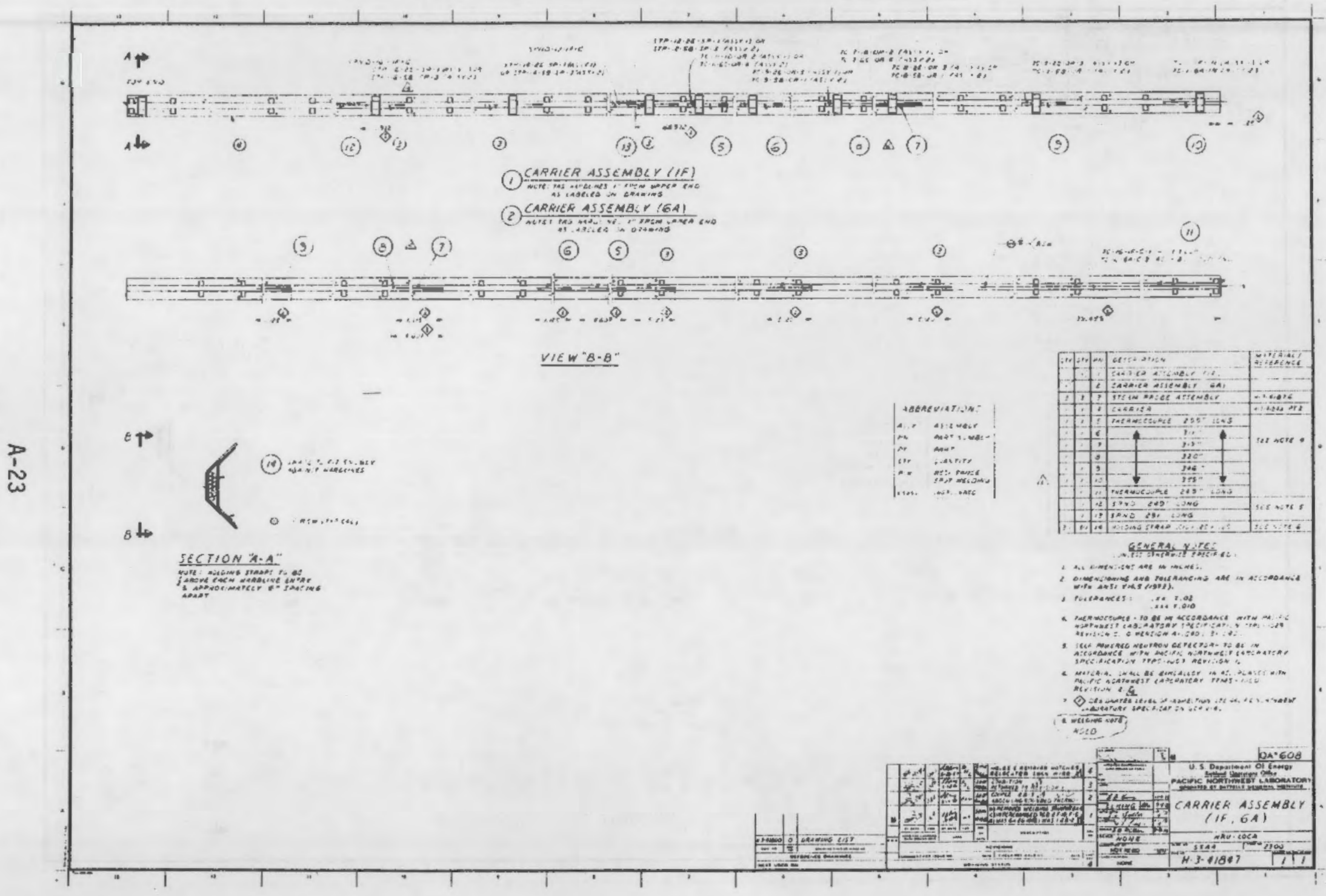




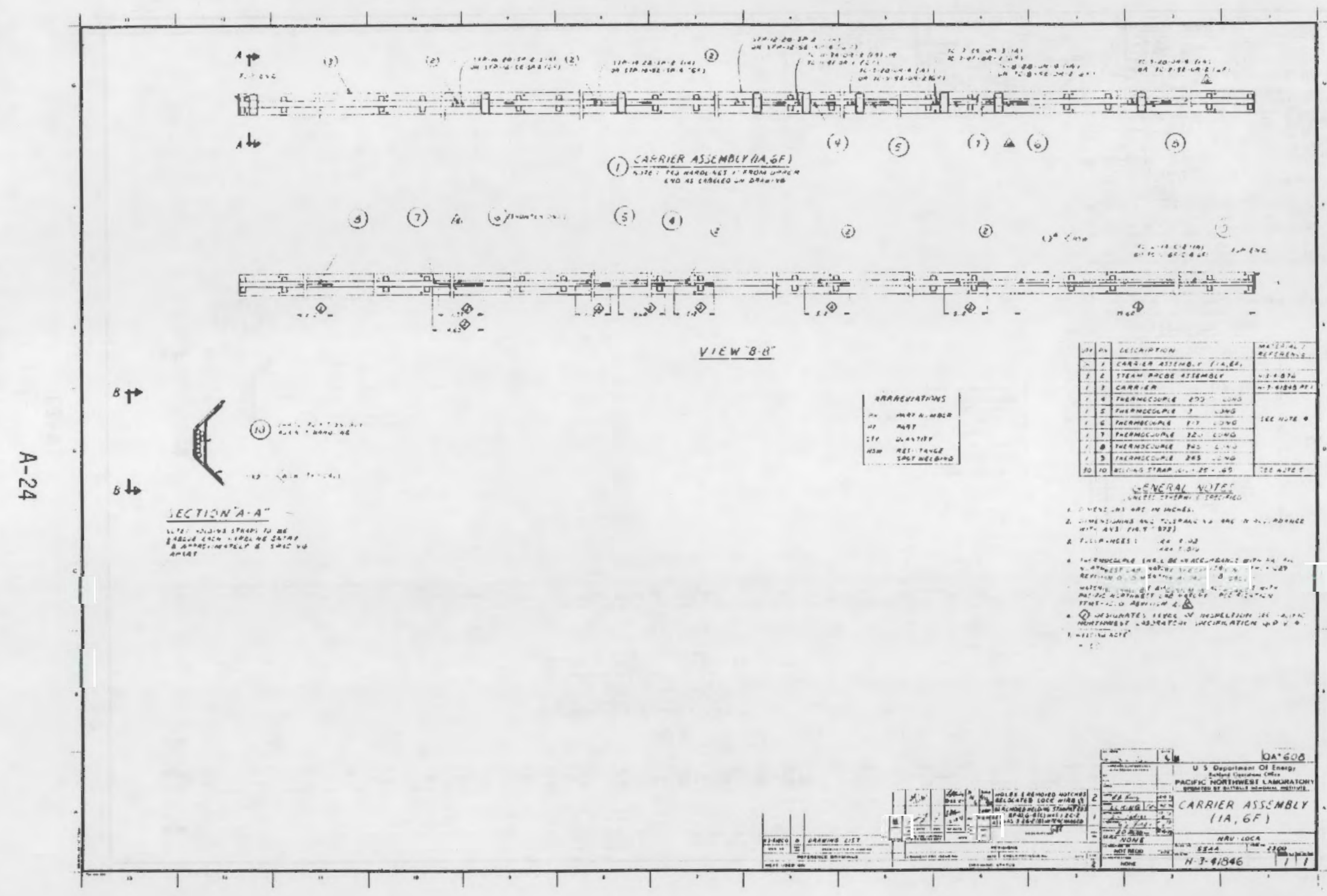




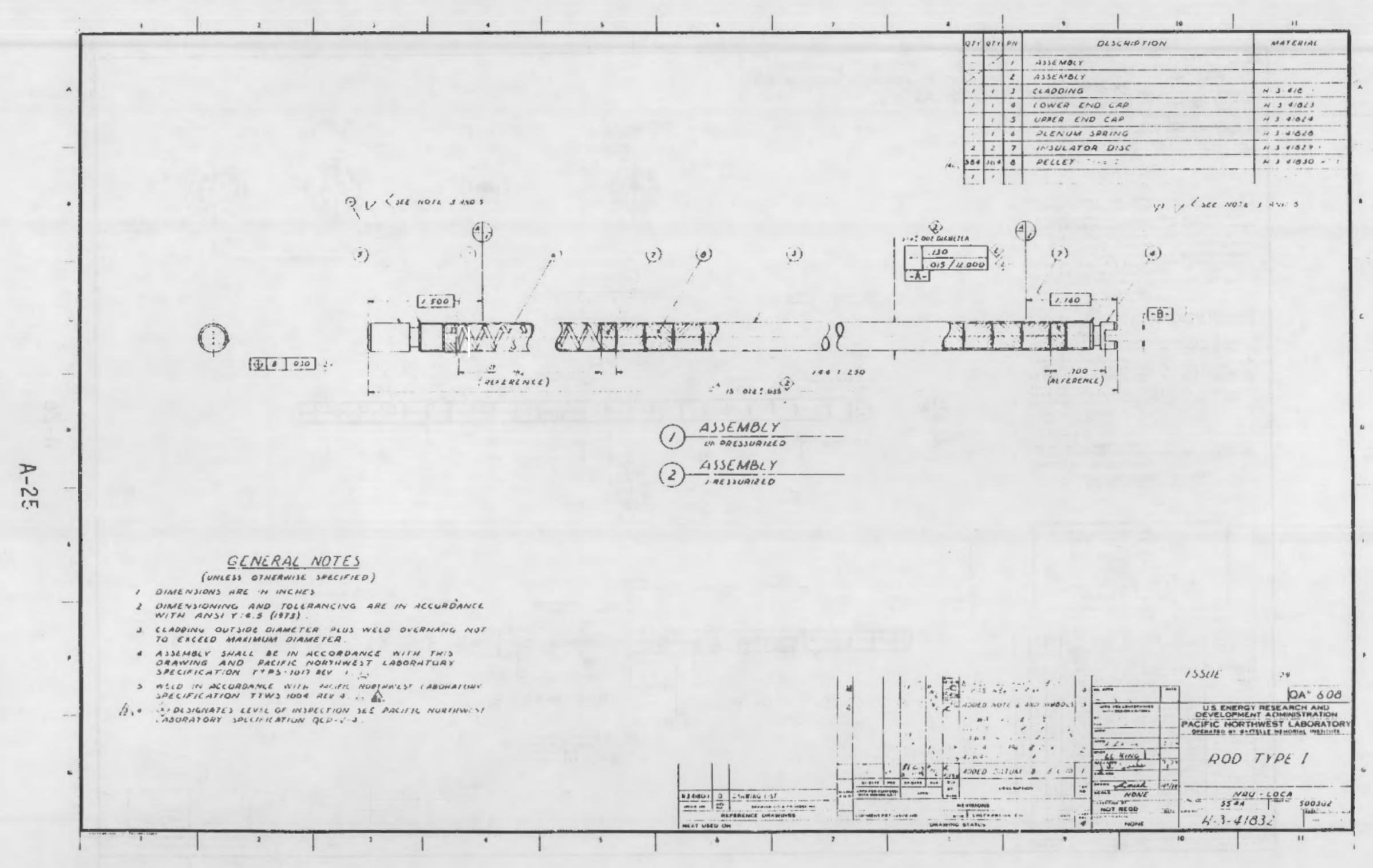




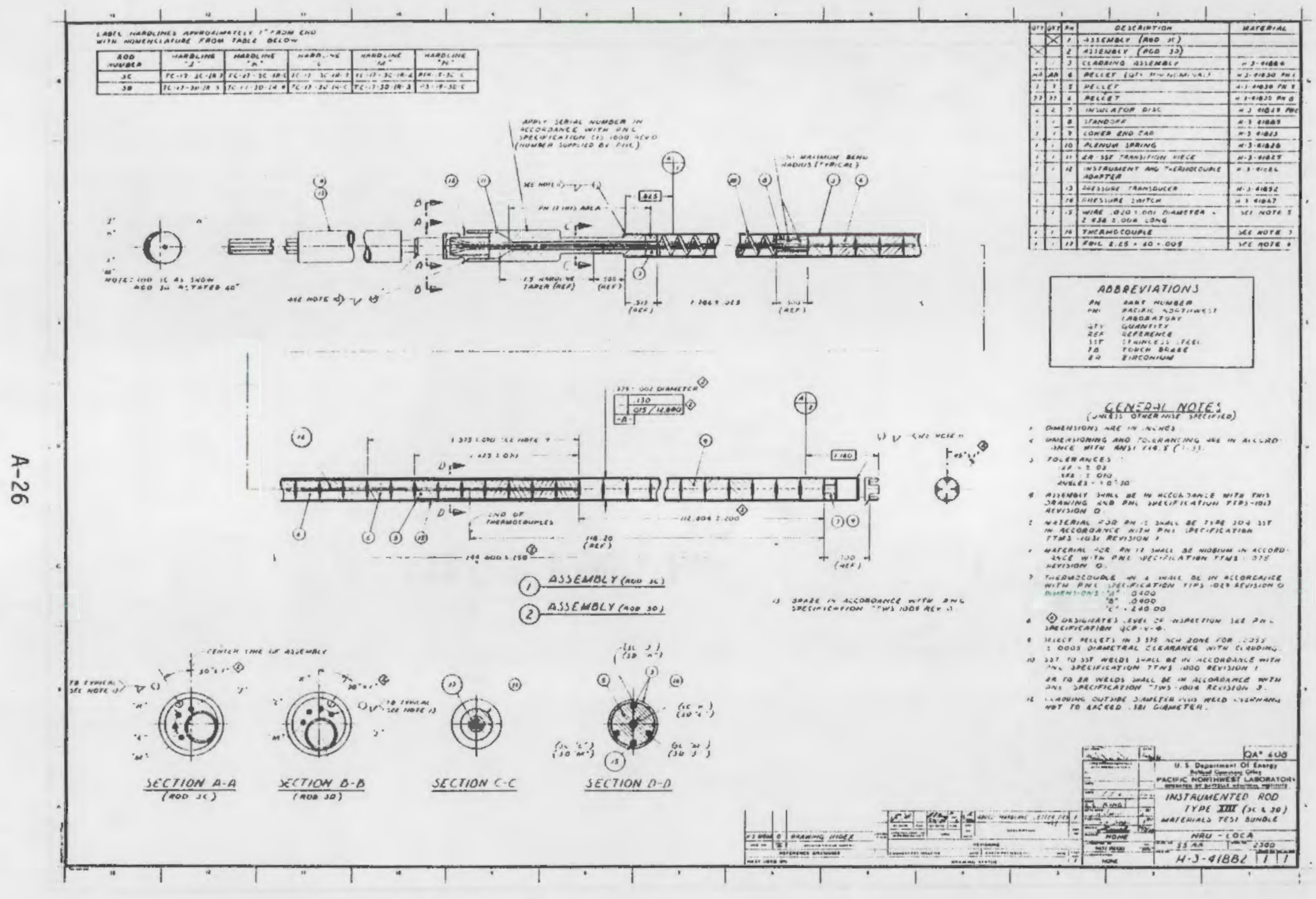




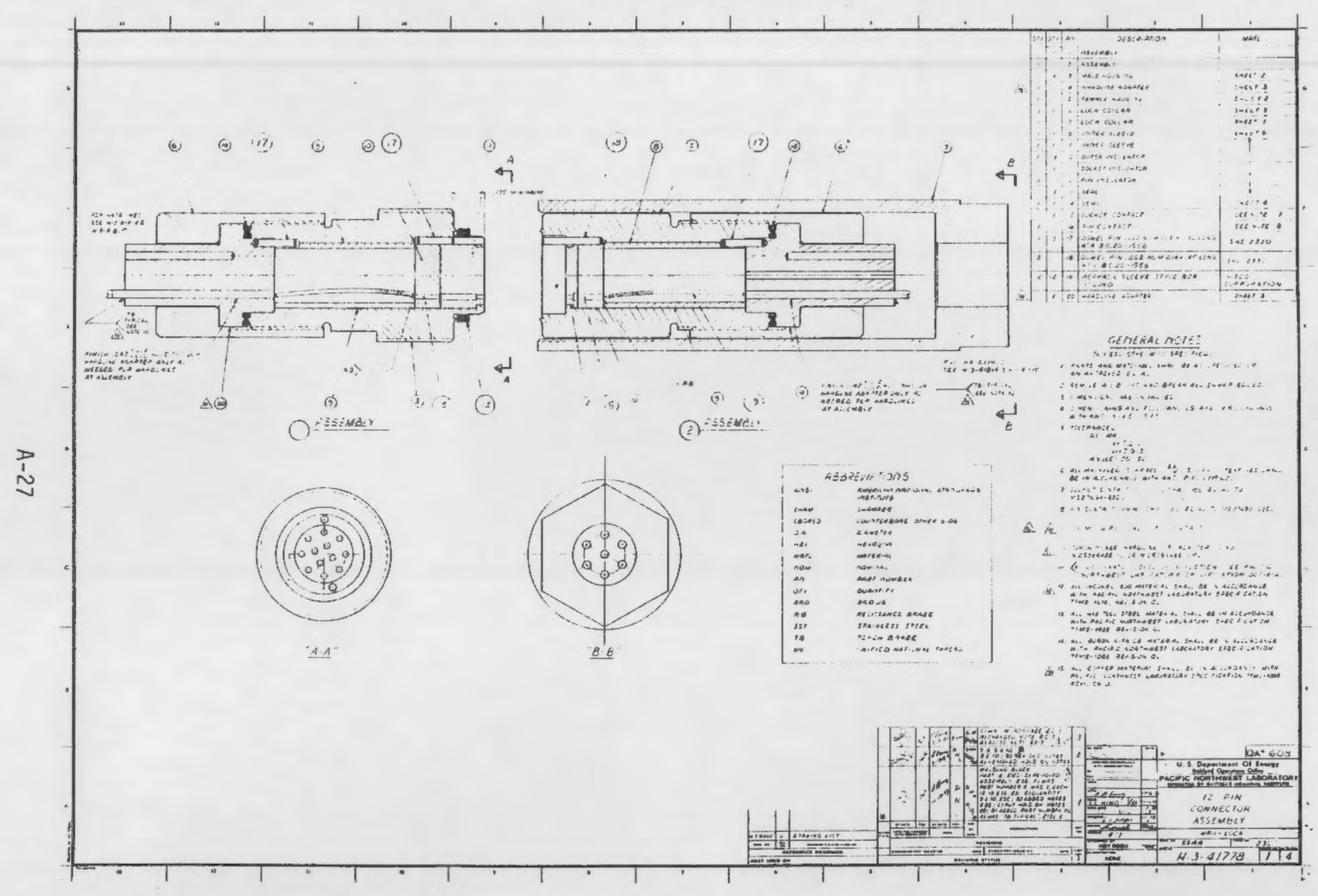



APPENDIX B

MATERIALS SPECIFICATIONS 
MATERIAL SPECIFICATIONS

Specification

TTMS-1000 Rev 2

TTMS-1001 Rev 2

TTMS-1002 Rev

ITMS-101

TTMS-1015

Rev 1

Rev 0

TTMS-1016 Rev 0

TMS-1031 Rev

TTMS-1032 Rev

TTMS-1033 Rev 1

TTMS-1035 Rev 2

TTMS-1037 Rev 0

TTMS-1039 Rev 0

TTMS-1060 Rev 0

TTMS-1062 Rev 0

TMS-1063 Rev D

TTMS-107D Rev 0

TTMS-1075
Rev 0
Title

Zircaloy Alloy Sheet, Strip and Plate

Zirconium Alloy Seamless Tubes

Zirconium Alloy Bar, Rod and Wire Stock

Inconel $X-750$ Spring Wire

Incone 1718 Sheet, Strip, and Plate

Inconel 600 Bar and Rod

Stainless and Heat Resisting Steel Wire

Stainless Steel Plate, Sheet and Strip

Stainless Steel Bars and Shapes

Seamless Stainless Stee 1 Tubing

Precipitation Hardening Stainless Steel

H13 Tool Steel

Uranium Dioxide Powder

Boron Nitrate

Aluminum 0xide Powder

Wrought Platinum

Niobium Alloy Strip, Sheet, Foil and Plate
Page Number

$B-2$

$B-3$

B-5

B-6

B-7

B-8

B-9

B-10

B- 11

B- 12

$B+13$

B- 14

B-15

B-27

B-28

B-32

B-33 
TTMS-1000, Rev 2

$$
\begin{gathered}
\text { Zircaloy ATloy Sheet, Strip, and Plate } \\
\text { C. Nealley }
\end{gathered}
$$

1.0 SCOPE: This material specification describes the materiat requirements for zircaloy alloy sheet, strip, and plate.

2.0 APPLICABLE DOCUMENTS: The following document forms a part of this specification.

ASTM B 352 Zirconium and Zirconium Alloy Sheet, Strip, and Plate for Nuclear Application

\subsection{MATERIAL REQUIREMENTS:}

3.1 Grade: The grade of the alloy shall be as designated on the fabrication drawing or in the ordering data.

3.2 Heat Treatment: The material shali be in the annealed condition.

4.0 TECHNICAL REQUIREMENTS:

4.1 Mechanical Properties: The mechanical properties shall conform to the requirements of ASTM B 352, for the designated grade.

4.2 Alloy Composition: The chemical anaiysis shall meet the requirements of ASTM B 352, for the designated grade.

4.3 Surface Condition: The surface condition and finish shail conform to that specified in ASTM B 352 .

5.0 QUALITY ASSURANCE:

5.1 Inspection: The sheet, strip or plate shall be visually inspected for cleanliness, workmanship, and defects.

5.2 Certification: The supplier shall provide certifications on ail tests conducted to meet the requirements of this specification. 


\section{Zirconium Alloy Seamiess Tubes}

\section{Nealley}

1.0 SCOPE: This material specification describes the requirements for zirconium alloy seamless tubes.

2.0 APPLICABLE DOCUMENTS: The following document forms a part of this specification except where modified by this specification.

ASTM B 353 Wrought Zirconium, Zirconium Alloy Seamless and Welded Tubes for Nuclear Service.

\subsection{MATERIAL REQUIREMENTS:}

3.i Grade: The grade of the alloy shall be UNS R60804, commonly designated Zircaioy-4.

3.2 Condition: The tubing shatr be cold worked to a minimum of $70 \%$ reduction and stress relieved at $500^{\circ} \mathrm{C}\left(930^{\circ} \mathrm{F}\right)$ for 4 hours.

\subsection{IECHNICAL REQUIREMENTS:}

4.1 Mechanical Properties: The minimum room temperature tensile strength shall be $483 \mathrm{MPa}(70,000 \mathrm{psi})$. The minimum room temperature yieid strength (0.2\% offset) sha 17 be $414 \mathrm{MPa}(60,000 \mathrm{psi})$. The zirconium tubes sha 11 have a minimum elongation of $14 \%$ at room temperature. Tensile tests shall be performed at $385^{\circ} \mathrm{C}\left(725^{\circ} \mathrm{F}\right)$ for information only.

4.2 Alloy Composition: The chemical analysis shall meet the requirements of ASTM B 353, Grade UNS R60804.

4.3 Surface Condition: The tubes shall be supplied with a belt ground OD and an etched ID.

4.4 Grain Size: The grain size of the recrystallized tubing shall be ASTM Size No. 7 or finer prior to final tube reduction.

4.5 U1trasonic Inspection: Uitrasonic inspection shall be made as soecified in ASTM B 353. The inspection technique shall detect a longitudinal notch $1.6 \mathrm{~mm}(0.062 \mathrm{in.})$ in length by $0.06 \mathrm{mrn}(0.002 \mathrm{in.})$ in width and depth on the ID and on the 0D; and shall detect a 
transverse notch $5 \mathrm{~mm}(0.187 \mathrm{in.})$ in length by $0.06 \mathrm{~mm}(0.002 \mathrm{in.})$ in width and depth on the ID and the OO of the standard sample.

4.6 0xygen Content: The amount of oxygen shall be determined by analyzing samples from two finished tubes. Oxygen content shall not exceed $1600 \mathrm{ppm}$.

4.7 Corrosion Properties: The corrosion properties shall be determined per paragraph 11.2 .1 of ASTM B 353.

4.8 Hydride Orientation: The hydride orientation ratio shal? not exceed 0.30 in accordance with the requirements of Appendix A2 of ASTM B 353.

\subsection{QUALITY ASSURANCE:}

5.1 Inspection: Each tube shall be visually inspected for cleanliness, workmanship, and defects. Each tube shall be identified with an electro etched number one inch from one end. Analog test charts showing 00 , ID and wall thickness dimensiois shall be furnished for each tube. The orientation of the test chart shall be indexed to the electro etched number. A11 analog charts, test results and certifications will be delivered with the rubing.

5.2 Certification: The manufacturer shall provide certifications on the starting material and on all tests made to meet the requirements of this specification. 
TTMS-1002, Rev 0

\author{
Zirconium Alloy Bar, Rod, and Wire Stock \\ C. Nealley
}

1.0 SCOPE: This material specification describes the requirements for zirconium alloy bar stock used in fabricating test train components.

2.0 APPLICABLE DOCUMENTS: The following document forms a part of this specification except where modified by this specification.

ASTM B 351 Hot-Rolled and Cold-Finished Zirconium, Zirconium Alloy Bars, Rod, and Wire for Nuclear Application (latest edition).

\title{
3.0 TECHNICAL SPECIFICATIONS:
}

3.1 Grade: The grade of the alloy shall be UNS R60804, commonly designated Zircaloy-4.

3.2 Condition: The material shall be in the fully annealed condition.

3.3 Mechanical Properties: The mechanical properties shall conform to the requirements of ASTM B 351.

3.4 Alloy Composition: The chemical analys is shall meet the requirements of ASTM B 351, Grade UNS R60804.

3.5 Grain Size: The grain size of the bars shall be equal to ASTM Size No. 7 or finer.

3.6 Ultrasonic Inspection: Each bar shall be ultrasonicaliy inspected over its entire length for internal defects by a method that will detect a mutuaily agreed upon standard.

3.7 Dye Penetrant Inspection: The ends of each bar shail be dye penetrant inspected for stringers and center bursts.

4.0 QUALITY ASSURANCE:

4.1 Inspection: Each bar shall be visuaily examined for cleaniliness, workmanship, and defects.

4.2 Certification: The manufacturer shall provide certifications on a 11 tests made to meet the requirements of this specification. 
TTMS-1014, Rev 1

Inconel $X-750$ Spring Wire

C. Neailiey

1.0 SCOPE: This specification describes material requirements for Inconel $x-750$ spring temper wire used in fabricating pienum compression springs for fuel rods.

2.0 APPLICABLE DOCUMENTS: The following document: forms a part of this specification except where modified by this specification.

AMS 56998 Alloy Wire, Corrosion and Heat: Resistant, Revised 1-15-63.

3.0 TECHNICAL REQUIREMENTS:

3.1 Form: The wire shall be cold drawn, round wire.

3.2 Composition: The composition shall conform to the requirements of AMS 5699B.

3.3 Mechanical Properties: The wire shall have a minimum tensile strength of $1000 \mathrm{MPa}(150,000 \mathrm{psi})$.

3.4 Wrapping: Wire shall withstand, without cracking, wrapping at room temperature for 5 full, closeiy spaced turns around a diameter equal to 3 times the nominal diameter of the wire.

3.5 Condition: The wire condition shall con*orm to the requirements of AMS 569gB. In addition, the wire shall be uniform in quality and free from pits, abrasions, kinks, twists, scrapes, splits, pipes, cold shuts, and other injurious imperfections.

3.6 Surface: The surface shall have a clean, smooth finish that is free from grease, oil, drawing lubricants, anc other contaminants.

\subsection{QUALITY ASSURANCE:}

4.1 Inspections and Reports: Inspections and reports shalt be in conformance with AMS 5699B.

4.2 Certification: Certifications shall be in compliance with AMS 56998 . 
Inconel 718 Sheet, Strip, and Plate C. Nealley

1.0 SCOPE: This material specification describes the material requirements for Inconel 718 Sheet, Strip, and Plate.

2.0 APPLICABLE DOCUMENTS: The following document forms a part of this specification.

AMS 5596C Alloy Sheet, Strip, and Plate, Corrosion and Heat

Resistant

\subsection{MATERIAL REQUIREMENTS:}

3.1 Grade: The grade of the alloy shall be Inconel 718 .

3.2 Heat Treatment: The material shall be solution heat treated at $954^{\circ} \mathrm{C} \pm 14^{\circ} \mathrm{C}\left(1750^{\circ} \mathrm{F} \pm 25^{\circ} \mathrm{F}\right)$, as specified in AMS $5596 \mathrm{C}$.

\subsection{TECHNICAL REQUIREMENTS:}

4.1 Mechanical Properties: The mechanical properties shal 1 conform to the requirements of AMS $5596 \mathrm{C}$.

4.2 Alloy Composition: The chemical analysis shall meet the requirements of AMS $5596 \mathrm{C}$.

4.3 Surface Condition: The surface condition and finish shall conform to that specified in AMS $5596 C$.

\subsection{QUALITY ASSURANCE:}

5.1 Inspection: The sheet, strip or plate shall be visually inspected for cleanliness, workmanship, and defects.

5.2 Certification: The supplier shall provide certifications on all tests conducted to meet the requirements of this specification. 
Inconel $600 \mathrm{Bar}$ and Rod

C. Nealley

1.0 SCOPE: This material specification describes the material requirements for Inconet 600 bar and rod.

2.0 APPLICABLE DOCUMENTS: The following document: forms a part of this specification.

ASTM B 166 Nickel-Chromium Alloy (UNS N06600) Rod and Bar

\subsection{MATERIAL REQUIREMENTS:}

3.1 Grade: The grade of the alloy shall be Inconel 600 .

3.2 Heat Treatment: The material shall be annealed.

4.0 TECHNICAL REQUIREMENTS

4.1 Mechanical Properties: The mechanical properties shall conform to the requirements of ASTM B 166.

4.2 Alloy Composition: The chemical anaiysis shall meet the requirements of ASTM B 166 .

4.3 Surface Condition: The surface condition and finish shall conform to that specified in ASTM B 166.

\subsection{QUALITY ASSURANCE:}

5.1 Inspection: The rod or bar shall be visually inspected for cleantiness, workmanship and defects.

5.2 Certification: The supplier shall provice certifications on all tests conducted to meet the requirements of this specification. 
TTMS-1031, Rev 1

\author{
Stainless and Heat-Resisting Steel Wire \\ c. Nealiey
}

1.0 SCOPE: This material specification describes the material requirements for stainiess and heat-resisting wire.

2.0 APPLICABLE DOCUMENTS: The following document forms a part of this specification.

ASTM A 580 Stainless and Heat-Resisting Steel Wire

3.0 MATERIAL REQUIREMENTS:

3.1 Grade: The grade of the ailoy shall be as designated on the fabrication drawing or in the ordering data.

3.2 Heat Treatment: The material shali be in the solution heat treated condition. This condition is specified in ASTM A 580 as Condition A.

4.0 TECHNICAL REQUIREMENTS:

4.1 Mechanical Properties: The mechanical properties shall conform to the requirements of ASTM A 580, for the designated grade.

4.2 Alloy Composition: The chemical analysis shall meet the requirements of ASTM A 580, for the designated grade.

4.3 Surface Condition: The surface condition and finish shall conform to that specified in ASTM A 580 .

5.0 QUALITY ASSURANCE:

5.1 Inspection: The wire shall be visually inspected for cleanliness, workmanship, and defects.

5.2 Certification: The supplier shall provide certifications on all tests conducted to meet the requirements of this specification. 
TTM5-1032, ReV i

\author{
Stainless Steel Plate, Sheet and Strip \\ c. Nealley
}

1.0 SCOPE: This material specification describes the material requirements for stainless steel piate, sheet or strip.

2.0 APPLICABLE DOCUMENTS: The following document forms a part of this specification.

ASTM A 240 Heat Resisting Chromium and Chromium-Nickel Stainless Steel Plate, Sheet and Strip for Fusion Welded Unfired Pressure Vessels.

3.0 MATERIAL REQUIREMENTS:

3.1 Grade: The grade of the alloy shall be designated on the fabrication drawing or in the ordering data.

3.2 Heat Treatment: The material shall be : $n$ the solution heat treated condition.

4.0 TECHNICAL REQUIREMENTS:

4.1 Mechanical Properties: The mechanical froperties shall conform to the requirements of ASTM A 240, for the designated grade.

4.2 Alloy Composition: The chemical analys is shall meet the requirements of ASTM A 240, for the designated grade.

4.3 Surface Condition: The surface condition and finish shall conform to that specified in ASTM A 240.

5.0 QUALITY ASSURANCE:

5.1 Inspection: The plate, sheet or strip shall be visually inspected for cleanliness, workmanship and defects.

5.2 Certification: The supplier shall provide certifications on ail tests conducted to meet the requirements of this specification. 


\author{
Stainless Steel Bars and Shapes \\ c. Neatiey
}

1.0 SCOPE: This material specification describes the material requirements for stainless steel bars or shapes.

2.0 APPLICABLE DOCUMENTS: The following document forms a part of this specification.

ASTM A 479 Stainless and Heat-Resisting Steel Bars and Shapes for Use in Boilers and Other Pressure Vesseis.

3.0 MATERIAL REQUIREMENTS:

3.1 Grade: The grade of the alloy shall be as designated on the fabrication drawing or in the ordering data.

3.2 Heat Treatment: The material shall be in the solution heat treated condition, as specified in ASTM A 479.

\title{
4.0 TECHNICAL REQUIREMENTS:
}

4.1 Mechanical Properties: The mechanical properties shall conform to the requirements of ASTM A 479, for the designated grade.

4.2 Alloy Composition: The chemical analysis shall meet the requirements Of ASTM A 479, for the designated grade.

4.3 Surface Condition: The surface condition and finish shall conform to that specified in ASTM A 479.

5.0 QUALITY ASSURANCE:

5.1 Inspection: The bar stock or shape shall be visually inspected for cleanliness, workmanship and defects.

5.2 Certification: The supplier shall provide certifications on al1 tests conducted to meet the requirements of this specification. 


\title{
Seamless Stainless Steel rubing
}

\author{
c. Nealley
}

1.0 SCOPE: This material specification describes the material requirements for seamiess stainless steel tubing.

2.0 APPLICABLE DOCUMENTS: The following document forms a part of this specification.

ASTM A 517 Seamless Stainiess Steel Mechanical Tubing

\subsection{MATERIAL REQUIREMENTS:}

3.? Grade: The grade of the alloy shall be as designated on the fabrication drawing or in the ordering data.

3.2 Heat Treatment: The material shall be in the solution heat treated condition, as specified in ASTM A 511.

4.0 TECHNICAL REQUIREMENTS:

4.1 Mechanical Properties: The mechanical properties shalt conform to the requirements of ASTM A 511 for the designated grade.

4.2 Alloy Composition: The chemical analysis shall meet the requirements of ASTM A 511 for the designated grade.

4.3 Surface Condition: The surface conditiori and finish shall conform to that specified in ASTM A 511.

\subsection{QUALITY ASSURANCE:}

5.1 Inspection: The tubing shall be visually inspected for cleantiness, workmanship and defects.

5.2 Certification: The supplier shall provide certifications on all tests conducted to meet the requirements of this specification. 
TTMS-1037, Rev 0

$$
\begin{gathered}
\text { Precipitation Hardening Stainless Steels } \\
\text { C. Nealley }
\end{gathered}
$$

1.0 SCOPE: This material specification describes the material requirements for precipitation hardening stainless steel bars or shapes.

2.0 APPLICABLE DOCUMENTS: The following document forms a part of this specification.

ASTM A 564 Hot-Rolled and Cold-Finished Age-Hardening Stainless and Heat-Resisting Stee $\mathrm{T}$ Bars and Shapes.

\subsection{MATERIAL REQUIREMENTS:}

3.1 Grade: The grade of the alloy shall be as designated on the fabrication or in the ordering data.

3.2 Condition: The material shall be supplied in the solution annealed condition in accordance with the requirements of the ASTM A 564.

4.0 TECHNICAL REQUIREMENTS:

4.1 Mechanical Properties: The mechanical properties shall conform to the requirements of ASTM A 564 for the heat treatment specified.

4.2 ATloy Composition: The chemical analysis shall meet the requirements of ASTM A 564 , for the designated grade.

4.3 Surface Condition: The surface condition and finish shall conform to Class A as specified in ASTM A 564.

5.0 QUALITY ASSURANCE:

5.1 Inspection: The bar stock or shape shali be visually inspected for cieanliness, workmanship and defects.

5.2 Certification: The supplier shall provide certifications on all tests conducted to meet the requirements of this specification. 
TTMS-1039, Rev 0

\author{
H13 Tool Stee? \\ C. Nealley
}

1.0 SCOPE: This material specification describes the materiat requirements for HI3 tool stee?.

2.0 APPLICABLE DOCUMENTS: The following document forms a part of this specification.

ASTM A 681 Alloy Tool Steel

\title{
3.0 MATERIAL REQUIREMENTS:
}

3.1 Grade: The grade of the alloy shall be $\mathrm{H13}$ tool 5 teel.

3.2 Heat Treatment: The material shall be in the austenitized, quenched and tempered condition, as specified in ASTM A 681 .

4.0 TECHNICAL REQUIREMENTS:

4. I Hardness: The minimum hardness shall conform to the requirements of ASTM A 681 for 413 tool steel.

4.2 Alloy Composition: The chemical analys is shall meet the requirements of ASTM A 68 ? for $\mathrm{H} 13$ tool steel.

4.3 Surface Condition: The surface condition shail conform to that specified in ASTM A 681.

\subsection{QUALITY ASSURANCE:}

5.1 Inspection: The Hi3 tool steel shali be visually inspected for cleanliness, workmanship, and defects.

5.2 Certification: The supplier shall provide certifications on al? tests conducted to meet the requirements of this specification. 
TTMS-1060, Rev 0

\title{
Reference Specification for Uranium Dioxide Powder
}

\author{
R. L. Goodman
}

1.0 INTRODUCTION: This specification is intended as a reference standard for nuclear applications. Insofar as practicable, it recognizes the diversity in specific product requirements and the methods of manufacture of specific products. It is therefore anticipated that a purchaser may supplement this specification with more stringent and/or additional requirements for specific applications.

2.0 SCOPE:

2.1 This specification is for nuclear grade, sinterable uranium dioxide powder. It appiies to uranium dioxide powder containing uranium of any ${ }^{235} U$ concentration.

2.2 This specification does not include (a) provisions for preventing criticality accidents or (b) requirements for health and safety. observance of this standard does not relieve the user of the obligation to be aware of and conform to ail federal, state, and loca 7 regulations pertaining to possessing, shipping, processing, or using source or special nuclear material.

2.3 Impurity and Equivalent Boron Specifications are listed in Appendix A.

2.4 Special tests and procedures are listed in Appendix B.

2.5 Applicable documents are listed in Appendix $C$.

\subsection{TECHNICAL REQUIREMENTS:}

3.1 Chemical Requirements: All chemical analyses shall be performed on portions of the representative sample prepared in accordance with Section 4.0. Analytical chemistry methods used shall be as stated in ASTM Method C696-77.

3.1.1 Uranium Content: The uranium content shail be a minimum of $87.7 \%$ by weight on a dry weight basis.

3.1.2 Impurity Content: The impurity content shall not exceed the individual element limit specified in Table 1, Appendix A, on a uranium weight basis. The sumation of the contribution 
of each of the impurity elements listed in rable $\mathrm{I}$, Appendix A, shall not exceed 1500 ppm.

3.1.3 Moisture Content: The moisture content sha 71 not exceed 0.40 weight percent.

\subsection{Nuclear Requirements:}

3.2.1 Isotopic Content: The isotopic content of the uranium in the $\mathrm{UO}_{2}$ powder shall be determined by mass spectrometry. The ${ }^{234} \mathrm{U}$, ${ }^{235} \mathrm{U},{ }^{236} \mathrm{U}$, and ${ }^{238} \mathrm{U}$ content of the uranium shall be reported on a weight percent basis. The isotopic concentrations shall be as specified by the buyer.

3.2.2 Equivalent Boron Content: For thermal reactor use, the total equivalent boron content ( $E B C$ ), based on a summation of the contributions from each of the elements indicated in Table 2, Appendix $A$, shall not exceed $4.0 \mathrm{ppm}$ on a uranium weight basis. (Factors for converting constitutent concentrations to equivalent boron concentrations are given in Table 2, Appendix A.) The ERC of each element shall be calculated individually using the following formula:

$E B C$ of impurity $=$ (EBC factor) $\times$ (opm of impurity)

where:

$E B C$ factor $=\frac{(\text { at.wt boron }) \times\left(\sigma_{a} \text { element }\right)}{\left(\sigma_{a} \text { boron }\right) \times(a t . w t \text { element })}$

Alternatively the $E B C$ may be deternined by a comparative reactivity test against a known standard. For fast reactor use, the above limitations do not ipply.

\subsection{Physical Craracteristics:}

3.3.1 Particle Size: All of the uranium dioxide shall pass through a 20-mesh U.S. Standard sieve. Sieving practice shall be in accordance with ASTM B214-76. 


\subsubsection{Bulk Density: Bulk density shall be a minimum of $0.75 \mathrm{~g} / \mathrm{cc}$ as determined by the Scott volumeter, ASTM B329-76.}

3.4 Sinterability: Test pellets produced and measured in accordance with the sintering performance test described in Appendix $B$ shall have a minimum density of $92.0 \%$ theoretical. (Theoretical density of natural $\mathrm{UO}_{2}=10.96 \mathrm{~g} / \mathrm{cC}$ ).

\subsection{LOT REQUIREMENT:}

4.1 A lot is defined as a quantity of uranium dioxide powder which is uniform in isotopic, chemical, physical, and sinterability characteristics.

4.2 The identity of a lot shali be retained throughout processing without mixing with other established lots.

4.3 A powder lot shall form the basis for defining sampling plans used to establish conformance to specification.

4.4 Sampling plans shall be mutually agreed upon by the buyer and the seller and will be as defined on the purchase requisition. ASTM Standard: E 105-58 (1975) is referenced as a guide.

5.0 SAMPLING: Uranium oxide is hygroscopic and can absorb sufficient water during exposure to a moist atmosphere to cause detectable analytical errors. Sampling, weighing of the sample, and handling the sample shall be done under conditions which do not alter the moisture content of the sample.

5.1 A representative sample of powder from each lot shall be taken for the purpose of determining chemical and physical properties and for sintering performance testing.

5.2 The lot sample shall be of sufficient size to perform quality assurance testing at the seller's plant, acceptance testing at the buyer's plant, and referee tests in the event they become necessary. 
5.3 The lot sample for acceptance testing at the buyer's plant shail be packaged in a separate container, clearly identified by lot number, and shipped with the lot. The referee sampie shall be clearly identified and retained at the seller's plant until the lot has been formally accepted by the buyer.

5.4 The lot sample shall be prepared by biending and splitting the container samples.

5.5 To obtain a container sample, specimens shail be taken with a thief at random locations along any vertical traverse through each sample container selected at random. The thief samples from the selected containers shall then be blended and split down to the required size.

5.6 The number of containers so sampled shall be $5+n / 10$, where $n$ is the total number of containers per lot rounded to the nearest decade. If there are five or fewer containers per lot, each container shall be so sampled.

\subsection{TESTING AND CERTIFICATION:}

6.1 The seller shail test the sample described in Section 4.0 to assure conformance of the powder to the requirements of Section 3.0. Ail testing shall be conducted by techniques mutualiy agreed to by the buyer and the seller.

6.2 The seller shall provide to the buyer documents certifying:

6.2.1 the isotopic content and identity of the starting material lot.

6.2.2 that the powder meets all the requirements of Section 3.0.

6.3 Test data on the following characteristics shall be supplied upon request:

- uranium isotopic content

- uranium content

- individual impurity levels

- moisture content

- sinterability test results 
6.4 Lot Acceptance: Acceptance testing may be performed by the buyer on either the sample provided by the seller or on a sample taken at the buyer's plant by sampling one or more individual containers with a thief. Acceptance shall be on a lot basis and shall be contingent upon the material properties meeting the requirements of Section 3.0.

6.5 Referee Method: The buyer and seller shall agree to a third party as a referee in the event of a dispute in analytical results.

7.0 PACKAGING AND SHIPPING:

7.1 Uranium dioxide powder shall be packaged in sealed containers to prevent loss of material and undue contamination from air or the container materiais. The exact size and method of packaging shall be as mutually agreed upon by the buyer and seller.

7.2 Each outer container sha11 bear as a minimum a label on the lid and side with the following information:

$\begin{array}{ll}\text { Seller's Name } & \text { Gross, Tare, Net Oxide Weights } \\ \text { Material in Container } & \text { Uranium Weight } \\ \text { Lot Number } & \text { Purchase Order Number } \\ \text { Uranium Enrichment } & \end{array}$

\subsection{QUALITY ASSURANCE:}

\begin{tabular}{llll} 
& Section and Item & Significance & Reference \\
\hline 3.1 & Chemical Requirements & & ASTM C696-77 \\
3.1 .1 & Uranium Cantent & Critical & \\
3.1 .2 & Impurity Content & Critical & \\
3.1 .3 & Moisture Content & & \\
3.2 & Nuclear Requirements & Critical & ASTM C696-77 \\
3.2 .1 & Isotopic Content & Critical & \\
3.2 .2 & Equivalent Boron Content & & \\
3.3 & Physical Characteristics & Major & ASTM B214-76 \\
3.3 .1 & Particle Size & Major & ASTM B329-76 \\
3.3 .2 Bulk Density & &
\end{tabular}




$\frac{\text { Section and Item }}{3.4 \quad \text { Sinterability }}$

4.0 Lot Requirements

5.0 Sampling

6.0 Testing and Certification

\section{Significance ${ }^{(a)}$ Critical}

Major

Major

Critical

(a) These terms are defined as follows:

\section{[ritica]}

Inadequate control of this characteristic car result in a critical defect that couid cause failure of fuel, especially in a reactor. A critical defect is a defect that judgment and experience indicate is likely to result in hazardous or unsafe conditions for individuals using, maintaining, or depending upon the profuct; or a defect that judgment and experience indicate is likely to prevent performance of the function of a major end product such as a fuel rod, fuel assembly, or reactor fuel core. $(8)$

\section{Major}

Inadequate control of this characteristic can result in a major defect. A major defect is a defect, other than critical, that is likely to result in failure, or to reduce materially the usability of the unit of product for its intended purpose. ${ }^{(8)}$ 


\section{APPENDIX A - IMPURITY ANO EOUIVALENT BORON SPECIFICATIONS}

The elements 1 isted in Table 1 require quantitative determination. The total impurity content, based on the summation of the contribution from each element listed in Table 1, shall not exceed 1500 ppm. The total equivalent boron content shall not exceed 4 ppm as determined from a s'dmation of the contribution from each element listed in Table 2. The equivalent boron factors listed in Table 2 shall be used to compute equivalent boron contents.

TABLE 1. Impurity Elements and Maximum Concentration Limits

\begin{tabular}{|c|c|}
\hline Element & $\begin{array}{l}\text { Maximum Concentration } \\
\text { Limit (ppm) }\end{array}$ \\
\hline Aluminum & 100 \\
\hline Barium & 250 \\
\hline Berylijum & 250 \\
\hline Carbon & 100 \\
\hline Calcium plus Magnesium & 200 \\
\hline Chlorine pius Flucrine & 125 \\
\hline Chromium & 200 \\
\hline Cobalt & 100 \\
\hline Copper & 250 \\
\hline Iron & 400 \\
\hline Lead & 250 \\
\hline Manganese & 250 \\
\hline Molybdenum & 250 \\
\hline Nickel & 200 \\
\hline Nitrogen & 200 \\
\hline Phosphorus & 250 \\
\hline Silicon & 200 \\
\hline Tantalum & 250 \\
\hline Thorium & 30 \\
\hline Tin & 250 \\
\hline Titanium & 250 \\
\hline Tungsten & 250 \\
\hline Vanadium & 250 \\
\hline Zinc & 250 \\
\hline Zirconium & 250 \\
\hline
\end{tabular}


TTMS-1060, Rev 0

TABLE 2. Equivaient Boron Factors

\begin{tabular}{|c|c|c|c|}
\hline Element & $\begin{array}{l}\text { Absorption Cross }(\mathrm{a}) \\
\text { Section, } \sigma \mathrm{a} \\
\text { (barns-2200 } \mathrm{m} / \mathrm{sec})\end{array}$ & Atomic weight & EBC Factor \\
\hline A)uminum & 0.235 & 26.98 & 0.0001 \\
\hline Barium & 1.2 & 737.34 & 0.0001 \\
\hline Boron & 759.0 & 10.81 & 7.0000 \\
\hline Cadmi um & $2,450.0$ & 112.40 & 0.3104 \\
\hline Calcium & 0.44 & $4 C .08$ & 0.0002 \\
\hline Cesium & 30.0 & 138.91 & 0.0031 \\
\hline Chlorine & 33.2 & 35.45 & 0.0133 \\
\hline Chromium & 3.1 & 52.00 & 0.0008 \\
\hline Cobalt & 37.2 & 58.93 & 0.0090 \\
\hline Copper & 3.8 & 63.54 & 0.0009 \\
\hline Dysprosium & 930.0 & 162.50 & 0.0815 \\
\hline Europium & $4,400.0$ & 151.96 & 0.4124 \\
\hline Gadolinium & $49,000.0$ & 157.26 & 4.438 \\
\hline Hafnium & 305.0 & 178.49 & 0.0084 \\
\hline Iron & 2.55 & 55.85 & 0.0007 \\
\hline Lithium & 71.0 & 6.939 & 0.1457 \\
\hline Manganese & 13.30 & 54.94 & 0.0034 \\
\hline Molybdenum & 2.70 & 95.94 & 0.0004 \\
\hline Nickel & 4.60 & 58.71 & 0.0011 \\
\hline Nitrogen & 1.85 & 14.01 & 0.0018 \\
\hline Phosphorus & 0.19 & 30.97 & 0.0001 \\
\hline Samarium & $5,820.0$ & 150.35 & 0.5513 \\
\hline Silicon & 0.16 & 28.39 & 0.0001 \\
\hline Tantalum & 21.0 & 108.95 & 0.0017 \\
\hline Titanium & 6.7 & 47.30 & 0.0018 \\
\hline Tungsten & 18.5 & 183.85 & 0.0014 \\
\hline Vanadium & 5.06 & 50.94 & 0.0014 \\
\hline Zinc & 1.10 & 65.37 & 0.0002 \\
\hline
\end{tabular}

(a) Brookhaven National Laboratory Publication BNL-325, Second Edition, July 1958 and Supplement No. 1, January 1960, and Supplement No. 2, 1964-1966. 
TTMS-1060, Rev 0

\section{APPENDIX B - SINTERING PERFORMANCE TEST}

B.1 A sinterability performance test shall be performed using ten pellets produced from each lot sample obtained according to the sampling procedure in Section 5.0. The density shall be determined and shall not deviate from the ten-pellet average by more than $+2.0 \%$ of the average. Minimum density of any one pellet shall not be less than $92.0 \%$ of theoretical. (The theoretical density of stoichiometric natural $\mathrm{UO}_{2}$ is $10.96 \mathrm{~g} / \mathrm{cc}$.)

B.2 The purpose of the sinterability test is to verify the sinterability of each lot of $\mathrm{UO}_{2}$ powder. It is not intended to simulate the buyer's pellet fabrication process. The buyer should select either the dry (B.5) or the wet (B.6) process performance test.

B.3 Ali parameters of the performance test, once established, shall remain unchanged throughout an lots of the order.

B.4 The geometrical density of the fired and unfired pellets shall be determined as follows:

B.4.1 Diameter: Record the average of four readings taken at equally spaced intervals along a $180^{\circ}$ helix $1 / 16 \mathrm{in}$. from each end of the pellet using a blade micrometer and reading to the nearest 0.0002 in.

B.4.2 Length: Record the average of three readings taken from end to end of the pellet at equally spaced intervals along a verically bisecting plane using a pointed anvil micrometer and reading to the nearest 0.0005 in.

B.4.3 Weight: Weight to the nearest $0.001 \mathrm{~g}$.

B.4.4 Density: Calculate the density of each pellet to the nearest $0.01 \mathrm{~g} / \mathrm{cc}$.

\section{B.5 Dry Process Performance Test}

B.5.1 The pellet shall be cold pressed, without addition of any binder or lubricant to the powder to a density between 45 and $55 \%$ of theoretical density. The density of each pellet shall vary no 
more than $\pm 0.5 \%$ TD from the average of the ten required test pellets. The density, pressing pressure, and dwell time shall be reported.

B.5.2 The dimension of the unfired test pe:1lets shall be approximately that of the production pellet. The length-to-diameter ratio shall be unity or greater. The variation in length of the unfired pellets shall be heid to $\pm 0.020 \mathrm{in}$. The type of press and pressing conditions, including die taper and identification of die lubricant, if used, shall be reported.

B.5.3 The pellets shall be fired as one batch in hydrogen or dissociated amonia through a firing schedule tc allow the pellets to be at $1625 \pm 25^{\circ} \mathrm{C}$ for a maximum of four hcurs. The type of furnace used and the atmosphere shall be reported and shall remain unchanged throughout all performance tests. The actual firing schedule shall be mutualiy agreed upon, and the location of the temperature measurement shall be indicated.

\section{B.6 Wet Process Performance Test}

B.6.1 While 5lowly adding 1.5 weight percent of polyvinyl alcohol water solution, the sample shall be mixed in a planetary mixer. Sufficient water shall be added to bring the mix to the consistency agreed upon between buyer and seller.

B.6.2 The oxide-binder mixture shal1 be granulated through a 20 -mesh U.S. Standard stainless steel screen. The granules shall be placed on a stainless stee 1 tray about $1 / 2$ in. deep in a Stokes (or equivalent) vacuum drying oven for five hours at $50^{\circ} \mathrm{C}$. After drying, the granules shall be regranulated through a 20 -mesh screen and blended with $0.4 \%$ weight dry Sterotex iubricant by slowly rolling the mix for five minutes in a polyethylene bottle.

8.6.3 The sample shail be cold pressed to a density between 50 and $60 \%$ TD. The density of each pellet shall vary by no more than $+0.5 \%$ TD from the average of the ten required test pellets. The density, pressing pressure, and dwell time shall be reported. 
B.6.4 The dimension of the unfired test peliets shall be approximately that of the production pellet. The length-to-diameter ratio shall be unity or greater. The variation in length of the unfired pellets shall be held to $\pm 0.020 \mathrm{in}$. The type of press and pressing conditions, including die taper, shall be reported.

B.6.5 The pellets shall be placed in a low-temperature (about $430^{\circ} \mathrm{C}$ ) furnace for removal of binder and lubricant. The type of furnace and atmosphere shall be reported and shall remain unchanged throughout all performance tests. The actual heating cycle time (approximately 28 hours) shall be reported to the nearest half hour, and the method of temperature measurement shall be indicated.

B.6.6 The pellets shall be fired in one batch in a hydrogen or dissociated ammonia atmosphere through a firing schedule to allow the pellets to be at $1,625^{\circ} \mathrm{C} \pm 25^{\circ} \mathrm{C}$ for a maximum of four hours. The type of furnace and atmosphere used shall be reported and shall rema in unchanged throughout all performance tests. The actual firing schedule shall be mutually agreed upon, and the location of the temperature measurement shall be indicated. 
TTMS-1060, Rev 0

\section{APPENDIX C - APPLICABLE DJCUMENTS}

1. Code of Federat Regulations, Title 10.

2. Nuclear Safety Guide, U.S. Atomic Energy CImmission Report TID-7016, Latest Edition.

3. "Handbook of Nuclear Safety," H. K. Clark, U.S. Atomic Energy Commission Report, DP-532.

4. ASTM Method C 696-77, "Standard Methods fol" Chemica1, Mass Spectrometric, and Spectrochemical Analysis of Nuclear-Grade Uranium Dioxide Powders and Pellets."

5. ASTM B214-76, "Standard Test Method for Sieve Analysis of Granular Meta? Powders."

E. ASTM 8329-76, "Standard Test Method for Apparent Density of Powders of Refractory Metais and Compounds by the Scot:t Volumeter."

7. ASTM E105-58 (1975), "Recommended Practice for Probability Sampling of Materials," Parts 15, 32 and 41.

8. Military Standard, MIL-STD-1098. Apri1 4, 1969. (Page 2, 3, 4 and 6). 


\section{BORON NITRIDE BAR STOCK}

$$
\text { C. Nealley }
$$

1.0 SCOPE: This material specification describes the material requirements for boron nitride bar stock.

2.0 MATERIAL REQUIREMENTS: The material shall be densified, solid boron nitride in bar form.

\subsection{TECHNICAL REQUIREMENTS:}

3.1 Mechanical Properties: The boron nitride bar stock shall have a density of $1.9 \mathrm{gm} / \mathrm{cm}^{3}$. The minimum compressive strength shall be 16,000 psi, and the minimum bending strength shall be 7800 psi.

3.2 Chemical Composition: The chemistry of the bar stock shall be determined. Minimum values shall be:

$\begin{array}{lc}\mathrm{B} & 42.0 \\ \mathrm{~N} & 53.5 \\ \mathrm{C} & 0.05 \\ \mathrm{~B}_{2} \mathrm{O}_{3} & 0.10 \\ \mathrm{SiO}_{2} & \text { Trace } \\ \mathrm{Ca} & 1.5 \\ \mathrm{Cl} & 0.20\end{array}$

3.3 Electrical Properties: The dialetric strength shall be measured, and shall be at least $790 \mathrm{volts} / \mathrm{mi}$ l.

\subsection{QUALITY ASSURANCE:}

4.1 Inspection: The bar stock shall be visually inspected for cleanliness, workmanship and defects.

4.2 Certification: The supplier shall provide certifications on all tests conducted to meet the requirements of this specification. 
TTMS-1063, Rev 0

Aluminum Oxide Powder

C. Nealley

1.0 SCOPE: This material specification describes the material requirements for aluminum oxide powder.

2.0 APPLICABLE DOCUMENTS: The following documents form a part of this specification.

MIL-STD- 109B

"Engineering Guide to Structural Ceramics," Materials Engineering, Special Report, November 1970.

\subsection{MATERIAL REQUIREMENTS:}

3.1 Aluminum 0xide Content: The aluminum cxide content of the insuiator pellet shall be at least $99.3_{i \circ}^{\circ}$ on a dry weight basis.

3.2 Impurity Limits: The impurity limits shall not exceed the individual element limit specified in Table 1.

3.3 Equivalent Boron Content: The equivalent boron content (EBC), based on a summation of the contributions from each of the elements listed in Table 2, shall not exceed $80 \mathrm{ppm}$. (Factors for converting constituent concentrations to equivalent boron concentrations are listed in Table 2.) The EBC of each element shall be calculated individualiy, using the following formula:

$$
E B C \text { of constituent }=(E B C \text { factor }) \times(p p m \text { of constituent })
$$

where:

$E B C$ factor $=\frac{\text { (at.wt boron }) \times\left(\sigma_{a} \text { element) }\right.}{\left(\sigma_{a} \text { boron }\right) \times \text { (at.wt element) }}$

Alternativeiy, the EBC of the alumina may be determined by a comparative reactivity test against a known standard. 
TTMS-1063, Rev 0

\subsection{TECHNICAL REQUIREMENTS}

4.1 Gas Content: The gas content, excluding moisture, as measured by vacuum outgassing at $3000^{\circ} \mathrm{F}$, shall not exceed $0.05 \mathrm{cc} / \mathrm{gram}$ of aluminum oxide with the gas at standard temperature and pressure.

5.0 QUALITY ASSURANCE:

5.1 Certification: The supplier shall provide certifications on all tests conducted to meet the requirements of this specification. 
TTMS-1063, Rev 0

TABLE I. Impurity Elements and Maximum Concentration Limits

Element

Carbon

Chlorine

Fluorine

Nitrogen
Maximum Concentration Limit (ppm)

100

10

10

75 
TTMS-1063, Rev 0

TABLE 2. Equivalent Boron Factors

$$
\begin{gathered}
\text { Absorption Cross } \\
\text { Section, } \sigma_{a}
\end{gathered}
$$

Element (barns-220 m/sec)

Atomic Weight EBC Factor

$\begin{array}{lccc}\text { Aluminum } & 0.235 & 26.98 & 0.0001 \\ \text { Barium } & 1.2 & 137.34 & 0.0001 \\ \text { Boron } & 759.0 & 10.81 & 1.0000 \\ \text { Cadmium } & 2,450.0 & 112.40 & 0.3104 \\ \text { Calcium } & 0.44 & 40.08 & 0.0002 \\ \text { Cesium } & 30.0 & 138.91 & 0.0031 \\ \text { Chlorine } & 33.2 & 35.45 & 0.0133 \\ \text { Chromium } & 3.1 & 52.0 & 0.0008 \\ \text { Cobalt } & 37.2 & 58.93 & 0.0090 \\ \text { Copper } & 3.8 & 63.54 & 0.0009 \\ \text { Dysprosium } & 930.0 & 162.50 & 0.0815 \\ \text { Europium } & 4,400.0 & 151.96 & 0.4124 \\ \text { Gadolinium } & 49,000.0 & 157.26 & 4.438 \\ \text { Hafnium } & 105.0 & 178.49 & 0.0084 \\ \text { Iron } & 2.55 & 55.85 & 0.0007 \\ \text { Lithium } & 71.0 & 6.939 & 0.1457 \\ \text { Manganese } & 13.30 & 54.94 & 0.0034 \\ \text { Molybdenum } & 2.70 & 95.95 & 0.0004 \\ \text { Nickel } & 4.60 & 58.71 & 0.0011 \\ \text { Nitrogen } & 1.85 & 14.01 & 0.0018 \\ \text { Phosphorus } & 0.19 & 30.97 & 0.0001 \\ \text { Samarium } & 5,820.0 & 150.35 & 0.5513 \\ \text { Silicon } & 0.16 & 28.09 & 0.0001 \\ \text { Tantalum } & 21.0 & 108.95 & 0.0017 \\ \text { Titanium } & 6.1 & 47.90 & 0.0018 \\ \text { Tungsten } & 18.5 & 183.85 & 0.0014 \\ \text { Vanadium } & 5.06 & 50.94 & 0.0014 \\ \text { Zinc } & 1.10 & 65.37 & 0.0002\end{array}$

(a) Brookhaven National Laboratory Publication BNL-325, Second Edition, July 1958; Supplement No. 1, January 1960, and Supplement No. 2, 1964-1966. 
TTMS-1070, Rev 0

Wrought Platinum

C. Neailey

1.0 SCOPE: This material specification describes the material requirements for wrought piatinum.

2.0 APPLICABLE DOCUMENTS: The following document forms a part of this specification.

ASTM B 61 Refined Platinum

3.0 MATERIAL REQUIREMENTS:

3.1 Grade: The grade of the alloy shall be as designated on the fabrication drawing or in the ordering data.

3.2 Heat Treatment: The material shatl be supplied in the anneaied condition.

4.0 TECHNICAL REQUIREMENTS:

4.1 Alloy Composition: The chemical analys is shall meet the requirements of ASTM B 61, for the designated grade.

4.2 Surface Condition: The surface condition and finish shall conform to that specified in ASTM B 61.

\subsection{QUALITY ASSURANCE:}

5.) Inspection: The wrought material shall be visually inspected for cleanliness, workmanship and defects.

5.2 Certification: The supplier shall prov de certifications on all tests conducted to meet the requirements of this specification. 
TTMS-1075, Rev 0

Niobium Alloy Strip, Sheet, Foil, and Plate C. Nealley

1.0 SCOPE: This material specification describes the material requirements for niobium alloy strip, sheet, foil, and plate.

2.0 APPLICABLE DOCUMENTS: The following document forms a part of this specification.

ASTM B 393 Niobium and Niobium Alloy Strip, Sheet, Foil, and Plate

\subsection{MATERIAL REQUIREMENTS:}

3.1 Type: The type of the alloy shall be as designated on the fabrication drawing or in the ordering data.

3.2 Heat Treatment: The material shall be in the annealed condition, as specified in ASTM B 393.

4.0 TECHNICAL REQUIREMENTS:

4.1 Mechanica1 Properties: The mechanical properties shali conform to the requirements of ASTM 8 393, for the designated grade.

4.2 Alloy Composition: The chemical analys is shall meet the requirements of ASTM B 393 for the designated grade.

4.3 Surface Condition: The surface condition and finish shall conform to that specified in ASTM B 393.

5.0 QUALITY ASSURANCE:

5.1 Inspection: The strip, sheet, foil or plate shati be visualiy inspected for cleanliness, workmanship and defects.

5.2 Certification: The supplier shall provide certifications on all tests conducted to meet the requirements of this specification. 

APPENDIX C

PRODUCT SPECIF ICATIONS 


\section{PRODUCT SPECIFICATIONS}

Specification

TTPS-1006 Rev 1

TTPS-1007 Rev 1

TTPS-1013 Rev 0

TTPS-1017 Rev

TTPS-1019 Rev

TTPS-1022 Rev

TTPS-1023 Rev

TTPS-1024 Rev

TTPS-1029 Rev 0

TTPS-1030 Rev 0

TTPS-1031

TTPS-1033
Title

Specifications for LVDT--Bellows-Type

Pressure Transducer for Nuclear Service

$C-2$

$C-9$

Emitter

C-16

$C-19$

$C-29$

C-39

in a Nuclear Reactor

C-45

C-46

Standard Multipar Extension Cable

Inconel-600 Sheathed Chromel-Alume]

Thermocouples with Single or Dual

Diameters for Nuclear Application

$C-47$

Metallic Sheathed Mineral-Insulated

Cables for Nuclear Service

C -54

$C-61$

$c-65$ 
TTPS-1006, Rev 1

\section{SPECIFICATIONS FOR LVDT-BELLOWS-TYPE PRESSURE TRANSOUCERS}

FOR NUCLEAR SERVICE.

R. K. Marshajl

\subsection{SCOPE: This specification presents the requirements for pressure} transducers of the Linear Variable Differential Transformer (LVDT)bellows type for measuring absolute pressures in a nuclear environment. In this type, the bellows is directly attached to the transformer core of the LVOT. The LVDT senses the motion of the bellows caused by a change in pressure and provides an electrical output signal linearly proportional to the change in pressure. Extension cables attached to the transducer transmit the electrical signal to readout instrumentation located outside of the nuclear environment. A summary of the design requirements is shown in Table 1. Applicabla documents are listed in Appendix A.

2.0 ENVIRONMENTAL CONDITIONS: The transducers and a portion of the extension cable will operate in flowing pressurized water up to 2500 psig and $345^{\circ} \mathrm{C}\left(650^{\circ} \mathrm{F}\right)$ and must be designed to withstand a total neutron fluence of $3 \times 10^{20}$ nvt at a flux of $5 \times 10^{13} \mathrm{nv}$ and a gamma flux of $1.0 \times 10^{9} \mathrm{R} / \mathrm{hr}$. At the end of some tests the tranducers will be subjected to temperatures as high as $760^{\circ} \mathrm{C}\left(1.400^{\circ} \mathrm{F}\right)$ for a maximum time of one hour.

The water in which the transducers operate is turbulent and moving at high velocities; consequently, flow induced vibrations and shocks can be expected.

3.0 OPERATING CONDITIONS: The pressure transducers will measure pressures within the $0-2500$ psig range. The fluid whose pressure is being measured 
will be either the water of the environment or helium contaminated with fission gasses. For the latter case, the transducer will be attached directly to an operating fuel rod.

The transducer and a portion of the extension cables will operate in the nuclear environment, the remainder of the cables will operate at roon temperature and pressure.

\subsection{CONSTRUCTION}

4.1 Transducer: A1l materials must be inorganic. The internal components of the transducers must be enclosed in an al? welded hermetically sealed Inconel case to withstand the environmenta? conditions. The transducer must be evacuated and sealed in such a manner to provide absolute pressure measurements. The volume within the transducer occupied by the fluid whose pressure is being measured should be less than $1.3 \mathrm{~cm}^{3}\left(0.080 \mathrm{in}^{3}\right)$.

The design of the transducer shall be such that if the bellows fails the fluid within the bellows cannot have access to the extension cables. The selection of materials and construction must be such as to minimize temperature related null shifts.

The transducers will be used in an in-reactor experimental assembly in which space is at a premium. The maximum envelope dimension for the transducers are 25.4 mm (1 in.) OD with 15.2 man $(0.6$ in.) 00 as a goal, and up to $102 \mathrm{~mm}$ (4 in.) long for $25.4 \mathrm{~mm}$ (1 in.) OD transducers, and up to 127 mat (5 in.) long for 15.2 man (0.6 in.) OD transducers. These dimensions are exclusive of extension cable attachment and pressure port.

A center tap conductor for the secondary windings shall be provided so that the sense of direction of core movement can be maintained and so that closed loop temperature compensation can be employed if desired. 
4.2 Extension Cabies: The extension cables must minimize space, be flexible enough to extend from the transducer to a location outside the reactor, and must withstand the same environmental conditions as the transducer. Two $1.59 \mathrm{~mm}(0.063 \mathrm{in}$.) Jiameter MgO insulated metallic sheathed cables, one containing two conductors and the other three conductors are required. Cables up to $11.6 \mathrm{~m}(38 \mathrm{ft})$ long are to be employed.

It is important that the extension cable be manufactured to standards that are applicable to in-reactor use. It is recommended that the cable sheath be either Inconel 600 having a carbon content $<0.05 \%$ or 347 stainless steel. The mineral insulation shall be MgO with a $99.4 \%$ minimum content of magnesia and with a maximum content of boron plus cadmium of $30 \mathrm{ppm}$. All impurities including boron and cadmium must be iess than $6000 \mathrm{ppm}$. The sulfur content must be less than $50 \mathrm{ppm}$ and the carbon content less thian $300 \mathrm{ppm}$.

The finished cables shall be annealed in a vacuum or an atmosphere of hydrogen.

The following certification should be obtained from the manuf acturer:

- Chemical analysis of the sheath material

- Certified results of insulation composition

- Test results on insulation tests

- Test results on sheath integrity tests

- Test results on metallurgical structure

- Results of liquid penetrant inspection

ASTM Specification E-235 can be used as a guide.

4.3 Extension Cable to Transformer Housing Attachment: In affixing the cables to a transition attachment a braze or weld may be employed. If a braze is considered, the braze procedure must be reviewed and approved by PNL before being used. 
TTPS-1006, Rev 1

4.4 Pressure Port: The pressure port shall be a tube $6.1 \mathrm{~mm}(1 / 4 \mathrm{in.})$ OD with a wall thickness of at least $2.41 \mathrm{~mm}(0.095 \mathrm{in}.) \times 152 \mathrm{~mm}$ (6 in.) long,

5.0 TESTS: Each completed transducer with leads attached shall be heated to $345^{\circ} \mathrm{C}\left(650^{\circ} \mathrm{F}\right)$ and maintained at that temperature for 24 hours. At least one foot of leads shall be heated. The wire continuity and insulation resistance of the coils shall be measured before, during, and after heating. Transducers which show changes in insulation resistance indicating a short or open circuit in the coil windings shall be subject to rejection. One transducer shall be heated to $760^{\circ} \mathrm{C}\left(1400^{\circ} \mathrm{F}\right)$ and tested as above.

All seal welds and brazes shall be tested with a helium mass spectrometer leak detector. A leak rate in excess of $6 \times 10^{-9}$ standard $\mathrm{cm}^{3} / \mathrm{sec}$ of helium shall be used as a basis for rejection.

6.0 CALIBRATION: A minimum of 20 calibration points on each transducer shaif be made at each of three temperatures over the specified pressure range. These data shall be taken for up runs and down runs with a minimum of 10 points for each run at $25^{\circ} \mathrm{C}, 270^{\circ} \mathrm{C}$, and $540^{\circ} \mathrm{C}\left(77^{\circ} \mathrm{F}, 500^{\circ} \mathrm{F}\right.$, and $1000^{\circ} \mathrm{F}$ ). The foregoing procedure shall be repeated twice.

\subsection{QUALITY ASSURANCE}

7.1 Documentation: Documentation of all manufacturing, materials, testing, and quality records for each detector shall be maintained and submitted to the purchaser.

7.2 Inspection: PNL reserves the right to inspect all materials and procedures during fabrication, testing, and before shipment to assure that the prescribed requirements are met. 
TPS-1006, Rev 1

7.3 Acceptance Tests at PNL: Acceptance testing at PNL will include the following:

- Visual inspection

- Verification of Sections 5.0 Tests and 6.0 Calibration.

\subsection{PREPARATION FOR SHIPMENT}

8.1 Cable Seals: The ends of the extension cables shall be sealed in such a manner that handling during shipment will not break the seal.

8.2 Cable Packing and Shipping: The cable shall be coiled for shipping in a diameter of not less than $460 \mathrm{~mm}$ (18 in.). The detectors and extension cables shall be cleaned, packaged and shipped in such a manner that they are received in an undamiged condition.

9.0 READOUT EQUIPMENT: A single channel signal corditioner for reading the output of the LVDT's and capable of expansion to four channel operation sha11 be provided ( $115 \mathrm{~V}, 60$ cycle). The signal conditioner shall provide compensating circuitry to substantially reduce the temperature sensitivity of the LVDT. The output of the signal conditioner shalt be capable of being read on a 4-1/2 digit type digital voltmeter. 
TABLE 1. Summary of Requirements for LVDT-Bellows Type Pressure Transducers for Nuclear Service

\section{Environmental Conditions}

Pressurized flowing water up to $2500 \mathrm{psig}$ and $354^{\circ} \mathrm{C}\left(650^{\circ} \mathrm{F}\right)$

Total thermal neutron fluence $-3 \times 10^{20}$ nvt

Thermal flux $-3 \times 10^{13} \mathrm{nv}$

Ganma flux $-1.0 \times 10^{9} \mathrm{R} / \mathrm{hr}$

\section{Transducer Dperating Conditions}

Range: $\quad 0-2500$ psia (transducer evacuated and sealed for zero pressure reference)

Accuracy: $\quad \pm 0.1 \%$ at al1 points in the linear range

Linearity: $\quad \pm 0.5 \%$ over the nominal range

Resolution: $\quad 0.025 \mathrm{~mm}(0.001 \mathrm{in}$.) or better

Response time: Less than $30 \mathrm{msec}$ (step change, 10-90\% F.S.)

Shock: $10 \mathrm{~g}$ a 11 milliseconds

Vibration: $\quad 10 \mathrm{~g}$ a $2 \mathrm{~K} \mathrm{~Hz}$

\section{Construction}

Transducer and extension cables to be an integral unit

Materials: all inorganic

Maximum Transducer EnveTope

Maximum Allowable:

Goal:

Maximum Measuring Volume:

Pressure Port:

Extension Cable Length:

Diameter:
$25.4 \mathrm{rmm}$ ( 1 in.) $00 \times 102 \mathrm{~mm}$ (4 in.) long $15.2 \mathrm{~mm}(0.6$ iп. $) 00 \times 127 \mathrm{~mm}$ (5 in.) long $1.3 \mathrm{~cm}^{3}\left(0.080 \mathrm{in.}^{3}\right)$ Tube, $6.1 \mathrm{~mm}(1 / 4 \mathrm{in.})$ OD with a wall thickness of at lease 2.41 minn (0.095 in.) $x$ $152 \mathrm{~mm}$ (6 in.) long.

up to $11.6 \mathrm{~m} \pm 0.3 \mathrm{~m}(38 \mathrm{ft} \pm 1 \mathrm{ft})$. Length to be specified in purchase order. $1.588 \pm 0.038$ (0.0625 \pm 0.0015 in.) 
TTPS-1006, Rev 1

APPENDIX A

APPLICABLE DOCUMENTS

ASTM E 235 - Thermocouples, Sheathed Type K, for Nuclear or for Other High Reliability Applications. 
TTPS-1007, Rev. I

Specification for a Self-Powered Neutron Detector With Cobalt Emitter R. K. Marsha 11

1.0 SCOPE: This specification presents the requirements for self-powered neutron detectors for monitoring the thermal neutron flux in a nuciear reactor under steady state and transient testing conditions.

2.0 APPLICABLE DOCUMENTS: The latest official issue of the following standards:

- ASTM B-166 Specifications for Nickel-Chromium-Iron Alloy Rod and Bar.

- ASTM B-167 Specifications for Nickei-Chromium-Iron Alloy Seamless Pipe and Tube.

3.0 ENVIRONMENTAL CONDITIONS: The detector and a portion of the extension cables will operate in flowing pressurized water up to $17.2 \mathrm{MPa}$ (2500 psig) and $616 \mathrm{~K}\left(650^{\circ} \mathrm{F}\right)$ under steady state conditions. The detectors will operate in steam up to $810 \mathrm{~K}\left(1000^{\circ} \mathrm{F}\right)$ and $0.34 \mathrm{MPa}(50 \mathrm{psig})$ for approximately 30 minutes under transient conditions. The detectors shall operate in a thermal neutron flux of $1 \times 10^{14} \mathrm{n} / \mathrm{cm}^{2} / \mathrm{sec}$ and a gamma flux of $1 \times 10^{9} \mathrm{R} / \mathrm{hr}$ for a duration equivalent to a detector lifetime of $1 \times 10^{21}$ nvt (therma 1 ).

4.0 CONSTRUCTION: The construction is the biaxial type with a cobalt emitter. In this type, the construction of the background component is identical to the self-powered component except that the emitter is not included. The two conductor wires are helically wound.

4.1 Sensor: The sensor consists of the emitter, mineral insulation, and collector.

4.7.1 Emitter:

(a) Material: Cobalt with a purity not less than $99.9 \%$.

(b) Diameter: Shall be determined by contractor to provide sensitivity given in 6.0 . 
TTPS-1007, Rev. T

(c) Length: $103.6 \pm 4.8 \mathrm{mrn}(4.00 \pm 0.19 \mathrm{in.})$.

(d) Mass difference: The emitter mass difference among finished sensors shall not exzeed 0.5 milligram.

4.1.2 Mineral Insulation:

(a) Material: The mineral insulation shall be electrically fused magnesia (MgO) with a $99.4 \%$ minimum content of magnesia and with a maximum content of boron plus cadmium of 30 ppm. Al] impurities including boron and cadmium shall be less than $6000 \mathrm{ppm}$. The sulfur content shall be less than $50 \mathrm{ppm}$ and the carbon content less than $300 \mathrm{ppm}$.

(b) Insulation Thickness: The minimum thickness shall be 0.127 пा $(0.005$ in. $)$.

4.1 .3 Collector:

(a) Material: Incone T-600 in accordance with ASTM B-167 with carbon content restricted to $<0.05 \%$.

(b) Diameter: $3.81 \pm 0.08 \mathrm{~mm}(0.150 \pm 0.003 \mathrm{in.})$.

(c) Length: Minimum length required to house and separate enitter from collector.

4.2 Extension Cable: The extension cable consists of the two inner conductors, mineral insulation, and sheath.

\subsubsection{Inner Conductors:}

(a) Material: Incone1-600 in accordance with ASTM B-166 with chemistry as specified in paragraph 4.7.3(a).

(b) Diameter: Nominal diameter sha?1 be $0.254 \mathrm{~mm}$ (0.010 in.).

(c) Helix pitch: The conductors shall be formed into a helix having a pitch of approximately $25.4 \mathrm{~mm}$ (1.0 in.).

\subsubsection{Mineral Insulation:}

(a) Material: As specified in paragraph 4.1.2(a).

(b) Insulation thickness: As specified in paragraph 4.1.2(b). 
TYPS-1007, Rev. 1

\subsubsection{Sheath:}

(a) Material: Incone1-600 as specified in paragraph 4.7.3(a).

(b) Diameter: $1.587 \pm 0.002 \mathrm{~mm}(0.0625 \pm 0.0010 \mathrm{in.})$.

(c) Wall thickness: Nominal wall thickness shall be $0.254 \mathrm{~mm}$ $(0.010$ in. $)$.

4.2.4 Cable Flexibility: The cable shall withstand a once-only bend at any location. The bend shall extend up to $360^{\circ}$ on a radius of not less than three diameters of any section undergoing the bend.

4.3 Detector: The detector consists of the sensor and extension cable as an integral unit.

4.3.1 Surface finish: The surface finish of the completed detectors shall not have a roughness greater than $0.00081 \mathrm{~mm}$ (32 microinches).

4.3.2 Length: The length of the completed detectors shatl be specified in the ordering data.

\subsection{TESTS:}

5.1 Insulation Resistance: The insulation resistance of the finished detectors sha 11 be measured at $294 \mathrm{~K}\left(70^{\circ} \mathrm{F}\right)$ and at $672 \mathrm{~K}\left(750^{\circ} \mathrm{F}\right)$. The minimum leakage resistance at $294 \mathrm{~K}\left(70^{\circ} \mathrm{F}\right)$ shall be $1 \times 10^{13}$ ohms and at $672 \mathrm{~K}\left(750^{\circ} \mathrm{F}\right) \mathrm{i} \times 10^{8}$ ohms.

5.2 Sheath and Collector integrity: The sheath and collector integrity of the finished detectors shall be tested. The manufacturer shall perform at least one of the following tests; the manufacturer can select which test to perform.

5.2.1 Helium Leak Test: Test the finished detectors as follows: weld the open end of the sheath or otherwise seal, and wipe the detector clean with a solvent-saturated material. The recommended solvents are alcohol, methyl ethyl ketone, or methyl iscbutyl ketone. Pressurize the sheath externally with he? ium to at least $6.9 \mathrm{MPa}$ (1000 psig) for a period of 
5 to $10 \mathrm{~min}$. Wipe the detector again with a solventsaturated tissue and insert within $2 \mathrm{hr}$ into a test chamber. Evacuate the interior of this chamber to a pressure of $50 \mathrm{im}$ $\mathrm{Hg}$ or less and test for the presence of helium using a mass spectrometer-type helium-leak detector. An indication of helium leakage of $6 \times 10^{-9}$ standard $\mathrm{cm}^{3} / \mathrm{s}$ or greater shall be taken as evidence of a leak, and the detector shall be rejected.

5.2.2 Calorimeter Test: Test the finished detectors as follows: Sea? weld the open end of the sheath and place the detector in a water environment in a hydrcstatic chamber. Operate the chamber at a pressure of $17.2 \mathrm{MPc}(2500 \mathrm{psig})$ and $616 \mathrm{~K}\left(650^{\circ} \mathrm{F}\right)$ for at least 24 hours. Remove from the chamber and measure the insulation resistance of the detectors in accordance with paragraph 5.1. If the detector joes not meet the requirements of paragraph 5.1, it shall be taken as evidence of a leak and the detector shall be rejected.

5.3 Short Circuit Test: Tests shall be performed on the finished detectors to demonstrate that the short circuit current is Timited to 0.1 nanoamp at a temperature of $616 \mathrm{~K}\left(650^{\circ} \mathrm{F}\right)$.

5.4 Thermal Shock Test: The testing medium shall be noncorrosive, and shail be maintained at a temperature of $586 \pm 14 \mathrm{~K}\left(775 \pm 25^{\circ} \mathrm{F}\right)$ during the test. Cycle by immersing the emitter end of the detector and at least $25 \mathrm{~mm}$ ( $1 \mathrm{in.}$ ) of cable in the tasting medium and hold for 2 to $5 \mathrm{~min}$. Remove from the testing medium and cool to room temperature by means of a water quench within $5 \mathrm{sec}$. The total elapsed time at room temperature shall be no les's than 1 min before recycling. The insulation resistance after testing shall be as specified in paragraph 5.1 .

6.0 SENSITIVITY: The emitter neutron sensitivity shall be $\geq 1.6 \times 10^{-23}$ $\mathrm{A} / \mathrm{nV}-\mathrm{Cm}$.

7.0 CALIBRATION: Calibration by the manufacturer is not required. 
TTPS-1007, Rev. I

\subsection{QUALITY ASSURANCE:}

\subsection{Inspections:}

8.1.1 Examination of Materials and Procedures: PNL reserves the right to inspect al1 materials and procedures during fabrication, testing, and before shipment to assure that the prescribed requirements are met.

8.1.2 Visual: The surface of the sheath shall be bright with no visible oxidation, scale or discoloration.

8.1.3 Radiographic Inspection: The emitter end and at ieast $51 \mathrm{~mm}$ (2 in.) of cable of the fabricated detector shall be examined by radiography for defects and shall be certified to be defect free. The detectors shall be radiographed in two directions $90^{\circ}$ apart and perpendicular to the detector axis. Defects which are cause for rejection are as follows:

(a) Cracks, voids or inclusions in the sheath wall or end weld greater than $10 \%$ of the sheath wall thickness or $0.025 \mathrm{~mm}(0.001 \mathrm{in.})$, whichever is greater, are cause for rejection.

(b) Cracks, voids, inciusions, discontinuities, and size reductions of the emitter, conductors, insulation, or sheath diameter greater than $0.025 \mathrm{~mm}(0.001 \mathrm{in}$.) are cause for rejection.

\subsection{Acceptance Tests at PNL:}

8.2.1 Visual inspection, paragraph 8.1.2.

8.2.2 Verification of insulation resistance, paragraph 5.1 .

8.3 Documentation: Certified copies of the following test and inspection reports shall be submitted to the purchaser.

\subsubsection{Dimensional:}

(a) Distance from center of emitter to end of collector.

(b) Distance from end of emitter to end of collector. 


\subsubsection{Chemical Analyses:}

(a) Emitter material (see 4.1.1(a)).

(b) Emitter mineral insulation (see 4.1.2(a)).

(c) Collector material (see 4.1.3(a)).

(d) Inner conductors (see 4.2.I(a)).

(e) Cable mineral insulation (see 4.2.2(a)).

(f) Sheath material (see 4.2.3(a)).

\subsubsection{Tests:}

(a) Insulation resistance (see 5.1).

(b) Sheath and collector integrity (see 5.2).

(c) Short circuit test (see 5.3).

(d) Therma 1 shock test (see 5.4).

8.3.4 Inspection: Radiographs of emitter end of detectors (see 8.1.3).

\subsection{PREPARATION FOR SHIPMENT}

9.l Cable Seals: The end of the mineral insulated cable shall be permanently sealed.

9.2 Cable Termination: The end of the cable shall have a temporary flexible lead approximately $152 \mathrm{~mm}$ (6 in.) in length, attached for the purpose of inspection and calibration. The leads shall be coded so that the emitter and background conductors may be identified. The coding information shall be inciuded with the shipment.

9.3 Cleaning: The surface of the finished detectors shall be free of grease, oil, fingermarks, dirt, scale, and other foreign matter before packaging.

9.4 Marking: Each detector shall be assigned a serial number. The serial number shall be inscribed on a corrosion-resisting metal tag and affixed to the assembiy with paper or plastic-coated corrosion-res istant wire approximately $152 \mathrm{~mm}$ ( 6 in.) from the end of the metal sheath cable. 


\section{TTPS-1007, Rev. I}

9.5 Packing and Shipping: The cable shall be coiled for shipping in a diameter of not less than $305 \mathrm{~mm}$ (12 in.). The detectors and cables shall be packaged and shipped in such a manner that they are received in an undamaged condition. 
TTPS-1013 Revision 0

Specification for Zircaloy-4 to Type 304L Stainless Steel

Transition Pieces Provided by Coextrusion

R. F. Klein

1.0 SCOPE: This specification defines the materials and the quality control provisions which shall apply to the parts machined to the applicable drawing. The finished machined part will be a transition piece from one metal to another.

The finished machined parts shall be made from Zircaloy-4 zirconium alloy and type $304 \mathrm{~L}$ stainless steel. These two materials shall be joined by a coextrusion process.

2.0 APPLICABLE DOCUMENTS:

- ASTM Specification B 351-67, "Hot-Rolled and Cold-Finished Zirconium and Zirconium Alloy Bars, Rod, and Wire for Nuclear Application."

- ASTM Specification A-276, "Specification for Stainless and HeatResisting Stee I Bars and Shapes."

- MIL-I-6866, latest revision, "Penetrant Method of Inspection."

3.0 SPECIAL PROVISIONS:

3.1 Parts: The total number of finished parts obtained from any one extrusion shall be at the vendor's option.

3.2 Lot: For the purpose of this specification, the term "lot" is defined as one unmachined extruded bar.

3.3 Tolerance: The tolerance on the diameter of the $2 \mathrm{r}-4 / 304 \mathrm{~L}$ interface shall be as shown on the drawing. However, it will be the vendor's responsibility to see that there will be no zircaioy in the area of the stainless steel weld freparation and no stainless steel in the area of the zircaloy weld preparation when the parts are finished machined to the dimensions of the drawing. 


\subsection{QUALITY CONTROL PROVISIONS:}

\subsection{Unmachined Extrusion:}

4.1.1 wafers: The unmachined extrusion shall be cut into sections long enough to obtain finished machined parts plus a wafer from both ends of each part. It will be necessary to have only three wafers for every two parts as long as the wafers from each part can be directly correlated to the ends from which they were cut. The thickness of the wafers shall be vendor's option but shall be sufficient to make possible the practical execution of all inspection steps pertaining thereto.

4.1.2 Interface Diameter: The bond interface diameter shall be measured on all wafers to assure that it is within the dimensjons shown on the drawing.

4.1.3 L.P. Inspection: A1l wafers shall be liquid penetrantinspected per MIL-I-6866 prior to machining on the part. Any evidence of a crack shali be cause to reject the next adjacent piece(s) of the extrusion.

4.1.4 Metallography: One wafer shall be selected at random from each lot, mounted and polished and one photomicrograph of the bond interface shall be obtained. The mount and photomicrograph shall be furnished to the customer.

\subsection{Finished Machined Parts:}

4.2.1 Leak Test: All finished machined parts shall be helium leak tested. A standard leak-rate ceil calibrated to $2.0 / 4.0 \times$ $10^{-8} \mathrm{std} \mathrm{cc} / \mathrm{sec}$ sha 11 be used. Any evidence of a leak in excess of the standard shall be cause for rejection of the part.

4.2.2 L.P. Inspection: All finished machined parts shall be liquid penetrant-inspected. Any indications of cracks, laps or unbonded areas shall be cause for rejection of the part. 
4.2.3 Dimensional Inspection: A dimensional inspection of the finished parts shall be performed. Parts with dimensions outside of the tolerance on the drawing shall be rejected.

4.2.4 Cleaning: All parts (wafers and finished machined parts) shall be thoroughly cleaned on the interior and exterior first with acetone, then alcohot.

4.2.5 Packaging: All parts (wafers and finished machined parts) shall be individually packaged in sealed plastic envelopes. The envelope of each machined part shall be marked with its serial number; likewise, the envel spes containing the wafers shall be identified. A separate list shall be provided to identify wafers with associated machined part and identify from which end of the machined part the wafer comes. The nature of markings shall prevent obliteration. If it becomes necessary to mark directly on a mathined part or a wafer at any time, only a chloride- or fluoride-free marking pen shall be used.

4.2.6 Part/Extrusion Location: A separa:e "map" of the extrusion shall be provided to show the location along the length of the extrusion from which each machined part was taken.

4.2.7 Shipping: All parts shall be shipped in a wooden box and packed in a manner to preclude in-transit damage. 
NRU STANDARD AND INSTRUMENTED FUEL RODS

C. Nealley

1.0 SCOPE: This product specification describes the test fue 1 rods used in the LOCA Simulations in NRU Project, the requirements for the final product, verification of these requirements and the associated documentation.

2.0 APPLICABLE DOCUMENTS: The following documents form a part of this specification.

TTMS-1001 Zirconium Alioy Seamless Tubs

TTMS-1002 Zirconium Alloy Bar, Rod, and Wire Stock

TMS-1014 Incone] $X-750$ Spring wire

TTMS-1033 Stainless Steel Bars and Shapes

TTMS-1060 Uranium Dioxide Powder

TTMS-1063 A7uminum 0xide Powder

THTS-1003 Incone $1 \times-750$ Heat Treatment Requirements

TTS-1013 Zircaloy-4 to Type 304L Stainless Steel Transition

Pieces Produced by Coextrusion

TTPS-1019 Uranium Dioxide Pellet

TTPS-1029 Inconel-600 Sheathed Chromel-Aiumel Thermocouples

with Single or Dual Diameters for Nuclear

Applications.

TTWS-1000 Specification for Welding Austenitic Stainless Steel

TTWS-1004 Zirconium Alloy Welding

ASTM A 276 Stainless and Heat-Resisting Stee 1 Bars and Shapes

ASTM B 352 Zirconium and Zirconium ATloy Sheet, Strip, and Plate for Nuclear Applications 
TTPS-1017, Rev I

\subsection{MATERIAL REQUIREMENTS:}

3.1 Cladding Assemblies: The cladding assemblies shall consist of cladding made from Zircaloy-4 in accordance with PNL specification TTMS-1001 and thermocouples made in accordance with PNL specification TTPS-1029.

3.2 End Caps: The upper and lower end caps shall be made from Zircaloy-4 in accordance with PNL specification TTMS-1002.

3.3 Plenum Springs: The plenum springs shall be made from Inconel $X-750$ in accordance with PNL specification TTMS-1014.

3.4 Insulator Discs: The insulator discs shall be made from aluminum oxide powder in accordance with PNL specification TTMS-1063.

3.5 Fuel Pellets: The fuel pellets shall be made from $\mathrm{UO}_{2}$ powder in accordance with PNL specification TTMS-1060.

3.6 Zirconium-to-Sainless Steel Transition Pieces: The zirconium-tostainiess steel transition pieces shall be made from coextruded Zircaloy-4 and 304L stainless steel in accordance with ASTM specifications 8352 and $A 276$, respectively.

3.7 Stand Offs: The stand offs shall be made from Zircaloy-4 in accordance with PNL specification TTMS-1002.

3.8 Instrument and Thermocouple Adapters: The instrument and thermocouple adapters shall be made from 304L stainless steel in accordance with PNL specification TTMS-1033.

3.9 Thermocouple Adapters: The thermocoup le adapters shall be made from 304L staintess steel in accordance with PNL specification TTMS-1033.

4.0 TECHNICAL REQUIREMENTS: There are 14 types of fue 1 rods in the LOCA Simulations in NRU test. These test fuel rods will be fabricated in accordance with PNL drawings: 
TTPS-1017, Rev 1

$\begin{array}{ll}\text { Rod Type I } & \mathrm{H}-3-41832 \\ \text { Instrumented Rod Type II } & \mathrm{H}-3-41833 \\ \text { Instrumented Rod Type III } & \mathrm{H}-3-41834 \\ \text { Instrumented Rod Type IV } & \mathrm{H}-3-41835 \\ \text { Instrumented Rod Type V } & \mathrm{H}-3-41836 \\ \text { Instrumented Rod Type VI } & \mathrm{H}-3-41837 \\ \text { Instrumented Rod Type VI I } & \mathrm{H}-3-41838 \\ \text { Instrumented Rod Type VIII } & \mathrm{H}-3-41839 \\ \text { Instrumented Rod Type IX } & \mathrm{H}-3-41840 \\ \text { Instrumented Rod Type X } & \mathrm{H}-3-41841 \\ \text { Instrumented Rod Type XI } & \mathrm{H}-3-41842 \\ \text { Instrumented Rod Type XII } & \mathrm{H}-3-41881 \\ \text { Instrumented Rod Type XIII } & \mathrm{H}-3-41882 \\ \text { Instrumented Rod Type XIV } & \mathrm{H}-3-41883\end{array}$

In addition, the requirements of the following section apply to the fabrication of the test fuel rods.

\subsection{Cladding Assemblies:}

4.1.1 Types: There are five types of cladding assembiies that shall be fabricated in accordance with PNL drawings:

$\begin{array}{ll}\text { Cladding Assembly Type I } & \mathrm{H}-3-41861 \\ \text { Cladding Assembly Type II } & \mathrm{H}-3-41864 \\ \text { Cladding Assembly Type III } & \mathrm{H}-3-41869 \\ \text { Cladding Assembly Type IV } & \mathrm{H}-3-41871 \\ \text { Cladding Assembly Type V } & \mathrm{H}-3-41884\end{array}$

4.1.2 Application: The five types of cladding assemblies shall be used in the test fuel rods in accordance with the requirements of Table 1. 
TABLE 1.

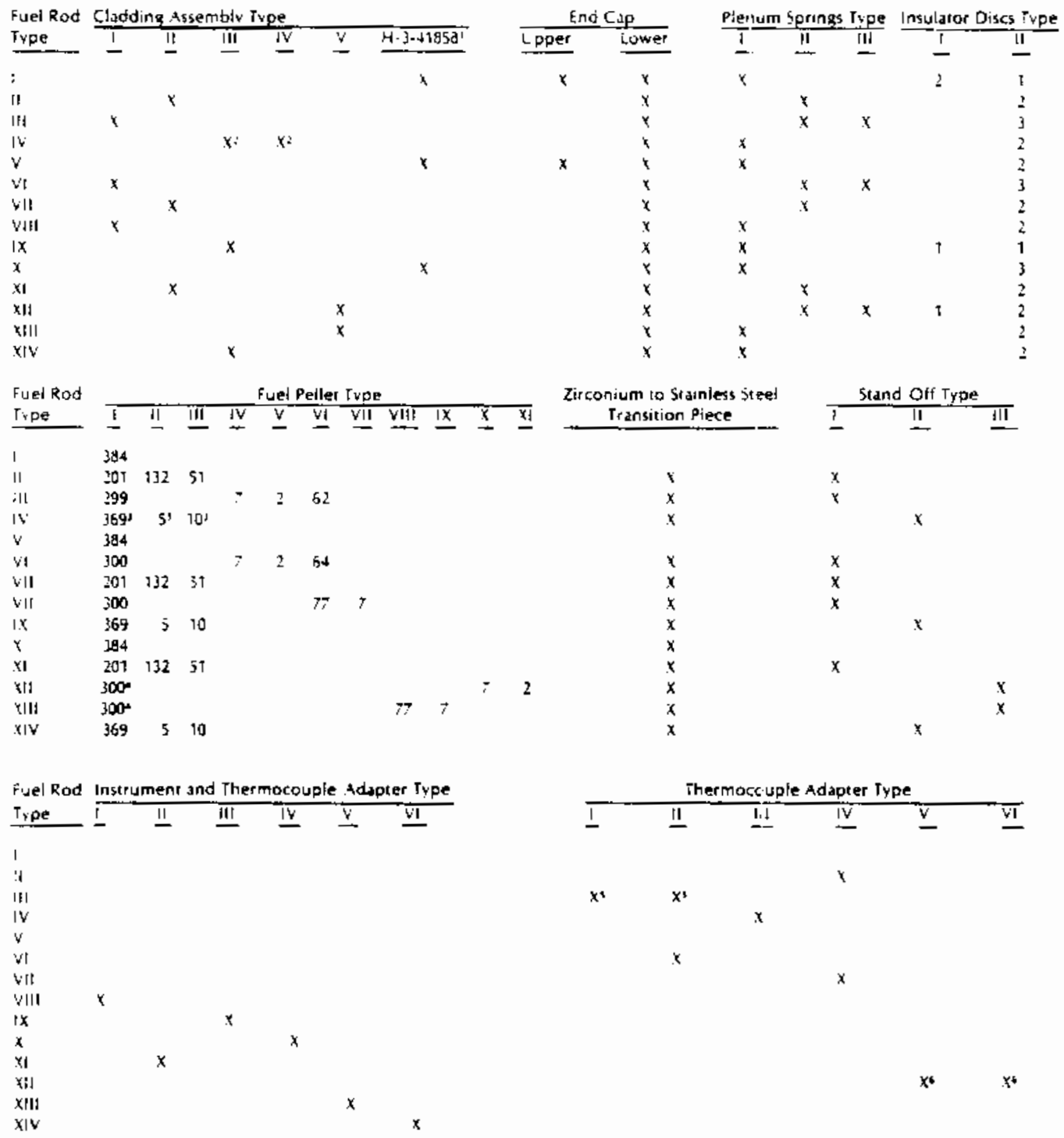

\footnotetext{
iThree fuel rod types do not have cladding rhermocoupiet. These 3 luel rod types wril nor have il cladding assernibly type. but will have a cladding made from PNL drawing H-1-41858.

ifuel rod type IV has six assemblies. Three of these assembiies will use cladding assembiy type ill and three oi these assemblies will use cladding asemnly type iv.

Ifyei sod type IV has six assemblies. Three of these assemblies will use 384 peflets of type I. The cther three assembalies will use 369 peliets or type I. 5 pellets of type 11 and 10 pellets of type ill.

This is a nominal value.

There are tour assemblies in fuei rod rype HI. Two assemblies have thermocouple adapter type I and two assemblies have thermocouple dopter type II.

There afe two assemblies in fuel rod type $X I 1$. One assembily has thermocouple adapter twpe $V$ atrd one assembly has thermocouple acapter type $V$.
} 
TTPS-1017, Rev 1

4.1.3 Cladding: The cladding assemblies shall be made from two different types of cladding. Cladding assemblies types I, II, III and $V$ shall be fabricated from cladding in accordance with PNL drawing H-3-41858. Cladding assembly IV shall be fabricated from cladding in accordance with PNL drawing $\mathrm{H}-3-41872$.

4.1.4 Thermocouples: Cladding assemblies types I, II, III and V shall have internal resistance spot welded thermocouples. Cladding assembly type IV shall have imbedded thermocouples. The location of these thermocouples shall be in accordance with the PNL drawings listed in Section 4.1.i.

\subsection{End Caps:}

4.2.1 Types: The lower end cap shall be fabricated in accordance with PNL drawing H-3-41823. The upper end cap shall be fabricated in accordance with PNL drawing H-3-41824.

4.2.2 Application: The upper and lower end caps shall be used in the test fuel rods in accordance with the requirements of Table 1 .

\subsection{Plenum Springs:}

4.3.1 Types: There are three types of plenum springs that shall be fabricated in accordance with PNL drawings:

\begin{tabular}{lc} 
Plenum Spring Type I & PNL Drawing \\
Plenum Spring Type II & $\mathrm{H}-3-41828$ \\
Plenum Spring Type III & $\mathrm{H}-3-41862$ \\
\hline
\end{tabular}

4.3.2 Application. The three types of plenum springs shall be used in the test fuel rods in accordance with the requirements of Table $i$. 
4.3.3 Heat Treatment: The plenun springs shall be heat treated in accordance with PNL specification THTS-1003.

4.4 Insulator Dises:

4.4.1 Types: The two types of insulator discs shall be fabricated in accordance with PNL drawing H-3-41829.

4.4.2 Application: The two types of inst: lator discs shall be used in the test fuel rods in accordance with the requirements of Table 1 .

4.5 Fuel Pellets:

4.5.1 Types: The eleven types of fuel pellets shall be fabricated in accordance with PNL drawing H-3-41830.

4.5.2 Application: The eleven types of fuel pellets shall be used in the test fuel rods in accordance with the requirements of Table 1.

4.5.3 Product Requirements: In addition to the above requirements, the requirements in PNL specification TTPS-1019 apply.

\subsection{Zirconium-to-Stain]ess Steel Transition Pieces:}

4.6.1 Types: The zirconium-to-stainiess stee 1 transition pieces shall be fabricated in accordance with PNL drawing H-3-41825.

4.6.2 Application: The zirconium-to-stainless steel transition pieces shall be used in the test fuel rods in accordance with the requirements of Table 1 .

4.6.3 Product Requirements: In addition to the above requirements, the requirements in PNL specification TTPS-1013 apply. 


\subsection{Stand Offs:}

4.7.1 Types: There are three types of stand offs that shall be fabricated in accordance with PNL drawings:

$\begin{array}{ll}\text { Stand Off Type I } & \text { PNL Drawing } \\ \text { Stand Off Type II } & H-3-41859 \\ \text { Stand Off Type III } & H-3-41870\end{array}$

4.7.2 Application: The three types of stand offs shall be used in the test fuel rods in accordance with the requirements of Table 1.

\subsection{Instrument and Thermocouple Adapters:}

4.8.1 Types: There are six types of instrument and thermocouple adapters that shall be fabricated in accordance with PNL drawings:

\begin{tabular}{lll} 
& \multicolumn{2}{c}{ PNL Drawing } \\
\cline { 3 - 3 } Instrument and Thermocouple Adapter Type I & $\mathrm{H}-3-41860$ \\
Instrument and Thermocouple Adapter Type II & $\mathrm{H}-3-41860$ \\
Instrument and Thermocouple Adapter Type III & $\mathrm{H}-3-41873$ \\
Instrument and Thermocoup le Adapter Type IV & $\mathrm{H}-3-41873$ \\
Instrument and Thermocouple Adapter Type V & $\mathrm{H}-3-41886$ \\
Instrument and Thermocouple Adapter Type VI & $\mathrm{H}-3-42081$
\end{tabular}

4.8.2 Application: The six types of instrument and thermocoupie adapters shal] be used in the test fuel rods in accordance with the requirements of Table 1.

\subsection{Thermocouple Adapters:}

4.9.1 Types: There are six types of thermocouple adapters that shall be fabricated in accordance with PNL drawings: 
TTPS-1017, Rev 1

$\begin{array}{lc}\text { Thermocouple Adapter Type I } & \text { PNL Drawing } \\ \text { Thermocouple Adapter Type II } & \mathrm{H}-3-41863 \\ \text { Thermocouple Adapter Type II } & \mathrm{H}-3-41863 \\ \text { Thermocouple Adapter Type IV } & \mathrm{H}-3-41865 \\ \text { Thermocouple Adapter Type V } & \mathrm{H}-3-41887 \\ \text { Thermocoup le Adapter Type VI } & \mathrm{H}-3-41887\end{array}$

4.9.2 Application: The six types of thermocouple adapters shall be used in the test fuel rods in accordance with the requirements of Table 1 .

5.0 FUEL ROD ASSEMBLY: The fuel rod components, which are listed in sections 4.1 to 4.9 of this specification, shall be assembled into a completed fuel rod as specified in the PNL drawings listed in section 4.0. In addition, the requirements of this section shall apply.

5.1 Bottom End Cap Welding: The bottom end cap shall be welded to the fuel rod cladding prior to any other assenbly step. Welding shall be performed in accordance with PNL speci*ication TTWS-1004.

5.2 Pellet 5tack Assembly: The pellet stack shall be assembled in a Vtrough for measurement and weighing. Pellet stack length shall conform to the dimensions given in the corresponding drawing listed in section 4.0. The pellet stack shall weigh between 1925 and 2050 grams.

5.3 Rod Assembly: The pellet handing and assembly procedure, including storage and assembly environments, shall be such that the moisture content of the loaded pellets does not exceed the limits set forth in PNL specification TTPS-1019. The pellets to be loaded in one lot shall be selected within $12 \mathrm{hr}$ of tube loading, and all pellets represented by the samples shall be held in the controlled humidity 
TTPS-1017, Rev 1

atmosphere of the weld box between the time the sample is selected and the rod is sealed. Total time of exposure outside a controlled atmosphere sha!l not exceed $3 \mathrm{hr}$.

5.4 End Cap Welding: The top end cap shall be aligned such that the rod identification number on the top end cap is parallel to within $10^{\circ}$ of the open slot in the lower end cap.

5.4.1 Upper End Caps and Zirconium-to-Stainless Steel Transition Pieces: The upper end caps and the zirconium-to-stainless steel transition pieces, when required in a fuel rod, shall be welded to the fuel rod in accordance with PNL specification TTWS-1004.

\subsubsection{Instrument and Thermocouple Adapters and Thermocouple} Adapters: The instrument and thermocouple adapters and the thermocouple adapters, when required in a fuel rod, shall be welded to the zirconium-to-stainless steel transistion pieces in accordance with PNL specification TTWS-1000.

5.5 Rod Pressurization: After or during welding of the top end cap, each fuel rod that is to be pressurized shall be pressurized with helium to the specified pressure. The helium shall conform to the requirements for pure helium as set forth by the National Bureau of Standards.

\subsection{Cleanliness:}

6.1 Prior to Assembly: The cladding, end caps, and springs shall be cleaned with ethanol or other appropriate residue-free solvent prior to assembly to remove oil, grease, or any other surface contaminant. 
TTPS-1017, Rev I

6.2 Radiation Leve?: Exterior surface smear tests shall be performed. No rod shall exceed a smearabie alpha activity leve? of 20 dpm per $100 \mathrm{~cm}^{2}$ or a smearable beta-plus-gamma activity level of $1000 \mathrm{dpm} /$ $100 \mathrm{~cm}^{2}$.

6.3 Prior to Bundle Assembly: All fuel rods shall be cleaned of oil, grease, and any other surface contaminant with ethanol or other appropriate residue-free solvent prior to bundle assembly.

7.0 QUALITY ASSURANCE:

7.1 Pellet Fabrication: The quality assurance requirements for fuel pellet fabrication shall be documented in a process outline. This document will be prepared by the peliet fabricator and approved by the Project Manager and Project Quality Representative.

7.2 Rod Assembly: The quality assurance requirements for fuet rod assembly shall be documented in an assembly procedure. This document will be prepared by the rod assembler and approved by the Project Manager and Project Quality Representative. 
Uranium Dioxide Pellet

Robert Goodman

1.0 INTRODUCTION: This specification is intended as a reference standard for nuclear applications. Insofar as practicable, it recognizes the diversity in specific product requirements and the methods of manufacture of specific product. It is therefore anticipated that a purchaser may supplement this specification with more stringent and/or additional requirements for specific applications.

2.0 SCOPE:

2.1 This specification is for sintered uranium dioxide pellets. It applies to uranium dioxide pellets containing uranium of any $235 \mathrm{U}$ concentration.

2.2 This specification does not include (a) provisions for preventing criticality accidents or (b) requirements for health and safety. Observance of this standard does not relieve the user of the obligation to be aware of and conform to a 11 federal, state, and local regulations pertaining to possessing, shipping, processing, or using source or special nuclear material.

2.3 The function of the uranium dioxide fuel pellet is to provide heat energy throughout the operating cycle(s) at rates specified by the fuel management program. The fuel pellet must operate without melting and within the irradiation swelling limits specified by clad strain inits.

2.4 Impurity and Equivalent Boron Specifications are 1isted in Appendix A.

2.5 Applicable Documents are iisted in Appendix B.

\subsection{TECHNICAL REQUIREMENTS:}

3.1 Chemical Requirements: All chemical analyses shall be performed on portions of the representative sample prepared in accordance with Section 5.0. Analytical chemistry methods used shall be as stated in ASTM Method C696-77. 
3.1.1 Uranium Content: The uranium content shari be a minimum of 87.7 percent by weight on a dry weight basis.

3.1.2 Impurity Content: The impurity zontent shall not exceed the individual element limit specified in Table 1 , Appendix $A$, on a uranium weight basis. The sumnation of the contribution from each impurity element 1 isted in Table 1, Appendix $A$, shall not exceed 1500 ppm.

3.1.3 Stoichiometry: The oxygen-to-uranium ratio of sintered fuel perlets shail be within the range of 1.99 to 2.02 .

3.1.4 Moisture Content: The moisture content of a given pellet shal1 not exceed $20 \mathrm{ppm}$ on a urarium weight basis. The average moisture content of the $\mathrm{UO}_{2}$ pellets in a fuel rod shal1 not exceed $10 \mathrm{ppm}$ on a urarium weight basis.

3.1.5 Gas Content: The gas content of a given sintered pellet, excluding moisture, shall not exceed, at standard temperature and pressure, $0.10 \mathrm{cc} / \mathrm{g}$ of uranium. The average gas content of the pellets in a fuel rod shall not exceed, at standard temperature and pressure, $0.05 \mathrm{cc} / \mathrm{g}$ of uranium. Gas content shal1 be determined by vacuum outgassing at $3000^{\circ} \mathrm{F}$.

\subsection{Nuclear Requirements:}

3.2.1 Isotopic Content: The isotopic content of the uranium in the UO, pellets shall be determined by mass spectrometry. The ${ }^{234} \mathrm{U},{ }^{2}{ }^{236} \mathrm{U}$, and ${ }^{238} \mathrm{U}$ content of the uranium sha 11 be reported on a weight percent basis. The isotopic concentrations sha11 be as specified by the buyer.

3.2.2 Equivalent Boron Content: For thermal reactor use, the total equivalent boion content ( $E B C$ ), based on a summation of the contributions from each of the elements indicated in Table 2, Appendix A, shali not exceed 4.0 Fpm on a uranium weight basis. (Factors for converting constituent concentrations to equivalent boron concentrations are given in Table 2, Appendix A.) The $E B C$ of each element shall be calculated individualiy using 


\section{TTPS-1019, Rev 1}

the following formula:

$E B C$ of impurity $=(E B C$ factor $) \times(p p m$ for impurity $)$

where:

EBC factor $=\frac{(\text { at.wt boron }) \times\left(\sigma_{a} \text { element }\right)}{\left(\sigma_{a} \text { boron }\right) \times(a t . w t \text { element })}$

Alternatively, the EBC may be determined by a comparative reactivity test against a known standard. For fast reactor use, the above iimitations do not apply.

\subsection{Physical Characteristics:}

3.3.1 Dimensions: The dimensions of the pellet shall be specified on the PNL drawing.

3.3.2 Pellet Density: The density of sintered pellets shall be as specified. The theoretical density for $\mathrm{UO}_{2}$ pellets shall be considered to be $10.96 \mathrm{~g} / \mathrm{cc}$.

3.3.3 Grain Size: No fuel pellet grain size is required.

\subsubsection{Defects:}

3.3.4.1 The imits for surface cracks and fissures are:

- radial cracks on the pellet ends - 1/8 in.

- circumferential cracks - 1/2 circumference

- axial crack - $1 / 8$ in.

3.3.4.2 The limits for chips are:

- pellet ends $-0.030 \mathrm{in}$. deep $\times 10 \%$ of surface area of the pellet end

- circumferential chips -0.030 in. deep $\times 10 \%$ of the pellet circumference

3.3.4.3 Pellets with intentional slits to accommodate thermocouple leads are exempt from the requirements of 3.3.4.

3.3.5 Cleanliness and Workmanship: Finished pellets shall be free of loose chips, powder and foreign residues. 
3.3.6 Identification: Each finished pellet shall have a mark placed on the end of the peliet that permits identification of the peilet enrichment.

3.3.7 Pellet Resintered Density: The density change (increase) of the resintered pellets shail be lesis than or equal to $1.0 \%$ TD. The theoretical density for $\mathrm{UO}_{2}$ pellets shall be considered to be $10.96 \mathrm{~g} / \mathrm{cc}$. The sintered pellets chosen for the resintering test shall be hald at a resintering temperature of $1700^{\circ} \mathrm{C}$ for 24 hours prior to determination of the resintered pellet densities.

\subsection{LOT REQUIREMENTS:}

4.1 A pellet lot is defined as a group of pellets, made from a single $\mathrm{UO}_{2}$ powder lot, which has undergone identical sintering procedures.

4.2 The identity of a lot shall be retained throughout processing without mixing with other established lots.

4.3 A pellet lot shall form the basis for defining sampling plans used to establish conformance to specification.

4.4 Sampiting plans(a) shal1 be mutually agreed upon by the buyer and the seller.

5.0 SAMPLING: Uranium dioxide pellets are hygroscopic and can absorb sufficient water during exposure to a moist atmosphere to cause detectabie analytical errors. Sampling, weighing, and handling the sample shall be done under conditions which do not alter the moisture content of the sample.

5.1 A representative sample $(a)$ of peliets from each peliet lot shail be taken for the purpose of determining chemical and physicai properties.

5.2 The lot sample shall be of sufficient size to perform quality assurance testing at the selier's plant, acceptance testing at the buyer's plant, and referee tests in the event they become necessary.

5.3 The lot sample for acceptance testing at the buyer's plant shall be packaged in a separate container, clearly identified by lot number,

(a) to be defined on the purchase requisition. 
and shipped with the lot. The referee sample shali be clearly identified and retained at the seller's plant until the lot has been formally accepted by the buyer.

5.4 The number of required archive pellets shall be specified on the purchase requisition.

\subsection{TESTING AND CERTIFICATION}

6.1 The seller shall test the sample described in Section 5.0 to assure conformance of the powder to the requirements of Section 3.0. A71 testing shalt be conducted by techniques mutualiy agreed to by the buyer and seller.

6.2 The seller shall provide to the buyer documents certifying:

6.2.1 the isotopic content and identity of the starting material lot, and

6.2.2 that the pellet meets all the requirements of Section 3.0.

6.3 Test data on the following characteristics shall be supplied upon request:

- uranium isotopic content

- uranium content

- individual impurity levels

- moisture content

- peliet density, both sintered and resintered.

6.4 The seller shall report the sintering time and temperature for the pellets.

6.5 Lot Acceptance: Acceptance testing may be performed by the buyer (a) on either the sample provided by the seller or on a sample taken at the buyer's plant. Acceptance shall be on a lot basis(a) and shall be contingent upon the material properties meeting the requirements of Section 3.0.

(a) to be defined on the purchase requisition. 
6.6 Referee Method: The buyer and seiler shall agree to a third party as a referee in the event of a dispute in analytical results.

7.0 PACKAGING ANO SHIPPING:

7.1 Uranium dioxide pellets shall be packaged in sealed containers to prevent loss of material and undue contamination from air or the container materials. The exact size and method of packaging shal1 be as mutually agreed upon by the buyer and seller.

7.2 Each outer container shall bear as a minimum a label on the Tid and side with the follawing information:

$\begin{array}{ll}\text { Selier's Name } & \text { Gross, Tare, Net Oxide Weights } \\ \text { Material in Container } & \text { Uranium Neight } \\ \text { Uranium Enrichment } & \text { Purchase Order Number } \\ & \text { Lot Number }\end{array}$

\subsection{QUALITY ASSURANCE}

\begin{tabular}{|c|c|c|c|}
\hline & Section and Item & Significance $^{(a)}$ & Reference \\
\hline 3.1 & Chemical Requirements & & ASTM C696-77 \\
\hline 3.1 .1 & Uranium Content & Major & \\
\hline 3.1 .2 & Impurity Content & Critical & \\
\hline 3.1 .3 & Stoichiometry & Critical & \\
\hline 3.1 .4 & Moisture Content & Critical & \\
\hline 3.1 .5 & Gas Content & Critical & \\
\hline 3.2 & Nuclear Requirements & & \\
\hline 3.2 .1 & Isotopic Content & Critical & ASTM C696-77 \\
\hline 3.2 .2 & $\begin{array}{l}\text { Equivalent Boron } \\
\text { Content }\end{array}$ & Major & \\
\hline
\end{tabular}

\subsection{Physical Characteristics}

3.3.1 Dimensions

3.3.2 Peitet Density

3.3.3 Grain Size

3.3.4 Defects
Critical

Critical

None

Major

(a) to be defined on the purchase requisition. 
TTPS-1019, Rev 1

Section and Item

\subsubsection{Cleanliness and} Workmanship

3.3.6 Identification

3.3.7 Peliet Resintered Density

4.0 Lot Requirements

5.0 Sampling

6.0 Testing and Certification $\underline{\text { Significance }}{ }^{(a)}$

Critical

Major

Major

Major

Major

Critical

(a) These terms are defined as follows:

\section{Critical}

Inadequate control of this characteristic can result in a critical defect that could cause failure of fuel, especially in a reactor. A critical defect is a defect that judgment and experience indicate is likely to result in hazardous or unsafe conditions for individuals using, maintaining, or depending upon the product; or a defect that judgment and experience indicate is likely to prevent performance of the function of a major end product such as a fuel rod, fuel assembiy, or reactor fuel core.

\section{Major}

Inadequate control of this characteristic can result in a major defect. A major defect is a defect, other than critical, that is likely to result in faiture, or to reduce materially the usability of the unit of product for its intended purpose. 
APPENDIX A - IMPURITY AND EQUIVALENT BOFON SPECIFICATIONS

The elements Iisted in Table 1 require quantitative determination. The total impurity content, based on the summation of the contribution from each element listed in Table 1, shall not exceed $1500 \mathrm{prm}$. The total equivalent boron content shal1 not exceed $4 \mathrm{ppm}$ as determined from a summation of the contribution from each element listed in Table 2. The equivalent boron factors listed in Table 2 shall be used to compute equivalent boron contents.

TABLE 1. Impurity Elements and Maximum Concentration Limits

Elements

Aluminum
Carbon
Calcium plus Magnesium
Chiorine
Chromium
Cobalt
Fluorine
Hydrogen Exclusive of Moisture
Iron
Nickel
Nirtogen
Silicon
Thorium

Maximum Concentration Limit (ppm)

100

100

200

25

200

100

25

5

500

250

75

2.50

30 
TTPS-1019, Rev 1

TABLE 2. Equivalent Boron Factors

Absorption Cross (a)

Section, $\sigma_{a}$

Element (barns-2200 m/sec)

Aiuminum

0.235

Atomic Weight EBC Factor

Barium

1.2

26.98

0.0001

Boron

759.0

137.34

0.0001

Cadmium

$2,540.0$

10.81

1.0000

Calcium

0.44

112.40

0.3104

Cesium

30.0

40.08

0.0002

Chiorine

33.2

138.97

0.0031

Chromium

3.1

35.45

0.0133

Cobalt

37.2

52.00

0.0008

Copper

3.8

58.93

0.0090

Dysprosium

930.0

63.54

0.0009

Europium

$4,400.0$

162.50

0.0815

Gadol inium

$49,000.0$

Hafnium

105.0

151.96

0.4124

Iron

2.55

157.26

4.438

178.49

0.0084

Lithium

71.0

55.85

0.007

Manganese

13.30

6.939

0.1457

Molybdenum

2.70

54.94

0.0034

Nickel

4.60

95.94

0.0004

Ni trogen

7.85

Phosphorus

0.19

58.71

0.0011

14.01

0.0018

Sama rium

$5,820.0$

30.97

0.0001

Silicon

0.16

150.35

0.5513

Tantalum

21.0

28.09

0.0001

Tin

0.63

108.95

0.0017

Titanium

6.1

178.69

0.0001

Tungsten

18.5

47.90

0.0018

Vanadium

5.06

183.85

0.0014

zinc

1.10

50.94

0.0014

65.37

0.0002

(a) Brookhaven National Laboratory Publication BNL-325, Second Edition, July 1958 and Supplement No. 1, January 1960, and Supplement No. 2 1964-1966. 
TTPS-1019, Rev I

\section{APPENDIX B - APPLICABLE DOCUMENTS}

1. Code of Federal Regulations, Title 10.

2. Nuclear Safety Guide, U.S. Atomic Energy Commission Report TID-7016, Latest Edition.

3. "Handbook of Nuclear Safety," H. K. Clark, U.S. Atomic Energy Commission Report, DP-532.

4. ASTM Method C696-77, "For Chemical, Mass Spectrometric, and Spectrochemical Analysis of Nuclear Grade Uranium Dioxide Powder and Pellets."

5. Military Standard, MIL-STD-109B. Apri1 4, 1959. (Pages 2, 3, 4 and 6). 
Eddy Current Pressure Transducer System for Measuring

Fuel Rod Internal Pressure in a Nuclear Reactor

\author{
R. K. Marshall
}

1.0 SCOPE: This specification presents the requirements for high temperature, eddy current type pressure transducers for measuring the interal pressure of a fuel rod in an operating nuclear reactor. A summary of the design requirements is shown in Table 1 .

2.0 ENVIRONMENTAL CONDITIONS: The transducers and a portion of the extension cables will operate in flowing pressurized water up to 2500 psig and $345^{\circ} \mathrm{C}$ $\left(650^{\circ} \mathrm{F}\right)$ and must be designed to withstand a total thermai neutron fluence of $3 \times 10^{20}$ nvt at a fiux of $5 \times 10^{13}$ nv and a gamma flux of $1.0 \times 10^{9} \mathrm{R} / \mathrm{hr}$.

3.0 TRANSOUCER OPERATION: The transducer will be welded to the end of a fuel rod and will monitor the internal pressure of the fuel rod. The internal pressure range will be $0-500$ psi.

\title{
4.0 CONSTRUCTION:
}

\subsection{Transducer:}

Materials - ali inorganic

Size Limitations - As specified on vendor information drawings supplied with the ordering information.

4.2 Extension Cable: The extension cable shall consist of a metal sheathed cable coupled to a soft cable. The transition connector between the metal sheathed and soft cable and the terminating connector which connects the soft cable to the signat conditioner shall be vendor designed and supplied. The metal sheathed cable shall extend from the transducer housing to the transition connector and shall be capable of withstanding the environmental conditions listed in Section 2.0. The metal sheathed cable shall have a 
TTPS-1022, Rev 1

maximum 00 of $1.59 \mathrm{~mm}(0.063 \mathrm{in.})$. The cable insulation shal t be inorganic. The iength of the metal sheathed cable and, the length of the soft cable shall be specified in the ordering information. The finished cable shall be annealed in either a vacuum or hydrogen atmosphere.

As a goal, straightness of the metal sheathed cable should be such that a go-no-go gauge having a length of $1.59 \mathrm{~cm}(5 / 8 \mathrm{in.})$ and a hole diameter not greater than $0.051 \mathrm{~mm}(0.002 \mathrm{in.})$ greater than the cable diameter should pass over the ful length of the metal sheathed cable without binding.

PNL reserves the right to review the verdor quaity assurance plan for fabrication of the metal sheathed cables to assure adequacy for nuclear service.

4.3 Signal Conditioner: Each transducer and extension cable shall be calibrated with its signal conditioner and matching circuit cards supplied for each transducer as required.

\subsection{SYSTEM ASSEMBLY:}

5.1 Extension Cable Routing: The transducer housing will be located in the core of an operating nuclear reactor with the metal sheathed cable routed through a pressure boundary penetration to the readout instrumentation. The transition connector attached to the end of the metal sheathed cable must be designed so that it can be removed and installed in the field without signi"icantly affecting the system calibration. The sheathed cable with the connector renoved must be capable of being inserted through a hole not greater than $0.051 \mathrm{~mm}(0.002 \mathrm{in.})$ greater than the cable diameter. The remova? of the connector is required to permit the transducer and metal sheathed cable to be assembled as part of an experimental 
TTPS-1022, Rev 0

apparatus. In addition, the pressure transducer metal sheathed cable along with a number of other instrument cables (no power cables) will penetrate a Hastealloy plug to which the metal sheathes wili be brazed.

Cables from several eddy current type pressure transducers in the same test assembly will be assembled with other instrument cables such as thermocouples, linear variable differential transforms, turbine flow meters, and self powered neutron detectors into protective metal tubes within the reactor core. It is not possible to isolate the pressure transducer cable from ground between the sensor and the electronics.

Depending on the location of the transducer in the reactor test facility, up to $3.7 \mathrm{~m}(12 \mathrm{ft})$ of the metal sheathed cable will operate at approximately $315^{\circ} \mathrm{C}\left(600^{\circ} \mathrm{F}\right)$. A transition temperature zone occurs below and above the pressure boundary penetration. This zone is approximately $3 \mathrm{~m}(10 \mathrm{ft})$ long and the temperature of the cable decreases from $315^{\circ} \mathrm{C}\left(600^{\circ} \mathrm{F}\right)$ to $21^{\circ} \mathrm{C}$ $\left(70^{\circ} \mathrm{F}\right)$ within this region. The remaining cable length of approximately $4.9 \mathrm{~m}(16 \mathrm{ft})$ as well as the signal conditioner operate at $21^{\circ} \mathrm{C}\left(70^{\circ} \mathrm{F}\right)$.

5.2 Transducer End Fittings: The transducer will be welded to the fuel rod. The end fitting design is shown on the vendor information drawing supplied with the ordering information. The cable end of the transducer will be attached to other instrumentation. The design requirements for this end of the transducer are shown on the vendor information drawing.

\subsection{CALIBRATION: A minimum of 20 calibration points on each transducer} system shall be made at each of three temperatures over the specified pressure range. These data shal1 be taken for up runs and down runs with a minimum of 10 points for each run at $25^{\circ} \mathrm{C}, 270^{\circ} \mathrm{C}$, and $540^{\circ} \mathrm{C}\left(77^{\circ} \mathrm{F}\right.$, $500^{\circ} \mathrm{F}$, and $\left.1000^{\circ} \mathrm{F}\right)$. The foregoing procedure shall be repeated twice. 
TTPS-1022, Rev I

\subsection{QUALITY ASSURANCE}

7.1 Documentation: Documentation of all manufacturing, materials testing, and quality records for each transducer system shall be maintained and submitted to the purchaser.

7.2 Inspection: PNL reserves the right to inspect all materials and procedures during fabrication, testing. and before shipment to assure that the prescribed requirements; are met.

7.3 Acceptance Tests at PNL:

Acceptance testing at PNL will include the following:

Visuat inspection

Verification of Section 6.0, Calitration.

\subsection{PREPARATION FOR SHIPMENT:}

8.1 Cable Seals: The ends of the extension cables shall be sealed in such a manner that handling during shipment will not break the seal.

8.2 Cable Packing and Shipping: The cable shall be coiled for shipping in a diameter of approximately $25 \mathrm{~cm}(12 \mathrm{in.})$. The transducer systems shall be cleaned, packaged, and shipped in such a manner that they are received in an undamaged sondition. 
TTPS-1022, Rev 1

TABLE 1. Summary of Requirements for High Temperature Eddy Current Type Pressure Transducer System for Measuring Water Pressure in a Nuclear Reactor Facility

\section{Environmental Conditions}

Pressurized flowing water up to $2500 \mathrm{psig}$ and $650^{\circ} \mathrm{F}$

Total neutron fluence: $\quad 3 \times 10^{20}$ nvt

Neutron flux: $\quad 5 \times 10^{13} \mathrm{nv}$

Gamma flux: $\quad 1.0 \times 10^{9} \mathrm{R} / \mathrm{hr}$

Pressure Transducer System Specification

Pressure

Range $\quad 0-500 \mathrm{psi}$

Temperature

Design Temperature Range

Sensor and Metal Sheathed Cable $-75^{\circ} \mathrm{C}$ to $540^{\circ} \mathrm{C}\left(-100^{\circ} \mathrm{F}\right.$ to $\left.1000^{\circ} \mathrm{F}\right)$

Connector on Metal Sheathed $\mathrm{Cab} l e-75^{\circ} \mathrm{C}$ to $150^{\circ} \mathrm{C}\left(-100^{\circ} \mathrm{F}\right.$ to $\left.300^{\circ} \mathrm{F}\right)$

Soft $\mathrm{Cable}$ and Connector $\quad-55^{\circ} \mathrm{C}$ to $105^{\circ} \mathrm{C}\left(-67^{\circ} \mathrm{F}\right.$ to $\left.220^{\circ} \mathrm{F}\right)$

Electronics $\quad 0^{\circ} \mathrm{C}$ to $55^{\circ} \mathrm{C}\left(32^{\circ} \mathrm{F}\right.$ to $\left.132^{\circ} \mathrm{F}\right)$

Calibration $\quad 25^{\circ} \mathrm{C}, 270^{\circ} \mathrm{C}, 540^{\circ} \mathrm{C}\left(77^{\circ} \mathrm{F}, 500^{\circ} \mathrm{F}\right.$, $1000^{\circ} \mathrm{F}$ ) See Section 6.0 for additiona?

requirements.

Rate of Temperature Change for

Specified Thermal Zero or

Sensitivity Shifts $\quad 0.5^{\circ} \mathrm{C} / \mathrm{sec}\left(0.9^{\circ} \mathrm{F} / \mathrm{sec}\right)$ max.

Therma? Zero Shift $\left(25^{\circ} \mathrm{C}\right.$ to max.

operating temperature)

Sensor

Less than $\pm 0.0270 \mathrm{FSO} /{ }^{\circ} \mathrm{C}$

Electronics

Less than $\pm 0.04 \% \mathrm{FSO} /{ }^{\circ} \mathrm{C}$ 
TTPS-1022, Rev 1

System Performance

Frequency Response

Sensor

Electronics

Linearity, Least Squares

Repeatability $025^{\circ} \mathrm{C}\left(77^{\circ} \mathrm{F}\right)$

Hysteresis $\left(25^{\circ} \mathrm{C}\left(77^{\circ} \mathrm{F}\right)\right.$

Output Voltage, Analog
$25 \mathrm{~K} \mathrm{~Hz}$

zero to $10 \mathrm{~K} \mathrm{~Hz}$

within $\pm: \%$ FSO

within $0.1 \%$ FSO

$0.5 \%$ FSO

0 to $1 \mathrm{Vdc}$

\section{Construction}

Pressure transducer and metal sheathed cable to be an integral unit.

Materials: All inorganic

Extension Cable: Up to $11.6 \mathrm{~m} \pm 0.3 \mathrm{~m}(38 \mathrm{ft} \pm 1 \mathrm{ft})$ length specified

in purchase order.

Diameter: $1.588 \pm 0.038 \mathrm{~mm}(0.0625 \pm 0.0015)$

Maximum Envelope for Transducer: As specified on the vendor information drawing supolied with ordering information. 


\section{Specification for Special Multipair Extension Cable R. K. Marshall}

1.0 SCOPE: This specification presents the requirements for multipair extension cable for transmitting electrical signals from special quick disconnect connectors to signal conditioning electronics.

2.0 CONSTRUCTION: Extension cable with pairs of chromel-alumel conductors twisted to reduce magnetic interference. The number of pairs shall be specified in the ordering information. Each conductor to be 24 gauge stranded (7/32) wire insulated with PVC. Individual pairs shielded with aluminum backed Mylar tape and a 24 gauge bare stranded copper drain wire in contact with the aluminum to reduce electrostatic interference. A second overall aluminum backed Mylar tape shield with a 24 gauge bare stranded copper drain wire in contact with the aluminum and with a PVC outer jacket. Primary insulation to withstand ambient temperatures up to at least $378 \mathrm{~K}$ $\left(331^{\circ} \mathrm{F}\right)$. Outer jacket to withstand ambient temperatures up to at least $353 \mathrm{~K}\left(176^{\circ} \mathrm{F}\right)$. The outside diameter of the insulation over each conductor shall be less than $1.37 \mathrm{~mm}(0.054 \mathrm{in.})$ and greater than $0.76 \mathrm{~mm}(0.030 \mathrm{in.})$. Individual conductors shall be color coded and individual pairs shall be uniquely marked for easy identification. 
TTPS-1024 Rev. 0

Specification for Standard Multipair Exzension Cabie

\section{R.K. Marshall}

1.0 SCOPE: This specification presents the requirements for multipair extension cable for transmitting electrical signals from signal conditioning electronics to a data acquisition system.

2.0 CONSTRUCTION: Extension cable with pairs of copper conductors twisted to reduce magnetic interference. The number of pairs shall be specified in the ordering information. Each conductor to be 20 gauge copper insulated with PVC. Individual pairs shielded with aluminum backed Mylar tape and a bare copper. drain wire in contact with the aluminum to reduce electrostatic interference. A second overall aluminum backed Mylar tape shield with a bare copper drain wire in contact with the aluminum and with a PVC outer jacket. Primary insulation to withstand ambient temperatures to at least $378 \mathrm{~K}\left(221^{\circ} \mathrm{F}\right)$. Outer jacket to withstand ambient temperatures up to at least $353 \mathrm{~K}\left(176^{\circ} \mathrm{F}\right)$. Individual conductors shall be coior coded and individual pairs shall be uniquely marked for easy identification. 
Specification for Incone $7-600$ Sheathed Chromel-Alumel Thermocouples with Single or Dual Diameters for Nuclear Application R. K. Marshall

1.0 SCOPE:

1.1 Intent: This specification presents the requirements for sheathed, Type $K$ (chromel-alumel) thermocouples for nuclear service. The requirements of this specification include Inconel-600 for sheathing, magnesium oxide or aluminum oxide as insulation and Type $k$ thermocouple wires for thermoe lements.

1.2 Genera 7 Design: The general design of the finished thermocuples is shown in Figure 1. By appropriate selection of dimensions $A, B, C, D$ and $E$, either single diameter or dual diameter thermocuples can be specified. Sheath dimensions and tolerances for each nominal dimension shal1 be in accordance with Table 1.

2.0 APPLICABLE DOCUMENTS: The latest official issue of the following standards:

2.1 ASTM Standards:

- B 167 Specifications for Nickle-Chromium-Iron Alloy Seamless Pipe and Tubing,

- E 2 Methods of Preparation of Micrographs of Metals and Alloys (Including Recomsended Practice of Photography as Applied to Meta1lography),

- E 3 Methods of Preparation of Metallographic Specimens,

- E 94 Recommended Practice for Radiographic Testing,

- E 142 Method for Controlling Quality of Radiographic Testing,

- E 165 Method for Liquid Penetrant Inspection,

- E 220 Method for Calibration of Thermocouples by Comparison Techniques,

- E 230 Standard Temperature Electromotive Force (EMF) for Thermocouples, and

- E 235 Thermocouples, Sheathed, Type K, for Nuclear or Other High Reliability Applications. 


\subsection{ANSI Standard}

- B 46.1 Surface Texture

\subsection{ORDERING INFORMATION}

- The quantity, lengths, and nominal diameters of the sheathed themocouple (dimension A, B, C, D, E of Figure i),

- The limits of error if other than standard limits (see Tables E 230)

- Ine type of ceramic insulation required, either magnesia (MgO) or alumina $\left(\mathrm{Al}_{2} \mathrm{O}_{3}\right)$,

- The class of thermocouple measuring junction, either grounded (CIass 1) or ungrounded (Class 2), see Figures 2 and 3 ,

- The type of dye-penetrant inspection procedure to be used.

\subsection{MATERIALS AND MANUFACTURE:}

4.1 Sheath Material: The Inconel-600 tubirg used for the sheath material shall conform to $B 167$ with carbon content restricted to $<0.05 \%$.

4.2 Thermocouple Wires: Thermocouple wires referred to in the specification shall be Type $K$ with standard limits of error.

4.3 Insulation: As specified in E 235 paragraph 5.1.3 and subparagraphs $5.1 .3 .1,5.1 .3 .2$, and 5.7 .3 .3 .

4.4 Processing: Cleanliness as specified in paragraph 5.2.1.

\subsection{INSPECTION AND METHODS OF TEST}

5.1 General Procedure: As specified in paragraph 6.1 and subparagraphs 6.1 .1 and 6.1 .2 in $E 235$.

5.2 Insulation Resistance: As specified in paragraph 6.2 of E 235 except that resistances shall be greater than $10^{9}$ ohms. Measurements shall be made at room temperature. Conditions and resistances as specified in Table 2 of $E 235$ shall not apply. 
5.3 Radiographic Inspection: As specified in 6.3.1, 6.3.1.1, $6.3 .2,6.3 .3,6.3 .4,6.3 .4 .1,6.3 .5,6.3 .6$, and 6.3 .7 of E 235 .

5.4 Sheath Integrity: As specified in $6.4 .1,6.4 .2$ and 6.4 .3 of E 235 .

5.5 Surface Finish: As specified in 6.5 of $E 235$.

5.6 Surface Defects: As specified in 6.6 of $E 235$.

5.7 Metallurgical Structure of the Sheath: As specified in $6.7 .1,6.7 .3$ of $\mathrm{E} 235$.

5.8 Thermal Cycling of Measuring Junction: As specified in $6.8,6.8 .1$, and 6.8 .2 of $E 235$.

5.9 Insulation Resistance After Thermal Cycling: As specified in 6.9 of $E 235$.

6.0 CALIBRATION: As specified in 6.10 .1 and 6.10 .2 of $E 235$.

7.0 CERTIFICATION ANO TEST REPORTS:

- Chemical analysis of the sheath material in accordance with 4.1

- Certification that the type of thermocouple wire used in the manufacture of the thermocouples is in accordance with the purchaser's ordering documents and the requirements of Tables E 230 for the designated material descrithed in 4.2 .

- Certified results of insulation composition tests (see 4.3).

- Test results in insulation resistance tests (see 5.2).

- Radiograph resuits of radiographic inspection (see 5.3).

- Test results of sheath integrity tests (see 5.4).

- Results of liquid penetrant inspection (see 5.6).

- Test results on metallurgical structure (see 5.7)

- Test results from thermal cycle tests (see 5.8).

- Calibration results (see 6.0). 


\subsection{PREPARATION FOR SHIPMENT}

8.1 Cable Seals: The end of the mineral insulated cable shall be permanently sealed.

8.2 Cable Termination: The end of the cab'e shall have a temporary flexible lead approximately 152 man (6 n.) in length, attached for the purpose of inspection and calitiration. The leads shal1 be coded so that the chromel and alumel conductors may be identified. The coding information shall be included with the shipment.

8.3 Cleaning: The surface of the finished thermocouples shall be free of grease, oil, fingermarks, dirt, scale, and other foreign matter before packaging.

8.4 Marking: Each thermocouple shali be assigned a serial number. the serial number shalt be inscribed on a corrosion-resisting metal tag and affixed to the assembly with paper or plasticcoated corrosion-resistant wire approxinately $152 \mathrm{~mm}$ (6 in.) from the cold junction end of the metal sheath cable. For dual diameter thermocouples, the metal tag shall include the nominal diameter and length of the reduced portion of the cable.

8.5 Packing and Shipping: The thermocouple shall be coiled for shipping in a diameter of not less than $305 \mathrm{~mm}$ (12 in.). The thermocouples shall be packaged and shipped in such a manner that they are received in an undamaged condition. 


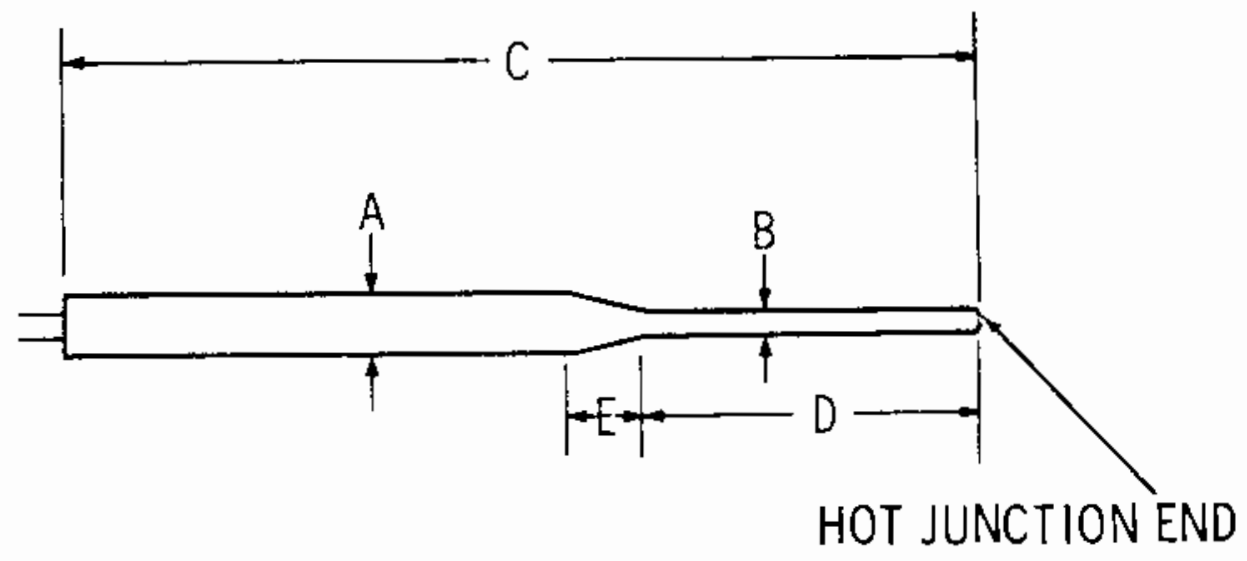

FIGURE 1. General Design of Sheathed Thermocouples 
TABLE 1. Dimensions and Tolerances for Sheathed Thermocouples, see Figures 2 and 3 .

\begin{tabular}{|c|c|c|c|c|c|c|c|c|c|}
\hline \multirow{2}{*}{$\begin{array}{l}\text { Sheath } \\
\text { Nominal }\end{array}$} & \multicolumn{2}{|c|}{ Tolerance } & \multirow{2}{*}{$\begin{array}{l}\text { Minimum } \\
\text { Sheath } \\
\text { Wall } \\
\text { B }\end{array}$} & \multirow{2}{*}{$\begin{array}{l}\text { Minimum } \\
\text { Insulation } \\
\text { Thickness } \\
\text { C }\end{array}$} & \multirow{2}{*}{$\begin{array}{l}\text { Minimum } \\
\text { Wire } \\
\text { Diameter } \\
\quad 0\end{array}$} & \multicolumn{2}{|c|}{ E, Tolerance } & \multicolumn{2}{|c|}{$F$, Tolerance } \\
\hline & $\min$ & $\max$ & & & & $\min$ & $\max$ & $\min$ & $\max$ \\
\hline \multicolumn{10}{|c|}{ Millimeters } \\
\hline 1.588 & 1.562 & 1.624 & 0.23 & 0.13 & 0.25 & 0.23 & 0.81 & 0.13 & 0.81 \\
\hline 0.508 & 0.483 & 0.533 & 0.069 & 0.05 & 0.094 & 0.069 & 0.381 & 0.076 & 0.381 \\
\hline 0.254 & 0.241 & 0.267 & 0.036 & 0.025 & 0.033 & 0.036 & 0.254 & 0.076 & 0.254 \\
\hline
\end{tabular}

\begin{tabular}{|c|c|c|c|c|c|c|c|c|c|}
\hline \multicolumn{10}{|c|}{ Inches } \\
\hline 0.0625 & 0.0615 & 0.0640 & 0.009 & 0.005 & 0.010 & 0.009 & 0.032 & 0.005 & 0.023 \\
\hline 0.0400 & 0.0390 & 0.0415 & 0.006 & 0.004 & 0.005 & 0.006 & 0.020 & 0.004 & 0.021 \\
\hline 0.0200 & 0.0790 & 0.0210 & 0.0027 & 0.002 & 0.0037 & 0.0027 & 0.015 & 0.003 & 0.015 \\
\hline 0.0100 & 0.0095 & 0.0105 & 0.0014 & 0.001 & 0.0013 & 0.0014 & 0.010 & 0.003 & 0.010 \\
\hline
\end{tabular}




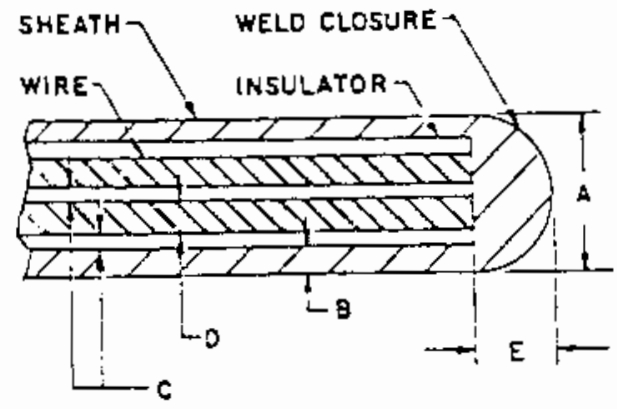

FIGURE 2. Grounded Measuring Junction, Class 1

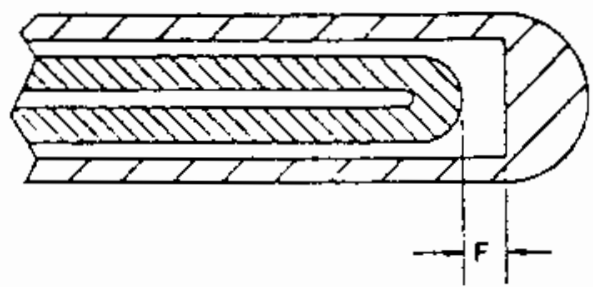

FIGURE 3. Ungrounded Measuring Junction, Class 2 
TTPS-1030, Rev 0

Metallic Sheathed Mineral-Insulated Cable:s for Nuclear Service

R. K. Marshat?

1.0 SCOPE: This specification presents the requirements for a metallic sheathed, minerai-insulated cables extending from in-reactor sensors to out-of-reactor signal conditioners.

2.0 APPLICABLE DOCUMENTS: The latest official issue of the following standards.

\subsection{ASTM Standards:}

- A262 Recommended Practives for Detecting Susceptibility to Intergranular Attack in Stainless Steels

- Bi67 Specifications for Nickel-Chronium-Iron Alloy Seamless Pipe and Tube

- A632 Specifications for Seamiess and Welded Austenitic Stainless Steel Tubing (small diameter) for General Service

- E2 Methods of Preparation of Micrographs of Metal A1loys (including recomnended practice for photography as applied to metallography)

- E3 Method of Preparation of Metallographic Specimens

- E94 Recommended Practice for Radiographic Testing

- E]12 Methods for Estimating the Average Grain Size of Metals

- El42 Method for Controlling Quality of Radiographic Testing

- E165 Methods for Liquid Penetrant Inspection

- E235 Specifications for Thermocouples, Sheathed, Type $K$, for Nuclear or other High-Reliability Applications.

\subsection{ANSI Standard:}

- B46. 1 Surface Texture.

3.0 ENVIRONMENTAL CONDITIONS: The metal sheathed cables will operate under both steady-state and transient conditions in a recirculating loop facility in a nuclear reactor and shall be designed to operated under the following environmental conditions. 
3.1 Nuclear: A thermal neutron fiux up to $1 \times 10^{14} \mathrm{n} / \mathrm{cm}^{2} / \mathrm{sec}$ and a gamma flux of $1 \times 10^{9} \mathrm{R} / \mathrm{hr}$.

3.2 Steady State: Pressurized flowing water up to $17.2 \mathrm{MPa}$ (2500 psig) and $616 \mathrm{~K}\left(650^{\circ} \mathrm{F}\right)$.

3.3 Transient: Steam up to $0.34 \mathrm{MPa}(50 \mathrm{psig})$ and $977 \mathrm{~K}\left(1300^{\circ} \mathrm{F}\right)$.

4.0 ORDERING INFORMATION: The purchase order documents shall specify the following information.

- The quantity, length, and nominal diameters of sheathed cable, either $1.588 \mathrm{~mm}(0.0625 \mathrm{in.})$ or $1.016 \mathrm{~mm}(0.0400 \mathrm{in.})$

- the type of ceramic insulation required, either alumina $\left(\mathrm{Ai}_{2} \mathrm{O}_{3}\right)$ or magnesia (MgO)

- the type of tubing material

- the type and quantity of conductor wires.

\subsection{MATERIALS AND MANUFACTURE}

5.1 Cable:

5.1.1 Materia7: AISI types $304,308,310,316,321$, or 347 stainless stee 1 in accordance with A632. Inconel-600 in accordance with 8167 except that carbon content sha 17 be $<0.05 \%$.

5.1.2 Conductor wire: Material and quantity to be specified by the buyer

5.1.3 Insulation: The insulating material shall be either magnesia (MgO) or alumina $\left(\mathrm{Al}_{2} \mathrm{O}_{3}\right)$ and shall comply with the following requirements as to composition:

- the magnesia shall be electrically fused with a 99.4 percent minimum content of magnesia and with a maximum content of boron plus cadmium of 30 ppm. A11 impurities inciuding boron and cadmium shall be less than $6000 \mathrm{ppm}$. The sulfur content shall be less than $50 \mathrm{ppm}$ and the carbon content less than $300 \mathrm{ppm}$.

- The alumina shair be alpha alumina with a minimum content of 99.5 percent alumina. The maximum boron plus cadmium content shail be $30 \mathrm{ppm}$. Sulfur shall not exceed 50 ppm while carbon shall not exceed 300 ppm. All impurities 
in the alumina, inciuding the boron and cadmium, shall be no more than $5000 \mathrm{ppm}$.

- A certified analysis of the composition of the insulating material as supplied to the thermocouple manufacturer shall be furnished to the purchaser. The thermocouple manufacturer shall be responsible for maintaining the purity within the specified limits in the finished product.

\subsection{Processing:}

5.2.1 Cleaniiness: The surface of the completed cables at the time of delivery shall be free of residues containing nuclear poisons such as boron and cadmium compounds, or foreign substances such as chlorine compourds, strong acids, bases, oils, greases, or dust that could tecome the source of corrosions of chemistry changes in a primary coolant or heat-transfer medium. The use of compounds containing halogens is prohibited for final cleaning. Alcohol or methyl isobutyi ketone may be used unless otherwise specified.

\subsubsection{Annealing: The sheath of the finished cable shall be soiution} annealed and shail not be sensitized.

\subsection{INSPECTION AND TEST METHODS}

6.1 Insulation Resistance: The electrical resistance between conducting wires and between each conducting wire and sheath shall be in accordance with Table 7 , with the applied voltabe specified (both direct and reversed polarity) for a cable length not exceeding $15 \mathrm{~m}$ (50 ft).

\subsection{Radiographic Inspection:}

6.2.1 A length of the fabricated cable extending a minimum of $102 \mathrm{~mm}$ (4 in.) from one end of the cable shall be examined by radiography to determine that the dimensions are in accordance with Table 2 and that any defects do not exceed the following requirements:

- Cracks, voids or inclusions in the sheath wall greater than 15 percent of the sheath wall thickness, or $0.05 \mathrm{~mm}$ $(0.002$ in.), whichever is greater. 
TTPS-1030, Rev 0

- Cracks, voids, inclusions, discontinuities, or loca? reduction of the conductors, insulation, or sheath diameter greater than $0.05 \mathrm{~mm}(0.002 \mathrm{in.})$.

6.2.2 The cable shall be radiographed in two directions 90 degrees apart and perpendicular to the cable axis. The radiography shall be performed in accordance with Recommended Practice E94, and the design of the penetrameter shall be as specified in E\}42 as modified according to E235, Section 6.3.4.1.

The radiograph shall be supplied to the purchaser along with appropriate means of identifying the cable with its radiograph.

6.3 Sheath Integrity: The sheath integrity of the finished cables shall be tested. The manufacturer shall perform at least one of the following tests, the manufacturer can select which test to perform.

6.3.1 Helium Leak Test: Test the finished cables as follows: weld the open end of the sheaths or otherwise seal, and wipe the cable clean with a solvent-saturated material. The recommended solvents are alcohol, methyl ethyl ketone, or methy! isobutyl ketone. Pressurize the sheath externally with helium to at least 6.9 $\mathrm{MPa}$ (1000 psig) for a period of 5 to $10 \mathrm{~min}$. Wipe the cable again with a solvent-saturated tissue and insert within $2 \mathrm{hr}$ into a test chamber. Evacuate the interior of this chamber to a pressure of $50 \mathrm{\mu m} \mathrm{Hg}$ or less and test for the presence of helium using a mass spectrometer-type heliumleak detector. An indication of helium leakage of $6 \times 10^{-9}$ standard $\mathrm{cm}^{3} / \mathrm{s}$ or greater shall be taken as evidence of a leak, and the cable shall be rejected.

6.3.2 Hydrostatic Test: Test the finished cables as follows. Seal weld the ends of the sheath and place the cable in a water environment in a hydrostatic chamber. Operate the chamber at a pressure of $24.1 \mathrm{MPa}$ (3500 psi) and room temperature for a minimum of one hour. Remove from the chamber and measure the insulation resistance of the cables in accordance with 6.1 . If the cable does not meet the 
TTPS-1030, Rev 0

requirements of 6.1 , it shail be taken as evidence of a leak and the cabie shall be rejected.

6.4 Surface finish: The surface of the sheaths of all cables in the completed condition shall have a bright appearance with a finish no rougher than $0.00081 \mathrm{~mm}$ (32 $\mu \mathrm{in.}$ ). Make a visual comparison with roughness standards in accordance with ANSI B46.1.

6.5 Surface Defects: There shal1 be no cracks, seams, holes, or other defects on the surface of the sheath of tre finished thermocouples when tested in accordance with Procedure $A 2$ of Methods E]65. Any indication of cracks, seams, holes, or other defects shall be cause for rejection.

6.6 Metallurgical Structure of the Sheath:

6.6.1 Select a sample cable at random from each "lot" of cables. A "lot" of cables is defined as a group of 15 cables or fraction thereof, manufactured from the same materials in the same production run. Using a section of the sample cable, closewind the selected section of the sheath three full turns on a mandrel that is twice the sheath diameter. Prepare the metallographic specimen in accordance with Method E3. The sheath material of the mounted specimen shall not contain evidence of cracks or localized wall thinning when longitudinally sectioned and examined by normal metallographic practice at a magnification of 200 to $500 X$ in accordance with Method E2.

6.6.2 Mount another section of the sample cable which has not been bent and examined for grain size. Conduct the grain size measurements in accordance with Methods E112. The maximum allowable grain size is ASTM Number 6 . The sheath material of the straight section shall not contain evidence, when examined at 200 to $500 \mathrm{X}$, of any cracks, inclusions, porosity, or grain boundary attack. In addition Types 304, 304L and 336 stainless stee? sheaths shall not contain continuous envelopes of precipitated carbides defined as "ditch structure" in Recommended Practice A262. 
7.0 CERTIFICATION AND TEST REPORTS: COPies of the following certified tests and inspection reports shall be submitted to the purchaser.

- Chemical analysis of the sheath material (see 5.1.1)

- chemical analysis of conductor wires (see 5.1.2)

- certified results of insulation composition tests (see 5.1.3)

- results or insulation resistance tests (see 6.1)

- results of radiographic inspection (see 6.2)

- results of sheath integrity tests (see 6.3)

- results of liquid penetrant inspection (see 6.5)

- test results on metallurgical structure (see 6.6).

\subsection{PREPARATION FOR SHIPMENT}

8.1 Cable Seals: The ends of the mineral insulated cable shall be permanently sealed.

8.2 Cable iermination: Both ends of the cable shall have a temporary flexible lead approximately $152 \mathrm{~mm}$ ( $6 \mathrm{in.}$ ) in length, attached for the purpose of inspection.

8.3 Cleaning: The surface of the finished cables shall be free of grease, oil, fingermarks, dirt, scale, and other foreign matter before packaging.

8.4 Marking: Each cable shall be assigned a serial number. The serial number shail be inscribed on a corrosion resisting metal tag and affixed to the cable with paper or plastic-coated corrosion-resistant wire approximately $152 \mathrm{~mm}$ (6 in.) from one end of the cable.

8.5 Packing and Shipping: The cable shals be coiled for shipping in a diameter of not less than $305 \mathrm{~mm}$ (12 in.). The cables shait be packaged and shipped in such a manner that they are received in an undamaged condition. 
TTPS-1030, Rev 0

\section{TABLE 1. Insulation Resistance}

\begin{tabular}{|c|c|c|}
\hline Sheath Outside 0iameter, mm (in.) & $\begin{array}{l}\text { Applied DC Voitage } \\
\text { (Both Direct and } \\
\text { Reverse Polarity } \\
\end{array}$ & $\begin{array}{c}\text { Required Minimum } \\
\text { Insulation Resistance } \\
\text { at Room Temperature, } \mathrm{M} \Omega \\
\end{array}$ \\
\hline $1.0(0.040)$ & $50 \mathrm{Vdc}(\mathrm{min})$ & 1000 \\
\hline $1.587(0.0625)$ & $500 \mathrm{Vdc}$ & 5000 \\
\hline
\end{tabular}

TABLE 2. Dimensions and Tolerances for Cables

\begin{tabular}{|c|c|c|c|c|c|}
\hline $\begin{array}{l}\text { Sheath } \\
\text { Nominal }\end{array}$ & $\begin{array}{l}\text { ide Di } \\
\text { Tolera } \\
\text { Min }\end{array}$ & $\begin{array}{l}\text { leter } \\
\text { Max } \\
\end{array}$ & $\begin{array}{c}\text { Minimum } \\
\text { Sheath } \\
\text { Wall } \\
\end{array}$ & $\begin{array}{l}\text { Minimum } \\
\text { Insulation } \\
\text { Thickness }\end{array}$ & $\begin{array}{l}\text { Minimum } \\
\text { Wire } \\
\text { Diameter }\end{array}$ \\
\hline & & & Mil11 imete & & \\
\hline 1.016 & $0.99\}$ & 1.054 & 0.15 & 0.10 & 0.13 \\
\hline 1.588 & 1.562 & 1.625 & 0.23 & 0.13 & 0.25 \\
\hline & & & Inches & & \\
\hline 0.0400 & 0.0390 & 0.0415 & 0.006 & 0.034 & 0.005 \\
\hline 0.0625 & 0.0615 & 0.0640 & 0.009 & 0.0 .05 & 0.010 \\
\hline
\end{tabular}


TTPS-1031, Rev ?

\title{
Seif-Powered Pressure Switch
}

\author{
R.K. Marshall
}

1.0 SCOPE: This specification presents the design and operating requirements for a self-powered pressure switch which, when attached to a fuel rod, will indicate cladding failure during reactor operation.

2.0 APPLICABLE DOCUMENTS: The latest official version of the following documents:

- PNL Specification: TTPS-1030, Revision 0, Metallic Sheathed Mineralinsulated Cables for Nuclear Service.

- PNL Design Drawings: H-3-41867, Sheets $1 \& 2$.

- ASTM A479 for 304L stainless stee?.

3.0 ENVIROMMENTAL CONOITIONS: The switch and metal sheathed cable will operate understeady-state and transient conditions in a recirculating loop facility in a nuclear reactor and shalt be designed to operate under the following environmenta? conditions.

3.1 Nuclear: A thermal neutron flux up to $1 \times 10^{14} \mathrm{n} / \mathrm{cm}^{2} / \mathrm{sec}$ and a ganma fiux of $1 \times 10^{9} \mathrm{R} / \mathrm{hr}$ for a maximum operating time of 48 hours.

3.2 Steady-State: Pressurized flowing water up to $17.2 \mathrm{MPa}$ (2500 psig) and $616 \mathrm{~K}\left(650^{\circ} \mathrm{F}\right)$.

3.3 Iransient: Steam up to $0.34 \mathrm{MPa}(50 \mathrm{psig})$ and $811 \mathrm{~K}\left(1000^{\circ} \mathrm{F}\right)$.

4.0 FUEL ROD INDICATOR OPERATION:

4.1 Description: The device is an on-off pressure-activiated switch combined with a thermocouple. The device is welded to the top end of a fuel rod. Pressure increase within the fuel rod causes compression of the two bellows shown in Drawing H-3-41863 sheet 1. The switch is open at atmospheric pressure and closes when the fuel rod internal pressure reaches a predetemined value. When the switch closes, continuity is established between each thermoelement conductor and the cable sheath. 
When the pressure drops below the predetemined value, the circuit is opened indicating the reduction in pressure. The break in continuity can be determined by electrical means.

4.2 Pressure Switch Adjustment: The adjustmert of the switch closing and opening pressure is accomplished by adjusting the gap between the thermocouple tip and bellows adapter extension, dimension $A$. The requirement for the gap width, Drawing H-3-41867, Sheet I, Dimension A is included in the ordering information.

4.3 Switch Design Operating Conditions: The s'witches shall be designed to be operated under the loop environmental conditions specified in Section 3.0 and under the following switch internal pressure and temperature conditions. The pressure difference across the bellows wall is approximately $8.10 \mathrm{MPa}$ (1175 psi) with the higher pressure on the bellows outside.

\subsubsection{Steady-state: $4.3 \mathrm{MPa}(870 \mathrm{psig})$ at $616 \mathrm{~K}\left(650^{\circ} \mathrm{F}\right)$.}

\subsubsection{Transient: $8.3 \mathrm{MPa}(1200 \mathrm{psig})$ at $811 \mathrm{~K}\left(1000^{\circ} \mathrm{F}\right)$.}

\subsection{CONSTRUCTION:}

5.1 Switch:

5.1.1 Materials: All inorganic.

5.1.2 Bellows: Inconel 718 or Inconel 750 . Material specification specified by bellows manufacturer.

5.2 Extension Cable: The extension cable consists of an Incone1-600 metai sheathed cable with chromel-aiumei conductors insulated with MGO. The cabie shalt be purchased in accordance with PNL Specification TTPS-1030, Revision 0 . The required ordering information is isted in TTPS-1030, Revision 0.

5.3 Welds and Brazes: Qualification tests of weld and braze procedures shall demonstrate that adequate weIds and brazes are produced. PNL reserves the right to review the weld and braze procedures and qualification tests before use. 
6.0 TESTS:

6.1 Leak Tests: A11 containment welds and brazes shall be tested with a helium mass spectrometer leak detector. A leak rate in excess of $6 \times 10^{-9}$ standard $\mathrm{cm}^{3} / \mathrm{sec}$ of helium shall be used as a basis for rejection.

6.2 Resistance Measurements: The resistance of the chromel-alumel conductors shall be measured to assure thermocouple continuity. The resistance shall conform to the calculated or premeasured values for the thermoelectric circuit. The resistance of each thermoeiement conductor to the cable sheath shali be measured when the switch is open and when closed. When the switch is open, infinite resistance should be read. When closed, the resistances should conform to the nominal resistance values for each conductor. The above measurements shail be made after assembly of the device has been completed.

6.3 Thermocouple Attachment Test: The weld or braze of the thermocouple sheath to the end bulkhead shall be designed to withstand and axial load of at least $18 \mathrm{~kg}$ ( $40 \mathrm{lbs}$ ) applied to the internal end of the thermocouple wire. Tests shall be performed to demonstrate that this requirement is net.

7.0 CALIBRATION: The switch shall be calibrated by internaliy pressurizing the assembiy with helium, argon, nitrogen or air at room temperature and recording the pressure at which the switch closes and opens. Switch closure and opening shall be determined by measuring the resistance of each thermoelement to the sheath. The values shall conform to those determined in 6.2. This procedure shail be repeated twice for a total of three runs. The design closure pressure and tolerances will be specified in the ordering information.

8.0 RUALITY ASSURANCE:

\subsection{Inspection:}

8.1.1 Examination of Materials and Procedures: PNL reserves the right to inspect al1 materials and procedures during fabrication, testing, and before shipment to assure that the prescribed requirements are met.

8.1.2 Visual: The surface of the indicator and cable shall show no visible oxidation, scale or discoloration. 


\subsection{Acceptance Tests at PNL:}
8.2.1 Visual inpsection, paragraph 3.1 .2
8.2.2 Verification of Section 7.0, Calibration.

8.3 Documentation: Certified copies of the following inspection and calibration reports shall be submitted to tre purchaser.

8.3.1 Chemical and Physical Analyses:

(a) Bellows

(b) 304L stainless stee 1

8.3.2 Extension cable documentation as specified in TTPS-1030, Rev. o

8.3.3 Results of leak tests, resistance meas drements, and thermocouple attachment tests (see 6.0).

8.3.4 Calibration data (see 7.0).

\subsection{PREPARATION FOR SHIPMENT:}

9.1 Cable Termination: The readout end of the cable shall have a temoorary, flexible lead approximately $152 \mathrm{~mm}(6 \mathrm{in}$.) in: length, attached for the purpose of inspection and calibration.

9.2 Cleaning: The surface of the finished assemblies shall be free of grease, oil, fingermarks, dirt, scale, and other foreign matter before packaging.

9.3 Marking: Each assembly shall be assigned a sarial numer. The serial number shall be inscribed on a corrosion-resistant tag and affixed to the assembiy with paper or plastic-coated, corrosion-resistant wire approximateiy 152 ( 6 in.) from the end of the metai sheath cable.

9.4 Packaging and Shipping: For shipping, the cable shall be coiled in a diameter of not less than $254 \mathrm{~mm}$ (10 in.). The assemblies shall be packaged and shipped in such a manner that they are recieved in an undamaged condition. 
TTPS-1033, Rev 1

Shroud Assenbly

C. Nea11ey

1.0 SCOPE: This specification describes the fabrication requirements for a shroud.

2.0 APPLICABLE DOCUMENTS: The following documents form a part of this specification:

ASTM A 276, Stainless and Heat-Resisting Steel Bars and Shapes

PNL Material Specification TTMS-1033, Revision 2

PNL Heat Treatment Specification TTHTS-1008

PNL Drawing $\mathrm{H}-3-41811$, Sheet 2

3.0 MATERIAL REQUIREMENTS: The material shall conform to PNL Specification TTMS-1033, Revision 2.

4.0 TECHNICAL REQUIREMENTS:

4.1 Shape and Dimensions: The shroud shall be machined to meet the shape and dimensions shown in PNL Drawing H-3-41811, Sheet 2.

4.2 Heat Treatment: The initial heat treatment of the material shal1 be in accordance with ASTM A 276, Stainless and Heat-Resisting Steel

Bars and Shapes. Any stress-relieving heat treatment performed during fabrication shall be in accordance with PNL Heat Treatment Specification TTHTS- 1008.

4.3 Pickling: After the final heat treatment, the shroud shall be pickled to remove any heat treatment discoloration. This pickling operation shall be performed in accordance with PNL Heat Treatment Specification TTHTS-1008.

4.4 Workmanship: All material shall be free of laps, cracks, voids, seams, and other defects. The surface finish of the shroud shall be in accordance with PNL Drawing $\mathrm{H}-3-41811$. In addition, the shroud shall be free of burrs which might interfere with assembly or 
function of the final shroud assembly and be free of chips, dirt, grease, corrosion or other foreign material.

5.0 QUALITY ASSURANCE:

5.1 Inspection: Each shroud shall be visually inspected for defects, surface condition and cleanliness. The shroud shall also be inspected for all items specified on PNL Drawing $\mathrm{H}-3-41811$, Sheet 2.

5.2 Certification: A11 tests and inspections shall be certified and reported to the buyer.

5.3 Acceptance: Acceptance shall be at the seller's facility by a buyer's representative.

6.0 PACKAGING: Each shroud assembly (two matched halves) shall be sealed with tape in a flat, plastic vinyl tube. The plastic wrapped shroud assembly shall then be crated in wooden containers for shipment to the buyer. Scrap or rejected parts shall be crated in a wooden container and shipped to the buyer. 
APPENDIX D

WELDING/BRAZING SPECIFICATIONS 
WELDING/BRAZING SPECIF ICATIONS

Specification

TTWS-1000 Rev 1

TTWS-1004 Rev 4

TTWS-1009 Rev 0
Titie

Specification for Welding Austenitic

Stainless Steels

Specification for Welding Inconel Alloys

Zirconium Alloy welding

Brazing Specification
Page Number

$D-2$

D-4

D-22

$0-24$ 
Specification for helding Austenitic Stainiess Steels

R. F. klein

1.0 SCOPE: This specification describes the requirements for welding austenitic stainless steel.

2.0 IECHNICAL SPECIFICATION:

2.1 Base Metals: Base metals shall be in accordance with HPS-230-W or an equivalent specification.

2.2 Filler Metals: Filler Metals shall be in accordance with HPS-230-W or an equivalent specification.

2.3 Welding Processes: Welding process shail be in accordance with the processes in HPS-230-W with the following exceptions:

1. Paragraph 2.1 shati not apply.

2. Paragraph 3.1.a shal1 be amended to read: Welding operations performed under this specification shall meet the requirements of the ASME Code, Sections III or VIII, or ANS1 E31.1.0, as applicable, or as approved by the Bilk Project Engineer except as modified herein or otherwise defined on drawings, in the construction specifications, or in the purchase order.

3. Paragraph 3.2.a(1) shail be amended to read: Welding procedure specifications shall be prepared for a 11 welding processes to be used on projects where this specification governs. The minimum elements to be included in the procedure specifications shail be as defined in Section IX of the ASHE Code or by the BNW Project Engineer. Except as otherwise defined herein, the procedures shall be qualified in accordance with Section IX and shall be formally approved by the Project Engineer prior to use in production operations.

4. Paragraph 3.2.a(2) shall be amended to read: Sheet metal welding procedures shall be qualified in accordance with Section $I X$ or as approved by the BNW Welding Engineer and Project Manager. The Contractor shall maintain current records of the procedure 
specifications, qualification test results and approval documentation; all of which shall be subject to audit. The contractor shall also maintain copies of the approved procedure specifications at the job site to permit their use for reference purposes by concerned personnel.

5. Paragraph 3.2.b shall be amended to read: Welders and Welding Operators, except those involved with special process welding such as sheet metal or other applications not directly addressed by national codes, shat1 be qualified in accordance with Section IX of the ASME Code. However, if the welder or welding operator performs the weld parameter development for a specific weld and these parameters and welds are approved by the BNW welding engineer or Bilk project engineer, the welder or welding operator shall be considered qualified to perform that specific weld.

6. Paragraph 3.6.n shall be amended to read: Water shall not be piaced on the weldment until the weld area has cooled to room or ambient temperature.

\subsection{GENERAL:}

3.1 Terminology: The term "administration" as used in the "Hanford Process Specifications" (HPS) shail be specifically defined as Batteile Memorial Institute, Pacific Northwest Laboratories (BNW).

3.2 Weldment Type: Weldments made under this specification sha11 be Type II. 
TTWS-1003, Rev 1

SPECIFICATION FOR WELDING INCONEL Al_LOYS $x-750$ and 718

R. F. Klein

1.0 SCOPE: This specification defines the minirnum requirements for weiding Incone $1 \mathrm{X}-750$, and Incone 178 .

2.0 REFERENCED CODES AND STANDARDS: The following codes and standards form a part of this specification to the extent defined herein. The issue in effect, including any addenda, on the date of invitation for bids or request for approval, shall be applicable.

- AMERICAN NATIONAL STANDARDS INSTITUTE

ANSI Z49.1 Safety Precautions

- AMERICAN SDCIETY OF MECHANICAL ENGINEEF:S (ASME)

ASME Code Boiler and Pressure Vessel Code

- AMERICAN SOCIETY FOR NDNDESTRUCTIVE TESTING (ASNT)

- AMERICAN WELDING SDCIETY (AWS)

AWS A2.4 Symbols for Welding and Nondestructive Testing

AWS A3.0 Terms and Definitions

AWS A5.12 Specification for Tungsten Arc Welding Electrodes

\subsection{REFERENCES:}

\section{I General:}

a. Welding operations performed under this specification shall meet the requirements of the ASME Code, Sections III or VIII, or ANSI B31.1.0, as applicable, or as approved by the Battelle Northwest project engineer, except as modified herin or otherwise defined on drawings, in the construction specifications or in the purchase order. 
b. Symbols, Terminology and Safety Precautions: Welding symbols and terminology used in communications and documentation sha 11 be in accordance with AWS A2.4 and A3.0 latest edition respectively. Safety precautions shall conform to ANSI 249.1 latest edition.

c. Definitions

(1) The term "Buyer" as used herein shall be interpreted as the Battelle PNL Project Manager or Welding Engineer. The term "As specified by contract documentation," used herein, shall mean as specified by product design drawings, project specification, purchase order, or other contract documentation.

(2) The term "Inspector" as used herein sha11 be interpreted as the person or persons designated by the Buyer to determine compliance with the requirement of this specification. For construction requiring ASME certification, the designated individuais sha11 be authorized inspectors who have been qualified as required by the applicable sections of the ASME Code.

\subsection{Qualification Requirements}

a. Welding Procedures:

(1) Welding procedure specifications shall be prepared for all welding processes to be used on projects where this specification governs. The minimum elements to be included in the procedure specifications shall be as defined in Section ix of the ASME Code or by the Buyer. Except as otherwise defined herein, the procedures shall be qualified in accordance with Section IX or as approved by the Buyer prior to use in production operations. 
TTWS-1003, Rev 1

(2) Current records of the procedure specifications, qualification test results and approval documentation shall be maintained and shall be subject to audit.

b. Personnel: Welders and welding operators, except those involved with special process welding such as sheet metal or other applications not directly addressed by national codes, shall be qualified in accordance with Section IX of the ASME Code. However, if the welder or welding operator develops the welding parameter for a specific weld, and these parameters and welds are approved by the Buyer, the welder or welding operator shall be considered qualified to penform that specific weid.

\subsection{Materials and Welding Processes}

a. Base Metals: Base metals covered by this specification shall be Incone $x-750$ in the annealed or solution-treated condition and Inconel 718 in the solution annealed condition. The material shall be purchased under the following specifications:

Inconel $X-750$

AMS 55426 for sheet

AMS 5582 for tube

AMS 5671 for bar
Inconel 718

AMS 55968 or 5597 A for sheet

AMS 5589 or 5590 for tube

AMS 55628, 55638, 5564A for bar

b. Welding Processes and Filler Metals: Except where otherwise approved by the Buyer, welding processes and filler metals used shall be capable of producing welds having corrosion resistance and mechanical properties equal to or exceeding those of the base metal being welded. Inconel filler metal 718 purchased to AMS 5832 is recommended for both base metals. The following welding processes shall be acceptable for use in manual, semiautomatic or automatic modes of operation, as applicable, subject to the provisions defined herein. 
TTWS-1003, Rev 1

(1) Gas Tungsten Arc Welding (GTAW) - GTAW may be employed for all applications and positions. Tungsten electrodes shall conform to AWS A5.12, Classification EWTh-2. Filler metal may be cut-length rod or spooled wire as appropriate for the mode of operation. Automatic GTAW not using filler wire, shall be permitted on base metal not exceeding $1 / 8$ inch thickness where it is shown in procedure qualification tests that no degradation in the properties of the base metal occurs. Such evidence may require Jimited testing beyond that specified in Section ix of the ASME Code and sellers proposing use of the process should review test requirements with the Buyer prior to conducting qualification tests. Current characteristic for GTAW shall be Direct Current Straight Polarity (OCSP). It is preferred that GTAW equipment have high frequency arc initiation capabilities. However, equipment without such capabilities may be used subject to provisions defined in Paragraph 3.6 of this specification. The welding torch shall be equipped with a gas lens cup for minimum shielding gas turbulance.

(2) Plasma Arc Welding (PAW) - PAW may be employed for joining materials in thicknesses from 0.1 to 0.3 inch. The arc system shall be of the transferred type using the keyhole method without filler metal. Tungsten electrodes shall conform to AWS A5.12, Classification EWTh-2. Shielding and orifice gases shall be similar to the shielding gases permitted for other welding processes except that oxidizing or reducing gas additives shail not be permitted. 
TWS-1003, Rev I

Argon containing not more than 6 percent dry hydrogen $\left(\mathrm{H}_{2}\right)$ may be used for the orifice gas but shall not be permitted as shielding gas. Joints in material over 0.3 inches thick can be plasma arz welded by use of the keyhole method, without fille' metal, for the root pass, followed by a nonkeyholing pass with filler metal added. In this case, filler metal may be cut-length rod or spooled wire as appropriate for the equipment involved.

(3) Electron Beam Welding (EBW) - EBW may be employed for a 11 practical applications. The parts to be welded shall be, at a minimum, thorough $1 y$ degreased per paragraph $3.5 \mathrm{c}$ (2). It may be necessary to chemically clean the parts prior to welding using a pickling solution as recommended by the metal supplier. A vacuum of at least $1 \times 10^{-4}$ torr shall be achieved prior to welding on the parts. The welded parts shall be allowed to cool prior to backfilling the chamber.

(4) Shielding and Purging Gases - Shielding gases for use with gas-shielded welding processes shall be argon (Ar) or helium (He) of welding grade, $99.99 \%$ or better purity and have a dewpoint of $-60^{\circ} \mathrm{F}$ or less. Mixed gases used for shielding such as Argon-Helium shall have a dewpoint of $-50^{\circ} \mathrm{F}$ or less and be of welding grade quality. Purging gases for use with all welding processes where an inert backing is required shall be argon or helium or duplex mix of same, unless otherwise approved by the Buyer. Oxidizing or reducing gas additives shall not be acceptable for purging applications. 
TWW-1003, Rev 1

3.4 Welding Materials Handiing and Control: Electrodes and filler wires shall be stored in a clean, dry location in a manner that assures complete protection from contamination of any type and freedom from condensation. Spooled electrode and bare filler wire shall not be left uncovered in the field or shop when not in use.

\subsection{Preweld Preparation}

a. Joint Design: Joint design shall be in accordance with the drawing requirements and applicable codes. Unusal joint designs which are required for special applications or to suit particular processes may be approved where the technical soundness of each for its proposed application is established to the satisfaction of the Buyer.

b. Edge Preparation: Joint edges shall be prepared by machining, grinding, power chipping, filing, shearing or by arc cutting with the plasma arc process. The edges of the base metal to be welded shall be free of shearing cracks, laminations, burrs, or other defects and the surface roughness shall not exceed 125 RMS.

c. Cleaning

(1) General - Surfaces to be welded and the weld zone (i.e. a distance of 2 inch minimum from the weld pass) and bare filler metal shall be thoroughly cleaned of moisture, grease, oil, point, cutting fluids, marking crayons or inks, temperature indicating markings and other foreign material that would prevent proper welding.

(2) Methods - Shop dirt and ojl or grease based materials can be vapor degreased with perchloroethylene. Other materials not soluble in this agent may be cleaned with 
TTWS-1003, Rev 1

methylene chloride, alkaline cleaners, alcohol, trichlorethylene, etc., not containing sodium sesquisilicate or sodium carbonate. Oxides shall be removed by grinding, abrasive blasting, machining or pickling in a solution approved by the buyer. Abrasion and wire brushing shali be linited to clean aluminum oxide abrasives and brushes having stainless steel bristies respectively. Chemically cleaned material shall be thoroughly rinsed or otherwise neutralized to assure all traces of cleaning solution have been removed, and imanediately dried.

d. Joint Alignment

(1) General Structure - Joint edges in fitup shall not be offset by greater than the 1 imits defined in Section 4.0 of this specification.

(2) Genera? Piping and Tubing - For general piping and tubing other than that used for structural or critica? appiication purposes, alignment shall not be offset by greater than the limits defined in Section 4.0. In addition, except where otherwise defined by drawings, misalignment (the deviation from $180^{\circ}$ is measured along the axes of two abutting pipes or tubes) shall not exceed $5^{\circ}$. Root openings prior to weiding shall be as specified in the joint design requirements of the approved welding procedure specification.

e. Tacking

(1) General - Tacking as required shall be of smail size and kept to the minimum necessary to maintain alignment of 
joint edges during welding. Tacks which will be incorporated into the finished weld shall be deposited in such a manner that complete fusion to the weld joint root occurs. Tacking shal! be accomplished by certified personnel only.

(2) Defective Tacks - Cracked, broken and otherwise defective tacks shall be completely removed before weiding is completed in the area where the faulty tacks were located.

f. Preheating: Where base metal temperature is below $60^{\circ} \mathrm{F}$ but above $0^{\circ} \mathrm{F}$, preheating of the material shali be required. In such cases, the weid area and two inches back from the prepared edge shall be heated to within a temperature range of $60-80^{\circ} \mathrm{F}$ (warm to bare hand) prior to tacking or welding. Preheating may be by flame, resistance, furnace, or induction techniques.

\subsection{Welding Operations}

a. Welding Process - The acceptable welding process or processes for specific applications shall be as defined on the drawings.

b. Base Metal and Ambient Temperatures - Welding shall not be permitted on base metals which are at a temperature of less than $60^{\circ} \mathrm{F}$ until the base metai has been preheated in accordance with Paragraph $3.5 f$ of this specification. Neither welding nor preheating shall be permitted where base metal temperature or ambient temperature is $0^{\circ} \mathrm{F}$ or less.

c. Protection from Adverse Environment - Protection from direct winds, drafts, air currents, rain, snowfall and other adverse conditions shall be required. Special observation of this provision shall be given where gas-shielded welding processes are involved. The protection given shall, as a minimum, shield the actual weld zone, weld gun or holder and the welder or welding operator. 
TTWS-1003, Rev 1

d. Minimum Root Openings - Except where otherwise approved by the Buyer, joint designs in base metal exceeding $3 / 8$ inch thickness shall have a maximum root opening of $1 / 16$ inch and for thicknesses of $3 / 4$ inch and greater shall have a maximum root opening of $1 / 8$ inch.

e. Condition of Joint Area - Weld joint areas shall be completely dry and clean before commencing the weiding operation. Drying of damp metal may be accomplished by flame heating or other means acceptable to the Buyer. Cleanliness of the base metal in the area to be welded shall be determined by visual examination and wiping with a clean, white, lintfree cloth moistened with a volatile compound such as isopropyl alcohol. Dangerous substances such as carbon tetrachioride $\left(\mathrm{CCI}_{4}\right)$, trichiorethylene $\left(\mathrm{C}_{2} \mathrm{HCl}_{3}\right)$ gasoline and similar materials shail not be permitted for such purposes. After wiping, the cloth shall exhibit no discoloration upon drying.

f. Cleanliness of Filler Metal - Bare filler rods and electrodes shall meet the same cleanliness criteria as the base metal to be welded.

9. Arc Striking - Runoff tabs and arc-striking plates may be employed as required providing the composition is identical to the alloy being welded or is composed of pure copper $(\mathrm{Cu})$. Use of arc striking plates shall be mandatory for GTAW processes not having high frequency arc initiating capabilities except where the arc strike area is to be removed from the subsequent weldment and discarded. Under no circumstances shall are striking be permitted on other than the tabs or piates or in the immediate joint area where weld metal will be deposited. 
h. Weld Positions and Deposition Techniques - Welding may be performed in any position. Weld deposition shall be essentially stringer passes. Vertical joints shall be welded in the upward direction except where otherwise specifically approved by the Buyer. For Inconel 718, the heat input should be low.

i. Multipass Deposition Requirements - In multipass welds, starting and stopping points shall be staggered. The points shall be faired by grinding before the subsequent passes are deposited. Each weld pass shall deposit a layer of weld metal not exceeding $1 / 8$ inch thick excluding depth of penetration except where otherwise approved by the Buyer for the particular application involved. For Inconel 718, many light beads are preferable to a few heavy beads. Minimum requirements for piping and tubing welds shall be similar except no less than 2 weld passes shall be deposited per joint unless otherwise approved by the Buyer.

j. Interpass Cleaning and Repair - Each weld pass shall be completely cleaned by abrasive blasting or grinding, prior to depositing a subsequent pass. Completely remove the abrasive grit before continuing to weld. Any defects noted shall be removed or repaired and recleaned before further welding.

k. Interpass Temperatures - Interpass temperature sha11 not exceed $350^{\circ} \mathrm{F}$ as determined by temperature sensing crayons or paints, thermocouple temperature measuring devices or by other means acceptable to the Buyer. Temperature measuring shall be accomplished in such a manner that no contaminants or residues reach the actual surfaces being welded or previously deposited weld passes. 
1. Shielding - Gas-shielded welding processes shall be handled or adjusted in such a manner that gas "low commences slightly ahead of arc initiation and continues to shield the weld zone until slightly after the arc is terninated. For GTAW and PAW processes being used in the manual node of operation, the heated end of the filler rod shall not be removed from the shieiding atmosphere during welding or until after the shield flow has stopped at termination of weiding. For all gasshielded processes operating at a travel speed of 25 inches per minute or greater, a trailing shield of the same gas used for shielding the weld zone shall be required except where welding is performed in an inert atmosphere filled enclosure.

m. Purging - For all welds to be deposited from one side except where welded into backing of similar alloy, or where welding is being performed in an inert atmosphere, the root side of the joint shall be protected by a purgirg gas until the weld and base metal have cooled to $700^{\circ} \mathrm{F}$ or lower. The purging gas flow shall be started and continued for a sufficient time prior to welding to assure all ambient air has been displaced. Water soluble barrier paper or tissue may be used for making a purging dame in pipe and tube weldments providing the type of barrier material is chemically neutral after dissolving in water and there is no prohibitation against use of water in the particular weldment. Water shall nct be placed in the weidment until the weld area has cooled to rcom or ambient temperature.

n. Weld Reinforcement - Weld reinforcement or crown shall not exceed the limits specified in Section 4.0. 
o. Repair or Defective Welding - The defective weld shall be totaliy removed in a manner acceptable to the Buyer except that flame and arc-gouging techniques shall not be permitted. Peening, caulking and other cover-up methods shall not be acceptable. No more than two repair attempts on major defects (those requiring correction of other than minor surface imperfections) shall be permitted on any weld joint without specific approval of the buyer. Repaired welds shall conform in all respects to requirements of the original weid.

p. Wash Passes - Wash passes, the act of smoothing a weld surface by remelting the upper surface layer but without addition of filler metal shall not be permitted.

q. Buttering or Buildup - Buttering or buildup of joint surfaces by welding to correct oversize root opening or other errors in joint preparation, or to facilitate welding operations shall be completed prior to final fitting and shall not exceed $3 / 8$ inch thickness on each joint edge. Where the degree of a deviation is such that correction cannot be accomplished within this limitation, the defective material shall be replaced, or the contractor may propose a suitable repair method for specific approval of the Buyer prior to beginning the repair. Buttering or buildup shall be considered part of the involved weld and shail be subject to all quality requirements applicable to the weld.

r. Removal of Temporary Attachments - In removing temporary attachments such as lifting pads, erection brackets, mounts for alignment devices, etc., the welds shall be removed by chipping, grinding, or machining. The base metal surfaces shall be restored by grinding (and polishing where required by 
TTWS-1003, Rev 1

service conditions) to fair out the temporary weld area providing the operation does not reduce the material thickness below the specified minimum. Where excess base metal would be removed in fairing, suitable preparation welding shall be completed prior to surface restoration. All restored temporary attachment areas shall be inspected by penetrant techniques after completion to assure surface integrity.

5. Heat Treatment - Heat-treating of these metals will not normally be required except for special purposes. Where, because of service requirements, such special heat-treating is necessary, the procedures to be followed shall be detailed on the drawings or in other contract documentation.

\subsection{QUALITY ASSURANCE PROVISIONS}

4.1 General: Inspection and acceptance requirements for the welds shall include visual inspection as a minimum and where required on the drawings or in other contract documentation, radiographic, ultrasonic and/or penetrant inspection. Nondestructive testing shall be in accordance with requirements of the applicable codes and/or specified by contract documentation.

\subsection{Visual Inspection}

a. General - Visual inspection shail be accomplished on welds which are in finished, as-welded =orm prior to any alteration of the deposits for purposes such as facilitating nondestructive testing. Inspection shall be $100 \%$ on pressure vessels, pressure piping, major structure and other critical weldments such as those subject to severe corrosive environment. Weldments of less critical nature may be subject to spot examination only where permitted by contract 
TTWS-1003, Rev 1

documentation. The first weld pass of critical weids and rear side preparation of joints to be weided from both sides may be subject to spot or $100 \%$ visual inspection as specified on the engineering drawings.

b. Supplementary Inspection Devices - Visual inspection of welds and base metals may be accomplished with the aid of supplementa? magnifying devices not exceeding 10X or with inspection mirrors and other remote examination devices. Resolution capability of supplementary inspection devices shall be at least equal to that obtainable by direct visual examination.

c. Acceptance Criteria - The minimum acceptance criteria specified herein shall be considered applicable to all welds regardiess of service application. Where other criteria are required, such shall be as specified on the drawing or in other contract documentation.

(1) Prohibited Defects - Welds and weid zones shall be free of the following defects.

- Cracks of any description

- Underfill (except for limits defined herein)

- Incomplete fusion

- Over laps

- Surface porosity and gas pockets

- Arc strikes

- Crevices of any type (except where permissible for the joint design type specified on the drawing)

- Weld spatter

- Crater pits and depressions

- Surface checking and crazing 
TTWS-1003, Rev I

- Gouge marks and other surface imperfections resulting from removal of slag or temporary attachments

(2) Excessive Melt-Through - Excessive melt-through including globules of any degree shall not he acceptable until properiy repaired so that the resulting welds meet minimum acceptance criteria.

(3) Undercut - Undercut (not to be corfused with underfili) shall not be acceptabie on pressure vessels, pressure piping and major structure. For a 11 other welds, undercut shall not exceed $1 / 64$ inch or $10 \%$ of the base metal thickness, whichever is less, except for base metal thicknesses of $1 / 2$ inch and greater, undercut not exceeding 1/32 inch may be allowed if the accumulated length of undercut deeper than $1 / 64$ inch does not exceed $20 \%$ of the joint length or 12 inches accumulative in any 36 inch length of weld, whichever is less.

(4) Surface oxidation - Weld and base netal surfaces showing evidence of oxidation accompanied sy a wrinkled or crystalline appearance (as caused orimarily by improper shielding or purging) shall not be acceptable. Tightiy adhering color temper films caused by local heating during welding shall not be considered as a defect.

(5) Weld Contour - The contour or configuration of welds shall blend smoothly and gradually into the base metal. Where grinding is required, it shail be performed in such a manner that the thickness of the weid and adjacent base metal is not reduced below the min mum specified thickness. 
TWS-1003, Rev 1

(6) WeId Reinforcement - Except where otherwise specified on the drawing, the as-deposited height of weld reinforcement, as measured from the base metal surface, shall be within the following limits:

Application $\begin{gathered}\text { Base Metal } \\ \text { Thickness }\end{gathered}$
to $1 / 2$ in. Feinforcement

(7) Pipe Root Reinforcement - The reinforcement of pipe and tube welds shall be as specified in Item (6) except that the root reinforcement for welds not using backing rings or consumable inserts and which are not welded on the rear side shall meet the following criteria. No concavity (internal underfi11) shall be permitted unless the resulting total thickness of weld melt is equal to or exceeds the minimum thickness of the adjacent base metal.

$\begin{array}{llc}\text { Condition } & \text { Pipe Size Nominal } & \text { Maximum Reinforcement } \\ \text { Convexity } & \text { Less than } 2 \text { inches } & 1 / 16 \text { inch } \\ \text { Convexity } & 2 \text { inches and over } & 3 / 32 \text { inch } \\ \text { Concavity } & \text { Less than } 2 \text { inches } & 1 / 32 \text { inch } \\ \text { Concavity } & 2 \text { inches and over } & 1 / 16 \text { inch }\end{array}$


TTWS-1003, Rev 1

(8) Weld Joint Offset - Except whene otherwise specified herein or on the drawing, the maximum permissible offset between components of a joint shall not exceed the following:

Base Metal Thickness

$1 / 4$ inch and less

over $1 / 4$ to $3 / 4$ inch
Maximum Offset

$20 \%$ of thickness of thinner member

25\% of thickness of thinner member but not exceeding $3 / 32$ inch

over $3 / 4$ to $1-1 / 2$ inch

over 1-1/2 inch
$1 / 8$ inch

$10 \%$ of thickness of thinner member but not exceeding $3 / 16$ inch

(9) Fillet Welds - The minimum size of fillet welds shall be as specified on the drawing. Maximum deviation shall not be greater than $1 / 16$ inch above that specified on the drawing for welds to $1 / 2$ inch nor greater than $1 / 8$ inch above that specified for welds over $1 / 2$ inch. Under no circumstances shall the size of a fillet weld leg be greater than the thickness of the base metal in the weld zone except where differing leg lengths for a given weld are specified on the drawing for particular applications. Weld convexity shall not be greater than $1.05+0.3$ inch nor concavity greater than $0.1 \$-0.01$ inch, where $S$ is the actual weld leg length in nches based on the shortest leg. 
TTWS-1003, Rev 1

4.3 Nondestructive Testing (NDT) - NDT including methods and applicable acceptance criteria shall be as specified on the drawing or in other contract documentation. Testing will generally be limited to pressure vesse?s, pressure piping, major structure, weldments exposed to highly corrosive or radioactive environments and similar critical applications, but may be required in other cases where in the judgment of the designer such testing is desirable to assure integrity of the weld for its service requirements. The following test methods, singly or in conjunction, may be empioyed subject to the provisions defined.

(a) Radiographic Inspection (RT) - RT inspection may be 100 percent or spot test as specified by the drawing or in other contract documentation. Where spot examination is involved, the examination shall meet requirements of Section III or VIII of the ASME Code, as applicable. Spot examination of particular weld joints shall include representation of the welding of each weider or welding operator irvolved in producing the joint.

(b) Uitrsonic Inspection (UT) - UT inspection may be 100 percent or spot test as specified by the drawing or in other contract documentation. Where spot examination is involved, the examination provisions shall be similar to that specified for RT above.

(c) Penetrant Inspection (PT) - PT inspection may be of dry (DPT) or fluorescent (FPT) type at the option of the Seller except where the method is specifically defined on the drawing or in other contract documentation. Examination shall meet requirements of Section III or VIII of the ASME Code as applicable. 
TTWS-1004, Rev 4

\section{Zirconium Alloy Welding}

$$
\text { R. F. Klein }
$$

1.0 SCOPE: This welding specification describes the requirements for welding zirconium alloys.

\subsection{TECHNICAL REQUIREMENTS:}

2.1 Method: The end caps shall be welded to the tubing by the Gas

Tungsten Arc Weiding (GTAW) method. No filler metal shall be allowed and an inert gas chamber shal $\mathrm{j}$ be used.

2.2 Gas Composition: The shield gas shall be at least $99.9 \%$ inert and shall consist of helium with an allowance for up to $10 \%$ argon to aid in maintaining the weld arc.

2.3 Weld Throat Thickness: The weld fusion bead shall provide a minimum thickness at the weld throat of $70 \%$ of the normal tube thickness.

2.4 Void Porosity, Defects, and Inclusions: The fusion zone shait not contain any inclusion or void porosity where the largest dimension of such inclusion or void porosicy is greater than $0.13 \mathrm{~mm}(0.005 \mathrm{in}$.$) .$ The fusion zone shall be free of fissures or cracks.

\subsection{QUALITY ASSURANCE:}

3.1 Tests and Inspections: The porosity, irciusions, and weld throat thickness requirements shail be determired by $100 \%$ radiographic inspection. Each end cap weld shall be $x$-rayed in two views $90^{\circ}$ apart. Each end cap weld shall be helium leak checked. A leak rate of less than or equal to $1.7 \times 10^{-7} \mathrm{STD} \mathrm{cc} / \mathrm{sec}$ is acceptable.

\subsection{Certification: A1\} inspections and test reports shall be recorded} and certified. 
TTWS-1004, Rev 4

3.3 Welding Procedures: Welding procedures shall be prepared for ail welding processes used.

3.4 Welding Operator Qualification: Welding operators who develop the welding parameters for a specific weld are qualified to perform that weld, if these parameters and welds are approved by the BNW WeIding Engineer or the BNW Project Engineer. Other welding operators may become qualified by demonstrating their skill in performing the welds to the satisfaction of the BNW Welding Engineer or BNW Project Manager. 


\section{BRAZING SPECIFICATIDN}

$$
\text { R. F. Klein }
$$

1.0 SCOPE: This brazing specification describes the general requirements for oxy-acetylene torch brazing to be performed during fabrication of fue 1 rods and fuel assembly components.

\subsection{TECHNICAL REQUIREMENTS:}

2.1 Filler Metal: Brazing filler metal shall meet the requirements prescribed in the American Welding Soc'ety "Specification for Brazing Filler Metal," AWS A5.8, latest issue. The filler metal used shall be recommended by the manufacturer for use with the torch brazing process.

2.2 Method: The process used for brazes performed under this specification shall be the oxy-acetylere torch brazing method.

2.3 Braze Length: The length of the braze or the amount of the joint fined with the braze material shall be determined on a case-by-case basis by the PNL Project Manager and tre PNL Welding Engineer.

\subsection{QUALITY ASSURANCE:}

\subsection{Qualification}

3.1.1 Braze Qualification: A particular brazing operation for a specific joint shall be considered qualified after the brazing parameters have been established to the satisfaction of the PNL Welding Engineer, three consecutive brazes have been made on actual or representative parts, and the brazes meet the standards established in paragraph 3.3. 
TTWS-1009, Rev 0

3.1.2 Brazing Operator Qualification: Brazing operators who develop the parameters for a specific braze, and these parameters and brazes are approved by the PNL Welding Engineer and/or the PNL Project Manager, shall be considered qualified to perform those specific brazes. Other brazing operators may become qualified by demonstrating their skill in performing these brazes to the satisfaction of the PNL Weiding Engineer or PNL Project Manager.

3.2 Tests and Inspections: Each braze, when practical, shall be helium leak checked. A leak rate not exceeding $1.7 \times 10^{-7} \mathrm{Std} \mathrm{cc} / \mathrm{sec}$ will be acceptable. Visual inspection of the brazes may be made for lack of fusion and cracks. A $10 x$ magnification may be used. Radiographic examination for lack of penetration and porosity may also be employed, when practical, at the discretion of the PNL Project Manager.

3.3 Certification: All inspection and test reports shali be recorded and certified.

3.4 Brazing Procedures: Brazing procedures shall be prepared for each different braze joint or each braze using a different filler material. 

APPENDIX E

HEAT TREATMENT SPECIF ICATIONS 
HEAT TREATMENT SPECIFICATIONS

Specification

TTHTS-1000 Rev 1

TTHTS-1003 ReV 1

TTHTS-1004 ReV 0

TTHTS-1006 Rev 0

TTHIS-1007 Rev 0

TTHTS-1008 Rev 1
Title

Aging Heat Treatment of Inconel 718

Incone $1 \mathrm{X}-750$ Heat Treatment Requirements

Precipitation Hardening Stainless Steel

$593^{\circ} \mathrm{C}$ Heat Treatment Requirements

$E-6$

Precipitation Hardening Stainless Steel

Alternate Heat Treatment Requirements

Solution Heat Treatment of Austenitic

Stainless Steels

$\mathrm{E}-10$

$E-12$

Page Number

$E-2$

$E-4$

$E-8$

Stainless Steel Stress Relieving Heat

Treatment Requirements
E-12 
TTHTS-1000, R.ev 1

\author{
Aging Heat Treatment of Inconel 718 \\ C. Nealley
}

1.0 SCOPE: This specification describes the aging heat treating procedure for Inconel 718 nickel base material.

2.0 APPLICABLE DOCUMENTS: The following document forms a part of this specification.

TTMS-1015, Revision 0, Inconel 718 Sheet, Strip and Plate

3.0 MATERIAL REQUIREMENTS: The material shall meet the requirements of PNL specification TTMS-1015, Revision 0.

4.0 HEAT TREATING PROCEDURE: The following procedure shall be followed during heat treatment.

4.1 Cleaning: The components shall be cleaned with a fresh commercial cleaning solvent to remove any traces of dirt, oil, marking crayons, or other possible contaminants. Clearliness of the parts shall be inspected to assure that all visible evidence of contaminants has been removed. Residues left from the cleaning solvent shall be removed by wiping with denatured alcohol and a clean cloth.

4.2 Handling: After cleaning, all parts shall be handled with clean gloves to avoid further contamination. If visible evidence of contamination from fingerprints or other sources is observed, the affected parts shall be recleaned in accordance with paragraph 4.1 , "Cleaning", prior to heat treating.

4.3 Racking: During the heat treating cycle, the parts shall be placed on a support of such size as to offer adequate but not constrained support. The support shall be Incone series of nickel base alloys or high purity refractory material. 
TTHTS-1000, Rev 1

4.4 Furnace Temperature: The parts shall be heated to $718^{\circ} \mathrm{C} \pm 8^{\circ} \mathrm{C}$ $\left(1325^{\circ} \mathrm{F} \pm 15^{\circ} \mathrm{F}\right)$ at a rate of $138.5^{\circ} \mathrm{C}$ per hour, and then held at this temperature for 8 hours, then furnace-cooled at a rate not to exceed $55.5^{\circ} \mathrm{C}$ per hour to $621^{\circ} \mathrm{C} \pm 8^{\circ} \mathrm{C}\left(1150^{\circ} \mathrm{F} \pm 15^{\circ} \mathrm{F}\right)$ and held for an additional 8 hours, and finally cooled to room temperature at a rate not to exceed $138.5^{\circ} \mathrm{C}$ per hour. Total aging time shall be 18 hours.

4.5 Furnace Atmosphere: The heat treating cycle can be performed in either a vacuum or an air atmosphere. If the parts are to be heat treated in air, the furnace shall be prebaked to $>1093^{\circ} \mathrm{C}\left(2000^{\circ} \mathrm{F}\right)$ for 4 hours to remove any potential contamination from prior heats.

4.6 Storage: After cooling, the parts shall be packaged and stored to prevent contamination.

\subsection{QUALITY ASSURANCE}

5.1 Inspections: Each part shall be visually inspected for defects, warpage, color and surface condition. Hardness and yield strength measurements shall be made on selected samples when required.

5.2 Certification: Certification that the parts were heat treated in conformance with this specification is required. 
Inconel $X-750$ Heat Treatment Requirements

c. Nealley

1.0 SCOPE: This specification describes the heat treating procedure for Inconel $\mathrm{X}$-750 nickel base material.

2.0 APPLICABLE DOCUMENTS: The following documents form a part of this specification.

TTMS-1014, Revision 1, Incone1 $x-750$ Spring Wire

AMS 56998, Alloy Wire, Corrosion and Heat Resistant, Revised 1/15/63.

3.0 MATERIAL REQUIREMENTS: The material shali meet the requirements of PNL specification TTMS-1014, Revision 1 and AMS 5699B.

4.0 HEAT TREATING PROCEDURE: The following procedure shall be followed during heat treatment.

4.1 Cleaning: The components shall be cleaned with a fresh commercial cleaning solvent to remove any traces of dirt, oil, marking crayons, or other possible contaminants. Cleanliness of the parts shall be inspected to assure that all visibie evidence of contaminants has been removed. Residues left from the cleaning solvent shall be removed by wiping with denatured alcohol and a clean cloth.

4.2 Handling: After cleaning, all parts shall be handled with clean gloves to avoid further contamination. If visible evidence of contamination from finger prints or other sources is observed, the affected parts shall be recleaned in accordance with paragraph 4.1, "Cleaning", prior to heat treating.

4.3 Racking: During the heat treating cycle, the parts shall be placed on a support of such size as to offer adequate but not constrained support. The support shall be the Inconel series of nicke? based alloys or a high purity refactory material.

4.4 Furnace Temperature: The part shall be heated to $650 \pm 14^{\circ} \mathrm{C}$ $\left(1200 \pm 25^{\circ} \mathrm{F}\right)$ for 4 hours and then air cooled. Temperature chart recordings of the furnace temperature shall be retained for certification. 
4.5 Furnace Atmosphere: The heat treating cycle can be performed in either a vacuum or an air atmosphere. If the parts are to be heat treated in air, the furnace shall be prebaked to $>1093^{\circ} \mathrm{C}\left(2000^{\circ} \mathrm{F}\right)$ for 4 hours to remove any potential contamination from prior heats.

4.6 Storage: After cooling, the parts shall be packaged and stored to prevent contamination.

\subsection{QUALITY ASSURANCE:}

5.1 Inspections: Each part shall be visually inspected for defects, warpage, color and surface condition. Hardness and yield strength measurements shal1 be made on selected samples when required.

5.2 Certification: Certification that the parts were heat treated in conformance with this specification is required. 
TTHTS-1004, Rev 0

Precipitation Hardening Stainless Stee?

$593^{\circ} \mathrm{C}$ Heat Treatment Requirements

c. Nealley

1.0 SCOPE: This specification describes the $593^{\circ} \mathrm{C}$ heat treating procedure for precipitation hardening stainless steels.

2.0 APPLICABLE DOCUMENTS: The following documents form a part of this specification.

TTMS-1037, Revision 0, Precipitation Hardening Stainless Steel

ASTM A 564, Hot-Rolled and Cold-Finishec Age-Hardening Stainless and Heat-Resisting Steel Bars and Shapes.

3.0 MATERIAL REQUIREMENTS: The material shall meet the requirements of PNL. specification TTMS-1037, Revision 0.

4.0 HEAT TREATING PROCEDURE: The following procedure shall be followed during heat treatment.

4.1 Cleaning: The components shall be cleaned with a fresh commercial cleaning solvent to remove any traces of dirt, oil, marking crayons, or other possible contaminants. Cleanlizess of the parts shalt be inspected to assure that all visible evidence of contaminants has been removed. Residues left from the cleaning solvent shall be removed by wiping with denatured aicohol and a clean cloth.

4.2 Handling: After cleaning, all parts shail be handled with clean gloves to avoid further contamination. If visible evidence of contamination from finger prints or other scurces is observed, the affected parts shall be recleaned in accordance with paragraph 4.7 , "Cleaning", prior to heat treating.

4.3 Racking: During the heat treating cycie, the parts shall be placed on a support of such size as to offer adequate but not constrained support. The support shall be stainiess steel or high purity refractory material. 
4.4 Furnace Temperature: The part shall be heated to $593 \pm 8^{\circ} \mathrm{C}$ $\left(1100 \pm 15^{\circ} \mathrm{F}\right)$ for 4 hours and then air cooled. Temperature chart recordings of the furnace temperature shall be retained for certification.

4.5 Furnace Atmosphere: The heat treating cycle can be performed in either a vacuum or an air atmosphere. If the parts are to be heat treated in air, the furnace shall be prebaked to $>1093^{\circ} \mathrm{C}\left(2000^{\circ} \mathrm{F}\right)$ for 4 hours to remove any potential contamination from prior heats.

4.6 Storage: After cooling, the parts 5 hall be packaged and stored to prevent contamination.

\subsection{QUALITY ASSURANCE:}

5.1 Inspections: Each part shall be visually inspected for defects, warpage, color and surface condition. Hardness and yield strength measurements shall be made on selected samples when required.

5.2 Certification: Certification that the parts were heat treated in conformance with this specification. 
TTHTS-1006, ReV 0

\author{
Precipitation Hardening Stainiess Steel \\ Alternate Heat Treatment Requirements \\ c. Nealley
}

1.0 SCOPE: This specification describes the allernate heat treating procedure for precipitation hardening stainless steel.

2.0 APPLICABLE DOCUMENTS: The following documerits form a part of this specification.

TTMS-1037, Revision 0, Precipitation Hardening Stainless Steel

ASTM A 564, Hot-Rolled and Cold Finished Age-Hardening Stainiess and Heat-Resisting Steel Bars and Shapes.

3.0 MATERIAL REQUIREMENTS: The material shall meet the requirements of PNL Specification TTMS-1037, Revision 0.

4.0 HEAT TREATING PROCEDURE: The following procedure shall be followed during heat treatment.

4.] Cleaning: The components shall be cleaned with a fresh commercial cleaning solvent to remove any traces of dirt, oil, marking crayons, or other possible contaminants. Cleanliness of the parts shall be inspected to assure that all visible evidence of contaminants has been removed. Residues left from the cieaning solvent shall be removed by wiping with denatured alcoho: and a clean cioth.

4.2 Handling: After cleaning, all parts shaill be handled with clean gloves to avoid further contamination. If visible evidence of contamination from finger prints or other sources is observed, the affected parts shall be recleaned in accordance with paragraph 4.7 , "cleaning", prior to heat treating.

4.3 Racking: During the heat treating cycle, the parts shall be placed on a support of such size as to offer adequate but not constrained support. The support shall be stain?ess steel or high purity refactory material. 
4.4 Furnace Temperature: The part shall be heated to $760 \pm 15^{\circ} \mathrm{C}$ $\left(1400 \pm 25^{\circ} \mathrm{F}\right)$ for 90 minutes, and then cooled to $15 \pm 3^{\circ} \mathrm{C}\left(55 \pm 5^{\circ} \mathrm{F}\right)$ within one hour. This temperature shail be held for not less than 30 minutes. After holding this temperature, the part shall be heated to $566 \pm 6^{\circ} \mathrm{C}\left(1050 \pm 10^{\circ} \mathrm{F}\right)$ for 90 minutes and then air cooled. Temperature chart recordings of the furnace temperature shall be retained for certification.

4.5 Furnace Atmosphere: The heat treating cycle can be performed in either a vacuum or an air atmosphere. If the parts are to be heat treated in air, the furnace shall be prebaked to $>1093^{\circ} \mathrm{C}\left(2000^{\circ} \mathrm{F}\right)$ for 4 hours to remove any potential contamination from prior heats.

4.6 Storage: After cooling, the parts shall be packed and stored to prevent contamination.

\subsection{QUALITY ASSURANCE:}

5.1 Inspections: Each part shall be visually inspected for defects, warpage, color and surface condition. Hardness and yeild strength measurements shall be made on selected samples when required.

5.2 Certification: Certification that the parts were heat treated in conformance with this specification and ASTM A 564 is required. 
TTHTS-1007, Rev 0

\author{
Solution Heat Treatme t \\ of Austenitic Stainless steel \\ C. Nea?ley
}

1.0 SCOPE: This specification describes the solution heat treating procedure for austenitic stainless steels.

2.0 APPLICABLE DOCUMENTS: The following document forms a part of this specification.

TTMS-1032, Revision 1, Stainless Steel Flate, Sheet and Strip

3.0 MATERIAL REQUIREMENTS: The material shall meet the requirements of PNL specification TTMS-1032, Revision 1.

4.0 HEAT TREATING PROCEDURE: The following procedure shall be followed during heat treatment.

4.1 Cleaning: The components shail be cleaned with a fresh commercial cleaning solvent to remove any traces of dirt, 0il, marking crayons, or other possible contaminants. Cleanliness of the parts shal be inspected to assure that all visible evidence of contaminants has been removed. Residues left from the cleaning solvent shali be removed by wiping with denatured alcohol and a clean cloth.

4.2 Handling: After cleaning, all parts sha $i$ be handled with clean gloves to avoid further contamination. If visible evidence of contamination from finger prints or other sources is observed, the affected parts shall be recleaned in acccrdance with paragraph 4.1, "cleaning", prior to heat treating.

4.3 Racking: During the heat treating cycle, the parts shall be placed on a support of such size as to offer adequate but not constrained support. The support shall be stainless steel or high purity refractory material. 
4.4 Furnace Temperature: The part sha 11 be heated to $1038^{\circ} \mathrm{C}\left(1900^{\circ} \mathrm{F}\right.$ ) for $1 / 2$ hour per inch of material thickness, and then water quenched. Temperature chart recordings of the furnace temperature shali be retained for certification.

4.5 Furnace Atmosphere: The heat treating cycle can be performed in either a vacuum or an air atmosphere. If the parts are to be heat treated in air, the furnace shall be prebaked to $>1093^{\circ} \mathrm{C}\left(2000^{\circ} \mathrm{F}\right)$ for 4 hours to remove any potential contamination from prior heats.

4.6 Storage: After cooling, the parts shail be packaged and stored to prevent contamination.

\subsection{QUALITY ASSURANCE}

5.1 Inspections: Each part shall be visualiy inspected for defects, warpage, color and surface condition. Hardness and yield strength measurements sha11 be made on selected samples when required.

5.2 Certification: Certification that the parts were heat treated in conformance with this specification is required. 
TTHTS-1008, Rev 1

Stainless Steel Stress Rel eving

Heat Treatment Requirements

C. Nealley

1.0 SCOPE: This specification describes the heat treatment requirements for stress relieving stainiess steel.

2.0 APPLICABLE DOCLMENTS: The following documents form a part of this specification.

TTMS-1033, Revision 2, Stainless Steel Bars and Shapes

ASTM A 276, Stainless and Heat-Resisting Steel Bars and Shapes

3.0 MATERIAL REQUIREMENTS: The material shall mest the requirements of PNL Specification TTMS-1033, Revision 2.

4.0 HEAT TREATING PROCEDURE: The following procedure shall be followed during heat treatment.

4.1 Cleaning: The components shall be cleaned with a fresh comercial cleaning solvent to remove any traces of dirt, oil, marking crayons, or other possible contaminants. Cleanliness of the parts shall be inspected to assure that all visible evidence of contaminants has been removed. Residues left from the cleaning solvent shali be removed by wiping with denatured alcohol and a clean cloth. A final cleaning shall be performed after all fatrication processes have been completed.

4.2 Handling: After cleaning, all parts shall be handled with clean gloves to avoid further contamination. If visible evidence of contamination from finger prints or other sources is observed, the affected parts shall be recleaned in accordance with paragraph 4.1, "Cleaning", prior to heat treating.

4.3 Fixturing: During the heat treating cycle, the parts shall be fixtured, if necessary, to obtain the optimum benefits from the stress relieving heat treatment. Materials used for fixturing shaii be stainless steel or high purity refractory material. 
TTHTS-1008, Rev 1

4.4 Furnace: The parts shall be heat treated in a vertical type furnace.

4.5 Furnace Atmosphere: The heat treating cycle can be performed in either a vacuum or an air atmosphere. If the parts are to be heat treated in air, the furnace shall be prebaked to $>1093^{\circ} \mathrm{C}\left(2000^{\circ} \mathrm{F}\right)$ for 4 hours to remove any potential contamination from prior heats.

\subsection{Therma i Treatment:}

4.6.1 Intermediate Stress Relieving Heat Treatment: If the parts require heat treatment to relieve internal stress between machining operations, they shall be heated to $900 \pm 8^{\circ} \mathrm{C}$ $\left(1650 \pm 25^{\circ} \mathrm{F}\right)$ for a minimum of two hours and furnace cooled to at least $205^{\circ} \mathrm{C}\left(400^{\circ} \mathrm{F}\right)$. The parts shall then be removed from the furnace and cooled to room temperature in still air.

\subsubsection{Final Stress Relieving Heat Treatment: If a final stress} relieving heat treatment is required after the final machining, the procedure shall be the same as in Section 4.6.1, "Intermediate Stress Refieving Heat Treatment."

4.7 Pickling: After final heat treatment, the parts shall be pickled to remove all heat treatment thermal discoloration. The parts shall be pickled by inmersing them in a 10 to 15 volume percent solution of concentrated hydrochloric acid at 60 to $66^{\circ} \mathrm{C}\left(140\right.$ to $\left.150^{\circ} \mathrm{F}\right)$ for 10 to 15 minutes, followed by a rinse in water. Then the parts shall be immersed in a 10 to 15 volume percent solution of nitric acid at 60 to $66^{\circ} \mathrm{C}\left(140-150^{\circ} \mathrm{F}\right)$ for 10 to 15 minutes. This is followed by a final water rinse.

4.8 Storage: After cooling, the parts shall be packed and 5 tored to prevent contamination. 
TTHTS-1008, ReV 1

\subsection{QUALITY ASSURANCE:}

5.1 Inspections: Each part shall be visually inspected for defects, warpage, color and surface condition. The parts shall be measured before and after heat treatment to deternine the effect of the heat treatment on the dimensions. This measurement data shall be furnished to the buyer.

5.2 Certification: Certification that the parts were heat-treated in conformance with this specification is required. 
APYENDIX F

THERM CODE CALCULATIONS (a)

(a) Prepared by Combustion Engineering, Inc. under subcontract to PNL 


\section{THERM CODE CALCULATIONS}

Peak Cladding Temperature History for Cladding Deformation Tests 0-second Reflood Initiation Delay Time, 2-in./sec Reflood Rate

Peak Cladding Temperature History for Cladding Deformation Tests 0 -second Reflood Initiation Delay Time, 5-in./sec Reflood Rate

Peak Cladding Temperature History for Cladding Deformation Tests 0-second Reflood Initiation Delay Time, 10-in./sec Reflood Rate

Peak Cladding Temperature History for Cladding Deformation Tests 10-second Reflood Initiation Delay Time, 2-in./sec Reflood Rate

Peak Cladding Temperature History for Cladding Deformation Tests 10-second Reflood Initiation Delay Time, 5-in./sec Reflood Rate

Peak Cladding Temperature History for Cladding Deformation Tests 10-second Reflood Initiation Delay Time, 10-in./sec Reflood Rate

Peak Cladding Temperature History for Cladding Deformation Tests 2D-second Reflood Initiation Delay Time, 2-in./sec Reflood Rate

Peak Cladding Temperature History for Cladding Deformation Tests 20-second Reflood Initiation Delay Time, 5-in./sec Reflood Rate

Peak Cladding Temperature History for Cladding Deformation Tests 20-second Reflood Initiation Delay Time, 10-in./sec Reflood Rate

Peak Cladding Temperature History for Cladding Deformation Tests 44-second Reflood Initiation Delay Time, 2-in./sec Reflood Rate

Peak Cladding Temperature History for Cladding Deformation Tests 60-second Reflood Initiation Delay Time, 2-in./sec Reflood Rate 


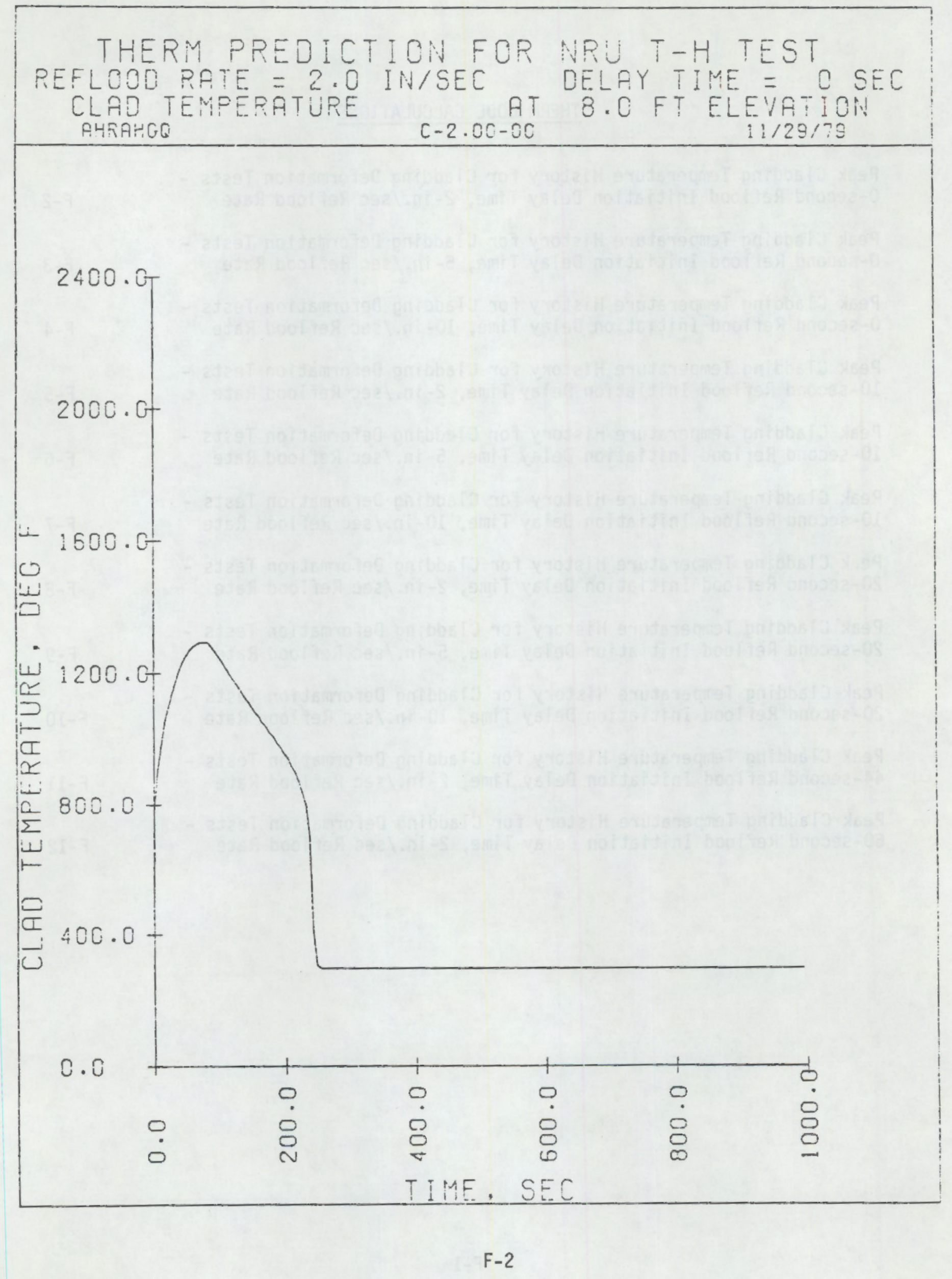


THERM PREDICTION FOR NRU T-H TEST REFLOOD RATE $=5.0$ IN/SEC DE!FY TIME $=$ O SEC CLAD TEMPERATURE. AHSFEUN

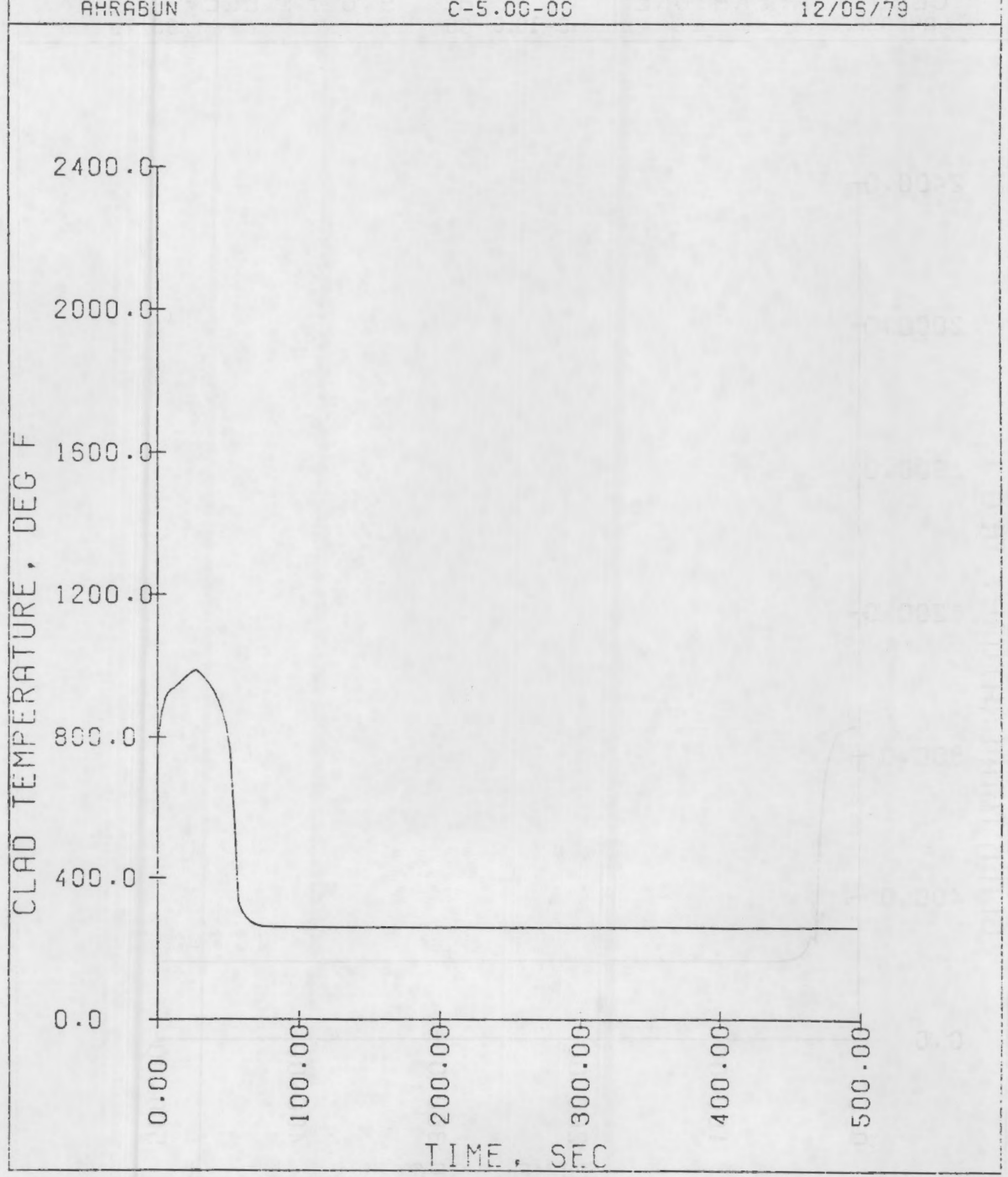


THERM PREDICTION FOR NRU T-H TEST REFLCOD RATE $=10.0$ INISEC CEIAYY TIME $=O$ SEC CLAD TEMDERATURE AT $9.0 \mathrm{FT}$ ELEVATION FUำดPF $c-10.0-.50$ $11 / 30 / 79$

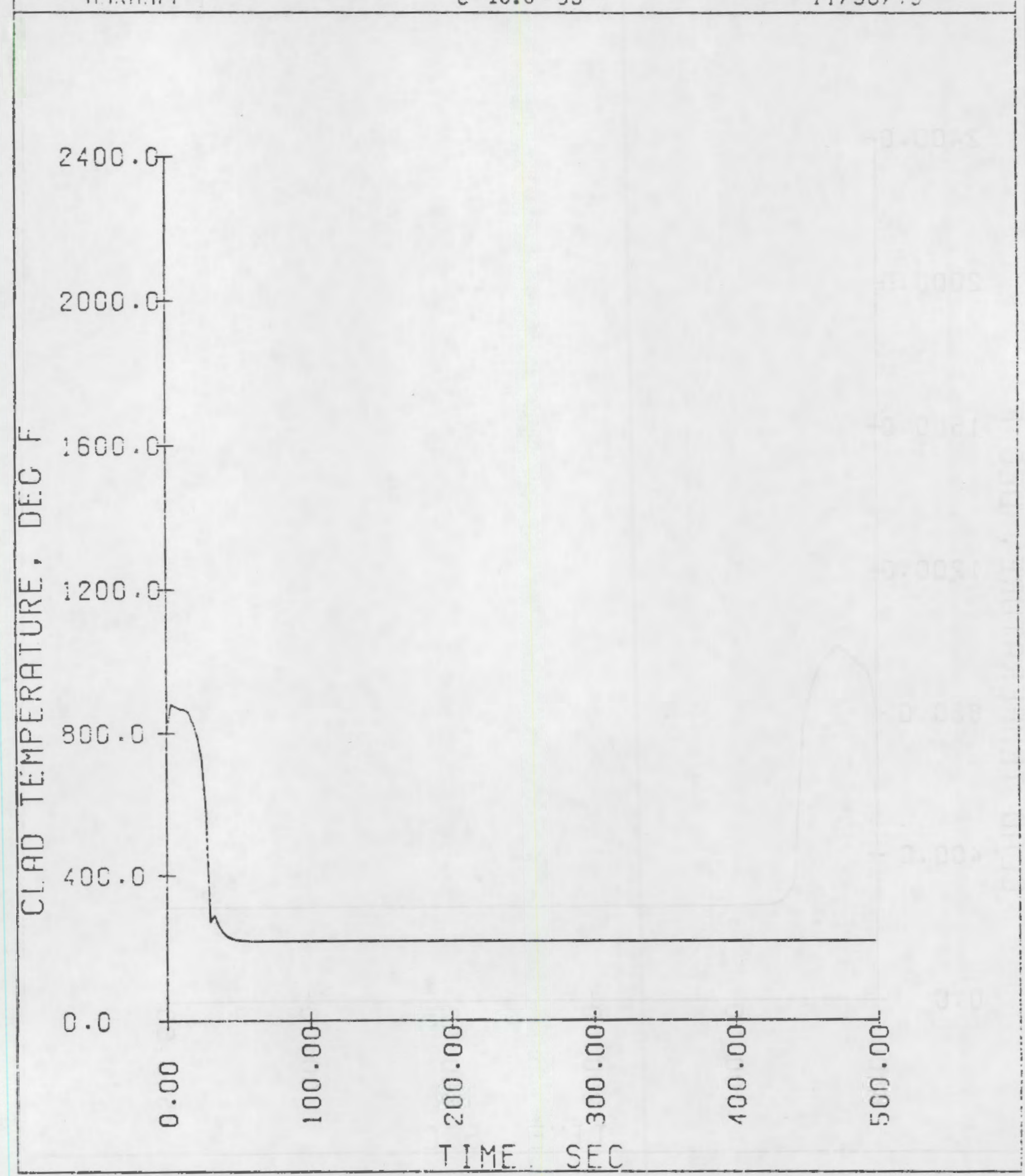




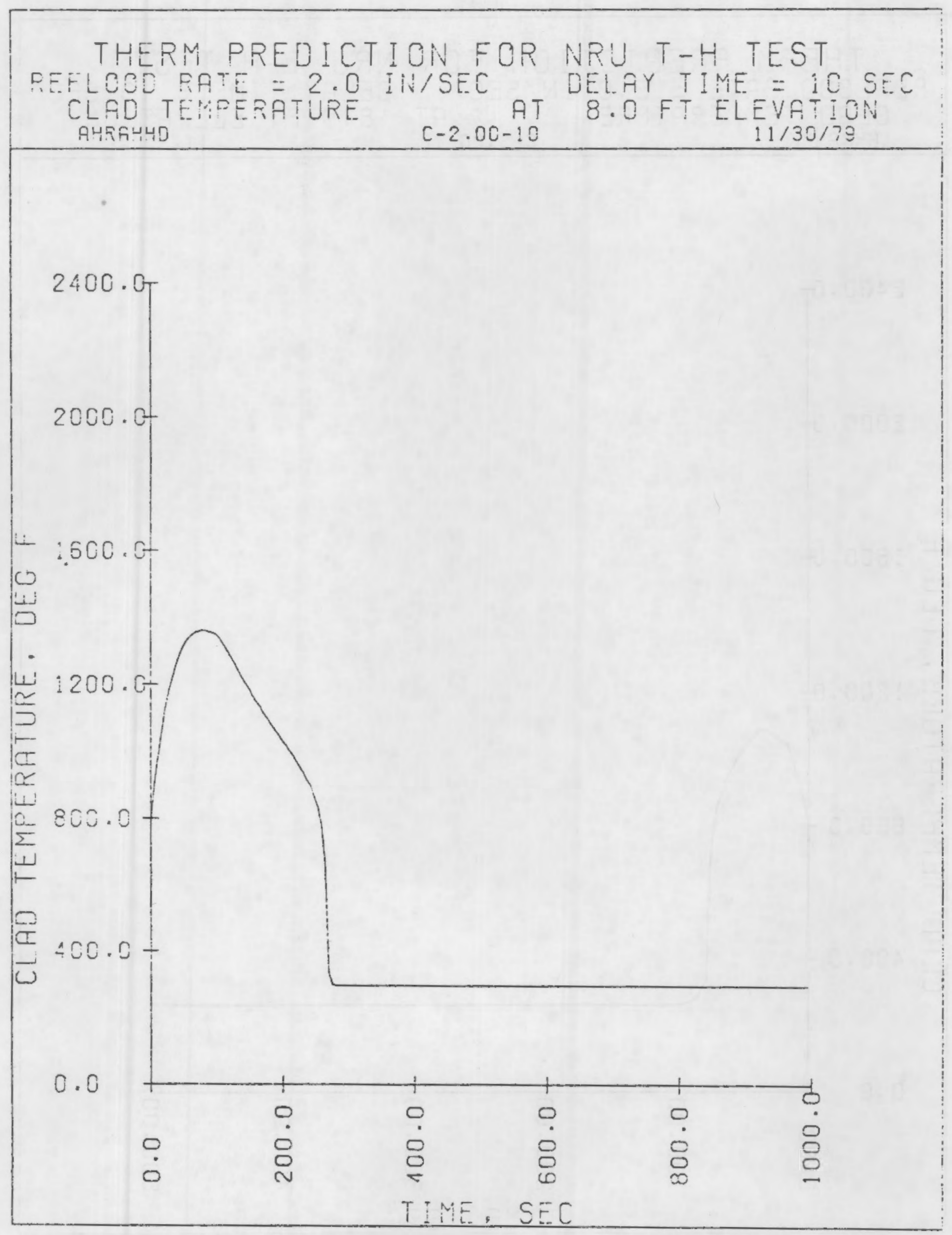




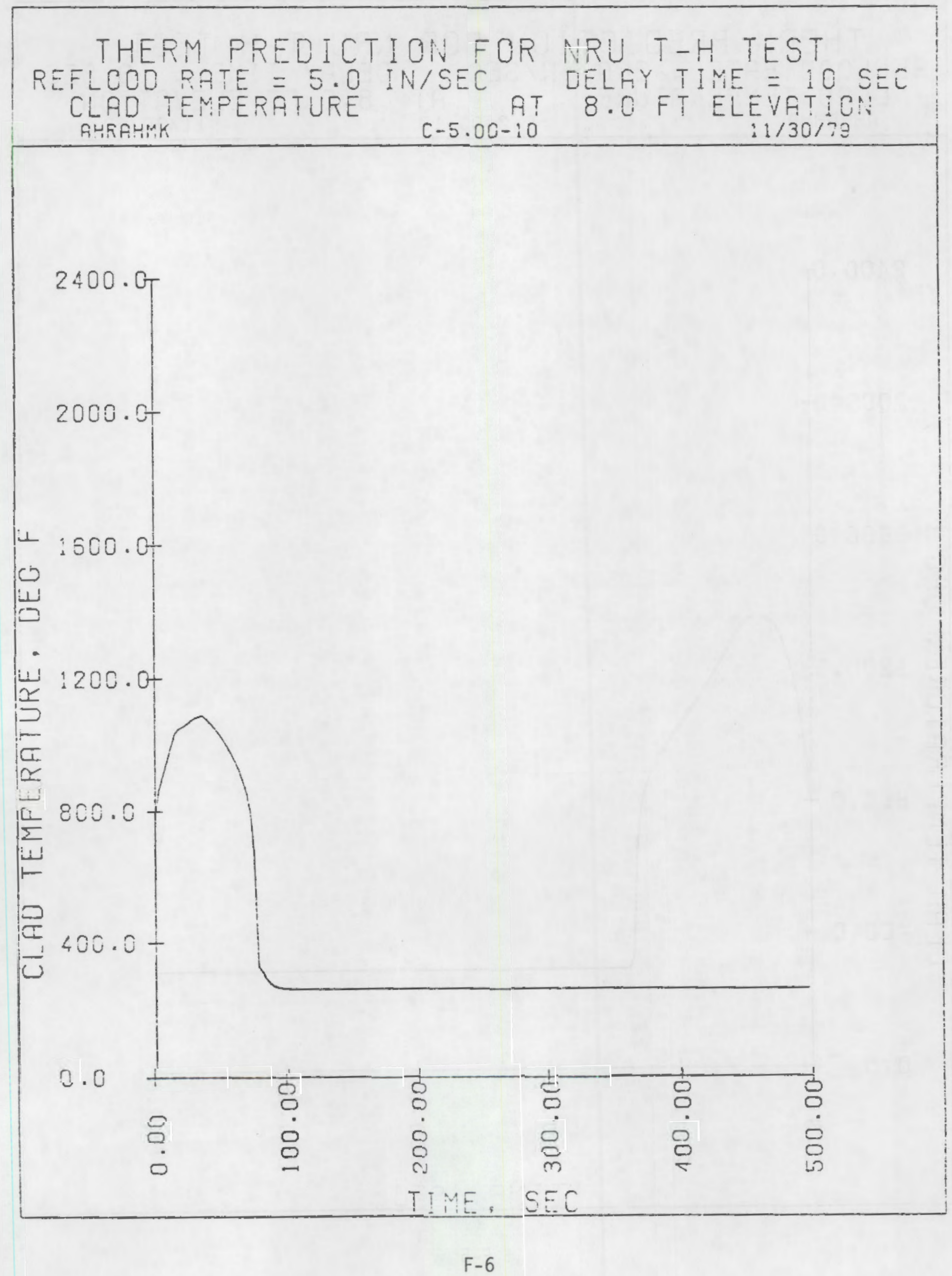




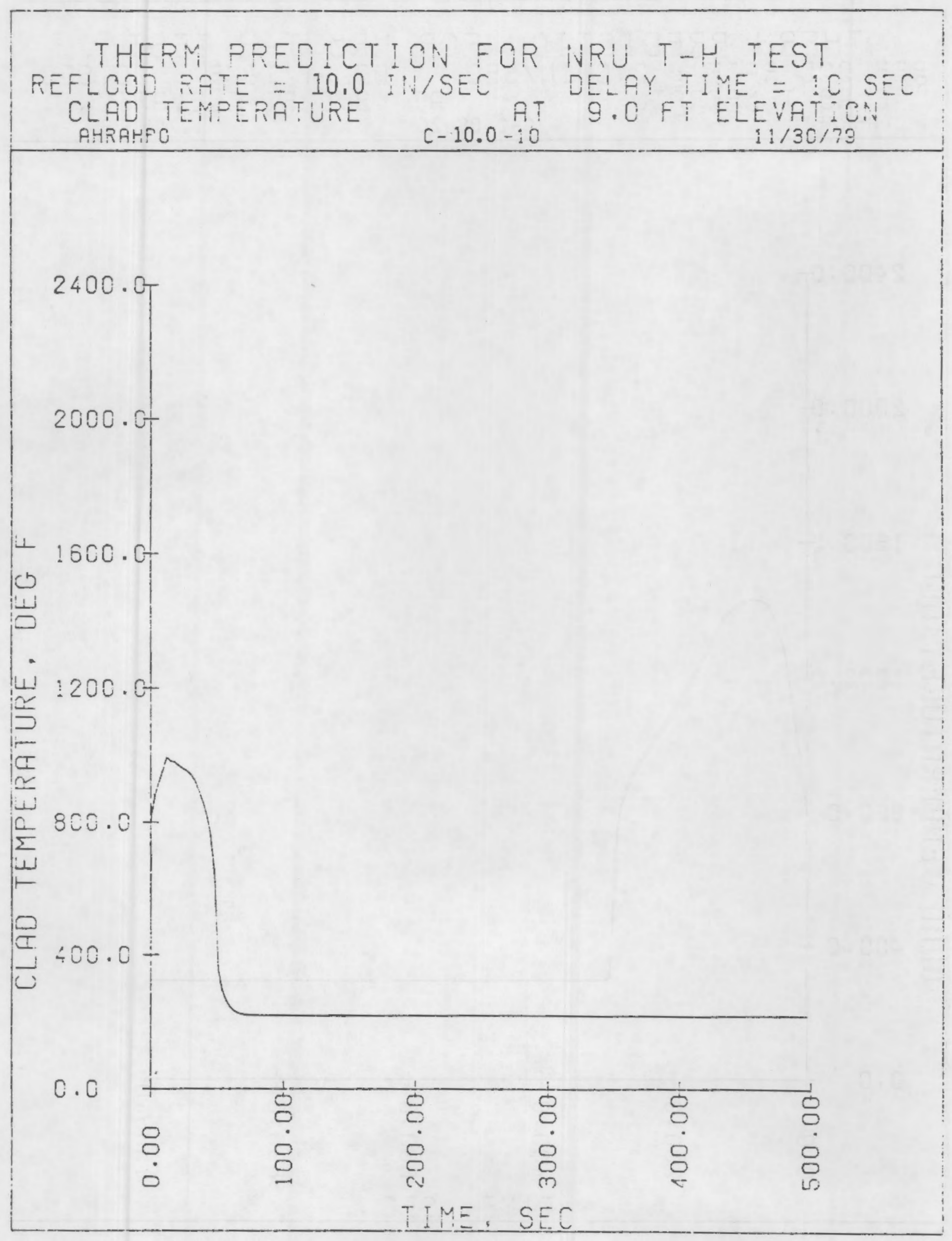


THERM PREDICTION FOR WRU T-H TEST REFLOCE FATE Ö2.O IN/SEC DELAY TIME ZO SEC CLFD TEMPERFTURE IN/SET Q.0 FT ELEVFTION FunASTO $\quad 0-2.00-20 \quad 12 / 05 / 73$

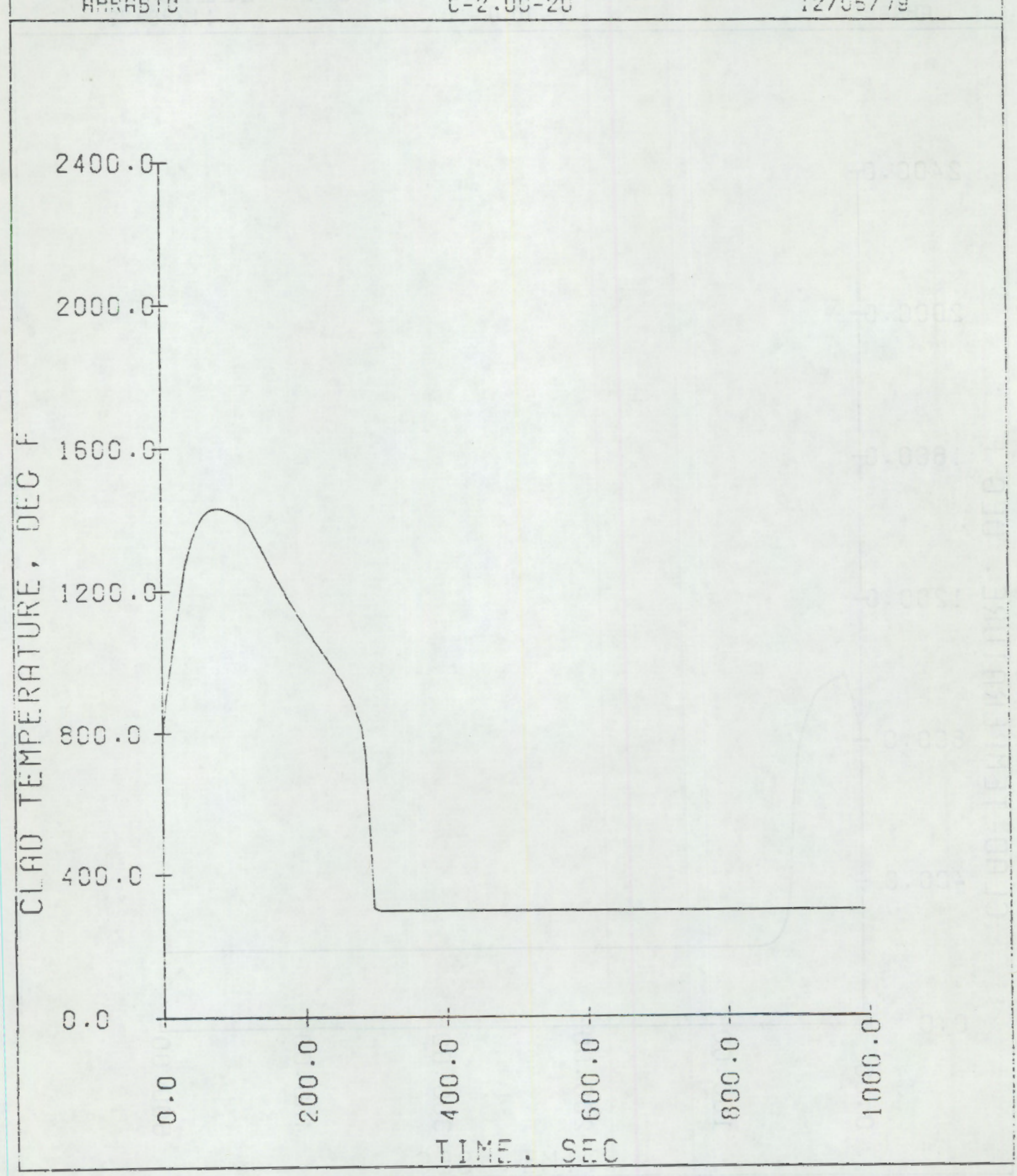




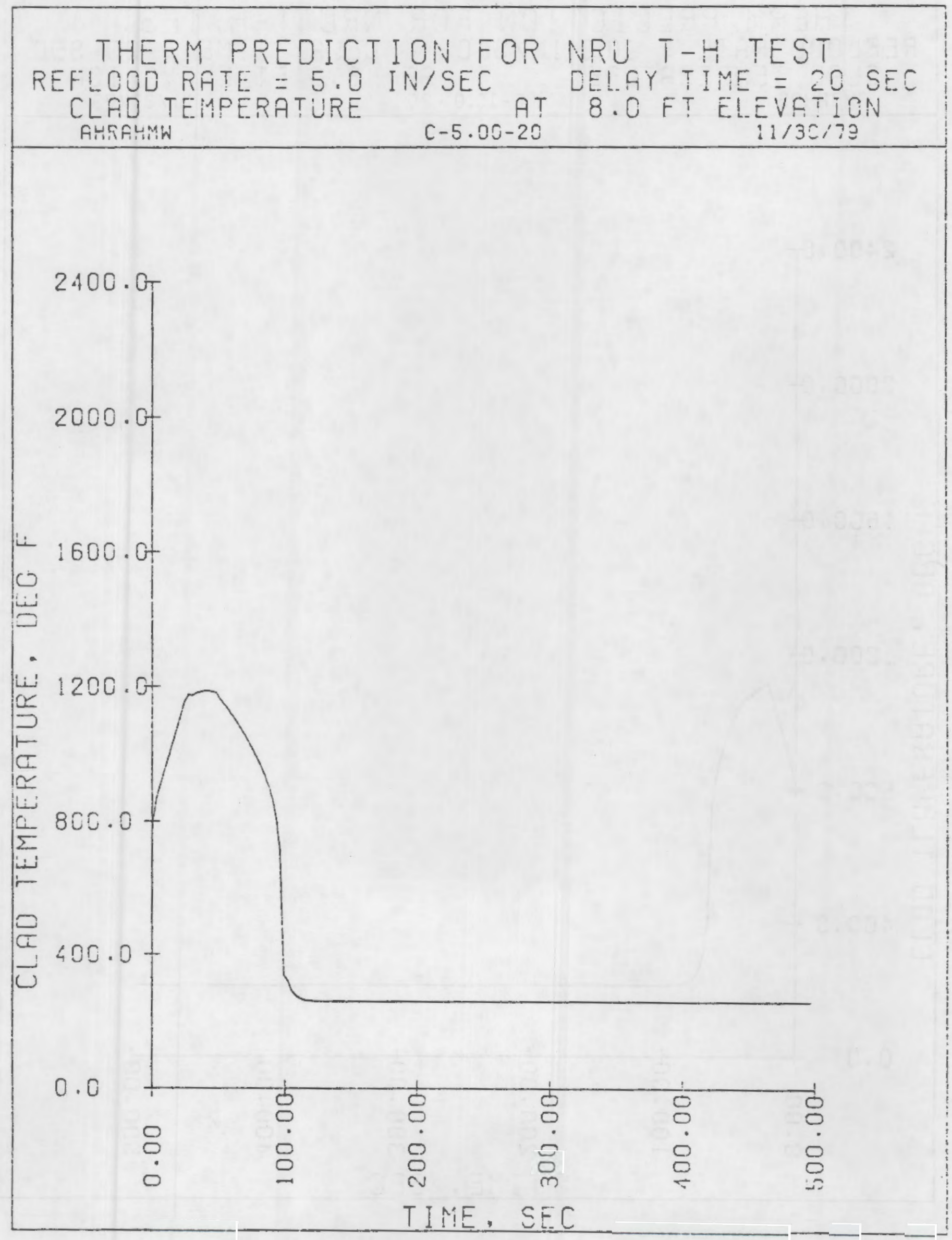




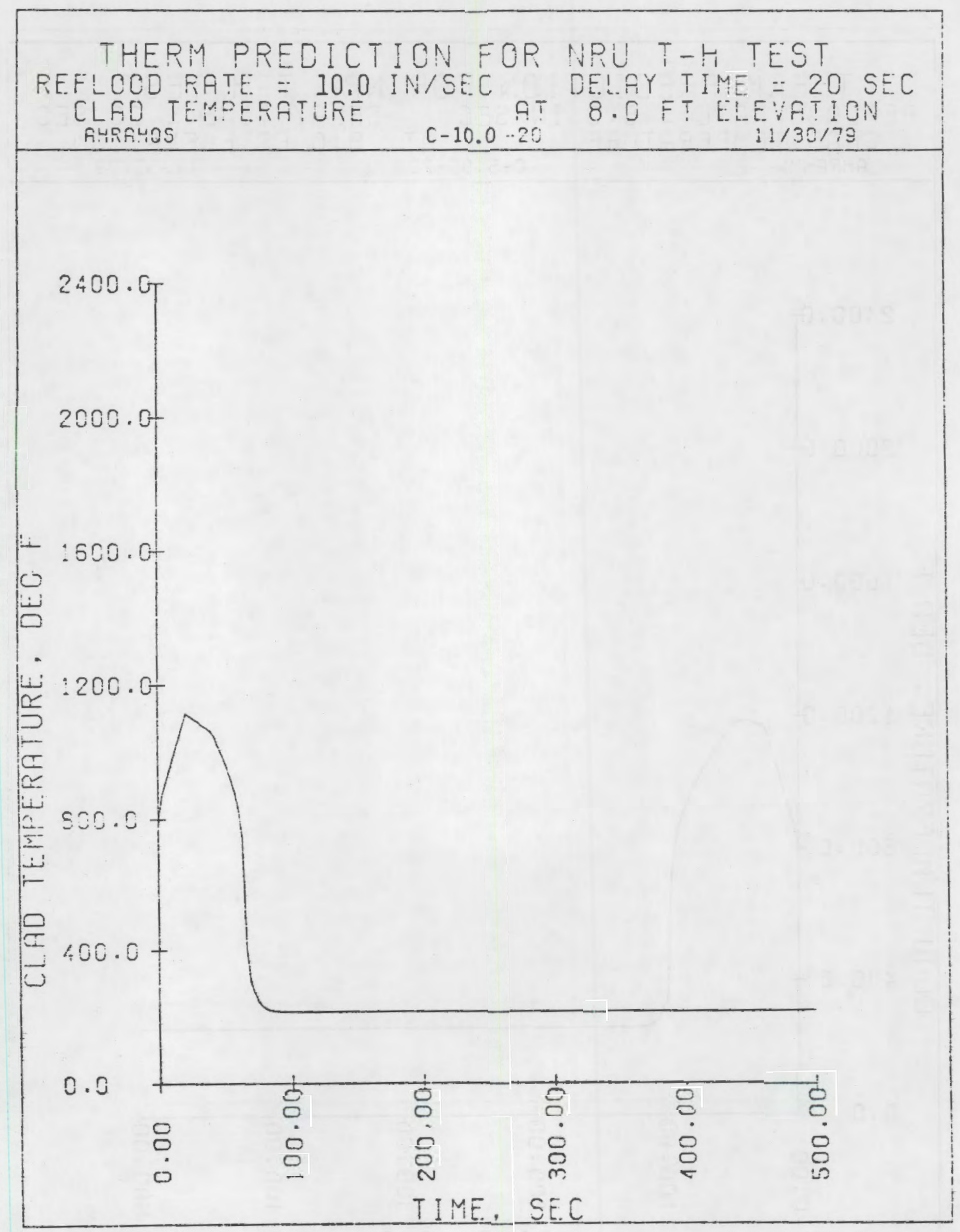


THERM PREDICTION FOR NRU T-H TEST REFLOOD RATE $=2$. O IN/SEC DELAY TIME $=44$ SEC CLAD TEMPERATURE. R.4ลㄱㄴ:Y AT 8.0 FT ELEVATIOH:

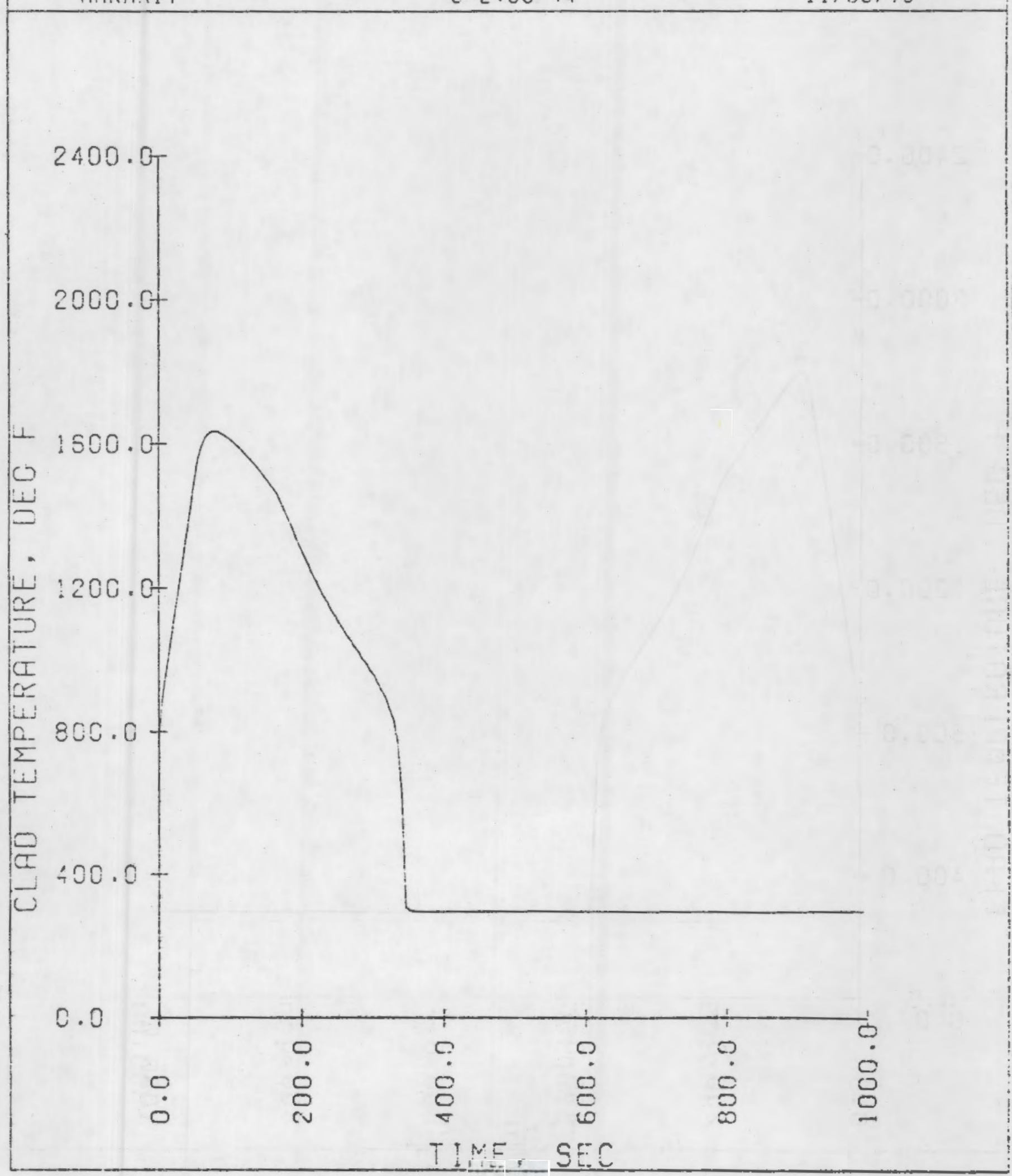




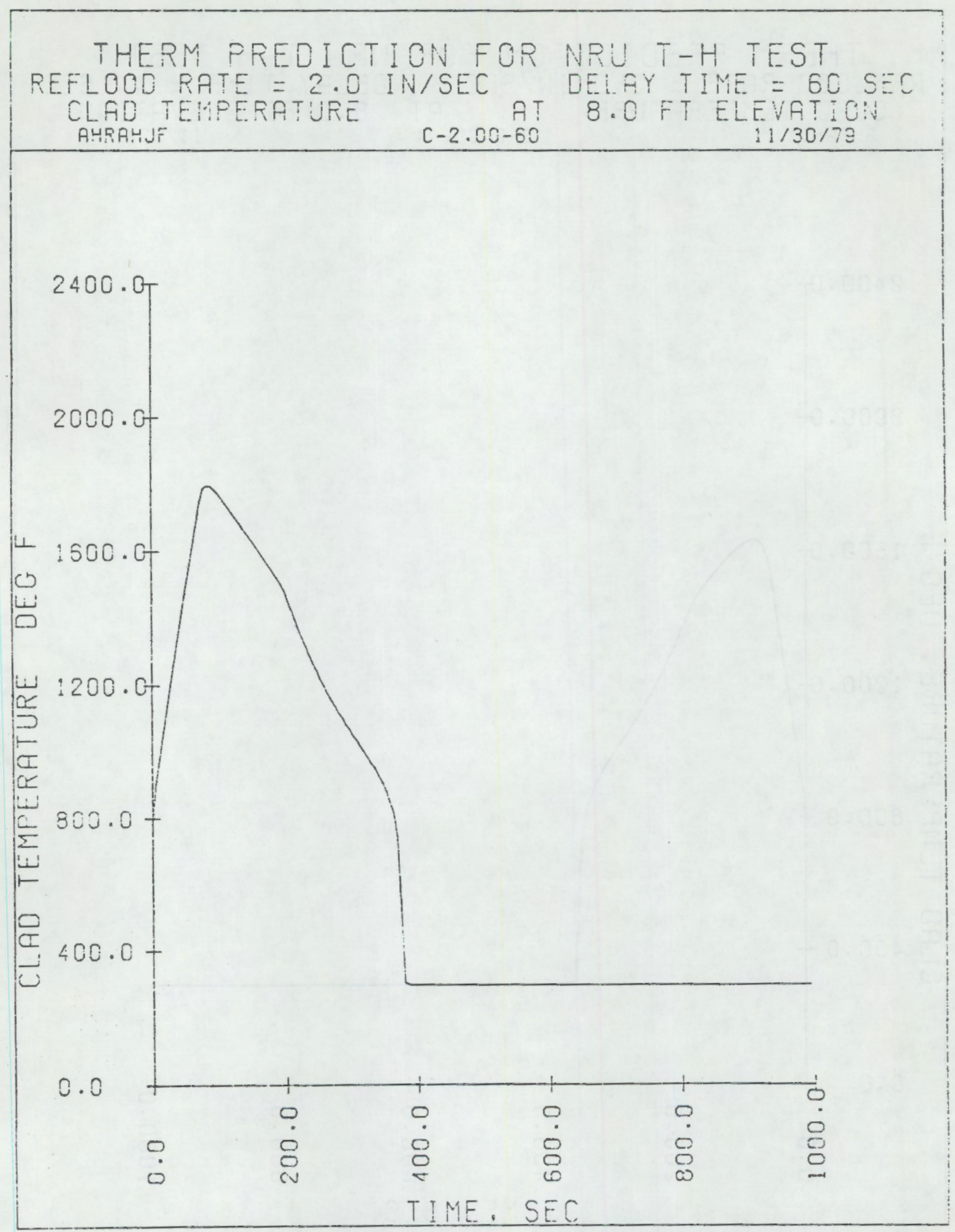


APPENDIX G

FUEL DESCRIPTION 


\section{FUEL DESCRIPTION}

\section{TEST ASSEMBLIES}

In all, six different test assemblies will be irradiated during the test program. The first to be tested will be the themal-hydraulic assembly. The remaining six are materials test assemblies. While there are significant differences between the themal-hydraulic assembly and the materials test assemblies (instrumentation, internal rod pressure, etc.) these differences have little impact on the nuclear physics behavior of the fuel. The basic design of the assemblies is uniform.

\section{FUEL}

The test bundle fuel element is a full-length, 31-rod design modeled after a typical Babcock and Wilcox $17 \times 17$ light water reactor element. The pertinent data are given in Table G.l and the test bundle is shown in Fiqure G.1.

The 31 fuel rods are placed inside a stainless steel shroud. Outside of the stainless steel shroud tube there is a double-wall pressure tube. The inner wall is constructed of cold-worked Zircaloy-2 while the outer wall is Zircaloy -2 . 


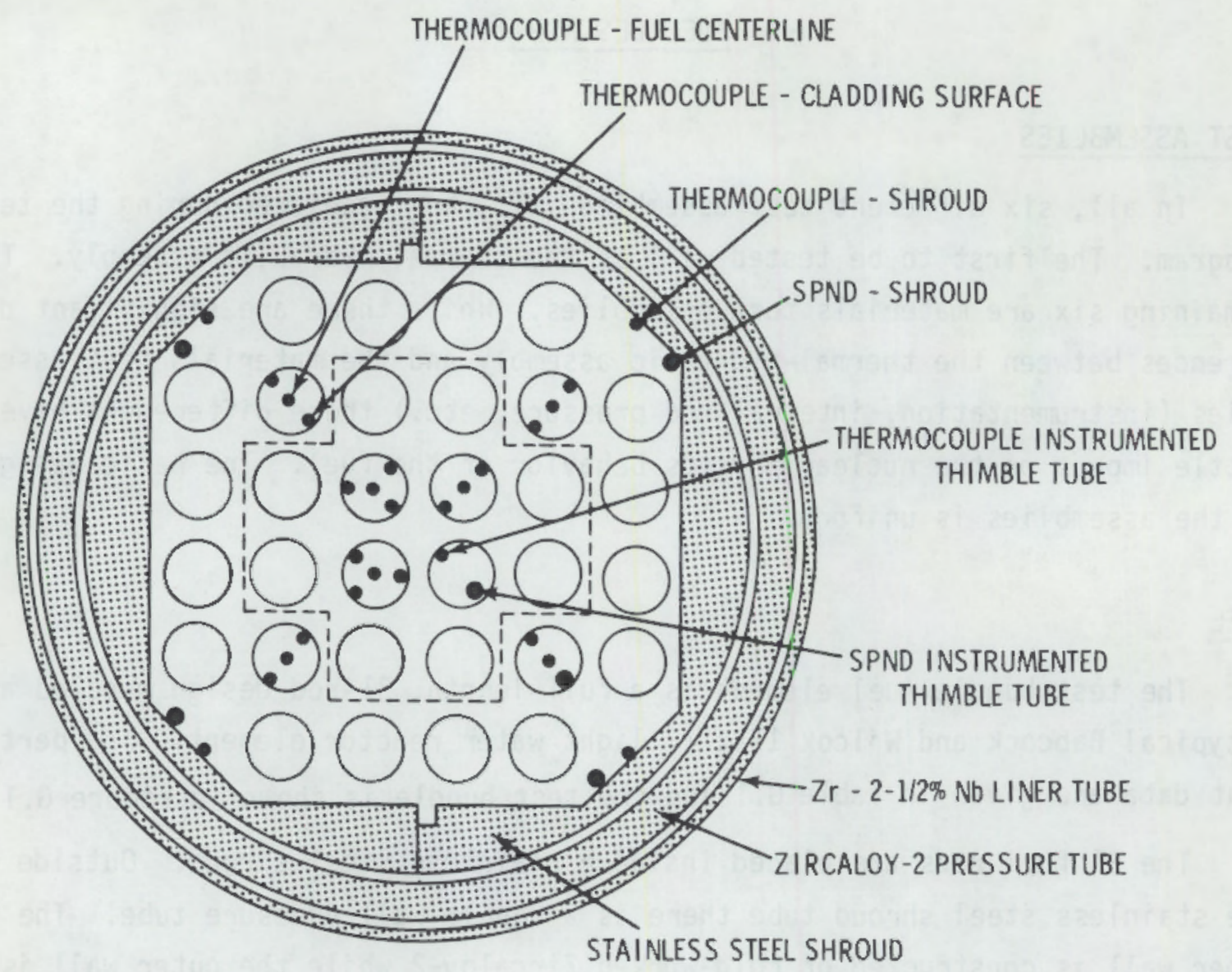

FIGURE G.1 Schematic Cross Section of Assentiy Illustrating Instrument Locations

TABLE G. T. Fuel Test Bundle Data

Fuel Element 0.D.

Fuel Element Pitch

Pitch/Diameter

Cladding Thickness

Fuel Pellet Diameter

Pellet-Cladding Gap

Instrumented Thimble O.D.

Instrumented Thimble I.D.

Pressure Tube 1.D.

Pressure Tube O.D.

Active Fuel Length

Fuel Enrichment
$9.6 \mathrm{~mm}$
$12.7 \mathrm{~mm}$
1.32
$0.597 \mathrm{~mm}$
$8.23 \mathrm{~mm}$
$0.10 \mathrm{~mm}$
$9.6 \mathrm{~mm}$
$8.406 \mathrm{~mm}$
$1 D 3.38 \mathrm{~mm}$
$113.54 \mathrm{~mm}$
$3.66 \mathrm{~m}$
$2.88 w t \% U^{235}$ 
NUREG/CR-1208

PNL-3093

\section{DISTRIBUTION}

No. of

Copies

OFFSITE

A. A. Churm DOE Patent Division 9800 S. Cass Avenue Argonne, IL 60439

400

U.S. Nuclear Regulatory Commission

Division of Technical Information and Document Control 7920 Norfolk Avenue

Bethesda, MD 20014

2 DOE Technical Information Center

5 R. Van Houten

U.S. Nuclear Regulatory Commission

Fuel Behavior Branch Division of Reactor Safety Research

Washington, D.C. 20555

6 C.A. Herriot Chalk River National

Laboratory

Chalk River, Ontario, Canada
No. of

Copies

ONSITE

29 Pacific Northwest Laboratory

E. L. Courtright

R. L. Goodman

S. W. Heabertin

G. M. Hesson

L. L. King

R. K. Marshall

G. W. McNair

W. D. Meitzler

C. L. Mohr (8)

C. Nealley

F. E. Panisko

L. J. Parchen

J. P. Pilger

G. E. Russcher

C. L. Wilson

Pub. Coord. (2)

Tech. Info. (5) 

Loss-of-Coolant Accident Simulations in the National Research Universal Reactor

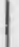

7. AUTHORISI W.D. Bennett and others

9. PERFORMING ORGANIZATION NAME AND MAILING ADDRESS (Include Zip Code)

Pacific No'rthwest Laboratory

Richland, Washington 99352

\begin{tabular}{l} 
5. DATE REPORT COMPLETED \\
$\begin{array}{l}\text { MONTH } \\
\text { JanuarY }\end{array}$ \\
$\begin{array}{l}\text { DATE REPORT ISSUED } \\
\text { MONTH } \\
\text { February }\end{array}$ \\
\hline 6. (Leave blank/ \\
\hline 8. (Leave blank) \\
\hline 10. PROJECT/TASK/WORK UNITNO. \\
\hline 11. CONTRACT NO \\
FIN NO. B2277
\end{tabular}

12. SPONSORING ORGANIZATION NAME AND MAILING ADDRESS (include Zip Code)

Division of Reactor Safety Research

Office of Nuclear Regulatory Research

U.S. Nuclear Regulatory Commission

Washington, DC 20555

Safety Analysis Report

16. ABSTRACT (200 words or less)

Pressurized water reactor loss-of-coolant accident (LOCA phenomena are being simulated with a series of experiments in the U-2 loop of the National Research Universal Reactor at Chalk River, Ontario, Canada. The first of these experiments includes up to 45 parametric thermal-hydraulic tests to establish the relationship among the reflood delay time of emergency coolant, the reflooding rate, and the resultant fuel rod cladding peak temperature. Subsequent experiments extabilish the fuel rod failure characteristics at selected peak cladding temperatures. Fuel rod cladding pressurization simulates high burnup fission gas pressure levels of modern PWRs.

This document contains both an experiment overview of the LOCA simulation program and a review of the safety analyses performed by Pacif Northwest Laboratory (PNL) to define the expected operating conditions as well as to evaluate the worst case operating conditions.

\begin{tabular}{|l|l|}
\hline 19. SECURITY ClASS (This report) & 21. NO OF PAGES \\
\hline Enclassified & \\
\hline $\begin{array}{l}\text { 20. SECUPITY GLASS (This page) } \\
\text { Unclassified }\end{array}$ & $\begin{array}{l}\text { 22. PRICE } \\
\text { S }\end{array}$ \\
\hline
\end{tabular}


